\title{
BIOACTIVE BORATE-BASED GLASS COATINGS FOR TITANIUM ALLOY FEMORAL STEMS
}

\author{
BY \\ Yiming Li \\ Master of Science, Biomaterials Engineering, Alfred University, Alfred, USA, \\ 2014 \\ A thesis \\ presented to Ryerson University \\ in partial fulfillment of the \\ requirements for the degree of \\ Doctor Of Philosophy \\ in the program of \\ Mechanical and Industrial Engineering \\ Toronto, Ontario, Canada, 2018 \\ (C) Yiming Li 2018
}




\section{Author's Declaration}

\section{AUTHOR'S DECLARATION}

I hereby declare state that I am the only author of this dissertation. This is a true copy of the dissertation, including any required final revisions, as accepted by my examiners.

I authorize Ryerson University to lend this dissertation to other institutions or individuals for the purpose of scholarly research.

I further authorize Ryerson University to reproduce this dissertation by photocopying or by other means, in total or in part, at the request of other institutions or individuals for the purpose of scholarly research.

I understand that my dissertation may be made electronically available to the public. 


\begin{abstract}
Bioactive Borate-Based Glass Coatings for Titanium Alloy Femoral Stems
\end{abstract}

Doctor of Philosophy, 2018, Yiming Li,

\title{
Mechanical and Industrial Engineering, Ryerson University.
}

Hydroxyapatite (HA)-coated Ti6Al4V stems are currently used in total hip replacement (THR) surgeries. However, the residual stress in the HA coating due to mismatch in coefficient of thermal expansion (CTE) between HA and Ti6Al4V limits their application. Borate-based glasses can be promising alternatives to HA because of their similar CTEs to that of Ti6Al4V and excellent bioactivity that can promote bone repair. In this project, six borate-based glasses $(L y-B O, L y-B 1$, $L y-B 2, L y-B 3, L y-B 4, L y-B 5)$ from the $\mathrm{B}_{2} \mathrm{O}_{3}-\mathrm{P}_{2} \mathrm{O}_{5}-\mathrm{CaO}-\mathrm{Na}_{2} \mathrm{O}-\mathrm{TiO}_{2}-\mathrm{SrO}$ series were formulated by increasing the concentration of strontium oxide $(\mathrm{SrO})$ from 0 to $25 \mathrm{in} \mathrm{mol} \%$ at the expense of $\mathrm{B}_{2} \mathrm{O}_{3}$ in the glass series. Increased $\mathrm{SrO}$ content induced larger amounts of non-bridging oxygens and resulted in gradual increases in glass transition temperature $\left(\mathrm{T}_{\mathrm{g}}\right)$. Discs of each glass powder were immersed in de-ionized water under 1, 7 and 30 days, and then the water extracts were used to determine the solubility and osteo-stimulatory effect of the glasses. $\mathrm{Sr}^{2+}$ doping retarded the dissolution rate of the glasses and the higher levels of $\mathrm{Sr}^{2+}$ doping (20 mol\% and $25 \mathrm{~mol} \%$ ) promoted proliferation of osteoblasts. Except for Ly-B5 (containing $25 \mathrm{~mol} \% \mathrm{SrO}$ ), discs of each glass powder exhibited bacteriostatic behavior against Staphylococcus aureus after 24 hours exposure. The glasses were enamelled onto Ti6Al4V substrates, and then bi-layer double cantilever beam (DCB) specimens were manufactured to measure the Mode I $\left(G_{I C}\right)$ and Mode II $\left(G_{I I C}\right)$ energy release rate of the glass coating/Ti6Al4V constructs. The mean $G_{I C}$ values increased 
from $6.56 \pm 0.9$ to $14.61 \pm 2.1 \mathrm{~J} / \mathrm{m}^{2}$ with increasing SrO content from $L y-B O$ to $L y-B 5$, and the mean $G_{I I C}$ values increased from $36.07 \pm 3.8$ to $46.92 \pm 3.3 \mathrm{~J} / \mathrm{m}^{2}$ with increasing $\mathrm{SrO}$ content from $L y-B O$ to $L y-B 5$, indicating that the incorporation of $15-25 \mathrm{~mol} \%$ SrO significantly increased the fracture toughness of the construct. Moreover, the $G_{I C}$ and $G_{I I C}$ values of the coating/substrate system for all the six glasses significantly reduced $(p \leq 0.05)$ due to degradation in de-ionized water. 


\section{Acknowledgements}

I would like to thank Dr. Mark Towler and Dr. Marcello Papini for being great advisors throughout the entire duration of my $\mathrm{Ph} . \mathrm{D}$. studies and for the many opportunities and valuable pieces of advice that they have given to me.

Additionally, I would like to thank Dr. Waldman (Chemical Engineering, Ryerson University, Toronto, Canada), Dr. Schemitsch (Keenan Research Centre, St. Michael's Hospital, Toronto,

Canada), Dr. Zalzal (Oakville Memorial Hospital, Oakville, Canada), Dr. Curran, Dr.Wendy Stone, Warren Tang, Qiang Li and Shawn McFadden for their great help on the experiments and writing of my publications and dissertation.

I also would like to thank all my colleagues and friends who gave me great advice on my research and life. I could not have done it without their help. I especially thank Dr. Omar Rodriguez and Dr. Adel Alhalawani for helping me start everything in Toronto, Mike Matinmanesh for the excellent co-operation, and Dr. Yin Liu and Dr. Yuxuan Gong for helping me perform the experiments at Alfred University.

I would especially like to express gratitude to Dr. Anthony W. Wren, a great friend, who enlightened and helped me in the research field from the very beginning.

Above all, I want to thank my family, my parents, my parents-in-law, and my husband, for their constant support.

This work is dedicated to Yiyu Li. 


\section{Table of Contents}

AUTHOR'S DECLARATION .............................................................................. ii

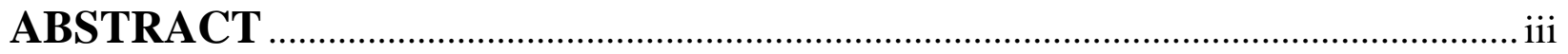

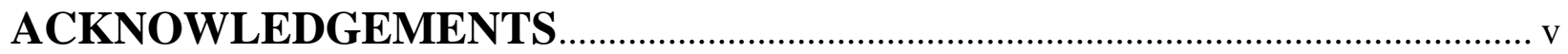

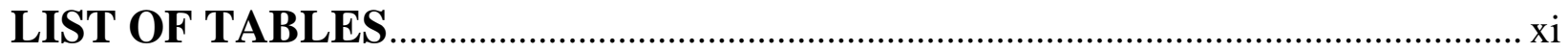

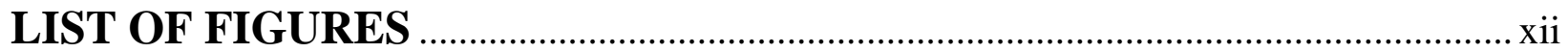

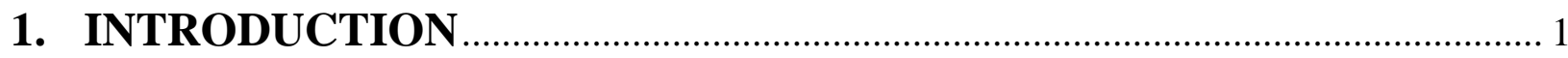

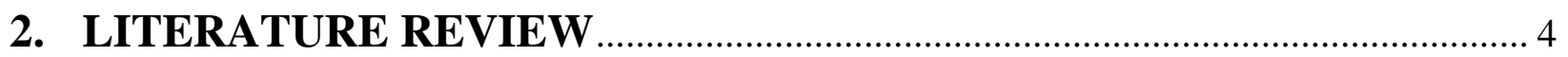

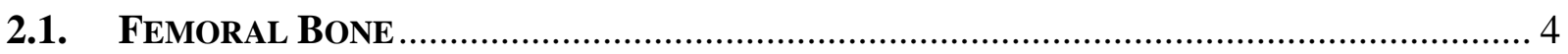

2.1.1. Bone construct .............................................................................................. 4

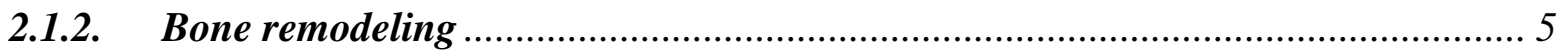

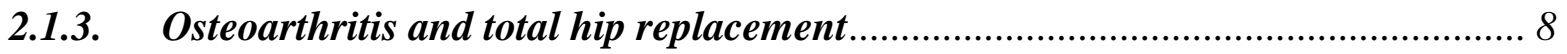

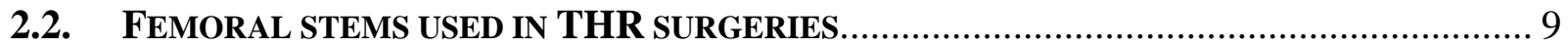

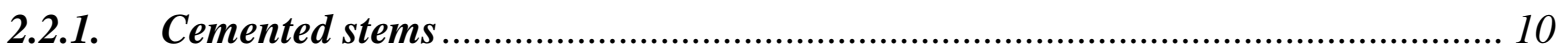

2.2.1.1. Polymethylmethacrylate bone cement................................................................ 10

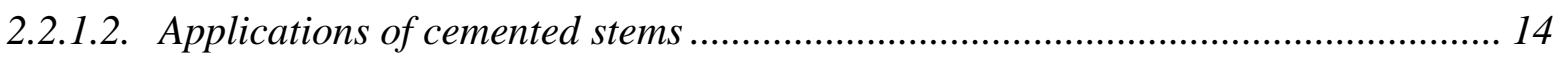

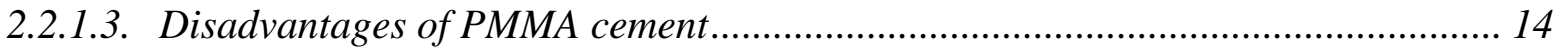

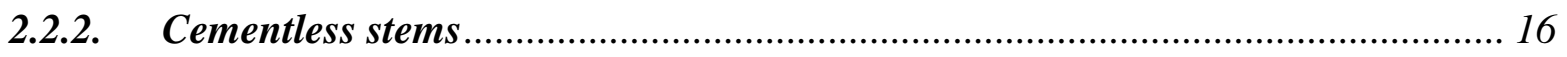

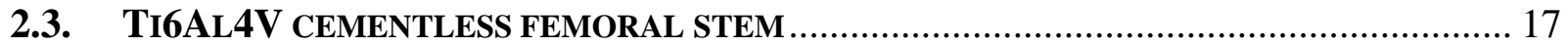

2.3.1. Application of Ti6Al4V cementless stems …………......................................... 17

2.3.2. Aseptic loosening of cementless Ti6Al4V stems ……………………................. 19

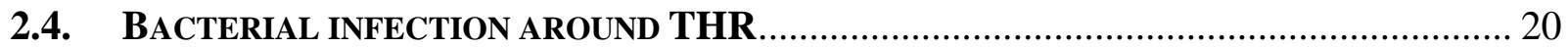

2.5. HYDROXYAPATITE COATING FOR TI6AL4V STEMS ………….................................. 23 
2.5.1. Osseointegration of HA coated Ti6Al4V stems............................................. 23

2.5.2. Antibacterial effects of Ag-HA coated Ti6Al4V implants ................................ 25

2.5.3. Residual stress in HA coatings on Ti6Al4V substrates ................................... 26

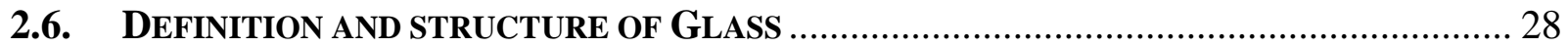

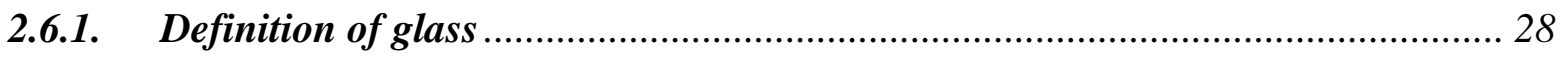

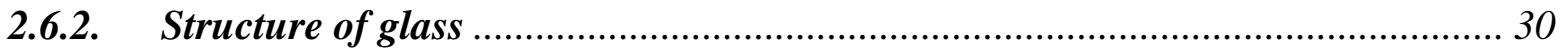

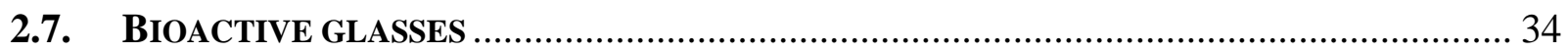

2.7.1. The fundamentals of bioactive glasses ........................................................... 34

2.7.2. Degradation and bioactivity of bioactive glasses ............................................ 35

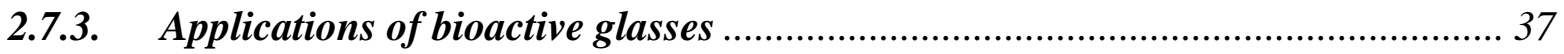

2.7.4. Bioactive silicate glass/glass-ceramic coatings for Ti6Al4V implants................ 39

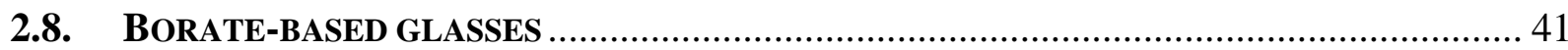

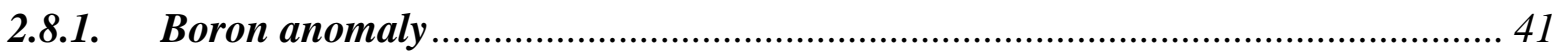

2.8.2. Dissolution of borate-based glasses............................................................ 43

2.8.3. Applications of bioactive borate-based glasses ............................................. 44

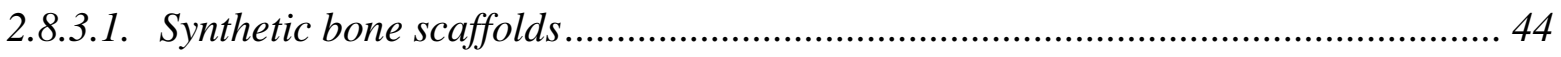

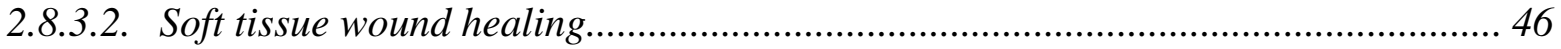

2.8.3.3. Drug delivery system.................................................................................. 47

2.8.4. Borate-based glass coatings for Ti6Al4V implants........................................ 48

2.8.5. Osseointegration of Titanium implants coated with borate glass ..................... 48

2.9. FunCtions OF TitaniUm (Ti) AND STRONTIUM (SR) IN THE BiOACTIVE GLASSES .... 49

2.9.1. Functions of Ti in bioactive glasses ......................................................... 50

2.9.2. Function of Sr in bioactive glasses ........................................................... 51 


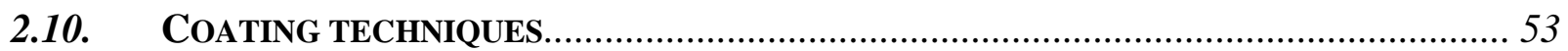

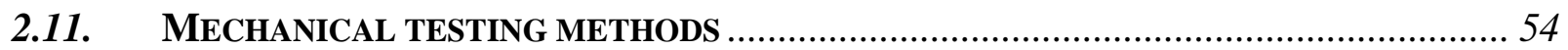

2.11.1. Qualitative methods for adhesion strength measurement .................................. 54

2.11.2. Quantitative method for adhesion strength measurement …….......................... 56

2.11.3. The method for residual stress measurement ………………............................. 58

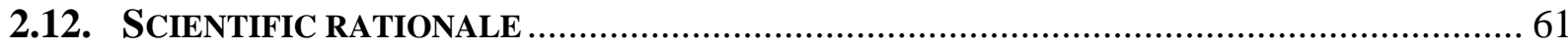

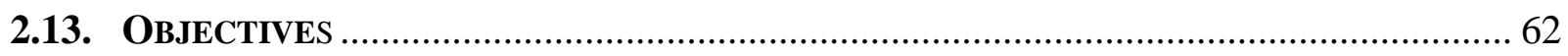

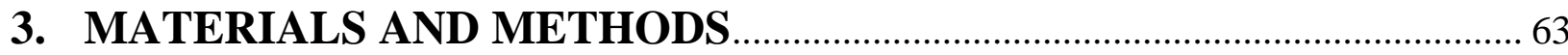

3.1. CHARACTERIZATION OF THE BORATE-BASED GLASS SERIES ........................................ 63

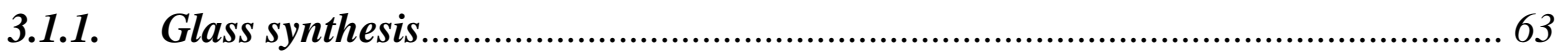

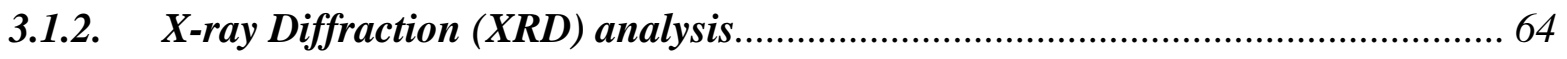

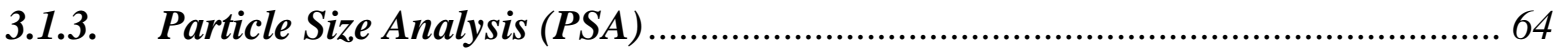

3.1.4. Scanning Electron Microscopy (SEM) and Energy-dispersive spectrometry

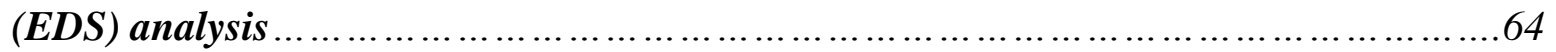

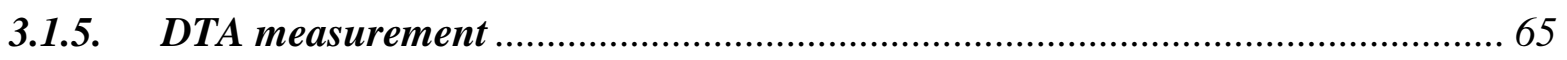

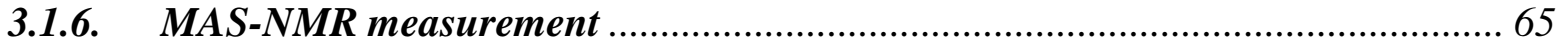

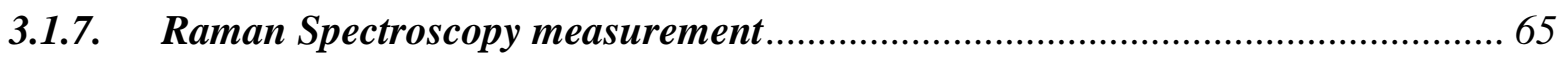

3.2. SOLUBILITY, ANTIBACTERIAL AND OSTEO-STIMULATORY EFFECTS OF THE BORATE-

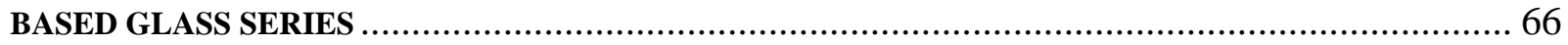

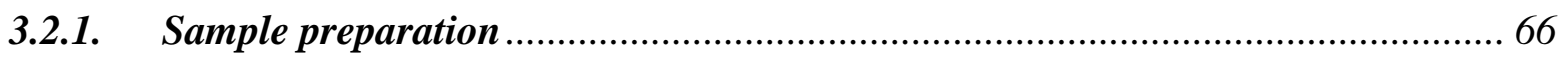

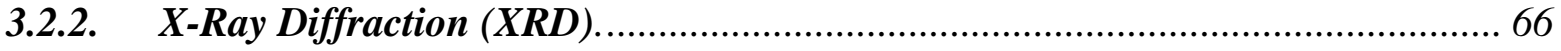

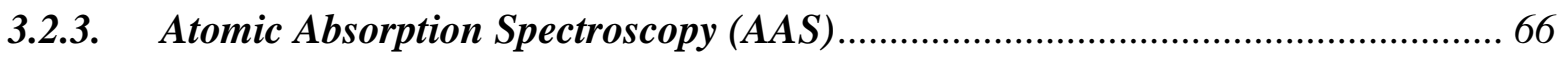

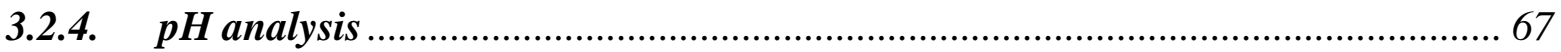

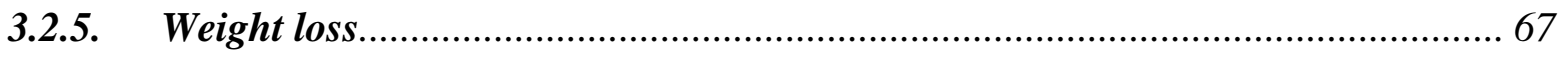




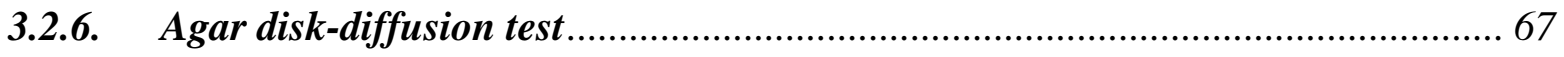

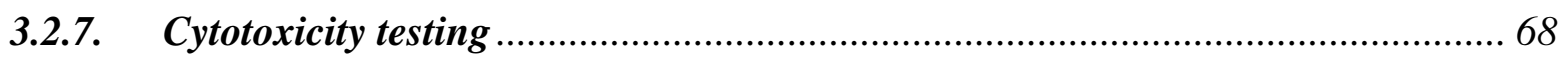

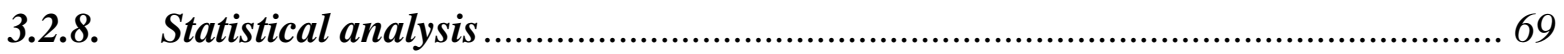

3.3. MEChANICAL PROPERTIES AND SOlUbILITY OF THE BORATE GLASS

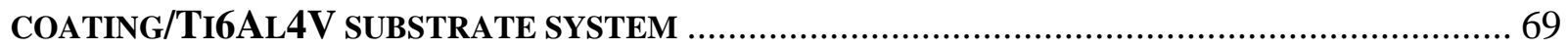

3.3.1. Fabrication of glass coatings onto Ti6Al4V substrates ......................................... 69

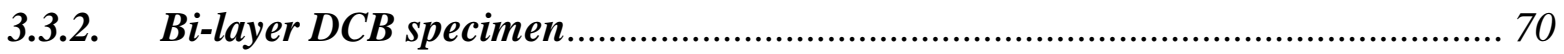

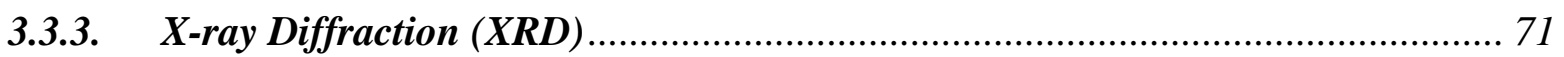

3.3.4. Measurement of the coefficient of thermal expansion (CTE) of the glasses....... 72

3.3.5. Measurement of Mode I critical strain energy release rate $\left(G_{I C}\right)$

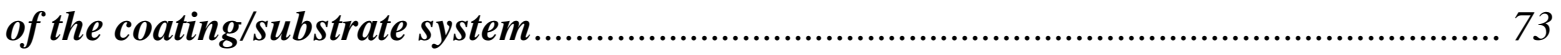

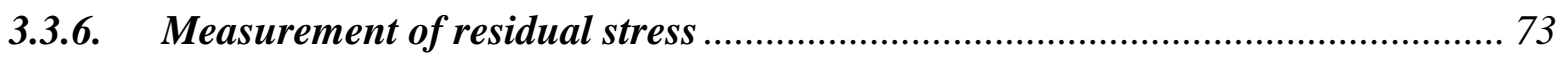

3.3.7. Measurement of Mode II critical strain energy release rate $\left(G_{I I C}\right)$

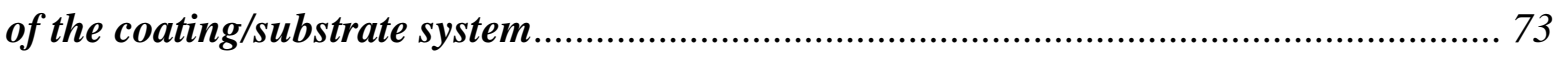

3.3.8. Degradation of the coatings and weight loss ................................................... 76

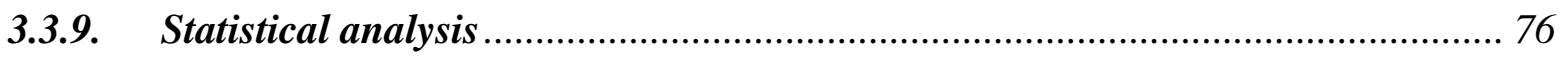

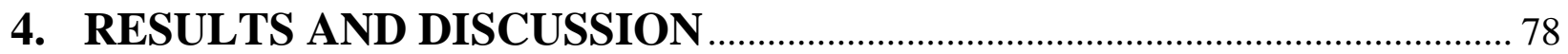

4.1. ChaRACTERIZATION OF THE BORATE-BaSED GLaSS SERIES .................................... 78

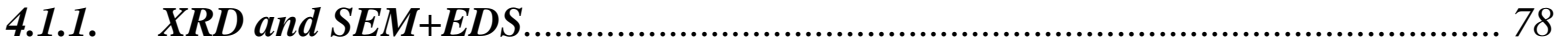

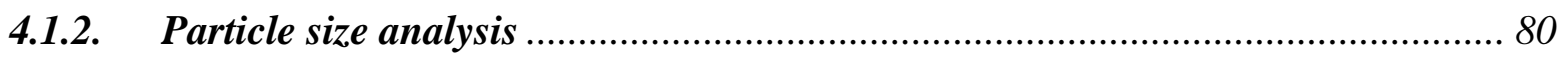

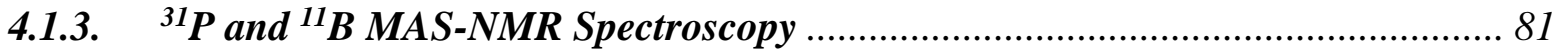

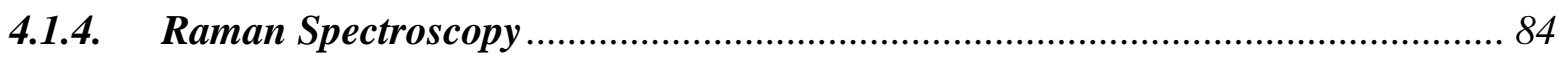

4.1.5. DTA 
4.2. SOLUBILITY, ANTIBACTERIAL AND OSTEO-STIMULATORY EFFECTS OF THE BORATE-

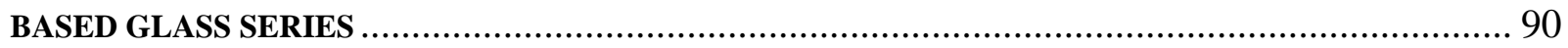

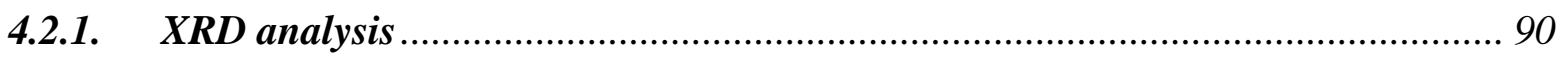

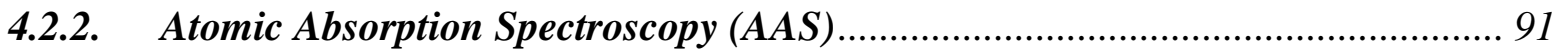

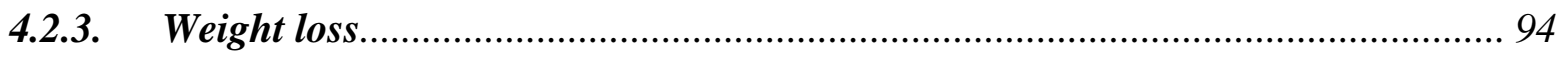

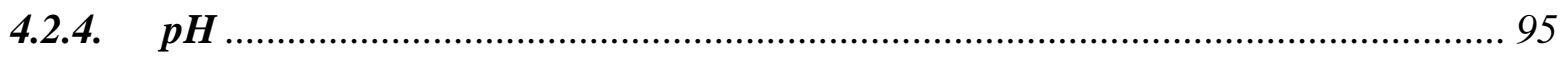

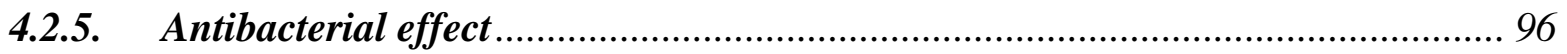

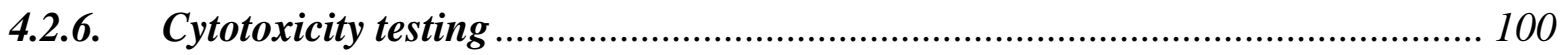

4.3. MECHANICAL PROPERTIES AND SOLUBILITY OF THE BORATE GLASS COATING/TI6AL4V SUBSTRATE SYSTEM .............................................................. 101

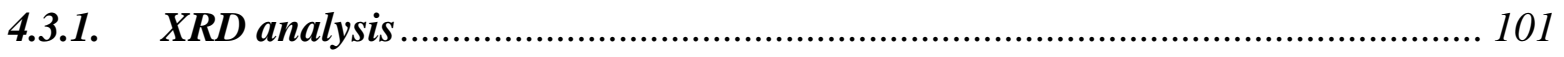

4.3.2. Measurement of Mode I critical strain energy release rate $\left(G_{I C}\right)$ of the constructs 102

4.3.3. Measurement of Mode II critical strain energy release rate (GII) of the constructs and residual stress............................................................................................. 105

4.3.4. Measurement of $G_{I C}$ and $G_{I I C}$ values of the constructs after degradation........ 109

5. CONCLUSIONS AND FUTURE WORK ................................................ 115

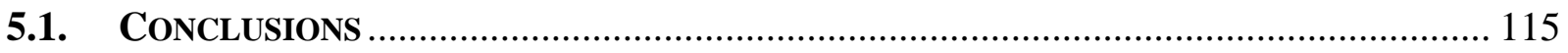

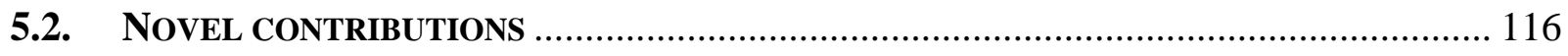

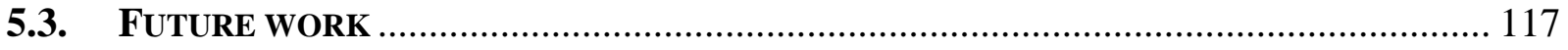

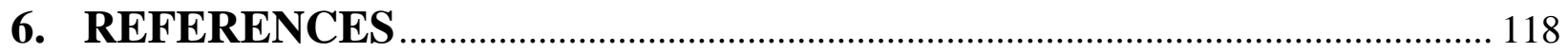




\section{List of Tables}

Table 2.1. Compositions of three commercial formulations of bone cement, where compositions are in percent. ${ }^{62}$

Table 2.2. Elastic modulus of 316 L-SS, Co-Cr, Ti6Al4V and bone. ${ }^{106,117}$............................ 18

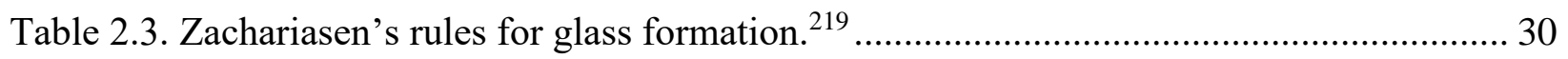

Table 2.4. The process of HA formation after bioactive glasses degradation in liquid. ${ }^{253} \ldots \ldots \ldots . . . . .36$

Table 2.5. Available data in the literature on the CTE of bioactive glasses. For each glass, the composition (in wt\%), the CTE and the reference are indicated. ${ }^{281}$

Table 3.1. Compositions of the borate based glass series, displayed in mol\% .......................... 63

Table 4.1. Assignments of Raman bands of the borate-based glass series.............................. 86

Table 4.2. Thermal profiles (DTA curve) of the borate based glass series. .............................. 88 


\section{List of Figures}

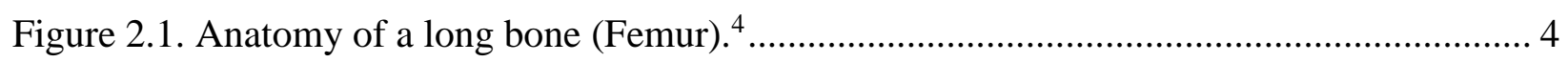

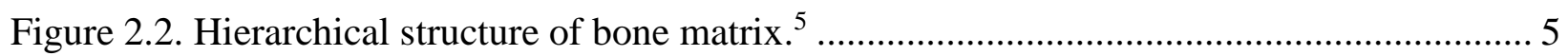

Figure 2.3. Bone remodeling process: osteoclasts (blue cell with black core) erode the bone matrix, and then osteoblasts (fat blue cells with blue core) derived from mononuclear cells (green cells) produce regulators of matrix mineralization, and transform into osteocytes (star shape cells) embedded in the mineralized matrix or lining cells (flat blue cell) covering the bone surface. ${ }^{20}$.. 6

Figure 2.4. A schematic diagram outlining the signals that control the generation of osteoblast and osteoclasts, where "+" represents positive influences and "-" represents negative influences. ${ }^{18} \ldots 8$

Figure 2.5. Fixation between bone and (a) a cementless stem though a coating, and (b) a cemented stem through bone cement. ........................................................................................... 9

Figure 2.6. Early model of an artificial hip joint in (a) $1938^{50}$ and (b) between 1956-1969. ${ }^{57} \ldots 10$

Figure 2.7. Polymerization of PMMA:(a) a free radical polymerization process between BPO and DMPT, (b) the polymerization of MMA and growth of PMMA chains . ${ }^{63}$ 12

Figure 2.8. (a) Photograph by oblique illumination to reveal the large surface area of the cement in contact with the bone, (b) Radiograph presenting prosthesis fixed by cement. ${ }^{71}$..... 14

Figure 2.9. Scanning electronic micrograph showing: (a) fractures through the cement mantle (small black arrows) initiating at the cement-metal interface (hollow arrows) and (b) the prosthesis had migrated into retroversion where the black arrows indicate the cement fractures. ${ }^{78}$ 15

Figure 2.10. Images of (a) cylindrical $\mathrm{stem}^{90}$, (b) anatomic stem ${ }^{91}$, and (c) tapered stem ${ }^{92} \ldots \ldots \ldots .16$

Figure 2.11. Schematic drawing presenting salient features of biofilm formation in a staphylococcal biofilm model. The blue boxes show the primary process in biofilm formation, the orange boxes present the chemical environment, and the red-brown boxes indicate the phenotype. EPS represents extracellular polymeric substances. ${ }^{150}$ 21

Figure 2.12. Bacterial attachment and fixation to biomaterials surface by a bacterial active process: Biofilm formation through (a) exopolysaccharide production, (b) release of eDNA, (c) protein factors. ${ }^{160}$ 22

Figure 2.13. HA-coated stems: (a) ABG-I stem made of Ti6Al4V and proximally coated with $\mathrm{HA}^{182}$ and (b) Corail ${ }^{\circledR}$ femoral stem made of Ti6Al4V and fully coated with $\mathrm{HA}^{183}$............... 24

Figure 2.14. SEM images of HA-coated Ti6Al4V implants implanted into (a) rabbits after 8 weeks ${ }^{192}$ and (b) dogs after 72 weeks ${ }^{193}$ in vivo, where the cracks on the HA coatings and the interface between the coatings and the substrates (black arrow) can be observed. 26 
Figure 2.15. SEM micrographs of the surface and the HA coating onto Ti6Al4V alloy substrate. ${ }^{201}$

Figure 2.16. Effect of temperature on the enthalpy of a glass forming melt. ${ }^{206}$ 29

Figure 2.17. The three-dimensional structure of silica, where silica tetrahedra bond together in a random arrangement. A silica tetrahedron consists a silicon atom (blue) surrounded by four oxygen atoms (black outline). 31

Figure 2.18. The structural fragment of $\mathrm{B}_{2} \mathrm{O}_{3}-\mathrm{SiO}_{2}-\mathrm{P}_{2} \mathrm{O}_{5}-\mathrm{Na}_{2} \mathrm{O}-\mathrm{CaO}$ glass. ${ }^{227}$ 32

Figure 2.19. The conversion of $\mathrm{Q}_{4}$ tetrahedron to $\mathrm{Q}_{3}$ tetrahedron introduced by a $\mathrm{Na}_{2} \mathrm{O}$. 33

Figure 2.20. Bioactivity map of compositions in the $\mathrm{SiO}_{2}-\mathrm{Na}_{2} \mathrm{O}-\mathrm{CaO}$ system $\left(6 \mathrm{wt} \%\right.$ of $\left.\mathrm{P}_{2} \mathrm{O}_{5}\right)$ showing regions of bioactive response. ${ }^{242}$ 35

Figure 2.21. BonAlive ${ }^{\circledR}$ (Meditech, MA, US), S5P5 bioactive glass particles $(500-800 \mu \mathrm{m})$, stored in a syringe. 38

Figure 2.22. Borate groups observed in different borate compounds. Dotted lines though the oxygen ions $(\varnothing)$ indicate the bridging type. ${ }^{291}$.... 42

Figure 2.23. Qualitative model for the conversion of bioactive silicate (45S5), borate, and borosilicate glasses to HA in a dilute phosphate solution. ${ }^{299}$ 43

Figure 2.24. (a) CAD models of five architectures: (i) cubic, (ii) spherical, (iii) X, (iv) diamond, and (v) gyroid; (b) 13-93B3 scaffolds with different architectures after sintering. ${ }^{311}$ 45

Figure.2.25 SEM images of borate-based bioactive glass scaffolds seeded with MLO-A5 cells and cultured for (a), (d) 2 days; (b), (e) 4 days and (c), (f ) 6 days. ${ }^{312}$ 46

Figure 2.26. Transmitted light images of TB-stained sections of rabbit tibiae, after implantation for six weeks with (a) animals implanted with bioactive borate glass-coated Ti devices and (b) animals implanted with uncoated Ti devices (ST: soft tissue IC: inflammatory cells). ${ }^{331} \ldots$ 49

Figure 2.27. Structural fragment of $\mathrm{Li}_{2} \mathrm{O}-\mathrm{K}_{2} \mathrm{O}-\mathrm{B}_{2} \mathrm{O}_{3}$ glass network doped with $\mathrm{TiO}_{2}{ }^{337} \ldots \ldots \ldots \ldots . . .50$

Figure 2.28. The composition of strontium ranelate .................................................... 51

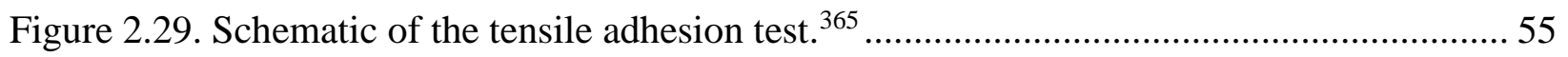

Figure 2.30. (a) Schematic of scratching adhesion test ${ }^{370}$ and (b) SEM image $\mathrm{e}^{364}$ of the scratch track

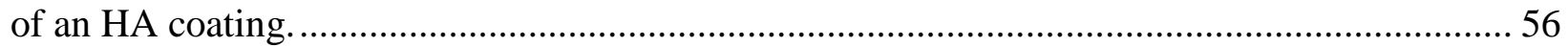

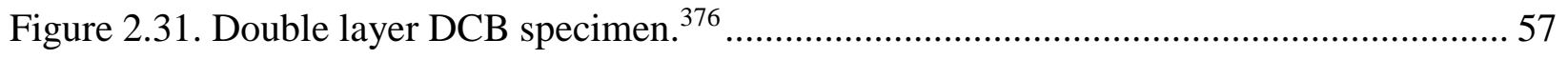


Figure 2.32. The schematic of the analysis of residual stresses during cooling phase of the coating

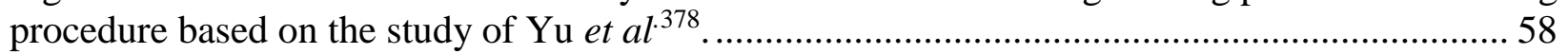

Figure 3.1. The coated samples used for the (a) Mode I and (b) Mode II tests......................... 71

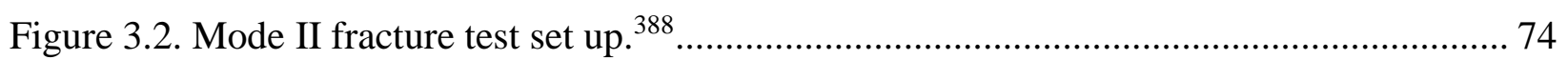

Figure 4.1. XRD patterns of the borate glass series........................................................ 78

Figure 4.2. SEM images with EDS data of the bioactive borate glass series.......................... 79

Figure 4.3. Particle size of the borate-based glasses $(n=3)$. Scatter bars indicate the standard

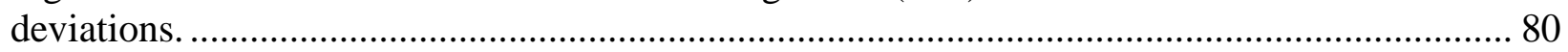

Figure 4.4. ${ }^{31} \mathrm{P}$ MAS-NMR spectra of the borate-based glass series. The peak position of each glass

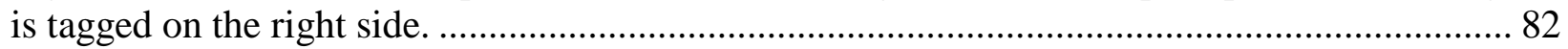

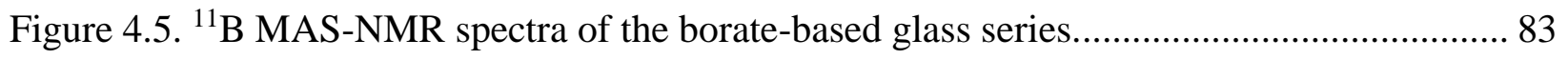

Figure 4.6. Raman spectra of the borate-based glass series................................................ 84

Figure 4.7. Fitted Raman spectra of the borate-based glass series, where $\mathrm{R}^{2} \geq 0.98 \ldots \ldots \ldots \ldots \ldots . . . .15$

Figure 4.8. The conversion of $\left[\mathrm{B} \emptyset_{4}\right]$ units into $\left[\mathrm{B} \emptyset_{2} \mathrm{O}\right]^{-}$and $\left[\mathrm{BO}_{3}\right]$, where $\varnothing$ represents bridging

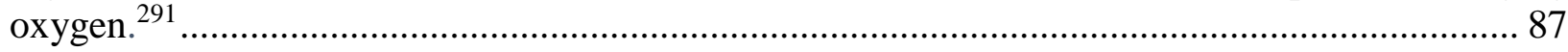

Figure 4.9. Glass transition temperature $\left(\mathrm{T}_{\mathrm{g}}\right)$ of the borate-based glass series......................... 88

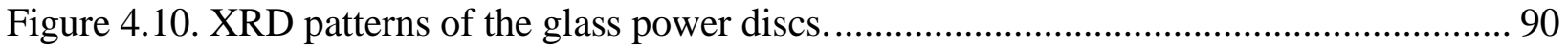

Figure 4.11. Concentration of $\mathrm{Na}^{+}$from the water extracts of the glass series $(n=3)$ versus incubation time. Scatter bars indicate the standard deviations. 91

Figure 4.12. Concentration of $\mathrm{Ca}^{2+}$ from the water extracts of the glass series $(n=3)$ versus incubation time. Scatter bars indicate the standard deviations. .92

Figure 4.13. Concentration of $\mathrm{Sr}^{2+}$ from the water extracts of the glass series $(n=3)$ versus incubation time. Scatter bars indicate the standard deviations. 93

Figure 4.14. Weight loss of the glass discs $(n=3)$ versus incubation time, where scatter bars represent the max and min values of the data, where the lines are used only to guide the eye.... 94

Figure 4.15. $\mathrm{pH}$ values of the water extracts of the glass series $(n=3)$ with different incubation times, where the $\mathrm{pH}$ values of 30-days incubation are tagged on the image. Scatter bars indicate the standard deviation of the data. 95 
Figure 4.16. Diameters of inhibition zones of the glasses against $S$. aureus after 24-hours incubation where the max and min values of the data are presented as scatter bars. 97

Figure 4.17. Cell metabolic activity from sintered glass powder discs ( $n=3)$ extracts after 30-days incubation. Scatter bars indicate the standard deviations. 100

Figure 4.18. XRD patterns of all the glass coatings, where the coating temperature are tagged in the image. 102

Figure 4.19. Mode I critical strain energy release rate $\left(G_{I C}\right)$ and the thickness of the borate-based glass coating-Ti6Al4V substrate system. Scatter bars indicate the standard deviation of the data. 103

Figure 4.20. The thickness and residual stress in the glass coatings $(n=3)$, where the scatter bars represent the max and min values of the data. 106

Figure 4.21. The CTEs of Ti6Al4V ${ }^{196}, L y-B O, L y-B 3$ and $L y-B 5(n=3)$. Scatter bars indicate the max and min values of the data. 108

Figure 4.22. The critical energy release rate of Mode I $\left(G_{I C}\right)$ and Mode II $\left(G_{I C}\right)$ of glass coating/Ti6Al4V substrate systems $(n=3)$, where the bars represent the max and min values of the data. 109

Figure 4.23. Weight loss of the coatings after different incubation times, where the scatter bars represent the max and min values of the data. 110

Figure 4.24. The critical strain energy release rate in (a) Mode I $\left(G_{I C}\right)$ and (b) Mode II ( $\left.G_{I I C}\right)$ of the borate-based glass coating/Ti6Al4V substrate systems before and after degradation with different incubation times, where scatter bars indicate the min and max values. 113 


\section{Introduction}

Hydroxyapatite (HA)-coated Ti6Al4V stems have been extensively employed in Total Hip Replacement (THR) surgeries, as the HA coatings can improve the osseointegration of cementless stems for stronger fixation with bone. However, the long-term application of HA-coated Ti6Al4V stems is problematic, because the residual stress between the coating and the Ti6Al4V substrate due to the mismatch in CTE can initiate cracks and even de-bond the coatings. This is driving innovation in the bioactive borate glass coatings field.

A review of pertinent literature was performed to provide the rationale for the project. In THR surgeries, artificial stems are implanted into the femur (femoral bone) (Section 2.1.1), influencing the bone remodeling process (Section 2.1.2). The stems are initially fixed with bone using Polymethyl methacrylate (PMMA) cements (Section 2.2.1-2.2.2), where successful applications have been widely reported. However, fractures in the cement and the osteolysis associated with the cement debris have led to the failure of the cemented stems (Section 2.2.1-2.2.2). Cementless stems can be used to avoid such issues (Section 2.2.3) but can result in other problems. Ti6Al4V is the most commonly used material for cementless femoral stems because of its corrosion resistance and biocompatibility. (Section 2.2). However, aseptic loosening of the Ti6Al4V cementless stems (Section 2.2.5) and bacterial infection (Section 2.2.6) around the stems can result in the need for revision surgery.

In order to achieve better fixation between cementless Ti6Al4V stems and bone, HA (Section 2.5) has been applied as bioactive coatings on the Ti6Al4V stems. Nevertheless, the mismatch in coefficient of thermal expansion (CTE) between HA and Ti6Al4V limits the long-term application 
of HA coatings (Section 2.5.2). Due to their ability to facilitate bone repair, bioactive glasses can be considered as bioactive coating materials for cementless Ti6Al4V stems.

Bioactive glasses, like all glasses, contain short-range atomic arrangements, where the glass network formers, such as $\mathrm{SiO}_{2}$ and $\mathrm{B}_{2} \mathrm{O}_{3}$, build up the framework, while glass network modifiers, such as $\mathrm{Na}_{2} \mathrm{O}$ and $\mathrm{CaO}$, are incorporated into the glass structure (Section 2.6) to disrupt it. In the 1960 's, Larry Hench formulated the first bioactive glass; $45 \mathrm{SiO}_{2}-24.5-\mathrm{Na}_{2} \mathrm{O}-24.5 \mathrm{CaO}-6 \mathrm{P}_{2} \mathrm{O}_{5}$ in wt\%, 45S5 Bioglass ${ }^{\circledR}$ (Section 2.7.1). Such bioactive silicate glasses can degrade in aqueous environments, such as body fluid, and release the dissolution products which can facilitate bone growth (Section 2.7.2). Due to their bioactivity, silicate glasses are used as bioactive coatings for Ti6Al4V substrates. However, the bioactivity of silicate glasses with similar CTE to that of Ti6Al4V is impaired by large amounts ( $\geq 60 \mathrm{wt} \%)$ of $\mathrm{SiO}_{2}$ (Section 2.7.4).

Borate-based glasses can have similar CTEs to that of Ti6Al4V. Moreover, bioactive borate glasses can promote new bone formation; confirmed by their successful application in the orthopedic field, such as in synthetic bone scaffolds (Section 2.8.3). Therefore, borate glasses are promising candidates for coatingTi6Al4V stems. It has been reported that the adhesive strength between a borate glass coating and a Ti6Al4V substrate is higher than that between Ti6Al4V and 45S5 Bioglass ${ }^{\circledR}$ or Ti6Al4V and HA (Section 2.8.4).

A novel coating material for Ti6Al4V stems may be developed from borate-based glasses containing different amounts of strontium ( $\mathrm{Sr}$ ) (Section 2.9). The incorporation of $\mathrm{Sr}^{2+}$ can promote bone regeneration and allow for tailoring of the glass degradation rate (Section 2.9.2). Additionally, a new method needs to be proposed to measure the adhesion strength between the coating and the Ti6Al4V substrate, because the commonly utilized methods, such as tensile adhesion test and 
adhesion scratch test, can only measure the adhesion strength in a qualitative manner. In order to quantitatively measure the cohesive or adhesive strength of the glass coating/Ti6Al4V substrate system, a method inspired by fracture mechanics in which the critical energy release rate $\left(G_{I C}\right)$ is measured has been employed (Section 2.11.2). 


\section{Literature Review}

\subsection{Femoral Bone}

\subsubsection{Bone construct}

There are four categories of bones in the human body: long, short, flat and irregular bones. ${ }^{1}$ The femoral bone (femur) is a long bone. ${ }^{2}$ The femur is composed of a diaphysis (which includes the medullary cavity), and proximal and distal epiphyses. The diaphysis is primarily built up by dense cortical (compact) bone, while the proximal and distal epiphysis, and endosteum are composed of cancellous (trabecular or spongy) bone. ${ }^{3}$ Figure 2.1 illustrates the structure of a femur.

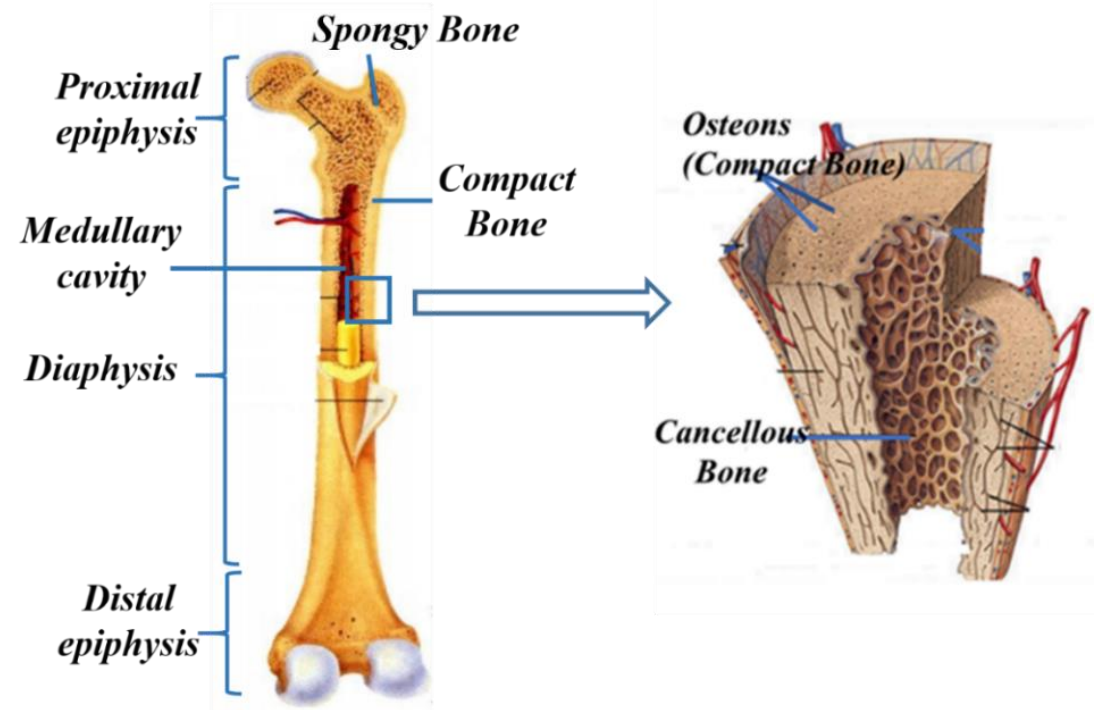

Figure 2.1. Anatomy of a long bone (Femur). ${ }^{4}$

Bone tissue consists of bone cells embedded in mineralized bone matrix. ${ }^{4}$ The two major nanophases of bone matrix are collagen, in fibrillary form, and hydroxyapatite (HA, $\left.\mathrm{Ca}_{10}\left(\mathrm{PO}_{4}\right)_{6}(\mathrm{OH})\right)$ in crystal form on the nano-scale. ${ }^{4}$ Collagen fibrils are composed of type-I 
collagen molecules, and HA nanocrystals are distributed along those fibrils. ${ }^{5,6}$ The sheets of lamellae, formed by parallel arranged collagen fibrils, wrap in concentric layers (3-8 lamellae) around a central canal constituting an osteon, referred to as the cortical bone Haversian system (Figure 2.2). ${ }^{7}$ The lamellae also run parallel to each other in trabecular bone. ${ }^{8}$ The bone cells that lie within the bone matrix regulate bone remodeling. ${ }^{9}$

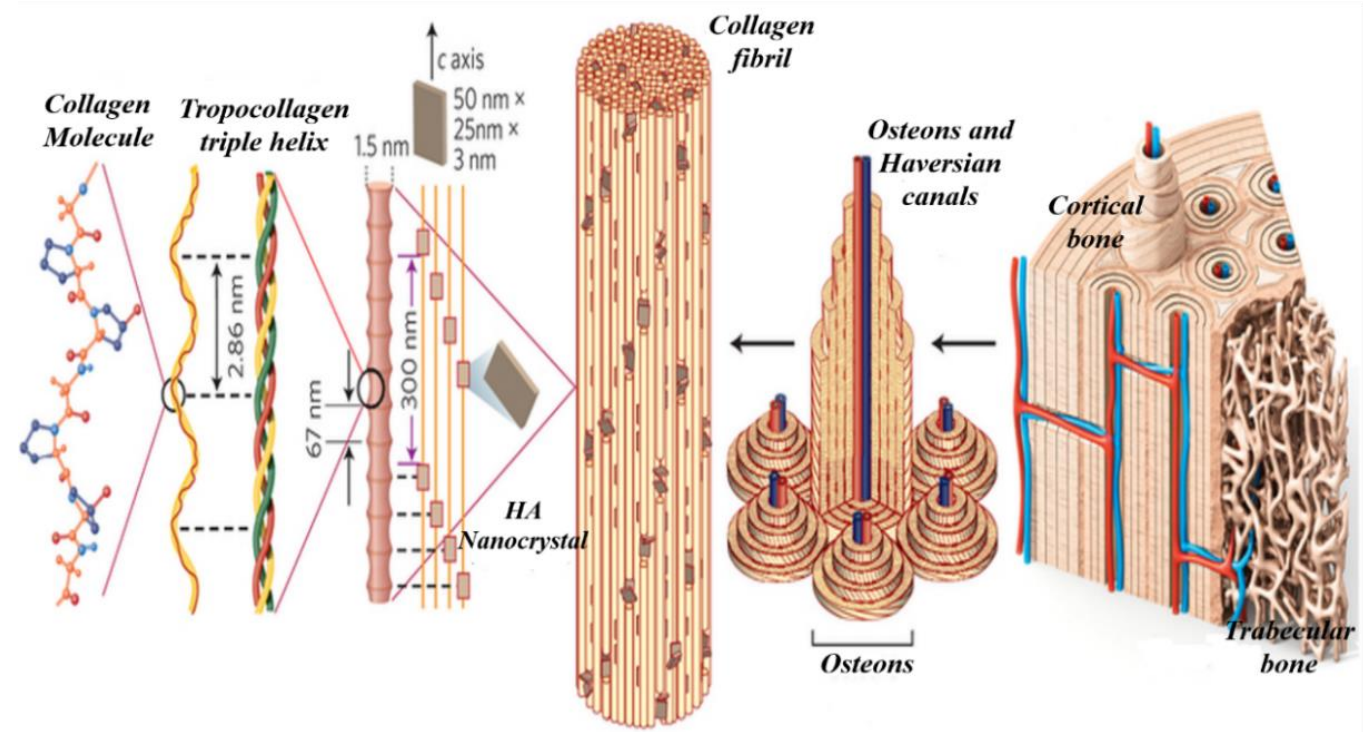

Figure 2.2. Hierarchical structure of bone matrix. ${ }^{5}$

\subsubsection{Bone remodeling}

Bone remodeling replaces old bone with new bone ensuring the integrity of the bone tissue. ${ }^{10}$ It is necessary to keep the balance between bone resorption and formation, because excessive bone loss can increase fracture risk, and excessive bone gain can be associated with illnesses, e.g., psoriatic arthritis and ankylosing spondylitis. ${ }^{11,} 12$ The bone remodeling cycle starts with osteoclastic resorption, where osteoclasts erode a resorption lacuna by secreting the acid phosphatase, isoenzyme. ${ }^{13,14}$ The resorption period is followed by the bone formation period. ${ }^{15}$ 
During the formation period, osteoblasts derived from mesodermal and neural crest progenitor cells produce regulators of matrix mineralization, and transform into osteocytes embedded in the mineralized matrix or lining cells covering the bone surface. ${ }^{16-18}$ The bone remodeling cycle completes when new bone fills the resorption lacuna. ${ }^{19}$ Figure 2.3 shows the bone remodeling process.

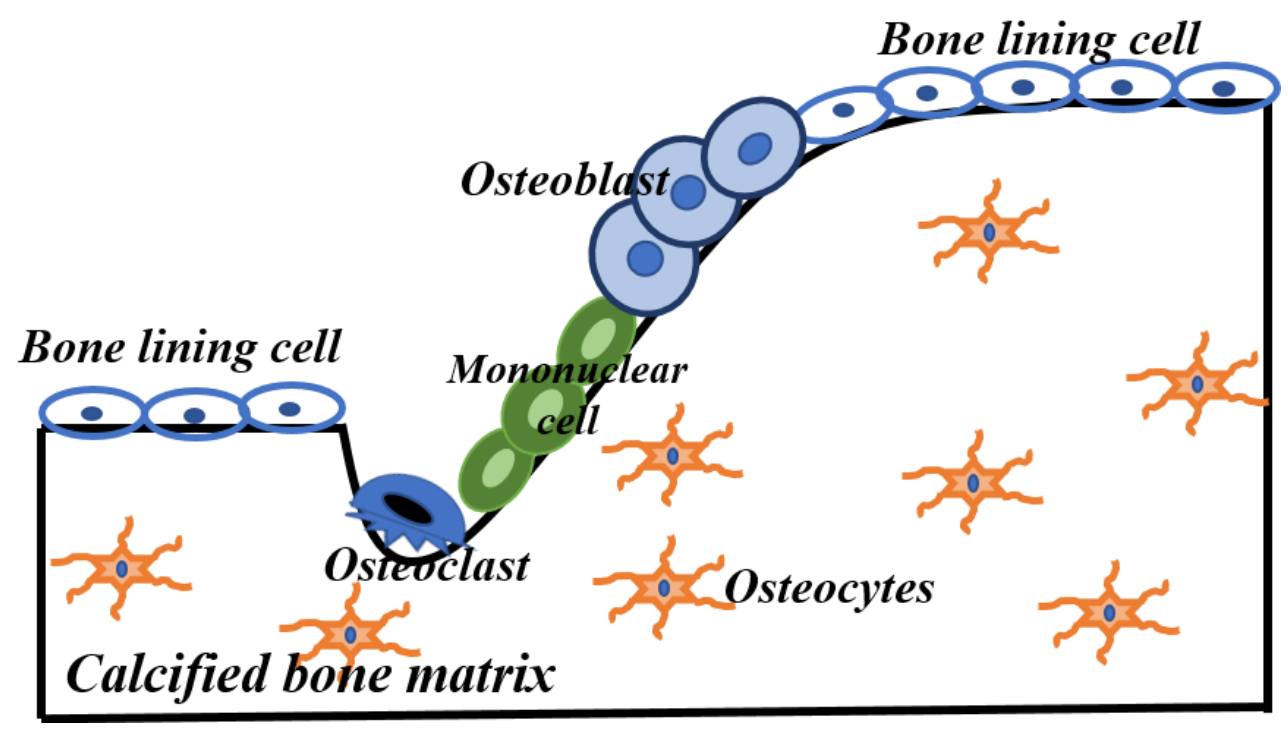

Figure 2.3. Bone remodeling process: osteoclasts (blue cell with black core) erode the bone matrix, and then osteoblasts (fat blue cells with blue core) derived from mononuclear cells (green cells) produce regulators of matrix mineralization, and transform into osteocytes (star shape cells) embedded in the mineralized matrix or lining cells (flat blue cell) covering the bone surface. $^{20}$

In the first step of bone formation, a transcription factor, Runt-related transcription factor 2 (Runx2), facilitates the progenitor cell differentiation along the osteoblast lineage. ${ }^{17,}{ }^{21}$ Runx2 is sufficient to encourage the expression of osteoblast markers in the non-osteoblastic cell. ${ }^{22}$ Runx 2 can also regulate the expression of genes encoding the activation of Receptor Activator of Nuclear Factor Kappa-B Ligand (RANKL), and dentin matrix protein 1 (DMP1) ${ }^{23}$ Another transcription factor required for the differentiation of pre-osteoblastic cells into mature osteoblasts is Osterix 
(Osx) ${ }^{21,}{ }^{24}$ In addition, the development and maturation of osteoblasts are influenced by bone morphogenetic proteins (BMPs), growth factors (FGF and IGF) and hormones like PTH. ${ }^{25}$ The fully mature osteoblasts synthesize the bone cell special products, such as Type I collagen (Collagen I) and alkaline phosphatase (ALP). ${ }^{26}$ The mineralization of extracellular matrix (ECM) is initiated by the exclusive co-expression of Collagen I and ALP. ${ }^{27-29}$

During the bone remodeling process, some key signals produced by osteoblasts also have impacts on osteoclasts. ${ }^{18,30,31}$ A member of the tumor necrosis factor-receptor (TNF-R) family, known as RANKL, exists on the surface of osteoblast cells. RANKL can bind to another TNF-R family member, RANK to facilitate osteoclasts formation. ${ }^{32,33}$ A soluble protein, osteoprotegerin (OPG), is also able to bind to RANKL and act as an antagonist of RANK. ${ }^{34,35}$ Therefore, RANKL promotes the formation of osteoclasts inducing bone resorption, while OPG inhibits this process enhancing bone density. ${ }^{36}$ Additionally, since matured osteoclasts express proteins such as cathepsin $\mathrm{K}$ and tartrate-resistant acid phosphatase (TRAP) to typify the osteoclast lineage, ${ }^{37-39}$ TRAP is usually described as a marker of osteoclasts differentiation and bone resorbing activity. ${ }^{24}$ Figure 2.4 presents a schematic diagram outlining the procedure of the key signals mediating the generation of osteoblasts and osteoclasts. 


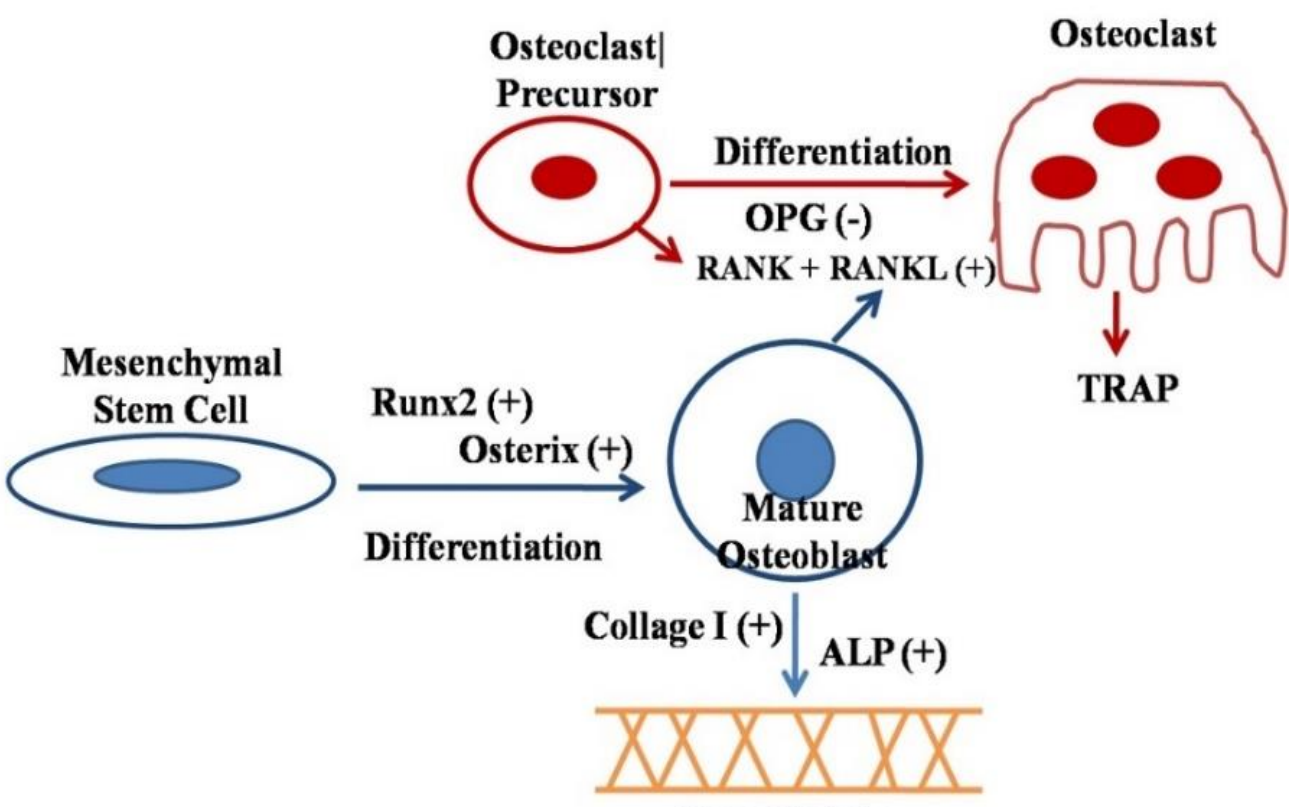

Bone Matrix

Figure 2.4. A schematic diagram outlining the signals that control the generation of osteoblast and osteoclasts, where "+" represents positive influences and "-" represents negative influences. ${ }^{18}$

\subsubsection{Osteoarthritis and total hip replacement}

Osteoarthritis $(\mathrm{OA})$ is a common disease resulting in progressive loss of articular cartilage. ${ }^{40}$ The main symptoms of OA of the hip are pain in the buttock, morning stiffness and dysfunction of the joint, which limits the daily activities of the patients. ${ }^{41}$ There are different treatments for OA in its different stages. Acetaminophen is the primary treatment for mild OA. ${ }^{42}$ Joint pain was reported to relieve when patients ingested $650-1000 \mathrm{mg}$ acetaminophen up to four times per day. ${ }^{42}$ When acetaminophen was unable to control the pain, nonsteroidal anti-inflammatory drugs (NSAIDs) were recommended to treat moderate to severe symptoms. Opiods ${ }^{43}$ are used to relieve pain when the patient has not responded to acetaminophen or NSAIDs. Total hip replacement (THR) surgery should be reserved for the patient who suffers the severe pain in the hip which cannot be controlled by other treatments. ${ }^{44}$ The THR device is composed of acetabular components 
and a stem which is implanted into the femur. ${ }^{45}$ Contact with the surrounding bone is through a hydroxyapatite (HA) coating (Figure 2.5 (a)) or a bone cement, such as polymethylmethacrylate (PMMA) (Figure 2.5 (b)). The fixation between bone and both cemented/cementless stems will be discussed in Sections 2.2.1 and 2.2.5, respectively. The dissolution productions released from glass coatings can influence the bone remodeling process and subsequently the fixation between bone and the implant ${ }^{46}$, which will be discussed in Section 2.5.

(a)

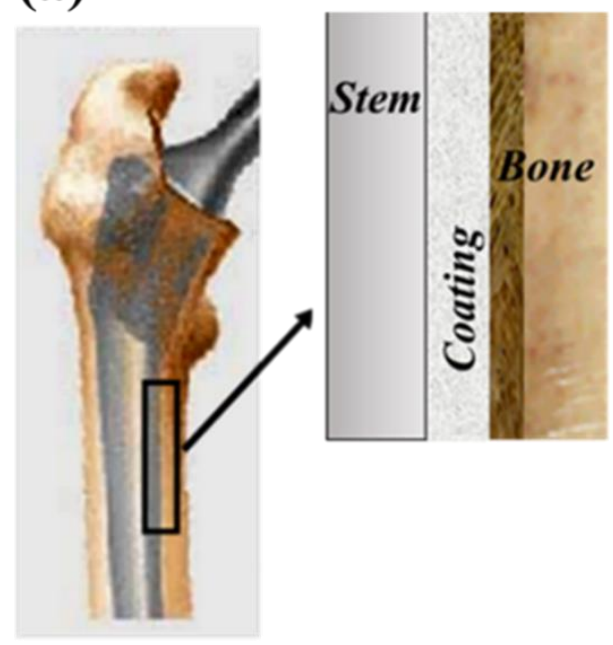

Cementless Stem (b)

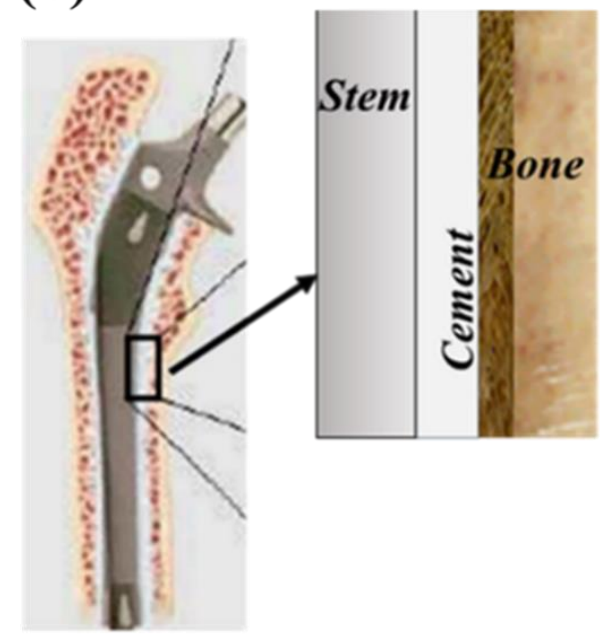

Cemented Stem

Figure 2.5. Fixation between bone and (a) a cementless stem though a coating, and (b) a cemented stem through bone cement.

\subsection{Femoral stems used in THR surgeries}

The large demand for THR surgery is a primary driving force for innovation in this space. In 2013-2014, there were 49,503 hip replacement surgeries performed in Canada. ${ }^{47}$ In the United States, approximately 2.5 million people are living with an artificial hip, ${ }^{48}$ and the demand for THR surgeries in the United States is expected to grow to $\sim 572,000$ per year by $2030^{49}$. 


\subsubsection{Cemented stems}

THR surgery was developed in 1938 (Figure 2.6 (a)) and was originally referred to as a sideplated fixation method. ${ }^{50}$ The total hip arthroplasty used in this method consisted of a stainless steel ball fixed to the femoral neck by means of a bolt and a stainless steel socket attached to the pelvis utilizing a plate and screws. ${ }^{51}$ The application of the total hip arthroplasty was not successful. ${ }^{52}$ Fink et al. ${ }^{53}$ reported about $40 \%$ failure of the device with pain over the side plate. In the late 1950s, John Charnley introduced a new THR design (Figure 2.6 (b)), consisting of a smalldiameter metallic femoral head articulating with a polymeric acetabular cup, and polymethylmethacrylate (PMMA) bone cement to fix the implant to bone. ${ }^{54-56}$
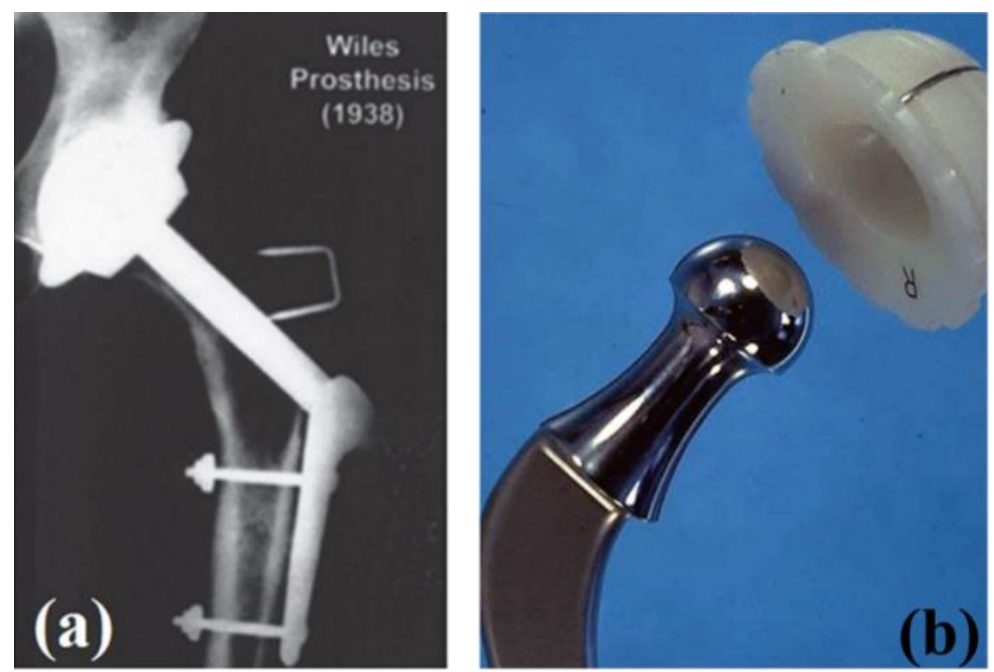

Figure 2.6. Early model of an artificial hip joint in (a) $1938^{50}$ and (b) between 1956-1969. ${ }^{57}$

\subsubsection{Polymethylmethacrylate bone cement}

Since its introduction over 40 years ago, the use of PMMA for femoral stem fixation has been the "gold standard" 58 in THR surgery. ${ }^{56,59,60}$ The commercial PMMA usually consists of powder components, containing pre-polymerized beads of PMMA (or PMMA/styrene copolymer), and a 
liquid containing MMA monomer. The benzoyl peroxide (BPO) initiator is incorporated into the powder and a chemical activator, such as dimethyl-p-toluidine (DMPT), is incorporated into the liquid. ${ }^{61}$ Barium sulphate (BaSO4) is also incorporated in the powder components as a radiopaque filler. When the powder and liquid components are mixed, polymerization of PMMA starts with a free radical polymerization process between BPO and DMPT (Figure 2.7 (a)), in which the phenyl radical (activated initiator) forms. Then the activated initiator initiates the polymerization of MMA (Figure 2.7 (b)). The PMMA chains grow by encapsulating the pre-polymerized PMMA beads within a solid matrix, resulting in increased viscosity of the cement. Compositions of three commercial formulations $^{62}$ of PMMA bone cement are collated in Table 2.1. 
(a)

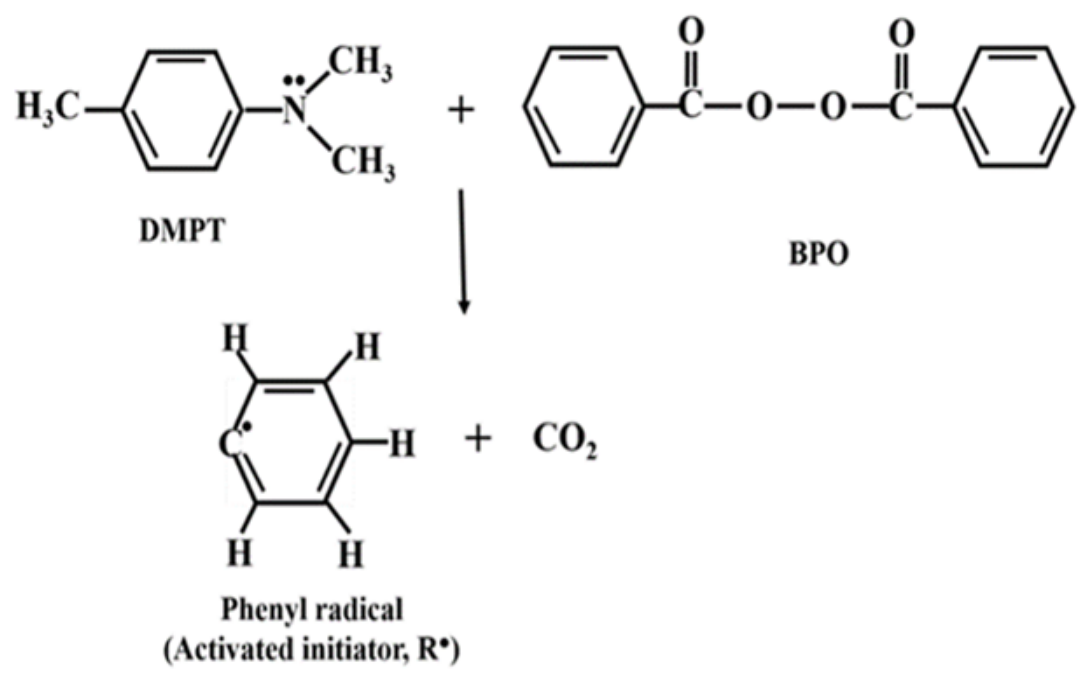

(b)<smiles>[Z7]C=C(C)C(=O)OCCP[C]C(C)(C)C(=O)OC</smiles><smiles>[R]CC(C)C(=O)OC</smiles><smiles>[R]CC(C)(CC(C)(C)C(=O)OC)C(=O)OC</smiles>

Growing PMMA chain

Figure 2.7. Polymerization of PMMA:(a) a free radical polymerization process between BPO and DMPT, (b) the polymerization of MMA and growth of PMMA chains . ${ }^{63}$ 
Table 2.1. Compositions of three commercial formulations of bone cement, where compositions are in percent. ${ }^{62}$

\begin{tabular}{cccc}
\hline Constituent & CMW $^{\text {TM }}$-1 & CMW $^{\text {TM_3 }}$ & Simplex P \\
\hline Powder & & & \\
BPO & 2.60 & 2.20 & 1.19 \\
BaSO4 & 9.10 & 10.00 & 10.0 \\
PMMA & 88.30 & 87.8 & 16.55 \\
P(MMA/ST) & & & 82.26 \\
Liquid Monomer & & & \\
N, N-DMPT & 0.40 & 0.99 & 2.48 \\
Hydroquinone & $15-20 \mathrm{ppm}$ & $15-20 \mathrm{ppm}$ & $75 \mathrm{ppm}$ \\
MMA & 98.66 & 98.07 & 97.51 \\
Ethanol & 0.92 & 0.92 & \\
Ascorbic acid & 0.02 & 0.02 & \\
\hline & & & \\
\hline
\end{tabular}

During THR, bone cement is injected into the dried femoral canal; then the cement is pressurized with a latex wedge. ${ }^{64,65}$ Peroxide cleavage and polymerization begin when the two components of the cement are mixed. ${ }^{61}$ The pressurization of cement into trabecular bone results

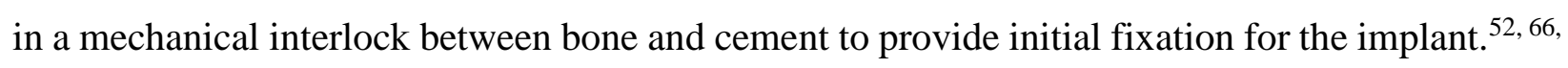
${ }^{67}$ After that, the stem is introduced and augmented by axial pressure. ${ }^{2}$ The stem is held in place and the polymerization of the cement continues $^{2}$, during which the viscosity of the cement increases and the growing polymer chains encapsulate the pre-polymerised PMMA beads within a solid matrix ${ }^{66}$. Cement-implant fixation is either achieved by selecting an implant texture which enables a mechanical interlock with the cement, or by employing an implant with geometry maintaining stability. ${ }^{68}$ Therefore, PMMA acts as a space-filler creating a tight space to hold the implant against the bone, and creates a large area of contact between the implant device and bone to distribute the load as widely as possible (Figure 2.8). ${ }^{69,70}$ 


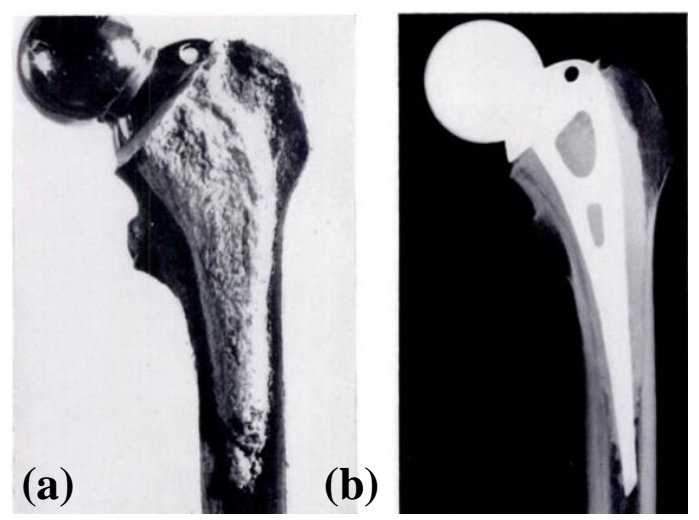

Figure 2.8. (a) Photograph by oblique illumination to reveal the large surface area of the cement in contact with the bone, (b) Radiograph presenting prosthesis fixed by cement. ${ }^{71}$

\subsubsection{Applications of cemented stems}

The success of PMMA fixation for cemented femoral stems has been widely reported. Berry et $a l{ }^{72}$ implanted cemented consecutive primary Charnley total hip arthroplasties into 1689 patients. After 25 years, among the 461 alive patients, the survivorship for aseptic loosening free of component removal or revision was about $90 \% .{ }^{72}$ Rasquinha et al. ${ }^{73}$ implanted cemented Omnifit (Osteonics, Allendale, NJ) stems into 275 patients; average age 70. After 12 years of the operations, among 198 living patients, the survivorship, free of revision, was approximately 95\%. In a clinical study by Kavanagh et $a l .{ }^{74}$, Charnley (Thackray, UK) total hip device implantations were performed for 300 patients, and 112 patients were living after 20 years of implantation. It was recorded that $84 \%$ of the hip devices functioned well without revision, and $76 \%$ of the remain patients could walk without difficulty.

\subsubsection{Disadvantages of PMMA cement}

Despite its widespread use, PMMA cement cannot be considered a perfect fixation material for artificial metallic stems. One of the issues of PMMA is the high exothermic temperature (between 
67 and $124^{\circ} \mathrm{C}$ in vivo ${ }^{62}$ ) which can cause thermal necrosis of bone and predisposition to membrane formation at the bone-cement interface. ${ }^{75}$ The high exothermic temperature can also damage collagen, because collagen protein molecules are denatured at $45{ }^{\circ} \mathrm{C}$ and become irreversibly damaged at $60{ }^{\circ} \mathrm{C} .{ }^{76}$ Furthermore, after implantation, fractures can occur on the cement-prothesis interface and within the cement itself. ${ }^{77}$ Jasty et al. ${ }^{78}$ studied 16 femora retrieved post-mortem from patients who had cemented THRs placed from two weeks to 17 years. Debonding of the cement and the implant occurred in two hips retrieved at 118 and 156 months, and the debonding for the other 14 femora was observed on the proximal anterior surface. Additionally, they found fractures in the cement mantle itself around all prostheses which had been in use for more than three years. ${ }^{78}$ The fracture through the cement mantle originating at the cement-prosthesis interface (Figure 2.9 (a)) and fractures through the cement mantle coupled with migration of the prosthesis (Figure 2.9 (b)) were both observed. ${ }^{78}$ The debonded stem-cement interfaces for total hip implants were also reported by Nuno et al..$^{65}$ and Harrigan et al. ${ }^{79}$.
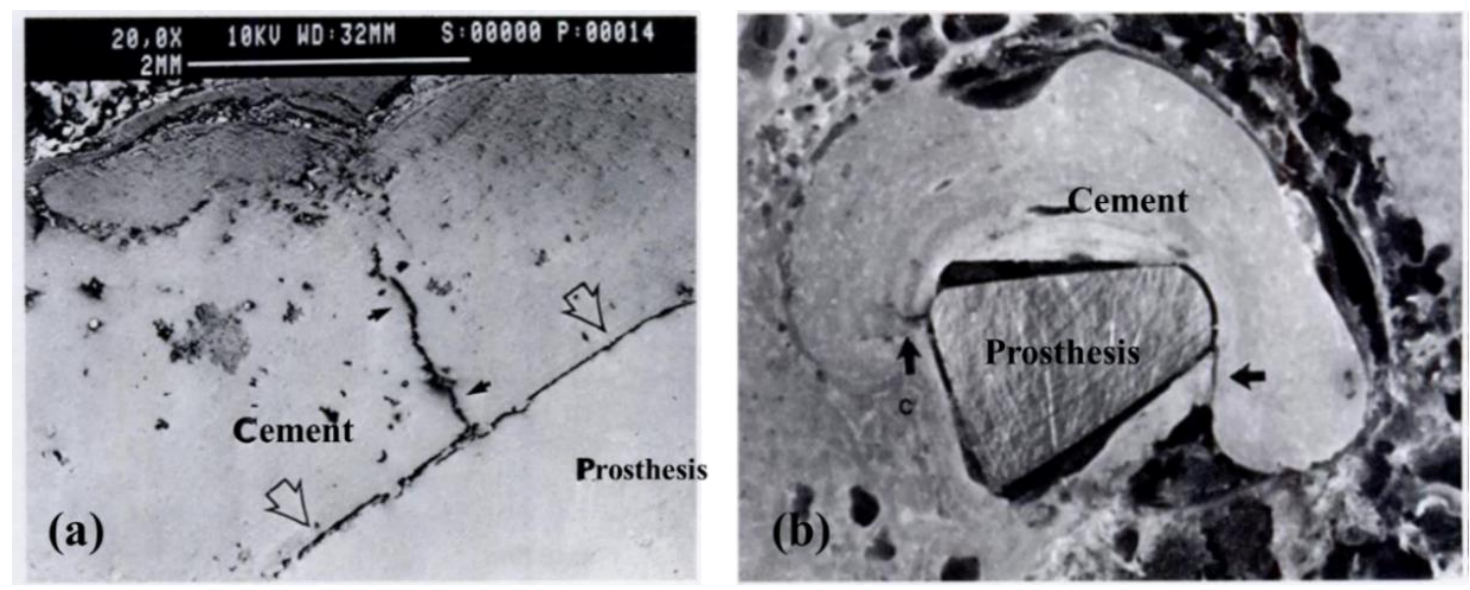

Figure 2.9. Scanning electronic micrograph showing: (a) fractures through the cement mantle (small black arrows) initiating at the cement-metal interface (hollow arrows) and (b) the prosthesis had migrated into retroversion where the black arrows indicate the cement fractures. ${ }^{78}$ 
Furthermore, wear particles resulting from the breakdown of PMMA during debonding from the implant can favor bone resorption by osteoclasts, i.e., osteolysis. ${ }^{80}$ When the cement particles appear around the implant, macrophages in the tissue will respond to the particles by releasing the inflammatory cytokines, such as interleukin (IL)-6 and tumor necrosis factor $\alpha$ (TNF- $\alpha$ ). IL-6 is a multifunctional cytokine produced by osteoclasts in response to bone-resorbing agents. ${ }^{81,82} \mathrm{TNF}-$ $\alpha$ can stimulate the activation and differentiation of osteoclasts to increase the amount of bone

resorption. ${ }^{83,84}$ PMMA particles (5 to $10 \mu \mathrm{m}$ ) were reported to induce the release of interleukin (IL)- $6^{85,86}$ and tumor necrosis factor $\alpha(\mathrm{TNF}-\alpha)^{87}$ in vitro. Therefore, the PMMA particles can cause the failure of the stems due to the osteolysis. ${ }^{88}$

\subsubsection{Cementless stems}

In order to alleviate the cement issues, un-cemented stems were fabricated to provide adequate initial stability and promote osteointegration ${ }^{89}$ between bone and the implant. The three most common designs of cementless stems are cylindrical, anatomic, and tapered stems (Figure 2.10).
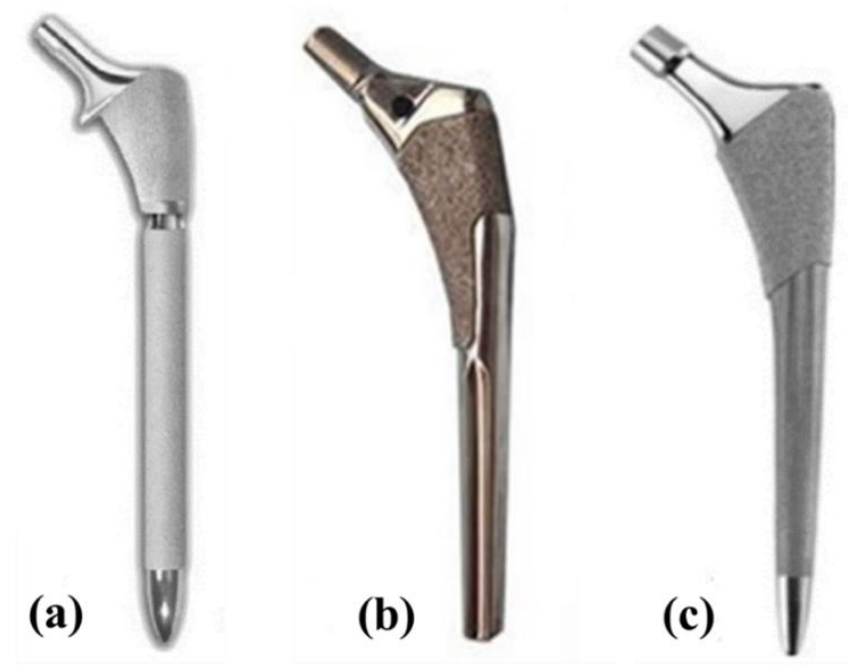

Figure 2.10. Images of (a) cylindrical stem ${ }^{90}$, (b) anatomic stem ${ }^{91}$, and (c) tapered stem ${ }^{92}$. 
Early designs of un-cemented stems were porous-coated. ${ }^{52}$ Lakstein et al. ${ }^{93}$ reported $94 \%$ survivorship in a 10-year follow-up clinical study with application of a porous-coated cylindrical cobalt-chromium stem $\left(\mathrm{ZMR}^{\circledR}\right)$, where 4 of the 69 follow-up patients experienced revisions. However, cylindrical stems are usually associated with proximal stress-shielding and thigh pain which can be a result of stem retroversion ${ }^{94}$ due to the combined force of gravity and muscle action. ${ }^{95,} 96$ The anatomic stems performed poorly with a high prevalence (up to $28 \%$ ) of thigh pain. ${ }^{97,98}$ Two designs of tapered stems commonly used in routine cases are tapered round and tapered rectangle stems. ${ }^{99}$ It was reported that approximately $90 \%$ of the follow-up patients implanted with tapered round stems did not experience the implant removal or revisions after 20 years. ${ }^{100,101}$ The tapered rectangle stems have been widely used in Europe, for which $92 \%$ of survivorship after 15 years ${ }^{102}$ and $95 \%$ of survivorship after 18 years ${ }^{103}$ have been documented.

\subsection{Ti6Al4V cementless femoral stem}

\subsubsection{Application of Ti6Al4V cementless stems}

Titanium-aluminum-vanadium alloy (Ti6Al4V) is commonly used in cementless femoral stem designs. ${ }^{99}$ The tensile strength of Ti6Al4V $(900 \mathrm{MPa})^{3}$ is higher than that of $316 \mathrm{~L}$ stainless steel (316L-SS) $(635 \mathrm{MPa})^{104}$, while its density is $55 \%$ less than that of 316L-SS ${ }^{105}$. Furthermore, it has

good corrosion resistance and biocompatibility ${ }^{106-108}$, defined as "the ability of a material to perform with an appropriate host response in a specific situation". ${ }^{109}$ In terms of biocompatibility, materials for long-term implantable medical devices, such as femoral stems, are required to minimize the release of corrosion products and wear debris to diminish the tissue inflammatory or 
immune response to them. ${ }^{110}$ Titanium is a relatively bio-inert material in the human body because it forms a very stable passive layer of $\mathrm{TiO}_{2}$ on its surface ${ }^{111}$ :

$$
\mathrm{Ti}+2 \mathrm{H}_{2} \mathrm{O} \rightarrow \mathrm{TiO}_{2}+4 \mathrm{H}^{+}+4 e^{-} \quad \text { Equation } 2.1 .
$$

The $\mathrm{TiO}_{2}$ film protects titanium and titanium alloys from corrosion. ${ }^{3}$ It has been indicated that Ti and its alloys have better biocompatibility than 316 L-SS and Co-Cr alloys. ${ }^{105,}$ 107, 112

Flexural rigidity of a material influences its suitability as a femoral stem, because the mismatch in flexural rigidity between bone and stem is the most likely cause of thigh pain. ${ }^{113}$ Flexural rigidity has a proportional correlation with the elastic modulus of the component. ${ }^{114,115}$ Compared with Co-Cr alloy and $316 \mathrm{~L}-\mathrm{SS}$, the elastic modulus of Ti6Al4V is closer to that of bone (Table 2.2), indicative of having lower flexural rigidity. Clinical research by Khanuja et al. reported that thigh pain caused by $\mathrm{Co}-\mathrm{Cr}$ alloy stems was two to four times greater in magnitude than that induced by titanium alloy stems. ${ }^{116}$

Table 2.2. Elastic modulus of $316 \mathrm{~L}-\mathrm{SS}$, Co-Cr, Ti6Al4V and bone. ${ }^{106,117}$

\begin{tabular}{ccccc}
\hline Material & 316 L-SS & Co-Cr & Ti-6Al-4V & Cortical Bone \\
\hline Elastic modulus (GPa) & 193 & 240 & 112 & $4.4-28.8$ \\
\hline
\end{tabular}

The successful application of Ti6Al4V total hip prostheses has been widely reported. ${ }^{118,119}$ Meding et al. followed up 42 hips implanted with un-cemented Ti6Al4V stems (Bi-Metric; Biomet, Inc, Warsaw, IN) for 15 years, and the survivability of the stems, with respect to revisions, was greater than 99\%. ${ }^{120}$ McLaughlin et al. ${ }^{121}$ reported 94\% survivorship of un-cemented Ti6Al4V stems (Taperloc) in a 26-year follow-up study, where only 3 of the 47 remaining patients received 
revisions. However, the failures of Ti6A14V stems caused by aseptic loosening also occurred, ${ }^{122-}$ ${ }^{124}$ where stem revision due to aseptic loosening was $10 \%{ }^{123}$ only after 5 -years implantation.

\subsubsection{Aseptic loosening of cementless Ti6Al4V stems}

The initial (or primary) fixation of un-cemented stems is obtained by press-fitting a slightly oversized stem and secondary (or long-term) fixation is achieved through bone ingrowth ${ }^{125}$, where new bone grows insides a porous, or onto a roughened, surface. ${ }^{126}$ Primary fixation is critical to achieving long-term fixation, because micro-motion between bone and implant due to poor initial fixation can induce fibrous bone tissue formation onto the implant surface instead of mature bone, resulting in inadequate bone growth. ${ }^{127,128}$ Furthermore, bone remodeling occurs around the stem as a consequence of bone adaption to the stress change. ${ }^{129}$ The implanted stem shares the external loads with the bone, which leads to the reduction of stress carried by bone itself. The external loads are borne by the femur only before implantation. Subsequently, the bone adapts itself to the reduction of stress by reducing its mass, which deteriorates the long-term fixation of the cementless stems. ${ }^{130,131}$ Bone resorption around the implanted stem can be as high as $50 \%$ after 4 to 7 postoperative years. ${ }^{132,133}$ The bone quality of the patients also has an impact on bone ingrowth. Shibli et al. ${ }^{134}$ reported that the mean bone-to-implant contact for the osteoporotic patients was about $70 \%$ of that for patients without osteoporosis after four years.

Additionally, aseptic loosening of un-cemented stems has a correlation with excessive motion. ${ }^{135}$ The magnitude of the relative micro-motion between bone and the implant depends on the extent of the applied force. ${ }^{136}$ In other words, the patients' physical movements can affect the long-term fixation of the stems. ${ }^{136}$ The micro-motion between the implant and bone has also been reported to prevent bony ingrowth resulting in the development of a fibrous tissue membrane, ${ }^{137}$, 
${ }^{138}$ and to accelerate the release of particle debris from the acetabular components. ${ }^{139}$ The particle debris can induce bone resorption and then the failure of the implant (Section 2.2.4).

\subsection{Bacterial infection around THR}

Alongside aseptic loosening, periprosthetic joint infection (PJI) is another important factor causing the failure of THR. ${ }^{140,141} \mathrm{~A}$ study by Mahomed et al. ${ }^{142}$ regarding an early failure in THR, indicated that the deep infection caused up to one-quarter of early revisions of the cementless stems. It has also been reported that $0.2 \%^{143}$ and $1.2 \%{ }^{144}$ of THR revisions were induced by deep infection during the first six, postoperative months. Usually, removal of the implant is required to treat the infection, and replacement of the implant is necessary after healing. ${ }^{145}$

It has been demonstrated that Staphylococcus aureus (S. aureus) is the major pathogen in metallic implant infections. ${ }^{146,147}$ S. aureus is a typical Gram-positive bacterium ${ }^{148}$ with a thick peptidoglycan cell wall providing better resistance to the antibacterial agent than Gram-negative bacteria. ${ }^{149}$ Humans usually coexist with $S$. aureus where it inhabits their skin. ${ }^{150}$ The dermis can exhibit antibacterial activity via bioactive molecules such as antimicrobial peptides (AMPs) $)^{151,152}$. However, during THR surgery, bacteria breach the natural barriers of the dermis becoming pathogens. ${ }^{150}$ Bacteria originally enter the human body to initiate local-inflammation generally in the planktonic, or free-floating, state. ${ }^{153}$ After entry, bacteria will adhere to the implant surface. ${ }^{154}$ Subsequently, bacteria will transfer from the planktonic state to a sessile, surface-attached biofilm community. Then the biofilm can disassemble through both mechanical and active processes once it is fully developed (Figure 2.11). ${ }^{150}$ 


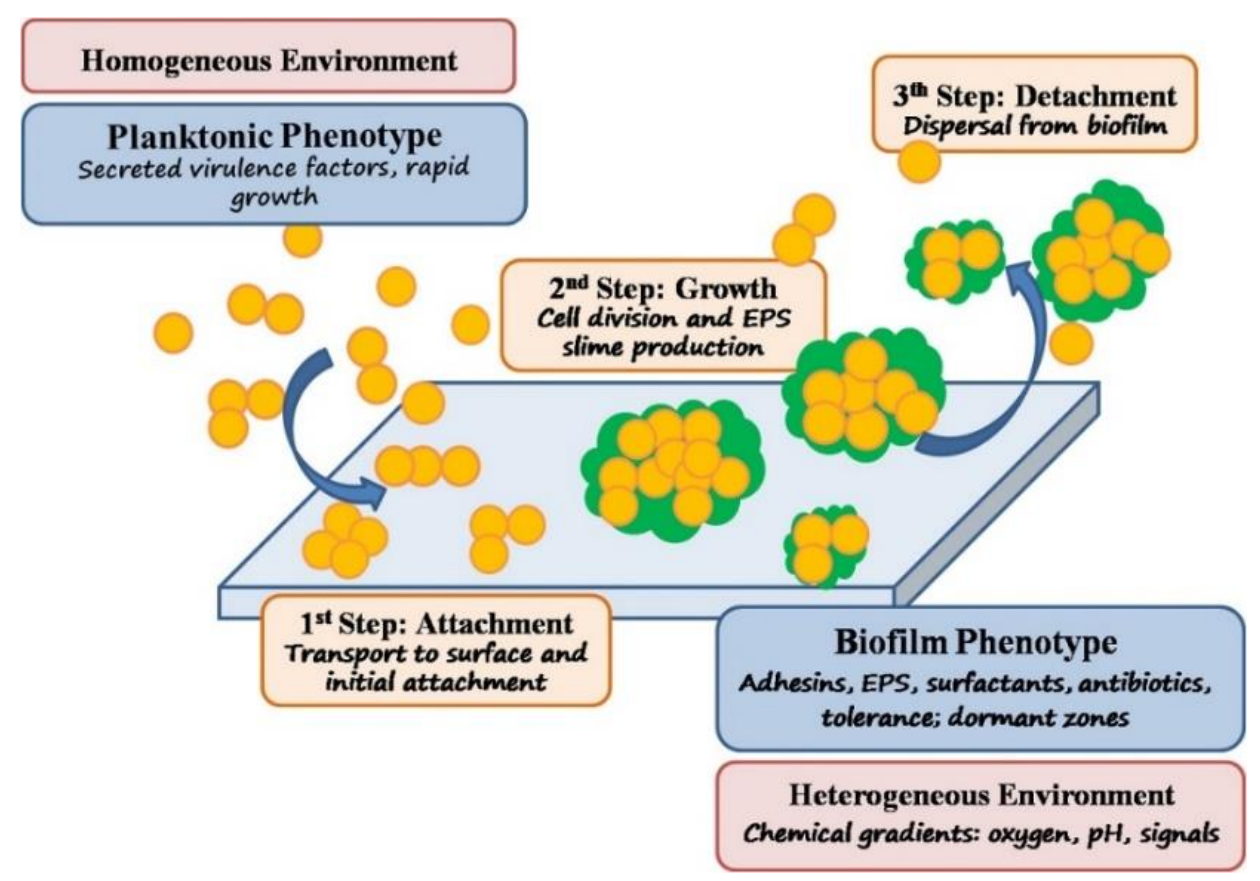

Figure 2.11. Schematic drawing presenting salient features of biofilm formation in a staphylococcal biofilm model. The blue boxes show the primary process in biofilm formation, the orange boxes present the chemical environment, and the red-brown boxes indicate the phenotype. EPS represents extracellular polymeric substances. ${ }^{150}$

The adhesion process of bacteria is mediated by specific proteins, autolysins ${ }^{155}$ and microbial surface components recognizing adhesive matrix molecules (MSCRAMMs) ${ }^{156}$. The autolysin/adhesion protein in S. aureus is AtlA, a $137 \mathrm{kDa}$ protein. ${ }^{157}$ The MSCRAMMs protein family can assist the bacteria to bind to a variety of extracellular matrix proteins. S. aureus has more than 20 genes encoding the first adhesion. ${ }^{150}$ After adhesion to a surface, the second step is intercellular adhesion with the growth and the colonization of bacteria, during which S. aureus also releases toxic factors to the host. ${ }^{157}$ A tightly regulated system of communication, termed quorum sensing, was found to help organize the overall growth of the colony, coordinate biofilm formation, and control virulence factors such as MSCRAMMs ${ }^{158,159}$ Subsequently, bacteria will become embedded in a matrix consisting of polysaccharides, extracellular DNA (eDNA) and proteins to form a biofilm (Figure 2.12). ${ }^{150}$ 


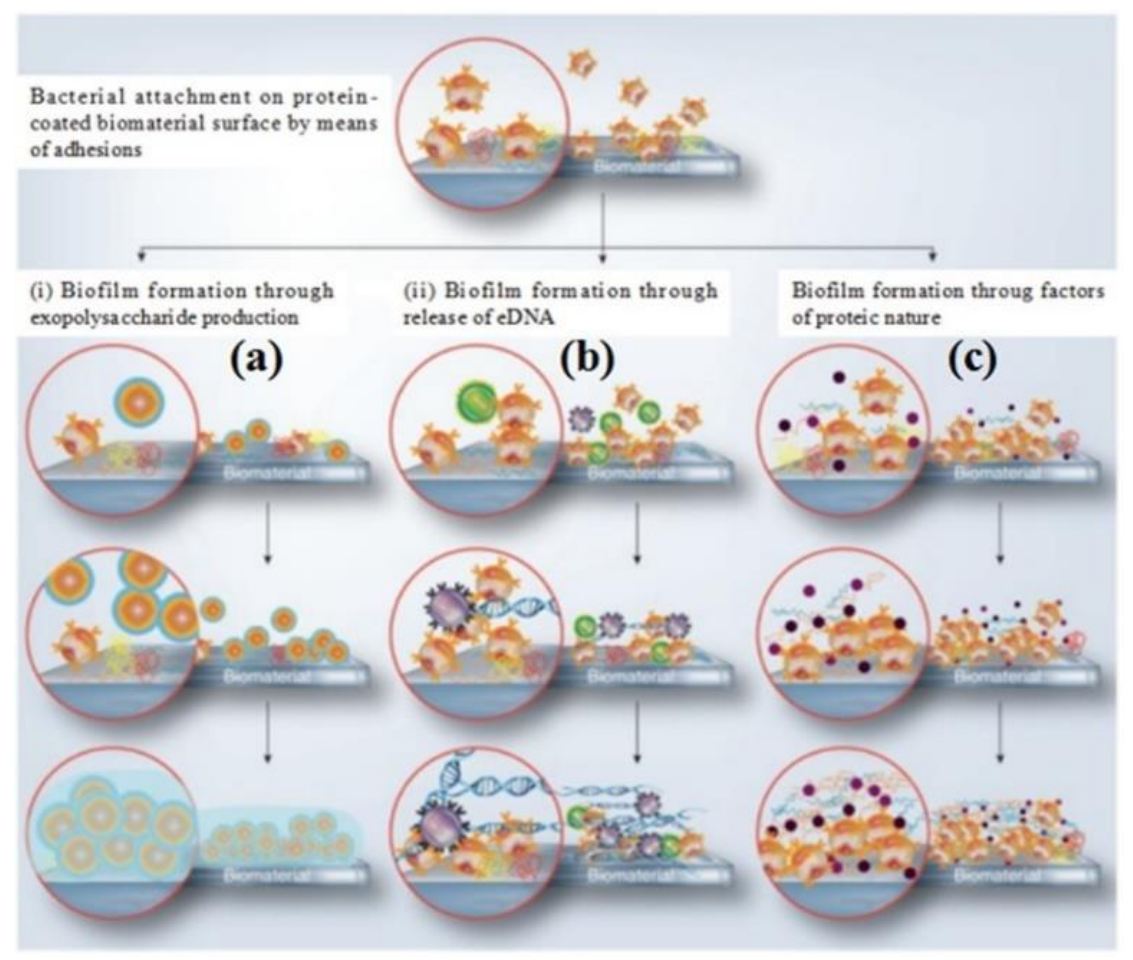

Figure 2.12. Bacterial attachment and fixation to biomaterials surface by a bacterial active process: Biofilm formation through (a) exopolysaccharide production, (b) release of eDNA, (c) protein factors. ${ }^{160}$

Poly-N-acetyl glucosamine (PNAG) is a surface polysaccharide in S. aureus which has effects on the intercellular adhesion. ${ }^{160,161}$ Thus, PNAG has been shown to play a critical role in biofilm infection using in vivo animal models. ${ }^{162,163}$ The autolytic activity from a subpopulation of cells leads to the release of eDNA during biofilm maturation. The release of eDNA performs a structural function in the $S$. aureus biofilm matrix, and plays an important role in gene transfer mechanisms to facilitate both cell-cell and cell-surface interactions. ${ }^{160,164}$ As a major biofilm matrix component, proteins, such as the fibronectin binding proteins, SasG and biofilm-associated protein (BAP), are as well as able to assist the cell-cell and cell-surface interaction. ${ }^{165}$ Beta toxin, a special protein in S. aureus, can bind to eDNA and form covalent crosslinks with itself to promote the biofilm formation. ${ }^{165,}{ }^{166}$ Bacteria embedded in biofilms are capable of resisting antibiotics, disinfectants 
and other armories of inflammatory defense systems of the host. ${ }^{167-170}$ Therefore, biofilm contributes to chronic infection after implantation. ${ }^{145}$

\subsection{Hydroxyapatite coating for Ti6Al4V stems}

The failure of Ti6Al4V cementless stems was primarily caused by aseptic loosening (Section 2.3.2) and bacterial infections (Section 2.3.3). Therefore, HA and silver (Ag)-containing HA have been used as coating materials for Ti6Al4V implants to improve the implant fixation and infection prophylaxis. ${ }^{171,172}$

\subsubsection{Osseointegration of HA coated Ti6Al4V stems}

HA is chemically similar to the apatite of natural bone (Section 2.2.1), providing a substrate for bone cells to attach and proliferate. ${ }^{173-175}$ In in vivo studies by Oonishi et al. ${ }^{181}$ and Poser et al. ${ }^{185}$, new bone was observed growing toward the HA-coated implant, promoting chemical bonding between bone and the implant. ${ }^{171,176}$ Therefore, HA coating was expected to improve the fixation between the stem and bone, i.e., osseointegration, defined as "direct contact between living bone and implant"177.

The plasma spraying technique is most commonly used to coat HA onto a Ti6Al4V substrate, during which the HA powders are melted by the heat of ionized inert gas (plasma) and then sprayed onto the Ti6Al4V surface. ${ }^{178}$ The chemical reaction between titanium alloy substrate and HA is ${ }^{179}$ :

$$
(n+1) \mathrm{Ca}_{10}\left(\mathrm{PO}_{4}\right)_{6}(\mathrm{OH})_{2}+n \mathrm{TiO}_{2} \stackrel{1000^{\circ} \mathrm{C}}{\longrightarrow} n \mathrm{CaTiO}_{3}+(n-1) \mathrm{Ca}_{10}\left(\mathrm{PO}_{4}\right)_{6}(\mathrm{OH})_{2}+3 n \mathrm{Ca}_{10}\left(\mathrm{PO}_{4}\right)_{2}+n \mathrm{H}_{2} \mathrm{O}
$$

Equation 2.2. 
HA coatings are usually highly (> 80\%) crystalline ${ }^{178}$, because amorphous HA degrades quickly in the physiological environment leading to the degradation of the coating and loss of adhesive strength between the coating and substrate. ${ }^{180,181}$ Commercially, HA is proximally or entirely coated onto the metallic stems, as shown in Figure 2.13 (a) and (b), respectively.

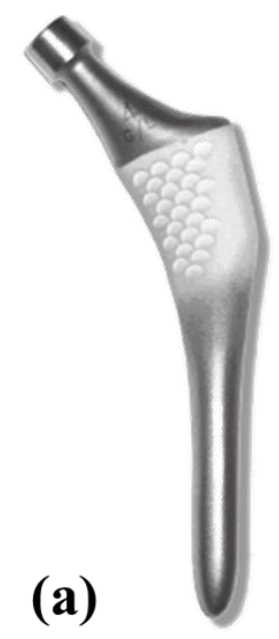

(b)

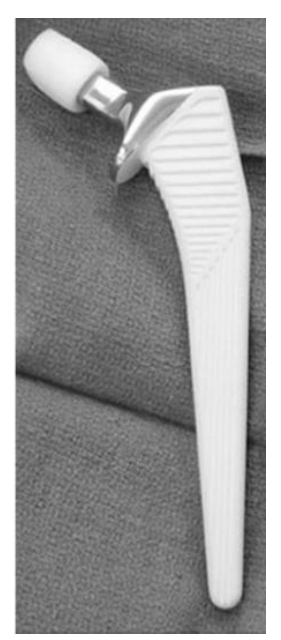

Figure 2.13. HA-coated stems: (a) ABG-I stem made of Ti6Al4V and proximally coated with $\mathrm{HA}^{182}$ and (b) Corail ${ }^{\circledR}$ femoral stem made of Ti6Al4V and fully coated with $\mathrm{HA}^{183}$.

Scott et al. ${ }^{130}$ reported that femoral bone mineral density (BMD) after 7-year implantation of HA-coated Ti6Al4V stems (Omnifit, Osteonics, Allendale, NJ) was up to $36 \%$ greater than that of porous-coated cobalt-chrome stems (Omnifit, Osteonics), which indicated better osseointegration of the HA-coated stems. A study by Coathup et al. ${ }^{184}$ also revealed good osseointegration of the HA coating. They investigated the implant-bone interface around porous-Ti-coated and HA-coated Bimetric stems (Biomet, Bridgend, UK) collected at postmortem, and found that mean bone ingrowth to the HA surface $(29.093 \pm 2.019 \%)$ was greater than that to the Ti surface $(21.762 \pm$ $2.068 \%$ ). Additionally, Herrera et al. ${ }^{182}$ reported that ABG I stems (Stryker) (Figure 2.13 (a)) survival at 10 -year follow-up was $97.1 \%$ among the remaining patients. The ABG I implant was 
made of Ti6Al4V, and the HA coating was applied through a plasma spraying process with a thickness of $50 \mu \mathrm{m}$, at $80 \%$ crystallinity after the manufacturing process.

\subsubsection{Antibacterial effects of Ag-HA coated Ti6Al4V implants}

In order to reduce infections and improve the long-term application of the implants, $\mathrm{Ag}$, as an antibacterial substance, has been incorporated into HA coatings. ${ }^{185-188}$ Few clinical studies have reported that Ag-HA-coated Ti6Al4V stems decrease infection rates, but Ag-containing HA coatings were reported to inhibit $S$. aureus growth in vitro. ${ }^{185-187}$ Chen et al. ${ }^{188}$ used the cosputtered technique to coat Ag-containing $(2.05 \pm 0.55 \mathrm{wt} \%) \mathrm{HA}$ on titanium discs $(\phi 13 \times 0.5 \mathrm{~mm})$. In the antimicrobial test, the coated and uncoated discs were placed into sterilized tubes containing $2 \mathrm{ml}$ bacterial (Cowan I strain S. aureus) suspension. After 3-hours incubation at $37^{\circ} \mathrm{C}$, the discs were rinsed with PBS. Subsequently, the discs were put into new tubes containing $5 \mathrm{ml}$ PBS, and then the tubes were vigorously vortexed to remove any adhering bacteria. The bacteria in PBS were counted by plating serial dilutions on THY agar plate after 24 -hours incubation at $37{ }^{\circ} \mathrm{C}$. It was revealed that the total colony-forming unit $(\mathrm{CFU})$ on Ag-containing HA-coated discs surface was only $\sim 20 \%$ of that on uncoated discs surface, indicating the excellent antibacterial effect of the Ag-containing $\mathrm{HA}$ coating. $\mathrm{Ag}^{+}$released from the coating into bacterial culture contributed to the inhibitory effect on $S$. aureus. ${ }^{185-187}$ Feng et al. ${ }^{148}$ reported that $\mathrm{Ag}^{+}$penetrated the cell wall of S. aureus to turn DNA into a condensed form to lose its replicating ability. $\mathrm{Ag}^{+}$also combined with thiol groups to deactivate the protein to inhibit the bacteria proliferation. ${ }^{148,} 189$ 


\subsubsection{Residual stress in HA coatings on Ti6Al4V substrates}

Despite the successful records of HA-coated Ti6Al4V stems application, their long-term application is still under debate. ${ }^{182}$ Significant loss of the HA on continuously loaded implants has been demonstrated in vivo: ${ }^{190}$ Overgaard ${ }^{190}$ used a plasma-spraying technique to coat HA onto the surface of Ti6Al4V implants and implanted the coated devices into dogs. 58-70\% reduction in the thicknesses of HA coatings was found after 25 weeks of stable weight-bearing. Cracking in the HA coatings themselves and fractures between the HA coatings and Ti6Al4V substrates were observed after implantation times of as short as eight weeks (Figure 2.14. (a)) and as long as 72 weeks (Figure 2.14. (b)) in vivo. ${ }^{191-193}$
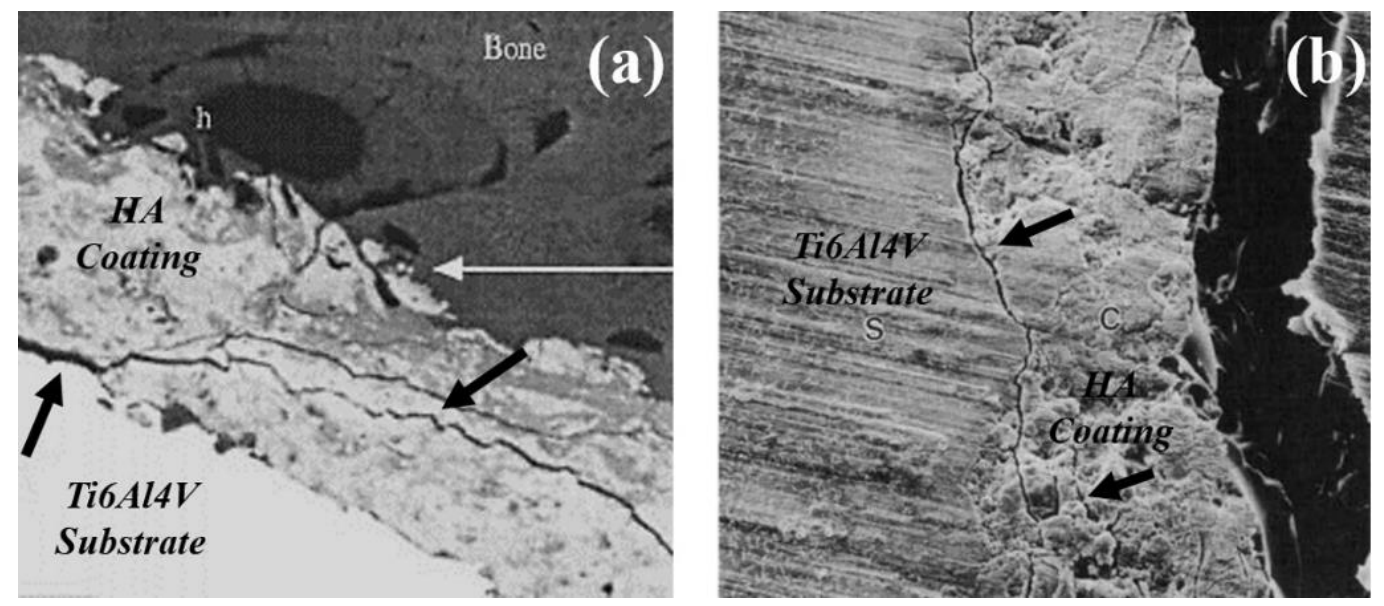

Figure 2.14. SEM images of HA-coated Ti6Al4V implants implanted into (a) rabbits after 8 weeks ${ }^{192}$ and (b) dogs after 72 weeks ${ }^{193}$ in vivo, where the cracks on the HA coatings and the interface between the coatings and the substrates (black arrow) can be observed.

The primary reason for the cracks in the HA coatings and fractures between HA coatings and Ti6A14V substrates is the residual stress due to the mismatch in CTE of HA $\left(11.5 \times 10^{-6} /{ }^{\circ} \mathrm{C}\right)^{194,195}$ and Ti6Al4V $\left(9.5 \times 10^{-6} /{ }^{\circ} \mathrm{C}\right){ }^{196}$, which can induce micro-cracking, thus initiating the debonding of the coating from the substrate. ${ }^{194,195,197}$ 
Zhang et al. ${ }^{198}$ coated pure HA and fluoridated hydroxyapatite (FHA) onto Ti6Al4V substrates, and calculated the residual stress in the coatings due to the mismatch in CTEs using the following equation:

$$
\sigma_{r e s}=\frac{\Delta T \Delta \alpha E_{c}}{\left(1-v_{s}\right)}
$$

Equation 2.3.

where

$\Delta T$ : difference between the coating temperature and room temperature, $\Delta \alpha$ : difference of CTE between the coating and the substrate, $v_{s}$ : Poisson's ratio of Ti6Al4V (0.34), $E_{c}$ : Young's modulus of the coating.

Based on Eq. (2.3), the residual stress in the coating is proportional to the difference in CTE between the coating and the substrate. Zhang et al. ${ }^{198}$ reported the residual stress in the HA coating ( 227 MPa) was higher than that in the FHA coating ( $77 \mathrm{MPa})$, because the CTE of FHA $(9.1 \times$ $\left.10^{-6} /{ }^{\circ} \mathrm{C}\right)$ was closer to that of Ti6Al4V $\left(8.9 \times 10^{-6} /{ }^{\circ} \mathrm{C}\right.$, in this reference $\left.{ }^{198}\right)$. Moreover, since the CTEs of HA and HFA were higher than that of Ti6Al4V, the residual stresses in HA and FHA coatings were positive (tensile). ${ }^{199}$ The residual tensile stress in the coating can be relieved, in part, by cracking of the coating. ${ }^{200}$ Therefore, the residual stresses generated by the CTE mismatch can induce microscopic cracks in the HA coating on the Ti6Al4V substrate even without implantation (Figure 2.15). ${ }^{201}$ 


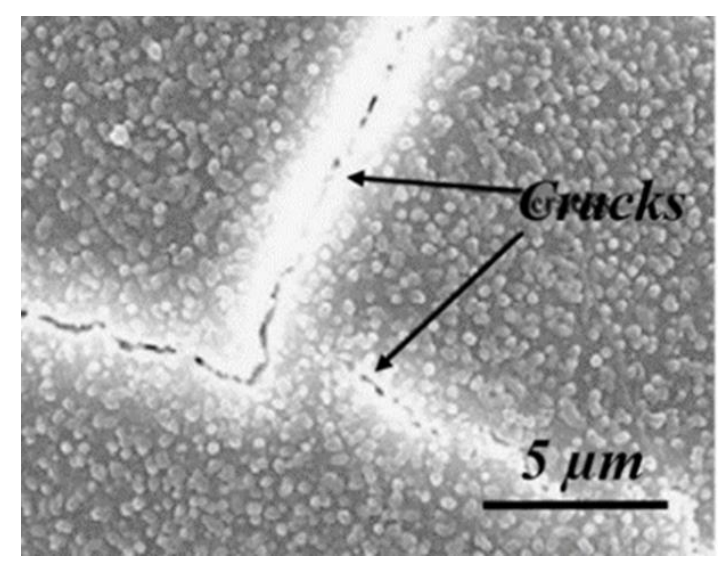

Figure 2.15. SEM micrographs of the surface and the HA coating onto Ti6Al4V alloy substrate. ${ }^{201}$

Bioactive silicate (Section 2.7.4) and borate (Section 2.8.4) glasses have also been applied as bioactive coating materials for Ti6Al4V substrates because silicate and borate glasses can have very similar CTEs to that of Ti6Al4V to reduce residual stress in the coatings and can improve osseointegration of the coated implant. Before discussing the silicate glass coatings, an overview of glass structure and the fundamentals of bioactive glasses will be introduced in Section 2.6 and Section 2.7, respectively.

\subsection{Definition and structure of Glass}

\subsubsection{Definition of glass}

All glasses have two common characteristics: random short-range atomic arrangements in the structure $^{202,203}$ and time-dependent glass transformation behavior ${ }^{204}{ }^{205}$. Therefore, a glass can be defined as "an amorphous solid without long range, periodic atomic structure, and exhibiting a 
region of glass transformation behavior" ${ }^{206}$ The transformation behavior can be described based on enthalpy versus temperature diagrams (Figure 2.16).

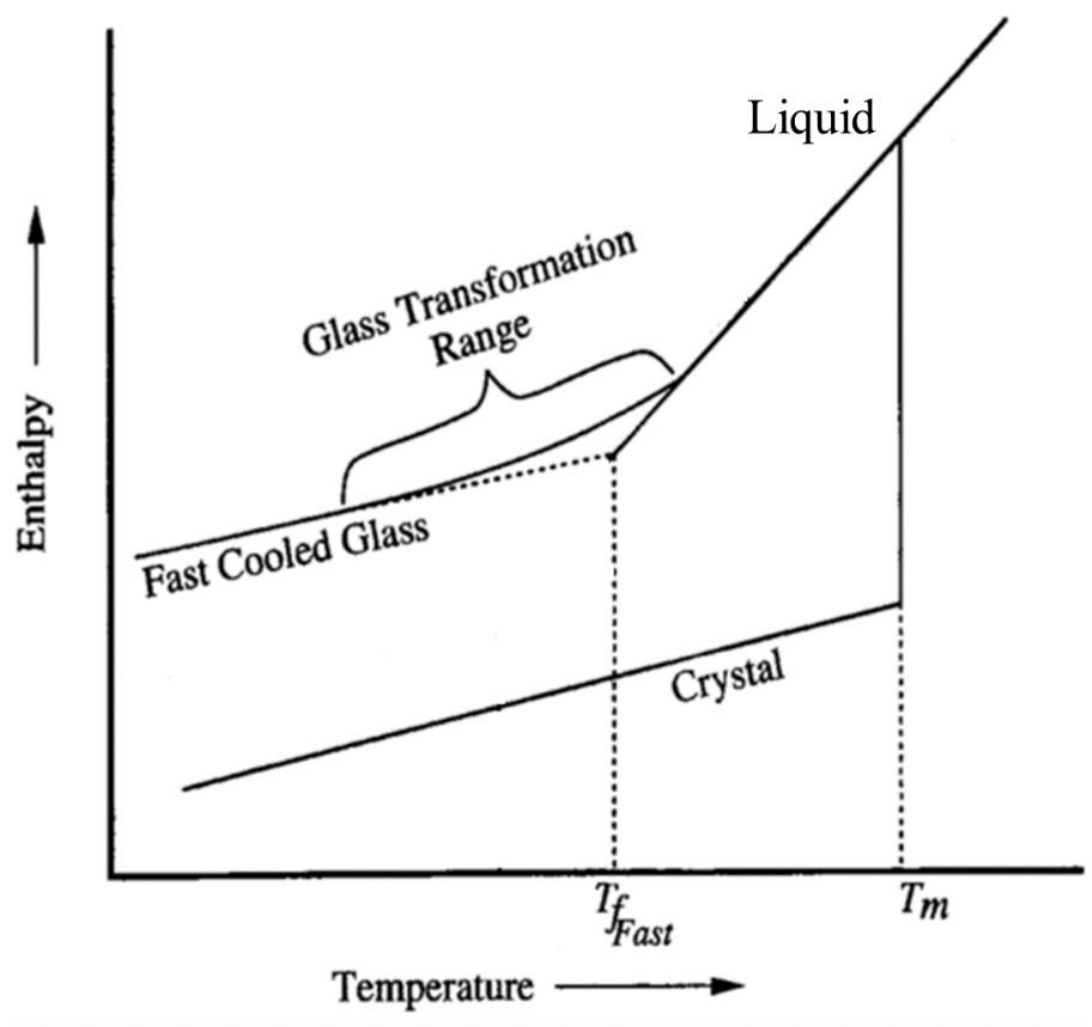

Figure 2.16. Effect of temperature on the enthalpy of a glass forming melt. ${ }^{206}$

In this process, a small volume of liquid above the melting temperature is cooled down with the atomic structure of the liquid changing gradually, and the crystalline state occurring below the melting point. ${ }^{205-207}$ Crystallization of a fluid initiates with "nucleation", the formation of crystallization centers (nuclei), resulting in a sharp decrease in enthalpy. ${ }^{208-210}$ The crystallization completes by the growth of these nuclei at the expense of the fluid, during which enthalpy decreases gradually. ${ }^{209,211}$ The nucleation strongly depends on the cooling rate. If the liquid is cooled fast enough, nucleation cannot occur. ${ }^{209}$ Subsequently, the viscosity of the liquid increases 
with decreasing temperature and eventually keeps the atoms from rearranging to form the equilibrium liquid structure. ${ }^{206,212}$ In the end, the viscosity of the liquid becomes stable to form the frozen solid, i.e. glass. ${ }^{206,213}$ The temperature region between the equilibrium liquid and that of glass is the glass transformation region. ${ }^{207,214}$ Usually, a certain set temperature, $\mathrm{T}_{\mathrm{g}}$, is used to describe the glass transformation ( transition), temperature. ${ }^{206}$ The enthalpy of glass is higher than that of crystal, because, compared with crystalline phase with periodic long-range arrangements, glass has a more discorded structure with random short-range arrangements. ${ }^{215-217}$

\subsubsection{Structure of glass}

The most common theory used to describe glass structures, the random network theory ${ }^{218}$, is based on the original ideas of Zachariasen, ${ }^{206,219}$ whose rules for glass formation are summarized in Table 2.3.

Table 2.3. Zachariasen's rules for glass formation. ${ }^{219}$

\section{Rules for glass formation in simple oxides \\ Modified rules for complex glasses}

1. Each oxygen atom is linked to no more than two cations
1. The sample must contain a high percentage of network cations which are surrounded by oxygen tetrahedra or triangles

2. The oxygen coordination number of the network cation is small: 3 or 4

3. Oxygen polyhedral share only corners and not edges or faces
2. The tetrahedra or triangles share only corners with each other

3. Some oxygens are lined only to two network cations and do not form further bonds with any other cations.

4. At least three corners of each oxygen polyhedron must be shared to form a 3-D network. 
The random network structure rules of Zachariasen were used to describe the structure of vitreous silica, also referred as silicon dioxide $\left(\mathrm{SiO}_{2}\right){ }^{220,221}$ The basic building block of the $\mathrm{SiO}_{2}$ glass network is the silicon-oxygen tetrahedron with a co-ordination number of four, which is in accord with the second rule for glass formation in simple oxides. These tetrahedra are linked at all four corners to form a continuous, three-dimensional (3D) network, as required by rules three and four. The 3D network of silica is presented in Figure 2.17, where, apparently, no oxygen atom is linked to more than two cations.

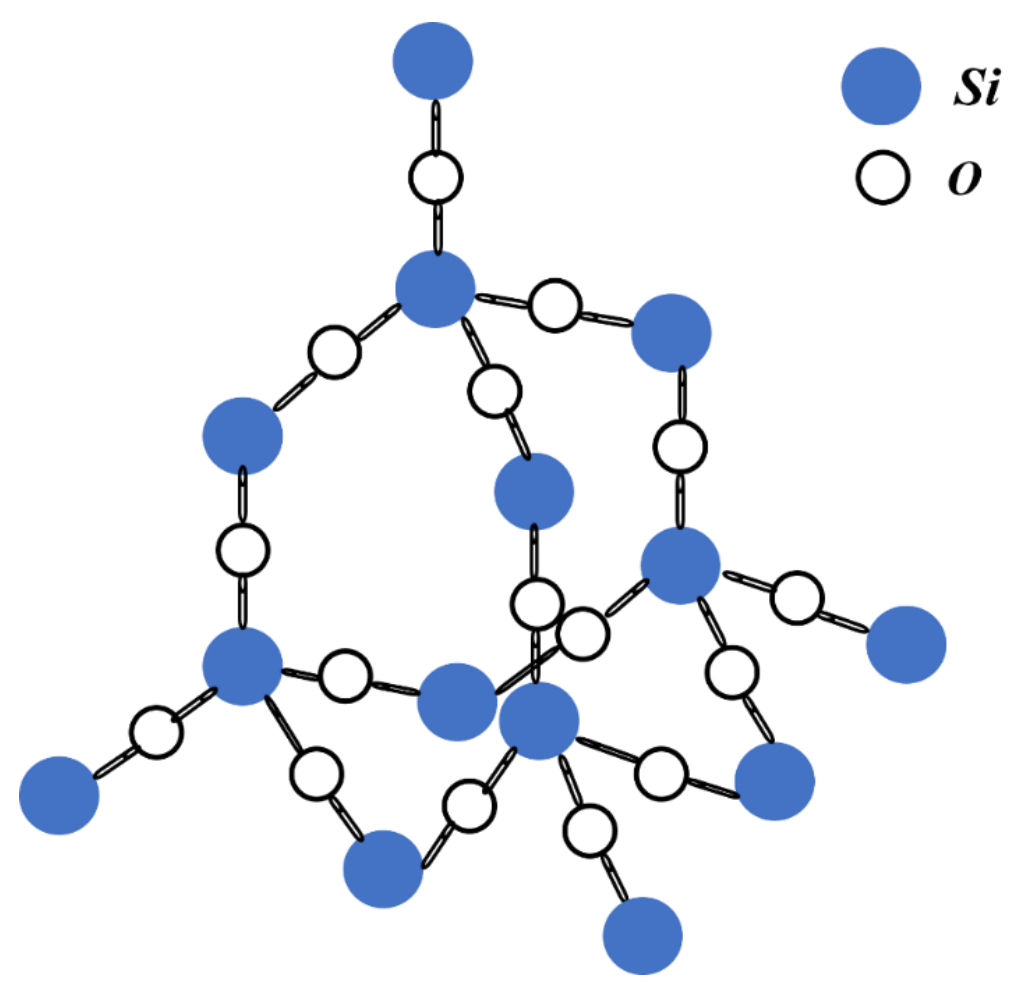

Figure 2.17. The three-dimensional structure of silica, where silica tetrahedra bond together in a random arrangement. A silica tetrahedron consists a silicon atom (blue) surrounded by four oxygen atoms (black outline).

The silicon-oxygen tetrahedron, or $\mathrm{SiO}_{2}$, which constitutes the framework of the silicate glass is termed as "glass network former". ${ }^{220,222,223}$ Besides $\mathrm{SiO}_{2}, \mathrm{P}_{2} \mathrm{O}_{5}$ and $\mathrm{B}_{2} \mathrm{O}_{3}$ are both common glass 
network formers. ${ }^{223-226}$ Moreover, there can be more than one network former in a glass structure. Figure 2.18 illustrates the structural fragment of a $\mathrm{B}_{2} \mathrm{O}_{3}-\mathrm{SiO}_{2}-\mathrm{P}_{2} \mathrm{O}_{5}-\mathrm{Na}_{2} \mathrm{O}-\mathrm{CaO}$ glass, where the $\mathrm{B}_{2} \mathrm{O}_{3}, \mathrm{SiO}_{2}$ and $\mathrm{P}_{2} \mathrm{O}_{5}$ are all glass network formers. ${ }^{227}$

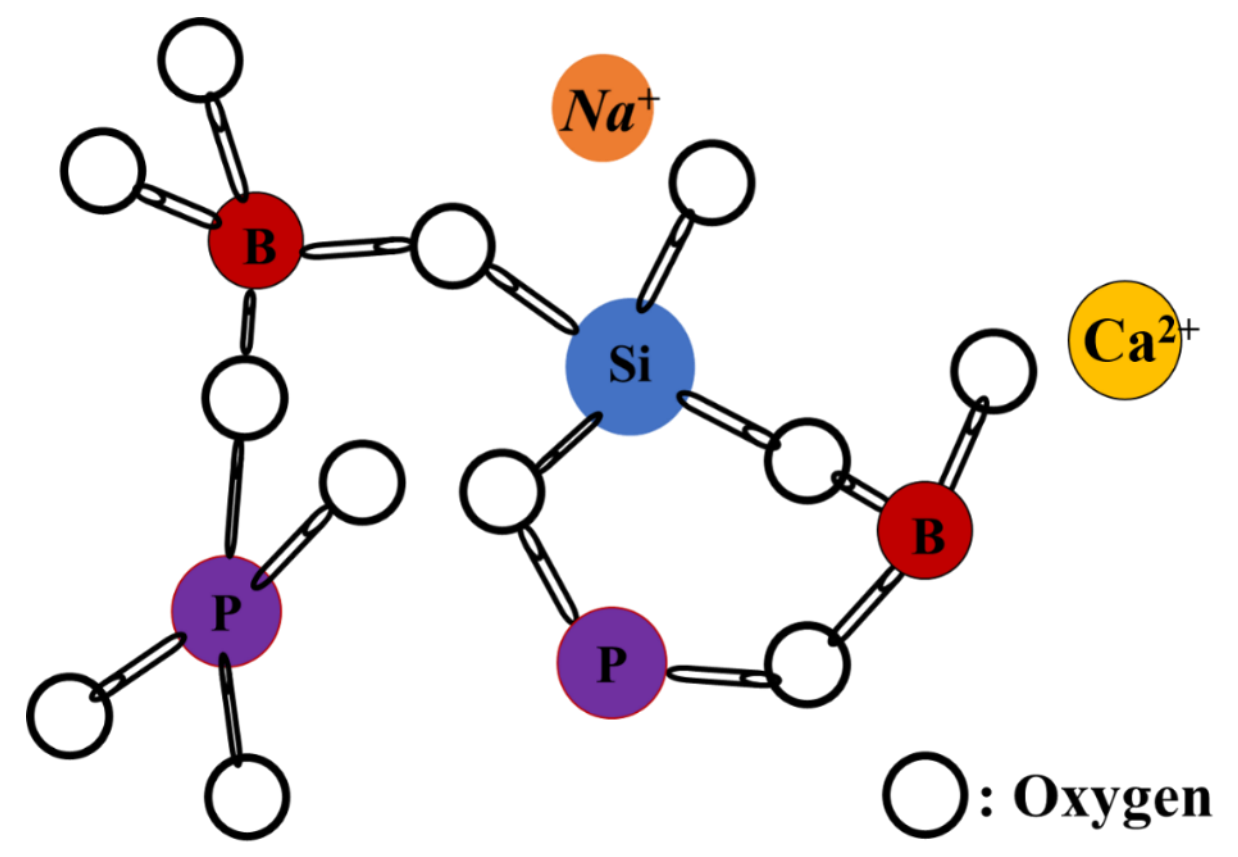

Figure 2.18. The structural fragment of $\mathrm{B}_{2} \mathrm{O}_{3}-\mathrm{SiO}_{2}-\mathrm{P}_{2} \mathrm{O}_{5}-\mathrm{Na}_{2} \mathrm{O}-\mathrm{CaO}$ glass. ${ }^{227}$

Apart from the glass network formers, a glass can contain other components, such as alkali oxides and alkali earth oxides, which can modify and disrupt the glass network. ${ }^{228}$ For example, in silicate glasses containing alkali or alkali earth oxides, the oxygen atoms are no longer fully bonded to two silicon atoms and are defined as non-bridging oxygen atoms (NBOs). The network of silicon-oxygen tetrahedra (Figure 2.17) is broken in connectivity by the formation of NBOs. Therefore, the components deconstructing the glass network are called "glass network modifiers". ${ }^{229,} 230$ Each NBO is associated with a nearby modifier ion to maintain the neutral local charge. The modifier ions occupy the interstices. Usually, the abundance of different $\mathrm{Q}_{\mathrm{n}}$ species 
are used to characterize the distribution of NBOs over the tetrahedral structure units, where n refers to the number of bridging oxygen (BO) atoms surrounding the tetrahedron. ${ }^{231-233}$ Figure 2.19 shows the conversion of $\mathrm{Q}_{4}$ tetrahedron to $\mathrm{Q}_{3}$ tetrahedron induced by a $\mathrm{Na}_{2} \mathrm{O}{ }^{4}$
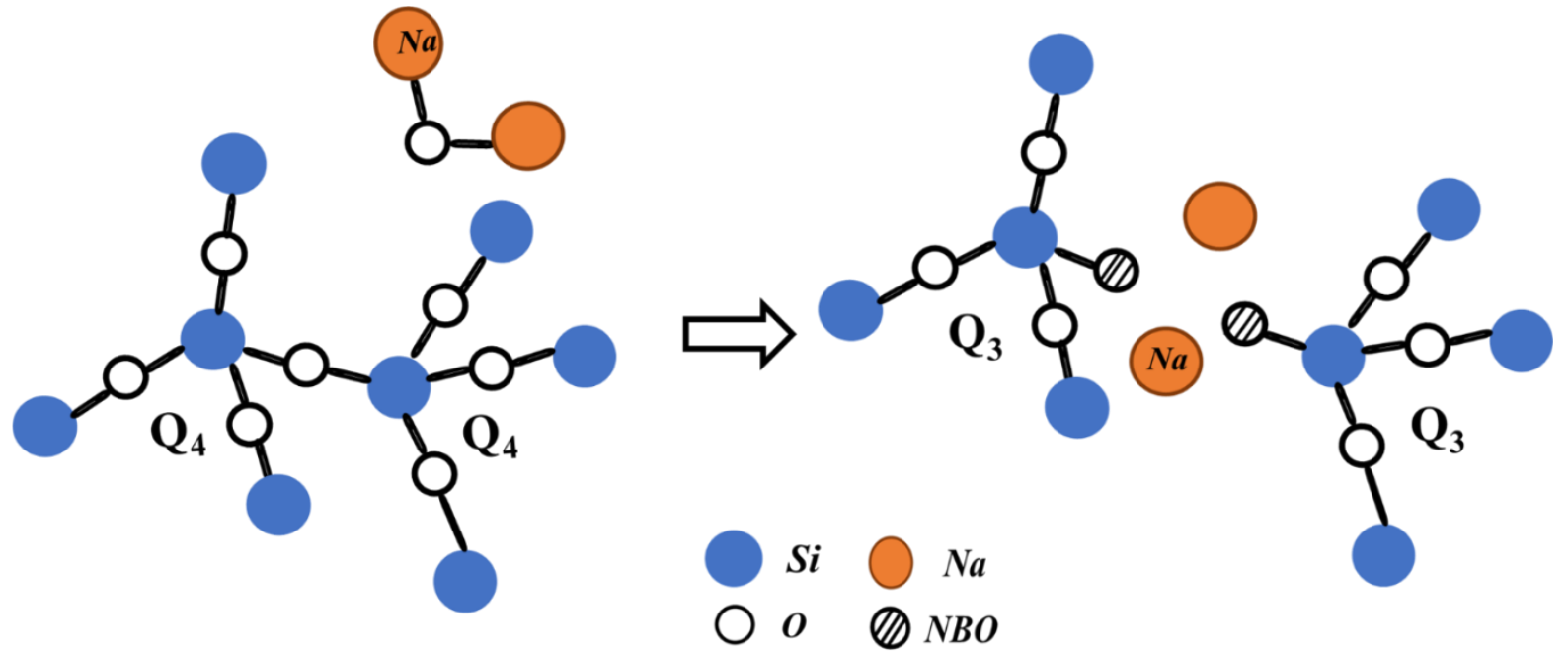

Figure 2.19. The conversion of $\mathrm{Q}_{4}$ tetrahedron to $\mathrm{Q}_{3}$ tetrahedron introduced by a $\mathrm{Na}_{2} \mathrm{O}$.

Another way to describe structural modification is regarding network connectivity (NC) which indicates the average number of NBOs on each tetrahedron. ${ }^{234,235} \mathrm{NC}$ can be calculated using the following equation:

$$
N C=2+\frac{B O-N B O}{G}
$$

where

$B O$ : total number of bridging oxygens per network-forming ion,

$N B O$ : total number of non-bridging oxygens per network modifier ion,

$G$ : the total number of glass-forming units. 
Taking $\mathrm{SiO}_{2}-\mathrm{Na}_{2} \mathrm{O}-\mathrm{CaO}$ as an example, $\mathrm{NC}$ can be calculated as:

$$
\mathrm{NC}=2+\frac{2 \times \mathrm{SiO}_{2}-\left(2 \times \mathrm{Na}_{2} \mathrm{O}+2 \times \mathrm{CaO}\right)}{\mathrm{SiO}_{2}}
$$

However, NC cannot be discussed solely in terms of the amount of glass network modifiers. The coordination of the network cations is also critical to determine the connectivity of the glass network. Borate-based glasses are a good example. The addition of small amounts of modifiers to these glasses convert boron ions from three-fold to four-fold coordination without formation of NBOs, which increases NC. ${ }^{236,237}$ This phenomenon will be elaborated on in Section 2.8.1.

\subsection{Bioactive glasses}

\subsubsection{The fundamentals of bioactive glasses}

In the 1960s, Larry Hench created a silicate glass $\left(45.0 \mathrm{SiO}_{2}-24.5 \mathrm{Na}_{2} \mathrm{O}-24.5 \mathrm{CaO}-6.0 \mathrm{P}_{2} \mathrm{O}_{5}\right.$, in wt $\%$ ), which was known as 45S5 bioactive glass or Bioglass ${ }^{\circledR} \cdot{ }^{238}$ Bioglass ${ }^{\circledR}$ was the first material discovered to form a direct chemical bond ${ }^{239}$ with bone, i.e. mature lamellar bone ${ }^{240}$ forms on the bone-glass interface, a phenomena known as 'bioactivity". ${ }^{239,} 241$ Figure 2.20 presents the relationship between the compositions and bone-bonding bioactivity of $\mathrm{SiO}_{2}-\mathrm{Na}_{2} \mathrm{O}-\mathrm{CaO}-\mathrm{P}_{2} \mathrm{O}_{5}$ bioactive glasses. 


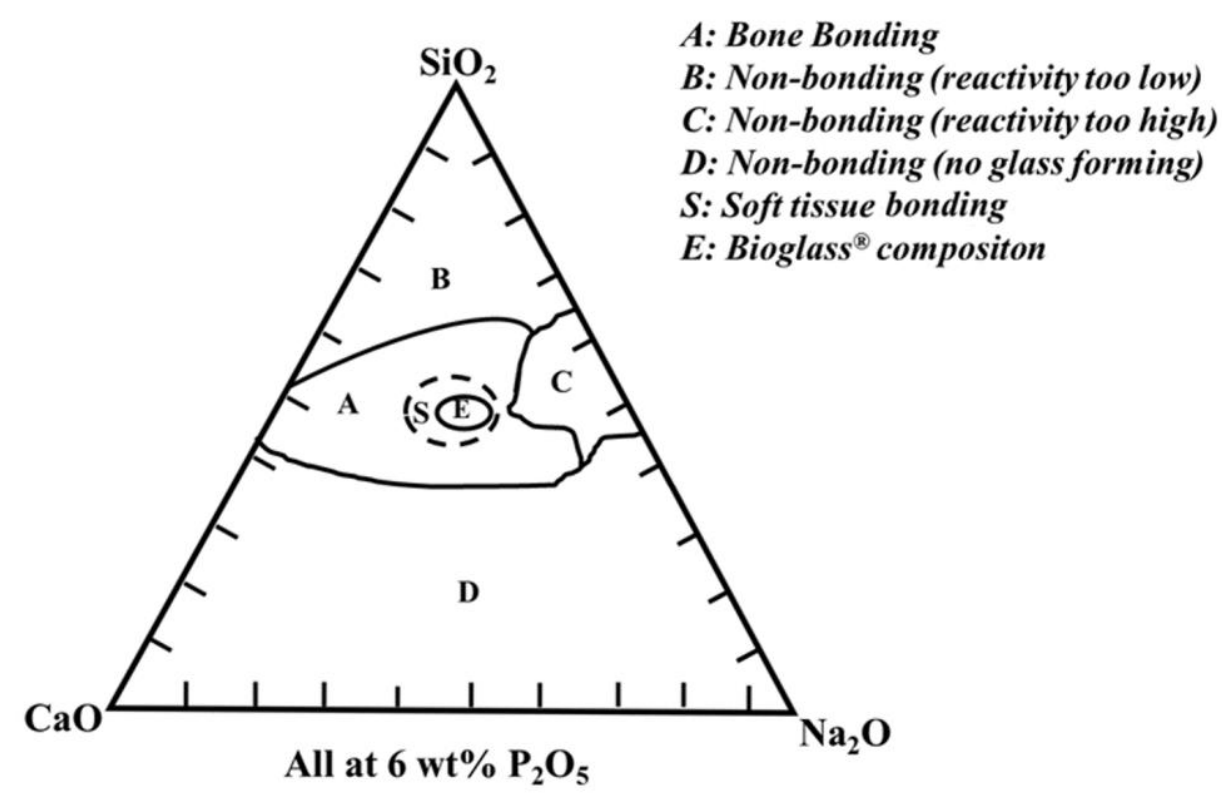

Figure 2.20. Bioactivity map of compositions in the $\mathrm{SiO}_{2}-\mathrm{Na}_{2} \mathrm{O}-\mathrm{CaO}$ system $\left(6 \mathrm{wt} \%\right.$ of $\left.\mathrm{P}_{2} \mathrm{O}_{5}\right)$ showing regions of bioactive response. ${ }^{242}$

The glasses in region A bond to bone. Glasses in region B, such as window and container glasses, are effectively bio-inert. ${ }^{242}$ These glasses contain a high percentage of $\mathrm{SiO}_{2}$ resulting in a high density of the silica network resisting reaction with body fluid. Consequently, these glasses are not able to stimulate bone cells to form new bone. ${ }^{26,243}$ Glasses with low silica but high soda contents that significantly disrupt the glass network ${ }^{244}$ are found in region C. These glasses react with the body fluid too aggressively to facilitate new bone growth. ${ }^{242,}{ }^{244}$ Region D contains glass compositions with very low $\mathrm{SiO}_{2}$ content where a glass network cannot form. ${ }^{242} 45 \mathrm{~S} 5$ Bioglass ${ }^{\circledR}$ falls in the regions $\mathrm{A}$ and $\mathrm{E}$, where the glasses are capable of strongly adhering to bone. ${ }^{245-247}$

\subsubsection{Degradation and bioactivity of bioactive glasses}

Bioactive glasses have been widely applied in the orthopedic field, ${ }^{246,248-250}$ because they can repair bone tissue repair through osteoconduction and osteostimulation processes as a consequence 
of rapid reactions between the glass and the body fluid..$^{251,252}$ There is a sequence of eleven reaction stages that occur at the surface of bioactive glass when it reacts with an aqueous environment. ${ }^{251}$ The first five stages involving in HA formation after the accumulation of dissolution products are summarized in Table 2.4:

Table 2.4. The process of HA formation after bioactive glasses degradation in liquid. ${ }^{253}$

1. Rapid cation exchange of $\mathrm{Na}^{+}$with $\mathrm{H}^{+}$from the solution creates ( $\left.\mathrm{Si}-\mathrm{OH}\right)$ on the glass surface:

$$
\mathrm{Si}-\mathrm{O}-\mathrm{Na}^{+}+\mathrm{H}^{+}+\mathrm{OH}^{-} \rightarrow \mathrm{Si}-\mathrm{OH}^{+}+\mathrm{Na}^{+}(\text {aq. })+\mathrm{OH}^{-}
$$

during which the $\mathrm{pH}$ of the solution increases and a silica-rich layer forms near the glass surface.

2. $\mathrm{OH}^{-}$coming from high-pH solution breaks $\mathrm{Si}-\mathrm{O}$ bonds in the silica glass network to form more $\mathrm{Si}-\mathrm{OH}$ (silanols) at the glass-solution interface:

$$
\mathrm{Si}-\mathrm{O}-\mathrm{Si}+\mathrm{H}_{2} \mathrm{O} \rightarrow \mathrm{Si}-\mathrm{OH}+\mathrm{OH}-\mathrm{Si}
$$

3. Formation of a $\mathrm{SiO}_{2}$-rich layer on the glass surface:<smiles>CO[Si]([O-])(O)O[Si]([O-])(O)O[18OH]</smiles>

4. The modifier cations, such as $\mathrm{Ca}^{2+}, \mathrm{Zn}^{2+}, \mathrm{Sr}^{2+}$, and $\mathrm{PO}_{4}{ }^{3-}$, migrate from the glass bulk toward the surface. $\mathrm{Ca}^{2+}$ and $\mathrm{PO}_{4}{ }^{3-}$ and incorporate with $\mathrm{Ca}^{2+}$ and $\mathrm{PO}_{4}{ }^{3}$ from the solution to form an amorphous $\mathrm{CaO}-\mathrm{P}_{2} \mathrm{O}_{5}$-rich layer.

5. Crystallization of the amorphous $\mathrm{CaO}-\mathrm{P}_{2} \mathrm{O}_{5}$ layer to $\mathrm{HA}$ layer by incorporation of $\mathrm{OH}^{-}$and $\mathrm{CO}_{3}{ }^{2-}$ from solution.

The HA layer provides a surface for bone cells to attach and proliferate. ${ }^{254}$ The phenomenon where bone grows on a surface is termed "osteoconduction". ${ }^{255,256}$ After these first five stages, the reaction layers enhance the adsorption and desorption of growth factors (stage 6) and greatly decrease the length of time to prepare the implant sites for bone tissue repair (stage 7). ${ }^{251,253}$ 
Osteoprogenitor cells colonize on the bioactive glass surface within 24-48 hours and start producing various growth factors to stimulate cell division and the production of extracellular matrix proteins (stage 10) after the attachment of stem cells (stage 8) and synchronized proliferation and differentiation of these cells into osteoblasts (stage 9). ${ }^{251}$ The final stage (stage 11) is the mineralization of the bone matrix occurring 6-12 days. ${ }^{253,257}$ The dissolution products of bioactive glasses, such as $\mathrm{Ca}^{2+}, \mathrm{Zn}^{2+}$, and $\mathrm{Sr}^{2+}$ can facilitate these processes. $\mathrm{Ca}^{2+}(2-8 \mathrm{mM})$ was reported to increase osteoblast proliferation by enhancing the expression of growth factors, e.g. IGF-I and IGF-II in vitro. ${ }^{258-260}$ It has been revealed that $\mathrm{Zn}^{2+}$ favored the differentiation of preosteoblastic cells into mature osteoblasts by stimulating the expression of Runx $2^{261}$ and increased the expression of Collagen I and ALP which initiate the mineralization of bone matrix ${ }^{26,262}$ in vitro. $\mathrm{Sr}^{2+}$ has been confirmed to be beneficial to new bone growth because, like $\mathrm{Zn}^{2+}$, it can stimulate the expression of Runx2, collagen I and ALP in vitro. ${ }^{263-266}$ The phenomenon that primitive, undifferentiated and pluripotent cells are stimulated to develop into the bone-forming cell lineage is referred as "osteoinduction". 255,256

\subsubsection{Applications of bioactive glasses}

Bioactive glasses have been applied in orthopedic surgeries due to their excellent bioactivity. The first commercial Bioglass ${ }^{\circledR}$ product was "Bioglass Ossicular Reconstruction Prosthesis" $\left(\mathrm{MEP}^{\circledR}\right)$ (American Biomaterials Corp, Princeton, NJ, USA) ${ }^{267}$, and it is used to treat conductive hearing loss by substituting for the middle ear bone. ${ }^{238}$ The $45 \mathrm{~S} 5$ Bioglass ${ }^{\circledR}$ middle ear prosthesis, once cast into shape, could conduct sound from the tympanic membrane to the cochlea. ${ }^{267} \mathrm{~A} 10$ year follow-up study by Rust et al. ${ }^{268}$ on such MEPs recorded that 4 out of 21 applications of MEP ${ }^{\circledR}$ failed because parts of the fractured prostheses extruded, while the others retained function. The 
second commercial 45S5 Bioglass ${ }^{\circledR}$ device, Endosseous Ridge Maintenance Implant $\left(\right.$ ERMI $^{\circledR}$ ) (University of Florida, Gainesville, FL, USA) ${ }^{269}$, was applied to repair tooth roots and provide stable bridges for dentures by being inserted into fresh tooth extraction sites. ${ }^{238,270}$

In 1993, PerioGlas ${ }^{\circledR}$ made of $45 \mathrm{~S} 5$ Bioglass $^{\circledR}$ granules $(90-710 \mu \mathrm{m})$ was developed as a synthetic bone graft to repair jaw defects. ${ }^{271,272}$ Studies have indicated that intrabony defects and osseous defects, treated with PerioGlas ${ }^{\circledR}$, were filled with over $70 \%$ new bone, while new bone filling was only about $35 \%$ for the controls which were treated with surgical debridement only. ${ }^{273-}$ 275

45S5 Bioglass ${ }^{\circledR}$ is not the only bioactive glass on the market. BonAlive ${ }^{\circledR}$ (Figure 2.21), S5P5 bioactive glass (53.0 $\mathrm{SiO}_{2}-20.0 \mathrm{CaO}-23.0 \mathrm{Na}_{2} \mathrm{O}-4.0 \mathrm{P}_{2} \mathrm{O}_{5}$ in wt\%) particles with size 500-800 $\mu \mathrm{m}$, was also commercialized as a bone graft substitute in $2006 .{ }^{276}$

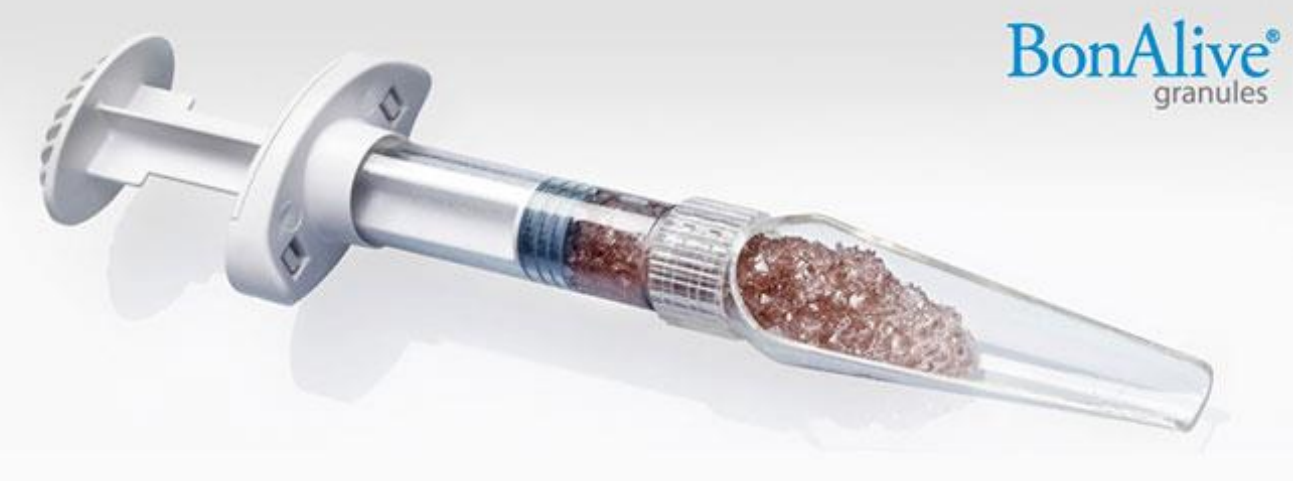

Figure 2.21. BonAlive ${ }^{\circledR}$ (Meditech, MA, US), S5P5 bioactive glass particles $(500-800 \mu \mathrm{m})$, stored in a syringe.

BonAlive ${ }^{\circledR}$ was utilized to treat defects in frontal sinuses. Peltola et al. ${ }^{277}$ used BonAlive ${ }^{\circledR}$ as an obliteration material in osteoplastic frontal sinus operations on 42 patients, where 39 patients 
underwent accurate obliteration of sinuses, and the bone produced by BonAlive ${ }^{\circledR}$ was proven by Fourier-transform infrared (FTIR) to be similar to natural frontal bone. Furthermore, BonAlive ${ }^{\circledR}$ has been applied in the treatment of osteomyelitis. ${ }^{278,}{ }^{279}$ Lindfors et al. ${ }^{278}$ treated chronic osteomyelitis in the lower extremities and the spine of 11 patients by filling the cavitary bone defect and the surrounding spine with BonAlive ${ }^{\circledR}$. It was found to be well incorporated into the bone and the bone cavity healed well with through new bone formation.

\subsubsection{Bioactive silicate glass/glass-ceramic coatings for Ti6Al4V implants}

Due to the ability to facilitate new bone formation (Section 2.7.2 and 2.7.3), silicate glasses/glass-ceramics have also been considered as bioactive coatings for Ti6Al4V implants. ${ }^{280}$ Wheeler et al. ${ }^{46}$ applied a plasma spray coating technique to coat Bioglass ${ }^{\circledR}$ and HA onto cylindrical Ti6Al4V intramedullary distal femoral implants, and they subsequently implanted the coated implants into rabbits. Bone ingrowth after 12 and 16 weeks for the 45S5-coated implants $(\sim 25 \%)$ was significantly higher than that $(\sim 14 \%)$ for the HA-coated implants, which indicated the 45S5 glass coating better promoted the osseointegration of the Ti6Al4V implants. ${ }^{46}$ However, the CTE of Bioglass ${ }^{\circledR}$ is higher than that of Ti6Al4V (Table 2.5) and the adhesion strength between the $45 \mathrm{~S} 5$ glass coating and the Ti6Al4V substrate was not measured in the study. ${ }^{46}$

Table 2.5. Available data in the literature on the CTE of bioactive glasses. For each glass, the composition (in wt\%), the CTE and the reference are indicated. ${ }^{281}$

\begin{tabular}{|c|c|c|c|c|c|c|c|c|c|}
\hline Code & $\mathrm{SiO}_{2}$ & $\mathrm{Na}_{2} \mathrm{O}$ & $\mathrm{CaO}$ & $\mathrm{P}_{2} \mathrm{O}_{5}$ & $\mathrm{MgO}$ & $\mathrm{K}_{2} \mathrm{O}$ & $\mathrm{Al}_{2} \mathrm{O}_{3}$ & $\mathrm{~B}_{2} \mathrm{O}_{3}$ & $C T E\left(\times 10^{-6} /{ }^{\circ} C\right)$ \\
\hline 45S5 Bioglass ${ }^{\circledR}$ & 45 & 24.5 & 24.5 & 6 & & & & & 15.1 \\
\hline $6 P 68$ & 67.7 & 8.3 & 10.1 & 6 & 5.7 & 2.2 & & & 8.8 \\
\hline$B 18^{282}$ & 6.0 & 11.9 & 30.1 & 2.2 & & & 5.5 & 44.3 & 10.1 \\
\hline$H 12^{282}$ & 7.5 & 8.0 & 40.0 & 2.5 & & & 2.0 & 40.0 & 9.7 \\
\hline$H A^{194,195}$ & & & & & & & & & 11.5 \\
\hline Ti6Al4V $V^{196}$ & & & & & & & & & 9.5 \\
\hline
\end{tabular}


Brow et al. ${ }^{282}$ reported that the adhesion strength between the $45 \mathrm{~S} 5$ coating and Ti6A14V substrate was only approximately $7.5 \mathrm{MPa}$, and between a borate glass $\left(40 \mathrm{CaO}-8 \mathrm{Na}_{2} \mathrm{O}-40 \mathrm{~B}_{2} \mathrm{O}_{3}-\right.$ 7.5 $\mathrm{SiO}_{2}-2 \mathrm{Al}_{2} \mathrm{O}_{3}-2.5 \mathrm{P}_{2} \mathrm{O}_{5}$, in mol\%; CTE: $9.7 \times 10^{6} /{ }^{\circ} \mathrm{C}$ ) coating and the Ti6Al4V substrate was about $40 \mathrm{MPa}$. Therefore, the mismatch in CTEs can impair bonding between the Bioglass ${ }^{\circledR}$ coatings and Ti6Al4V substrates. ${ }^{281,283,284}$ Chen et al. ${ }^{285}$ used an atmospheric plasma spraying system to deposit $\mathrm{CaO}-\mathrm{MgO}-\mathrm{SiO}_{2}$-based bioactive, partially crystalline, glass-ceramic (M2) ${ }^{239}$ powders onto Ti6Al4V substrates under Argon plasma spraying-parameters. Compared to HA and 45S5 Bioglass ${ }^{\circledR}$, the CTE of M2 $\left(10.79 \times 10^{6} /{ }^{\circ} \mathrm{C}\right)^{286}$ was closer to that of Ti6Al4V. However, micro-cracks were still found in the M2 coatings after heat-treatment. ${ }^{285}$

The mismatch in CTEs caused the poor adhesion between the silicate glass coatings and Ti6Al4V substrates. Therefore, an appropriate method is required to reduce the difference in CTE between the silicate glasses and Ti6Al4V to improve the adhesion of the coating/substrate construct. Increasing the $\mathrm{SiO}_{2}$ content in the glass composition is a simple way to reduce the CTE of silicate glasses (Table 5), although it can be at the cost of bioactivity. ${ }^{287}$ Saiz et al. ${ }^{288}$ created a silicate glass series with high $\mathrm{SiO}_{2}$ contents: $6 \mathrm{P} 57\left(56.5 \mathrm{SiO}_{2}-15.0 \mathrm{CaO}-8.5 \mathrm{MgO}-11.0 \mathrm{Na}_{2} \mathrm{O}-3\right.$ $\mathrm{K}_{2} \mathrm{O}-6 \mathrm{P}_{2} \mathrm{O}_{5}$, in wt $\left.\%\right), 6 \mathrm{P} 61\left(61.1 \mathrm{SiO}_{2}-12.6 \mathrm{CaO}-7.2 \mathrm{MgO}-10.3 \mathrm{Na}_{2} \mathrm{O}-2.8 \mathrm{~K}_{2} \mathrm{O}-6 \mathrm{P}_{2} \mathrm{O}_{5}\right.$, in wt $\left.\%\right)$ and $6 \mathrm{P} 68\left(67.7 \mathrm{SiO}_{2}-10.1 \mathrm{CaO}-5.7 \mathrm{MgO}-8.3 \mathrm{Na}_{2} \mathrm{O}-2.2 \mathrm{~K}_{2} \mathrm{O}-6 \mathrm{P}_{2} \mathrm{O}_{5}\right.$, in wt $\left.\%\right)$, and they coated these glasses onto Ti6A14V substrates using an enameling technique. The CTEs of the glass series were ${ }^{289}: 10.8 \times 10^{6} /{ }^{\circ} \mathrm{C}$ for $6 \mathrm{P} 57,10.2 \times 10^{6} /{ }^{\circ} \mathrm{C}$ for $6 \mathrm{P} 61$ and $8.8 \times 10^{6} /{ }^{\circ} \mathrm{C}$ for $6 \mathrm{P} 68$. Coated Ti6A14V samples were immersed in simulated body fluid (SBF) for two months, and then the formation of cracks reaching the 6P57 glass coating/substrate interface and initiating the coating delamination was observed. However, no cracks were found on 6P61 and 6P68 coatings, indicating better adhesion between the $6 \mathrm{P} 61 / 6 \mathrm{P} 68$ coating and Ti6Al4V substrate. ${ }^{288}$ Meanwhile, there was no 
apatite precipitated on the surface of 6P61 and 6P68 coatings even after two-month immersion in $\mathrm{SBF},{ }^{288}$ indicating that the high $\mathrm{SiO}_{2}$ contents significantly decreased the dissolution rate of the glasses, reducing their bioactivity. ${ }^{290}$

Based on the contents in Section 2.5.3 and 2.7.4, the primary issue of HA and silicate glasses as coating materials for Ti6Al4V substrates is the mismatch in CTEs. Moreover, silicate glasses having similar CTEs to that of Ti6Al4V exhibit retarded bioactivity due to the high loading of $\mathrm{SiO}_{2}$ in the glass compositions. Since borate-based glasses can have very similar CTE to that of Ti6Al4V (Table 2.5), borate-based glasses could be considered as candidates for the bioactive coating materials for Ti6Al4V substrates, which will be corroborated in Section 2.8.

\subsection{Borate-based glasses}

\subsubsection{Boron anomaly}

The structure of borate-based glasses has been studied extensively. ${ }^{291}$ Mozzi and Warren ${ }^{292}$ proved that the vitreous boron oxide $\left(\mathrm{B}_{2} \mathrm{O}_{3}\right)$ is primarily constructed of boroxol rings (Figure 2.22) using the fluorescence excitation method in their X-ray diffraction experiments. In the experiments, the position of boron-oxygen (B-O) peak in the measured curves indicated that boron atoms in vitreous $\mathrm{B}_{2} \mathrm{O}_{3}$ are predominantly in triangular coordination. ${ }^{292}$ The physical properties of boratebased glasses can be influenced by the addition of different alkali metal and alkaline earth oxides,

thus allowing for tunable solubility and bioactivity, ${ }^{230}$ through a phenomenon known as 'boron anomaly'. 293 


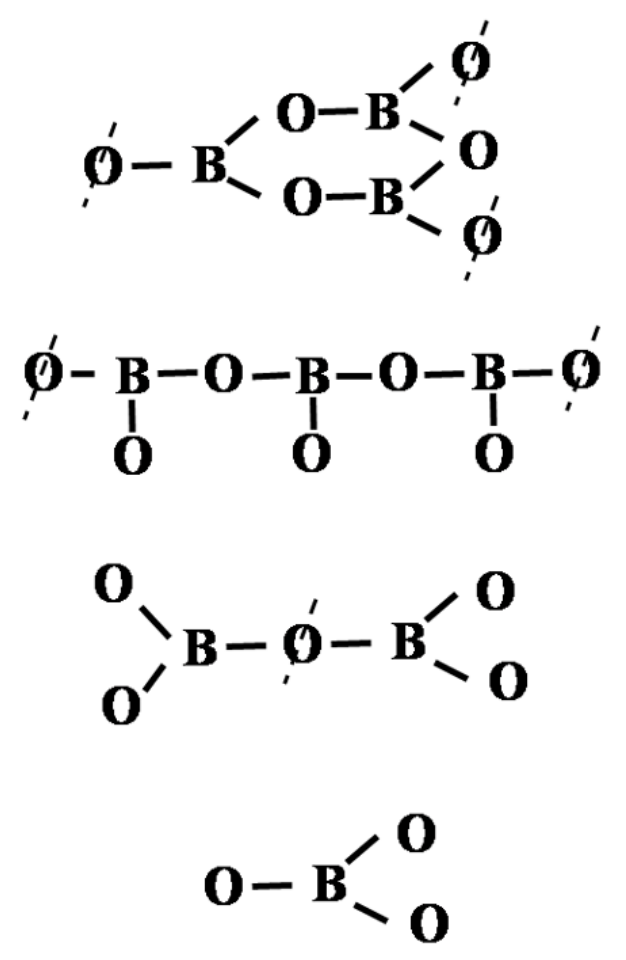

\section{The boroxol ring, observed in vitreous $\mathrm{B}_{2} \mathrm{O}_{3}$.}

The chain-type metaborate group, observed in the compounds $\mathrm{Li}_{2} \mathrm{O} \cdot \mathrm{B}_{2} \mathrm{O}_{3}$ and $\mathrm{CaO} \cdot \mathrm{B}_{2} \mathrm{O}_{3}$.
The pyroborate group, observed in the compounds $2 \mathrm{MgO} \cdot \mathrm{B}_{2} \mathrm{O}_{3}$ and $2 \mathrm{CaO} \cdot \mathrm{B}_{2} \mathrm{O}_{3}$.

Figure 2.22. Borate groups observed in different borate compounds. Dotted lines though the oxygen ions $(\varnothing)$ indicate the bridging type. ${ }^{291}$

The orthoborate group, observed in the compounds $3 \mathrm{MgO} \cdot \mathrm{B}_{2} \mathrm{O}_{3}$ and $3 \mathrm{CaO} \cdot \mathrm{B}_{2} \mathrm{O}_{3}$.

Pure $\mathrm{B}_{2} \mathrm{O}_{3}$ is primarily constructed of boroxol rings $\left(\left[\mathrm{B} \emptyset_{3}\right]\right)(\varnothing=$ bridging oxygen) (Figure 2.22) linked together through oxygen atoms. ${ }^{291}$ It has been reported that small amounts $(<30 \mathrm{~mol} \%)$ of alkali oxides $\left(\mathrm{R}_{2} \mathrm{O}\right)$ and alkaline earth oxides $(\mathrm{RO})$ introduce additional oxygen ions, which converts two $\left[\mathrm{B} \emptyset_{3}\right]$ units into two $\left[\mathrm{B} \emptyset_{4}\right]$ units. ${ }^{294-296}$ The transformation from $\left[\mathrm{B} \emptyset_{3}\right]$ to $\left[\mathrm{B} \emptyset_{4}\right]$ introduces a fourth bridging boron oxygen bond per boron center, resulting in an increase in rigidity of the glass, thus reducing the likelihood of the glass degrading in an aqueous environment. ${ }^{296,} 297$ Higher glass network modifier contents ( $\geq 30 \mathrm{~mol} \%$ ) bring non-bridging oxygens (NBOs) into $\left[\mathrm{B} \emptyset_{3}\right]$ units and $\left[\mathrm{B} \emptyset_{4}\right]$ tetrahedra. ${ }^{294-296}$ More formation of NBOs leads to decreased rigidity and increased dissolution rate in aqueous environments, where the $\left[\mathrm{B} \emptyset_{3}\right]$ and $\left[\mathrm{B} \emptyset_{4}\right]$ units convert into metaborate $\left[\mathrm{B}_{2} \mathrm{O}^{-}\right](\mathrm{O}=\mathrm{NBO})$, pyroborate $\left[\mathrm{B}_{2} \varnothing \mathrm{O}_{4}^{4-}\right]$ and orthoborate $\left[\mathrm{BO}_{3}{ }^{3-}\right]$, type units (Figure 2.22). ${ }^{296,297}$ 


\subsubsection{Dissolution of borate-based glasses}

The dissolution mechanism of silicate glasses was illustrated in Section 2.7.2, where the dissolution kinetics could be retarded by the "silica-rich" layer. The dissolution mechanism of borate glasses is very similar to that of the silicate glasses. ${ }^{298,299}$ However, unlike silicate glasses, borate glasses readily react with the aqueous environment without a significant reduction in the dissolution kinetics. ${ }^{206,300}$ Upon immersion of the borate-based glasses in a $\mathrm{K}_{2} \mathrm{HPO}_{4}$ solution or $\mathrm{SBF}$, the glass dissolution occurs directly to form $\mathrm{Na}^{+}, \mathrm{B}^{3+}$, coupling with the reaction of $\mathrm{Ca}^{2+}$ from the glasses with $\mathrm{PO}_{4}{ }^{3-}$ from the solution to precipitate $\mathrm{CaP} / \mathrm{HA}$ on the glass surface (Figure 2.23). ${ }^{298}$

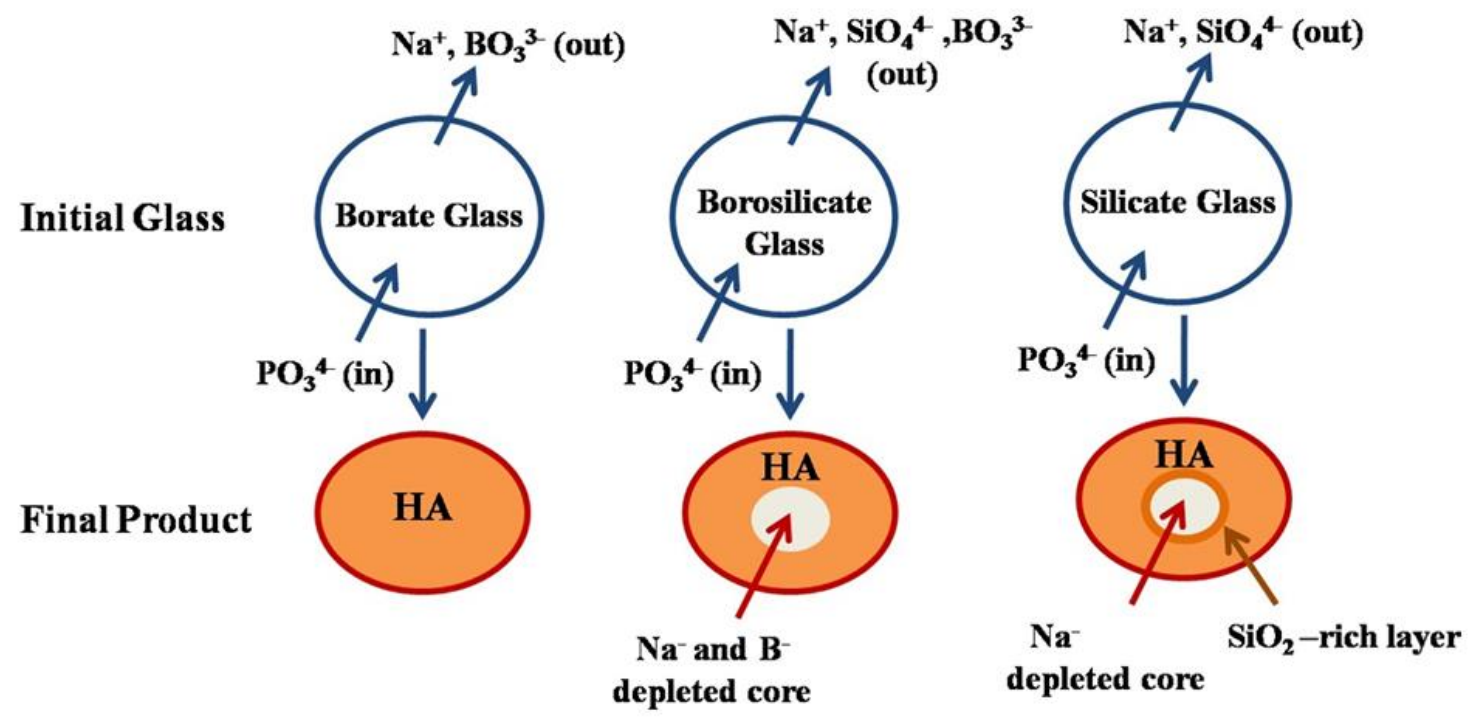

Figure 2.23. Qualitative model for the conversion of bioactive silicate (45S5), borate, and borosilicate glasses to HA in a dilute phosphate solution. ${ }^{298}$

This HA-conversion process continues until the glass is completely converted to HA. ${ }^{298}$ However, during the dissolution of silicate glasses, a porous silica-rich layer forms and separates the growing HA layer from the glass core. Therefore, the dissolution products have to dissolve and diffuse through the silica-rich layer to allow the HA-conversion process to continue (Figure 2.23), 
which explains why the dissolution process of silicate glasses stops well before the complete conversion to HA. ${ }^{298,299}$ Previous studies ${ }^{298,301}$ confirmed that borate glasses converted completely to $\mathrm{HA}$ at a faster rate than $45 \mathrm{~S} 5$ glass.

Bioactive glasses facilitate bone regeneration by converting to HA which provides a surface for bone cells to attach and proliferate, and releasing dissolution products which promote osteoblasts proliferation (Section 2.7.2). However, dissolution products of bioactive borate-based glasses do not always facilitate the formation of new bone, because the high dissolution rate of borate-based glasses tends to cause excessive concentrations of dissolution products. ${ }^{302,} 303$ Damage to osteoblasts can be induced by high concentrations of some ions, such as $\mathrm{Ca}^{2+}$ and $\mathrm{B}^{3+} \cdot{ }^{304} \mathrm{High}$ concentrations of $\mathrm{Ca}^{2+}(>32 \mathrm{mg} / \mathrm{L}$ ) decreased the viability of osteoblasts (mouse primary osteoblasts (mOBs) $)^{258}$, and higher than $2.5 \mathrm{mM} \mathrm{B}^{3+}$ inhibited osteoblast (MC3TC-E1) proliferation $^{305}$. Furthermore, as coating materials for metallic orthopedic devices, the degradation of borate-based glasses could result in the loss of the coating-substrate bond strength and subsequently retard implant fixation. ${ }^{306}$ It is therefore critical to tune the solubility of the boratebased glasses to avoid these adverse effects. Furthermore, the $\mathrm{pH}$ of the solution would dramatically increase due to the intense reaction between the solution and the borate glass. ${ }^{307}$ Since the mechanism of bone cell formation is very sensitive to changes in environment, the maintenance of $\mathrm{pH}$ value in blood and extracellular fluid is required. ${ }^{308}$

\subsubsection{Applications of bioactive borate-based glasses}

\subsubsection{Synthetic bone scaffolds}


Bioactive borate-based glasses have been applied as synthetic bone scaffolds, ${ }^{309}$ because, as well as being bioactive, borate glasses can be manufactured into porous 3D structures facilitating the formation of new bone. ${ }^{310}$ Borate-based glasses - termed $139-3 \mathrm{~B} 3\left(53 \mathrm{~B}_{2} \mathrm{O}_{3}-6 \mathrm{Na} 2 \mathrm{O}-12 \mathrm{~K}_{2} \mathrm{O}-\right.$ $5 \mathrm{MgO}-20 \mathrm{CaO}-4 \mathrm{P}_{2} \mathrm{O}_{5}$, in wt $\%$ ), were created for scaffolding purposes. Kolan ${ }^{311}$ utilized the selective laser sintering process to fabricate bone scaffolds with five different architectures using 13-93B3 glass (Figure 2.24). Cell proliferation tests using the tetrazolium salt MTT assays demonstrated that these borate glass scaffolds significantly increased the viability of the osteoblasts (MLO-A5 line), and the scaffolds with the diamond architecture were completely covered with osteoblasts. ${ }^{311}$
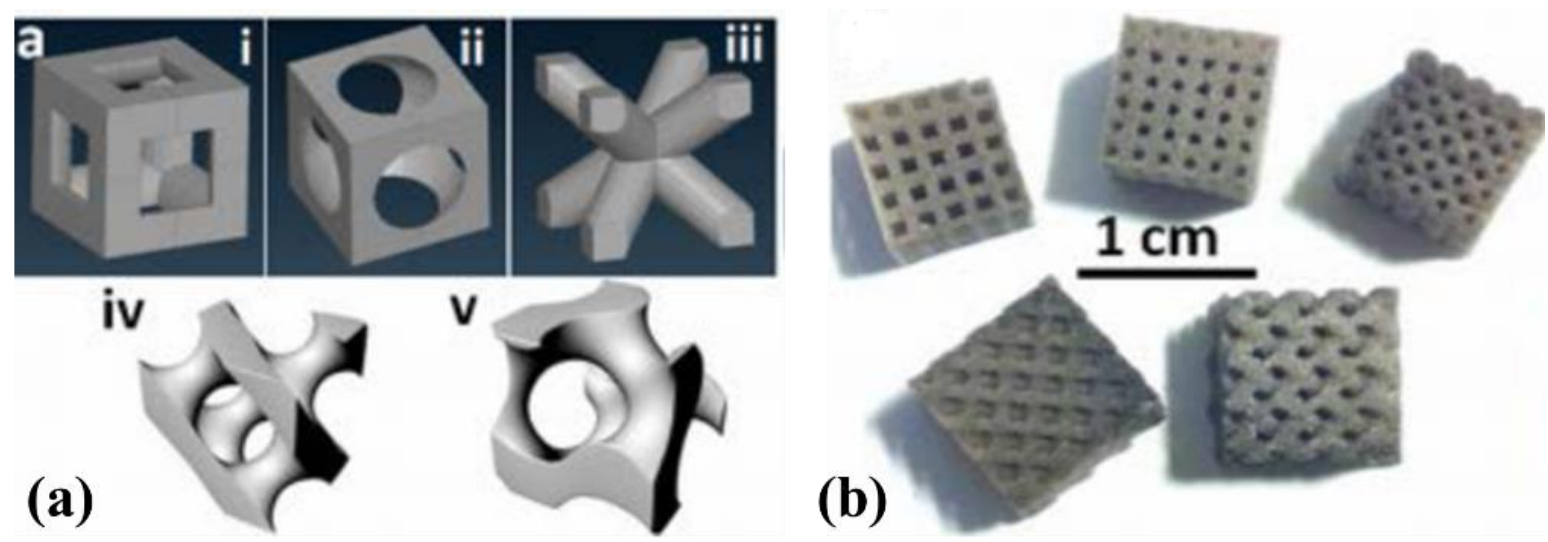

Figure 2.24. (a) CAD models of five architectures: (i) cubic, (ii) spherical, (iii) X, (iv) diamond, and (v) gyroid; (b) 13-93B3 scaffolds with different architectures after sintering. ${ }^{311}$

Synthetic bone scaffolds made of borate glass $\left(6 \mathrm{Na}_{2} \mathrm{O}-8 \mathrm{~K}_{2} \mathrm{O}-8 \mathrm{MgO}-22 \mathrm{CaO}-36 \mathrm{~B}_{2} \mathrm{O}_{3}-18 \mathrm{SiO}_{2}\right.$, $2 \mathrm{P}_{2} \mathrm{O}_{5}$, in mol\%:) were fabricated by Liu et al. ${ }^{312}$ using a polymer foam replication technique. These scaffolds, containing approximately $70 \%$ interconnected porosity and pore sizes of 200-500 $\mu \mathrm{m}$, provided a favorable substrate for the attachment and proliferation of osteogenic MLO-A5 cells after 6 days (Figure 2.25). 

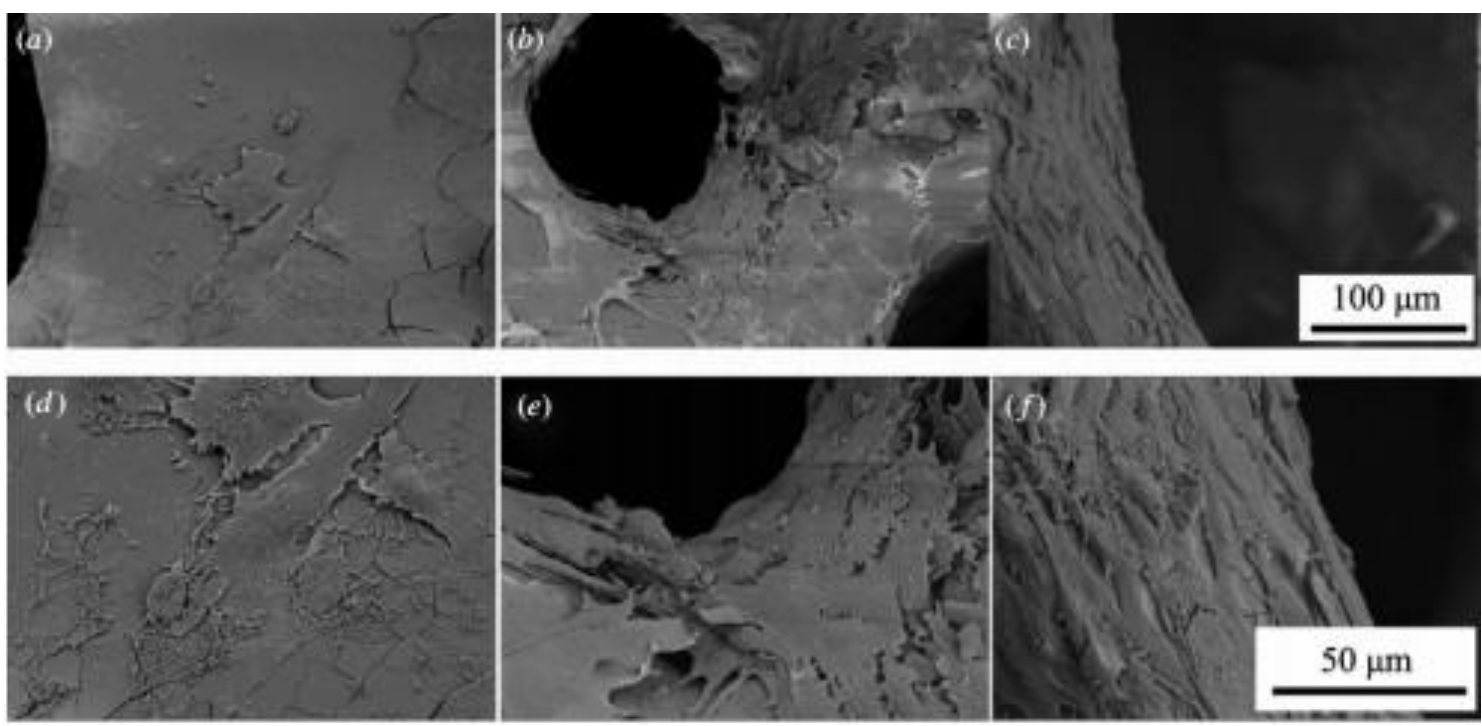

Figure.2.25 SEM images of borate-based bioactive glass scaffolds seeded with MLO-A5 cells and cultured for (a), (d) 2 days; (b), (e) 4 days and (c), (f ) 6 days. ${ }^{312}$

Furthermore, 13-93B3 bone scaffolds with approximately $60 \%$ porosity fabricated by thermally bonding randomly oriented short 13-93B3 fibers of diameter $100-300 \mu \mathrm{m}^{313}$ and by unidirectional freezing of suspensions ${ }^{314}$ were also reported to stimulate bone regeneration in the defects in vivo, where the new bone formation in the defects implanted with borate glass scaffolds (28\%) was comparable to that of autografts $(38 \%)^{314}$.

\subsubsection{2. $\quad$ Soft tissue wound healing}

Bioactive borate glasses were also capable of healing soft tissue wounds, an increasing problem associated with diabetes. ${ }^{315,316}$ Bioactive borate glass nanofibers in the form of pads have been used to heal chronic wounds, ${ }^{317}$ because bioactive borate-based glasses can facilitate new blood vessel formation which has a central role in wound healing. ${ }^{318}$ Lin et al. demonstrated that $13-$ 93B3 glass microfibers significantly increased the microvascular density in soft tissue, and did not release components or ions into the blood stream which can cause chronic kidney damage. ${ }^{319}$ This 
study also presented that the implantation of $\mathrm{Cu}$-containing 13-93B3 microfibers enhanced the growth of capillaries and small blood vessels in vivo. ${ }^{319}$ Since bone is a highly vascular material, angiogenesis can sustain and enhance new bone growth. ${ }^{320}$ Therefore, the angiogenic effect can be another application of bioactive borate glasses in the orthopedic field. ${ }^{319,321,322}$ In the study by Bi et al, ${ }^{314}$ 13-93B3 bioactive glass scaffolds and autografts were used to heal critical-size segmental defects in rat femurs. Autografts have been considered as the "gold standard" 323 for bone replacement, because they can provide the most osteoconductive and osteoinductive properties with minimum immunology rejection. ${ }^{324}$ There was no significant difference between the formation of new blood vessels in the defects implanted with the glass scaffolds (4-8\%) and that of autografts (5\%), while the new bone formation in the glass scaffolds (18\%) was more than double that in autografts $(8 \%)$, which confirmed the ability of bioactive glasses promoting the formation of both bone and blood vessel.

\subsubsection{3. $\quad$ Drug delivery system}

Another application of borate-based glasses is the drug delivery system. ${ }^{325-327}$ Pellets composed of a chitosan-bonded mixture of bioactive borate glass particles $(<50 \mu \mathrm{m})$ and teicoplanin powder (antibiotic) were utilized to treat chronic osteomyelitis induced by methicillin-resistant S. aureus in a rabbit model, where the teicoplanin-loaded borate glasses supported bone regeneration. ${ }^{328}$ Studies by Xie et al. ${ }^{259}$ and Goldstein et al. $^{329}$ both reported the better effectiveness of bioactive borate glass in the treatment of osteomyelitis as a carrier for vancomycin, replacing calcium sulfate. 


\subsubsection{Borate-based glass coatings for Ti6Al4V implants}

As discussed in Section 2.5.3 and 2.7.4, the primary issue limiting the long-term application of HA and bioactive silicate glasses as coating materials for Ti6Al4V implants is the mismatch in CTE. Unlike HA and bioactive silicate glasses, borate-based glasses can have very similar CTEs to that of $\mathrm{Ti} 6 \mathrm{Al} 4 \mathrm{~V}^{281}$, which can reduce the residual stress in the coating and then enhance the adhesion strength between the coating and substrate. Therefore, bioactive borate-based glasses are now being considered as bioactive coating materials for Ti6Al4V stems.

A study by Peddi et al. ${ }^{282}$ showed that the adhesion strength between a borate-based glass (H12, $8 \mathrm{Na}_{2} \mathrm{O}-40 \mathrm{CaO}-2.5 \mathrm{P}_{2} \mathrm{O}_{5}-2 \mathrm{Al}_{2} \mathrm{O}_{3}-40 \mathrm{~B}_{2} \mathrm{O}_{3}-7.5 \mathrm{SiO}$, in mol\%; CTE: $9.7 \times 10^{-6} /{ }^{\circ} \mathrm{C}$ ) and a $\mathrm{Ti} 6 \mathrm{Al} 4 \mathrm{~V}$ substrate was almost four-fold greater than that between an HA coating and Ti6Al4V. An enamelling technique was utilized in the study. The adhesion strength was determined using a pinpull coating adherence test based on Mil Std 883 method, where Nail-shaped, $2.6 \mathrm{~mm}$ diameter aluminum pins were bonded to the coating and the coated sample with a pin attached was mounted in a Romulus adhesion testing machine (Quad Group, Inc., Spokane, WA, USA). The force required to pull the pin loose was measured as the adhesion strength of the coatings; in this case $36 \pm 2 \mathrm{MPa}$ for H12 coating and 7.5 $\pm 0.3 \mathrm{MPa}$ for HA coating. Unfortunately, this method provided only the force as a measurement of adhesion strength instead of the true bonding strength of the coating/substrate system; it was, therefore, a qualitative method. ${ }^{330}$

\subsubsection{Osseointegration of Titanium implants coated with borate glass}

Since the development of borate-based glass coatings for Ti6Al4V stems is just in the initial stage, few studies involving the in vitro and in vivo studies on borate glass-coated Ti6Al4V devices 
exist. However, bioactive borate glass $\left(6 \mathrm{Na}_{2} \mathrm{O}-8 \mathrm{~K}_{2} \mathrm{O}-8 \mathrm{MgO}-16 \mathrm{CaO}-2 \mathrm{P}_{2} \mathrm{O}_{5}-6 \mathrm{SrO}-36 \mathrm{~B}_{2} \mathrm{O}_{3}-18 \mathrm{SiO}_{2}\right.$, in mol\%) coatings have been reported by Wei et al to improve the osseointegration of Ti implants in vivo. ${ }^{331}$ In this study, ${ }^{331} \mathrm{Ti}$ devices with/without borate glass coatings were implanted in rabbit tibial fracture models (10 animals in each group). One of the rabbits implanted with an uncoated Ti control died within a week, another suffered from internal fixation failure after three weeks, and five of them had significant swelling of the legs. However, all the rabbits implanted with coated devices survived for six weeks without leg swelling. Furthermore, good contact between the coated implants and bone was observed in histology. Osteoid tissues formed on the surface of the coatedimplants after six weeks (Figure 2.26 (a)), while animals implanted with uncoated devices showed more server inflamed tissues without formation of osteoid tissues (Figure 2.26 (b)).

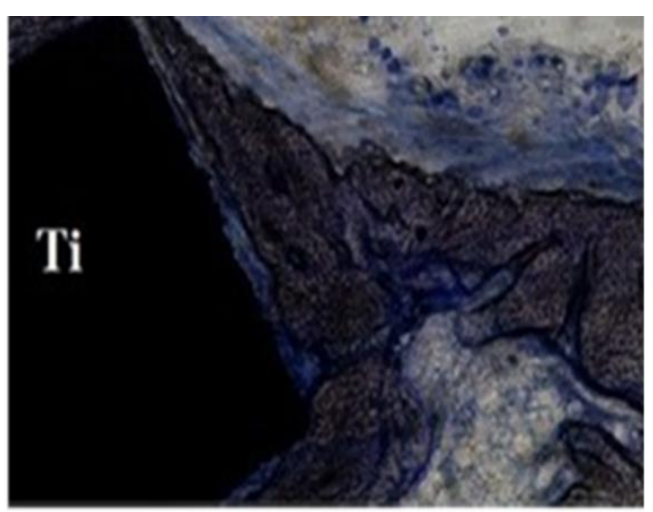

(a)

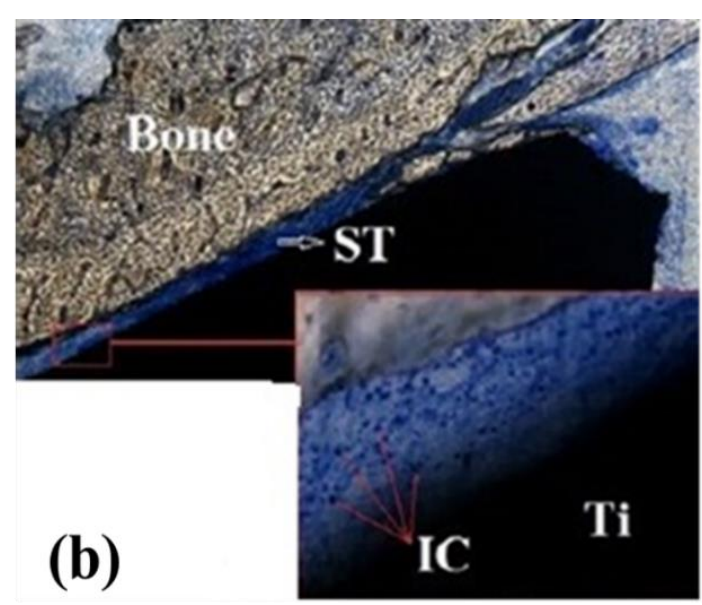

(b)

Figure 2.26. Transmitted light images of TB-stained sections of rabbit tibiae, after implantation for six weeks with (a) animals implanted with bioactive borate glass-coated Ti devices and (b) animals implanted with uncoated Ti devices (ST: soft tissue IC: inflammatory cells). ${ }^{331}$

\subsection{Functions of Titanium (Ti) and Strontium $(\mathrm{Sr})$ in the bioactive glasses}

Bioactive borate-based glasses have been usually derived from 45S5 Bioglass ${ }^{\circledR}$ ( composed of $^{\circ}$ $\mathrm{SiO}_{2}, \mathrm{Na}_{2} \mathrm{O}, \mathrm{CaO}$ and $\mathrm{P}_{2} \mathrm{O}_{5}$ ) where $\mathrm{SiO}_{2}$ is partially or totally substituted by $\mathrm{B}_{2} \mathrm{O}_{3}{ }^{321} 45 \mathrm{~S} 5$ 
Bioglass ${ }^{\circledR}$ does not contain titanium and strontium, even though they have been incorporated into bioactive glasses. $^{332,333}$

\subsubsection{Functions of Ti in bioactive glasses}

In glasses, the titanium ion can exist in three different valences: $\mathrm{Ti}^{2+}(\mathrm{TiO}), \mathrm{Ti}^{3+}\left(\mathrm{Ti}_{2} \mathrm{O}_{3}\right)$ and $\mathrm{Ti}^{4+}\left(\mathrm{TiO}_{2}\right) .{ }^{334}$ Usually, $\mathrm{Ti}$ ions exist in glass networks in $\mathrm{Ti}^{4+}$ form and act as network formers (Figure 2.27) enhancing both glass forming ability and chemical durability. ${ }^{332}$ Wren et al. $^{335}$ fabricated a scaffold using Ti-containing silicate glass ((62-x) $\mathrm{SiO}_{2}-14 \mathrm{Na}_{2} \mathrm{O}-24 \mathrm{CaO}-\mathrm{xTiO}, \mathrm{x}=0$, 5,10 , in mol\%). They found that the hardness of the bone scaffolds without Ti (2.4 GPa) was significantly lower than comparable bone scaffolds containing Ti (7.1 GPa with 5 wt\% Ti and 6.1 GPa with $10 \mathrm{wt} \% \mathrm{Ti}$ ). In some borate glasses, titanium ions can both exist in $\mathrm{Ti}^{4+}$ acting as network former and $\mathrm{Ti}^{3+}$ acting as network modifier elevating glass solubility (Figure 2.27). ${ }^{336}$

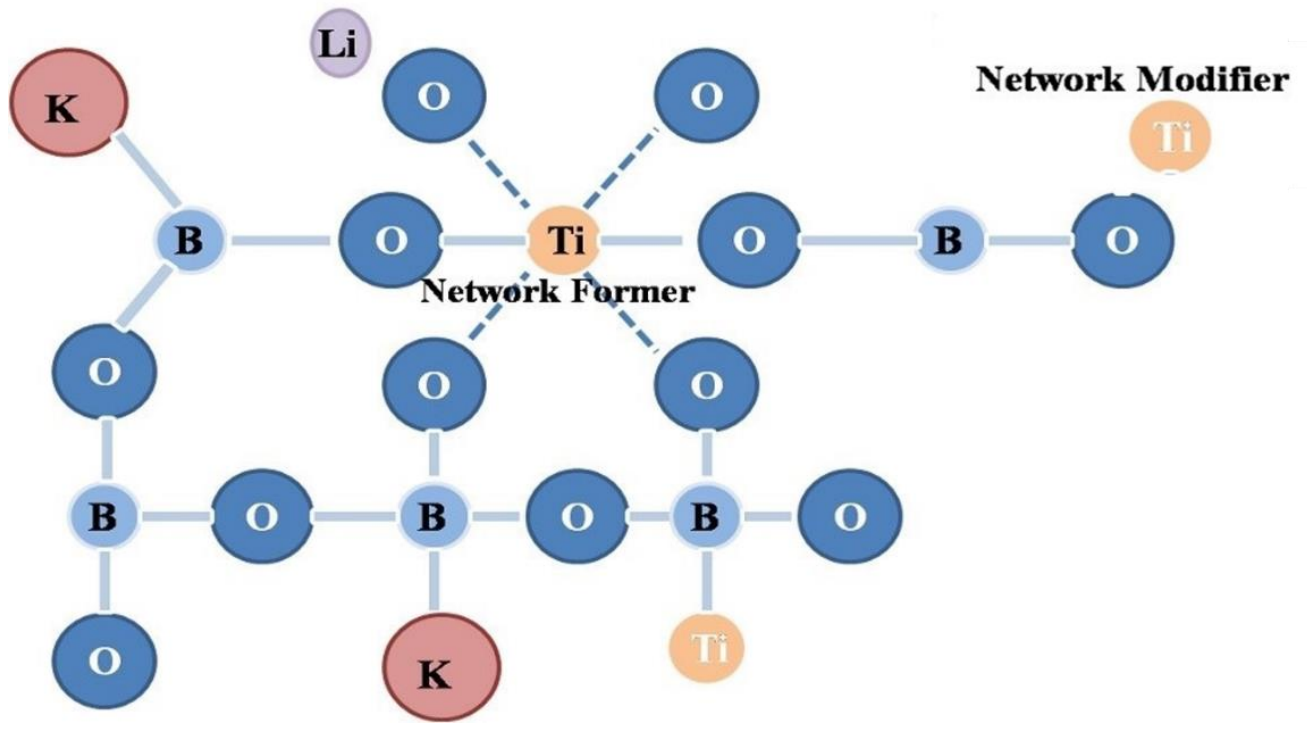

Figure 2.27. Structural fragment of $\mathrm{Li}_{2} \mathrm{O}-\mathrm{K}_{2} \mathrm{O}-\mathrm{B}_{2} \mathrm{O}_{3}$ glass network doped with $\mathrm{TiO}_{2}$. ${ }^{337}$ 


\subsubsection{Function of $\mathrm{Sr}$ in bioactive glasses}

Strontium $\left(\mathrm{Sr}^{2+}\right)$ has been incorporated into bioactive glasses applied in orthopedic fields, because it can facilitate bone regeneration. ${ }^{290}$ The increasing awareness of the biological role of $\mathrm{Sr}^{2+}$ started from the development of the drug strontium ranelate (Figure 2.28), marketed as Protelos (Servier Laboratories, Dublin, Ireland) an effective anti-osteoporotic therapy for treating osteoporosis resulting in both bone mass enhancement and prevention of bone loss. ${ }^{333} \mathrm{~A}$ study by Jiang et al. ${ }^{338}$ considered osteoporotic rats treated with strontium ranelate for 3 years. It revealed that strontium ranelate increased bone formation, assessed by both mineralization rate and osteoblast concentration. Moreover, higher numbers of trabeculae and an enhancement in cortical thickness were observed. ${ }^{338}$ Additionally, a clinical trial by Meunier et al. ${ }^{339}$ evaluated the effects of strontium ranelate on the risk of vertebral fracture in women with postmenopausal osteoporosis. A risk reduction of $49 \%$ was recorded after one year of treatment, reducing to $41 \%$ after 3 years.

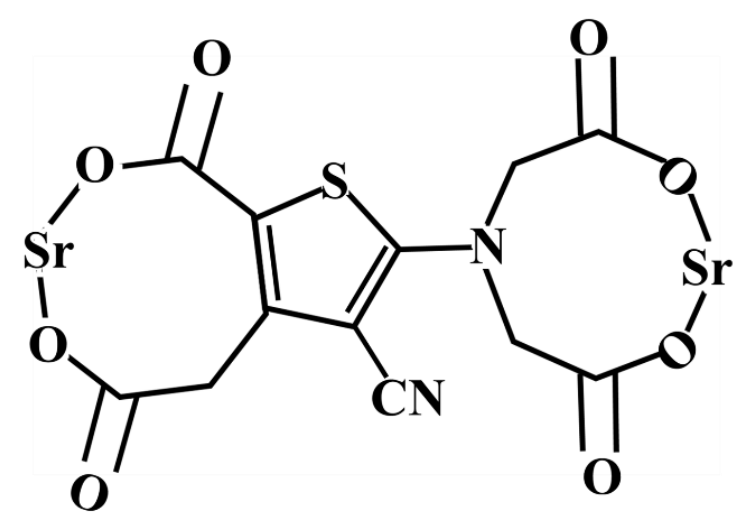

Strontium Ranelate

Figure 2.28. The composition of strontium ranelate.

The incorporation of $\mathrm{Sr}^{2+}$ in the bioactive glasses have also been confirmed to exhibit stimulatory effects on osteoblasts and inhibitory effects on osteoclasts. ${ }^{263,340,341}$ Isaac et al. $^{263}$ 
reported that addition of $\mathrm{SrO}$ in the $\mathrm{B} 75-\mathrm{SrX}$ glass series $\left(75 \mathrm{SiO}_{2}-(25-\mathrm{x}) \mathrm{CaO}-\mathrm{xSrO}, \mathrm{X}=0,1\right.$ and 5 , in mol\%) significantly increased the viability of osteoblasts isolated from fetal mouse calvaria in vitro after 24 hours; $100 \%$ for $\mathrm{B} 75-\mathrm{SrO}, \sim 125 \%$ for $\mathrm{B} 75-1 \mathrm{SrO}$, and $\sim 150 \%$ for $\mathrm{B} 75-5 \mathrm{SrO}$. In addition, Gentleman et al. ${ }^{340}$ treated osteoclasts (RAW264.7 cell line) with dissolution ions from a bioactive glass series $\left(46.46 \mathrm{SiO}_{2}-1.07 \mathrm{P}_{2} \mathrm{O}_{5}-26.38 \mathrm{Na}_{2} \mathrm{O}-(23.08-\mathrm{x}) \mathrm{CaO}-\mathrm{xSrO}\right.$, in mol\%). They found that, compared with the $\mathrm{SrO}-$ free control glass, $2 \mathrm{~mol} \%$ addition of $\mathrm{SrO}$ in the glasses decreased the osteoclast proliferation by approximately $25 \%$ after 6 days in vitro.

Additionally, Sr-containing biomaterials have been reported to reduce microbial contamination induced by Staphylococcus spp., because $\mathrm{Sr}^{2+}$ can impede bacteria cell wall synthesis and metabolism. ${ }^{32,}, 343$ Brauer et al. ${ }^{342}$ formulated a bioactive glass series $\left(\mathrm{SiO}_{2}-\mathrm{CaO}-\mathrm{CaF}_{2}-\mathrm{MgO}\right)$ with 0-50 mol\% $\mathrm{CaO}$ substituted with $\mathrm{SrO}$ and investigated their antibacterial effects against $S$. aureus (NCIMB6571). In the study, the glass discs $(\phi 7.6 \times 0.7 \mathrm{~mm})$ were put into $4.5 \mathrm{ml}$ bacteriacontaining $\left(10^{8} / \mathrm{ml}\right)$ tryptone soya broth (TSB) media, and the Miles and Misra technique ${ }^{342}$ was used to calculate the bacterial viability (CFU/ml) after 144 -hours incubation at $37{ }^{\circ} \mathrm{C}$. It was found that the bacterial viability decreased and more $\mathrm{Sr}^{2+}$ released into the media with $\mathrm{SrO}$ incorporation in the glass series, which indicated the antibacterial effect of $\mathrm{Sr}^{2+}$ against S. aureus. ${ }^{342}$ Therefore, when Sr-containing bioactive glasses are applied as coatings on Ti6Al4V stems, they may be able to reduce the infection caused by S. aureus.

Another function of $\mathrm{Sr}^{2+}$ in bioactive glasses is modifying their dissolution rate. The addition of heavy, less mobile ions, such as $\mathrm{Ca}^{2+}$ and $\mathrm{Sr}^{2+}$, have been reported to retard the dissolution rate of the glasses. ${ }^{344}$ The mechanism of $\mathrm{Sr}^{2+}$ slowing down glass solubility can impede the migration pathway of other dissolution products, like $\mathrm{Na}^{+}$and $\mathrm{Ca}^{2+}$, in the glass structure. ${ }^{345,346}$ One of the 
pathways of dissolution ion migration involves a change in its coordination, where some bonds between the modifier ions and oxygens (M-O) are broken. ${ }^{347,}{ }^{348}$ It is difficult to break the Sr-O

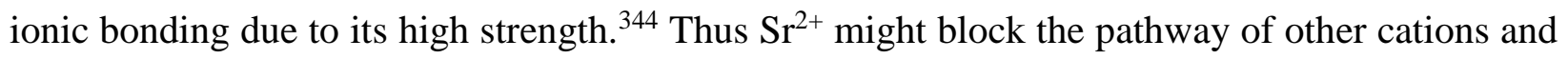
hinder the movement of other dissolution products, reducing the solubility of the glasses subsequently. Additionally, $\mathrm{Sr}^{2+}$ has a larger ionic radius (132 $\left.\mathrm{pm}\right)$ than that of other glass network modifiers, like calcium $\left(\mathrm{Ca}^{2+}\right)(114 \mathrm{pm})$ and magnesium $\left(\mathrm{Mg}^{2+}\right)(86 \mathrm{pm}) .{ }^{349}$ Thereby, $\mathrm{Sr}^{2+}$ may occupy more space in the glass structure inhibiting the movement and release of other ions from the glass network. Consequently, the addition of $\mathrm{SrO}$ in the borate glasses should address the issues caused by the high dissolution rate of the borate glasses when they are used as bioactive coatings for Ti6Al4V implants. ${ }^{302}$

\subsection{Coating techniques}

The particular coating technique utilized is another important factor affecting the function of the coating/substrate system. ${ }^{350}$ Plasma spraying and enamelling are two conventional coating techniques for Ti6Al4V substrates. However, plasma sprayed coatings can suffer from poor adhesion between the coating and substrate due to the non-melting particles covering the interface between the substrate and coating. ${ }^{351,352}$ The thermal spray process may also cause changes in the microstructure of the coating and substrate materials. ${ }^{174,} 329$ Moreover, the plasma sprayed technique is sometimes limited by the deposition stresses occurring during the cooling of the sprayed particles after solidification. ${ }^{353-355}$ Additionally, if the plasma spraying technique is applied to coat bioactive borate glasses onto Ti6Al4V substrates, the glass coatings are likely to 
be crystallized under the high temperature $\left(\sim 1000^{\circ} \mathrm{C}\right)$ in the coating procedure. ${ }^{178,179}$ The crystalline structure can impair the bioactivity of the glass coatings. ${ }^{356,357}$

The enameling technique is widely employed because it is relatively straightforward to perform and inexpensive. ${ }^{358,359}$ The thermal treatment required for enamelling can be carried out under a controlled atmosphere and temperature without inducing structural changes in the coatings and substrates. ${ }^{360}$ Therefore, the enamelling technique should be a better choice for coating borate glasses onto Ti6A14V substrates.

\subsection{Mechanical testing methods}

The adhesion strength between the coatings and the Ti6Al4V substrates (e.g. implant stems) critically influences their feasibility to be used in long-term applications. ${ }^{361}$ Therefore, measurement of the adhesion strength between the coating and the Ti6Al4V substrate is important when developing a novel coating material.

\subsubsection{Qualitative methods for adhesion strength measurement}

Usually, the tensile adhesion test ${ }^{282,362,363}$ and adhesion scratch ${ }^{364}$ tests are used to measure the adhesion strength between the HA or glass coatings and the Ti6Al4V substrates. In the tensile test, the coating is bonded to the face of a loading fixture, and the combination of coating and fixtures is subjected to a tensile load normal to the coating (Figure 2.29). The tensile load is applied with a constant rate until the components completely separate, and the maximum load is taken as the adhesion strength. ${ }^{365,366}$ 


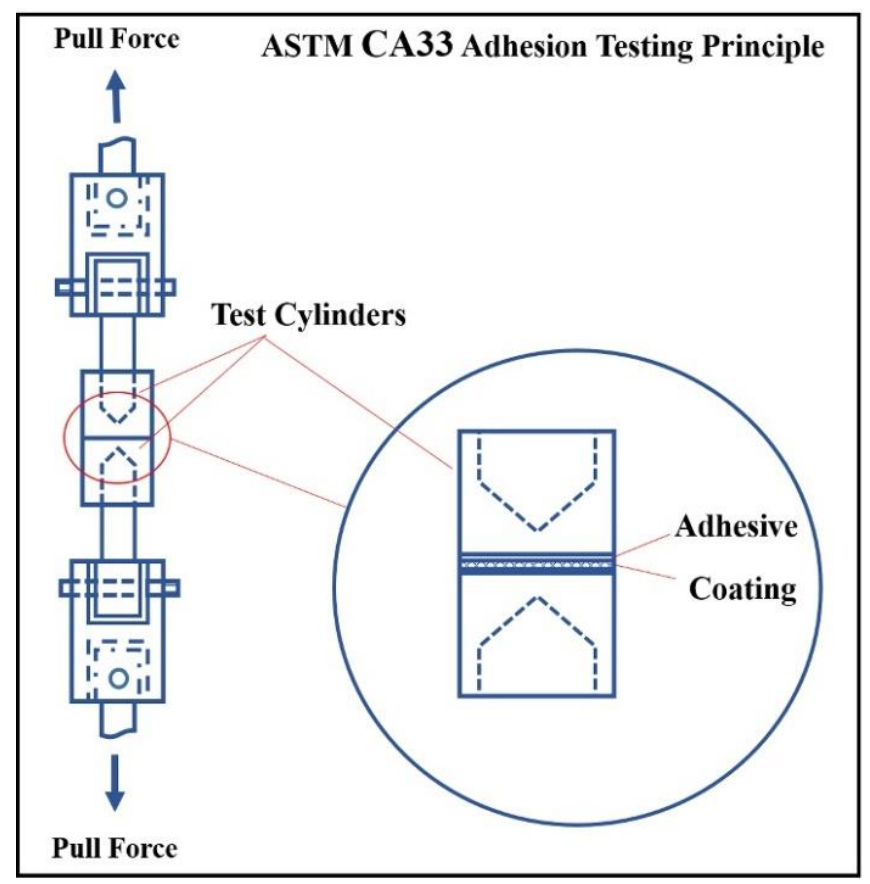

Figure 2.29. Schematic of the tensile adhesion test. ${ }^{365}$

Previous studies indicated that data obtained in this tensile adhesion test cannot be reliable unless the coatings have a thickness greater than $0.38 \mathrm{~mm} \cdot{ }^{199,} 367,368$ Furthermore, the method assumes that the interfacial stress is uniform, which invalidates its ability to reflect the real interface strength. ${ }^{365}$ It can thus only provide failure load data as a measurement of adhesion strength. Therefore, this test has long been considered, at best, to be applicable only for relative ranking purposes, rather than an absolute quantification of adhesion. ${ }^{199}$

In the scratch test, a spherically tipped diamond indenter draws across the coating with increasing continuous or stepwise load normal to the coating surface until the coating detaches from the substrate (Figure 2.30 (a)). ${ }^{369}$ The normal load inducing coating detachment is considered as a measurement of the coating-substrate adhesion strength. ${ }^{370}$ The coating detachment can be observed by scanning electron microscopy (SEM) (Figure 2.30 (b)). 
(a)

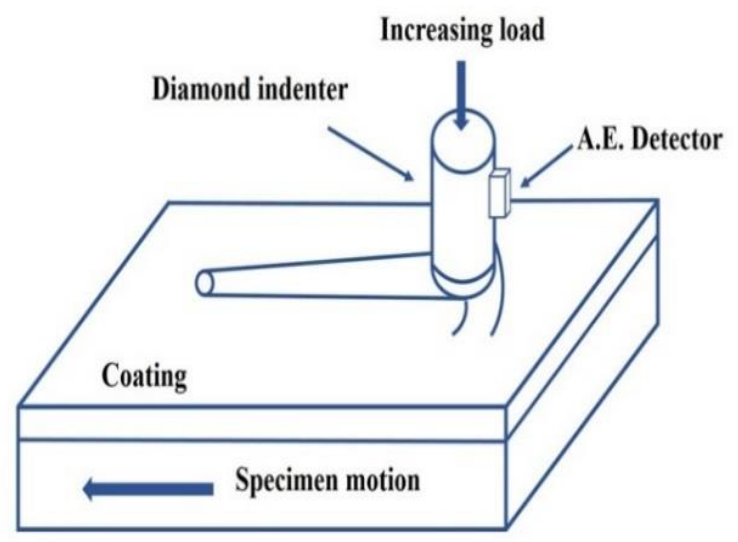

(b)

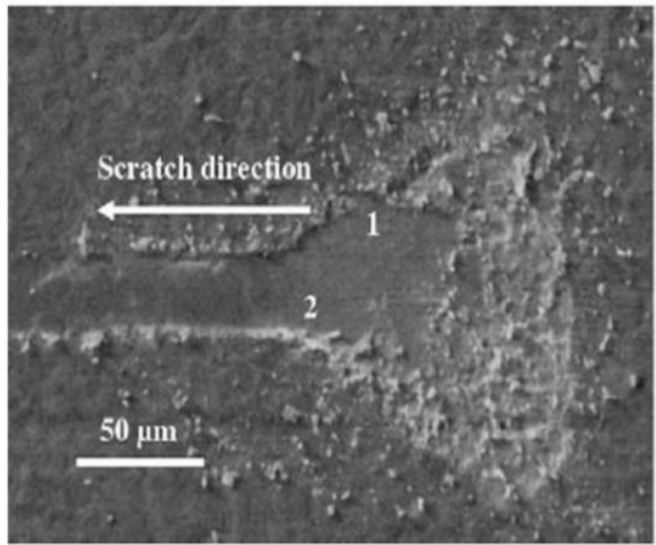

Figure 2.30. (a) Schematic of scratching adhesion test ${ }^{370}$ and (b) SEM image ${ }^{364}$ of the scratch track of an HA coating.

An important issue in scratch adhesion testing is to establish an accurate relationship between the critical load and the actual adhesion strength. Ideally, the coating detachment occurs ahead of the indenter when the induced compressive stress in the coating exceeds a critical value. ${ }^{371}$ However, other failure modes besides the adhesive failure of the coating, such as transverse cracking without coating detachment, have also been reported. ${ }^{372}$ In addition, the testing conditions, such as scratching speed, load rate, indenter wear, and coating thickness all can influence the critical load. ${ }^{373,374}$ Therefore, the scratch test is not a good choice for quantitative assessment of adhesion strength for the glass coating/Ti6Al4V substrate system.

\subsubsection{Quantitative method for adhesion strength measurement}

In order to quantitatively measure the cohesive or adhesive toughness of the glass coating/Ti6Al4V substrate system, a fracture mechanics based methodology, initially used as an assessment of the toughness of environmentally degraded structural adhesive joints ${ }^{375}$, can be used. The toughness is quantified by calculating the strain energy release rate, $G\left(\mathrm{~J} / \mathrm{m}^{2}\right)$, also known as 
'the crack driving force'. The crack extends when $G$ reaches a critical value $\left(G_{I C}\right)$, where $G_{I C}$ represents the amount of energy released in creating a unit area of crack extension ${ }^{376}$, i.e. a measure of the fracture toughness of the material or interface. ${ }^{377}$ Therefore, in this dissertation, the Mode I (opening) critical energy release rate $\left(G_{I C}\right)$ will be measured with special bi-layer double cantilever beam (DCB) specimens (Figure 2.31). ${ }^{376}$ A similar method will be used for determining the Mode II (in-plane shear) critical strain energy release rate $\left(G_{I I C}\right)$ in Section 3.3.7.

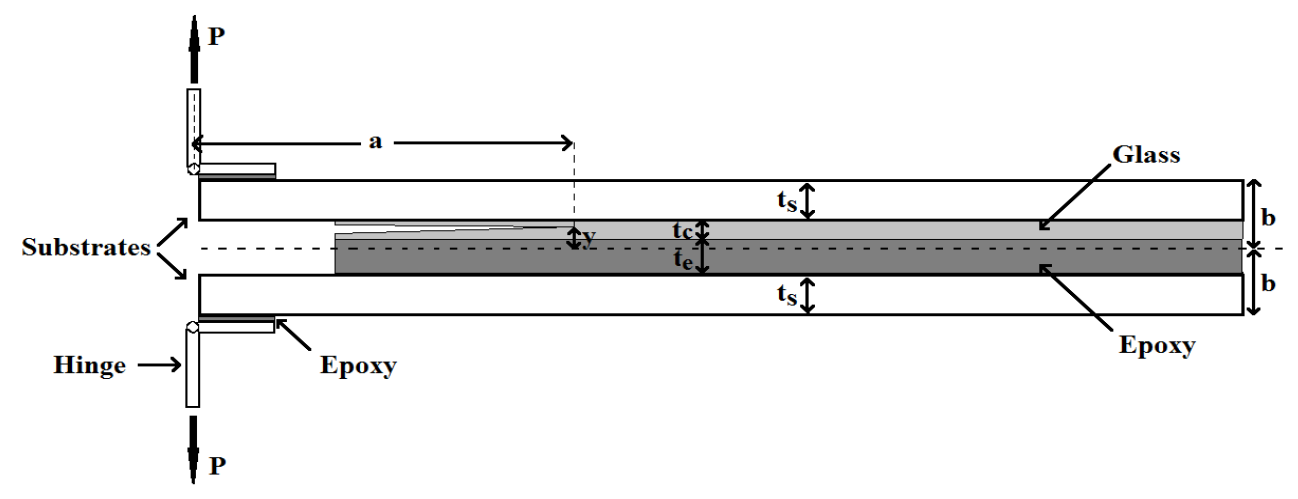

Figure 2.31. Double layer DCB specimen. ${ }^{376}$

The $G_{I C}$ value is calculated as ${ }^{377}$ :

$$
G_{I C}=\frac{12 P_{\max }^{2} a^{2}}{E_{s} w^{2} t_{s}^{3}}
$$

where

$P_{\max }$ the load necessary to propagate the crack

$w$ : the width of the substrate

$E_{s:}$ Young's modulus of the substrate $(110 \mathrm{GPa})$

a: distance from crack tip to the hinge's axis of rotation (Figure 2.31),

$\mathrm{t}_{s}$ : the thickness of the substrate. 


\subsubsection{The method for residual stress measurement}

The thermal residual stresses in the coating caused by the CTE mismatch between the coating and Ti6Al4V substrate has been deemed to be the primary reason for initiating cracks in the coatings. The procedure developed by $\mathrm{Yu}$ et al. ${ }^{378}$, which is based on the measurement of the change in the curvature of coated specimens before and after heating (Figure 2.32), has often been used to determine the thermal residual stress of the coatings.

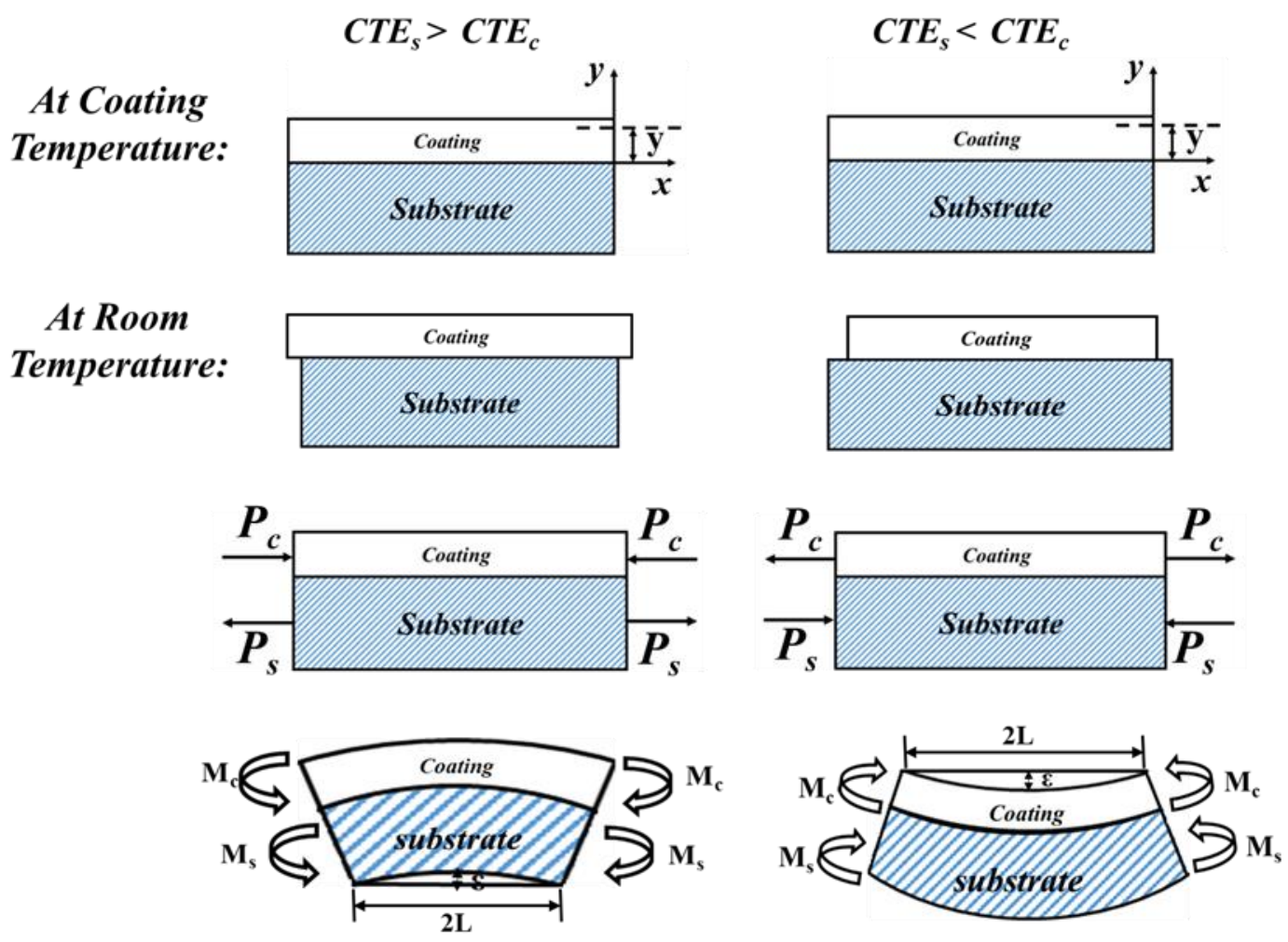

Figure 2.32. The schematic of the analysis of residual stresses during cooling phase of the coating procedure based on the study of Yu et al ${ }^{378}$.

The curvature, $\kappa$, is positive if the unit tangent rotates counter-clockwise and is negative if it rotates clockwise ${ }^{379}$ : 


$$
|\kappa|=\frac{2 \varepsilon}{\varepsilon^{2}+L^{2}}
$$

where

$\varepsilon$ : bending distance,

$L:$ half-chordal length.

When the coating/substrate system cools from the coating temperature to room temperature, there is a tendency for both the coating and substrate to shrink at different rates due to the mismatch of the CTEs. Axial forces $P c$ and $P s$ (Figure 2.32, subscripts $c$ and $s$ refer to the coating and substrate respectively), equal in magnitude and opposite in direction, develop to establish the strain continuity at the interface. Finally, bending moments $M c$ and $M s$ (Figure 2.32) develop in order to maintain moment equilibrium. Therefore, the residual stress is made up of two components:

$$
\sigma_{i}=\sigma_{p_{i}}+\sigma_{M_{i}}
$$

Equation 2.8.

where

$\sigma_{p}$ the axial stress component caused by the axial force,

$\sigma_{M}$ : the bending stress component,

$i=c$ or $s$ : represents the coating and substrate respectively.

$$
\sigma_{p_{i}}=\frac{p_{i}}{w t_{i}}
$$




$$
\begin{array}{rr}
\sigma_{M_{c}}=-\frac{M_{c}}{I_{c}}\left(y-\frac{t_{c}}{2}\right) & \text { Equation 2.10. } \\
\sigma_{M_{s}}=-\frac{M_{s}}{I_{s}}\left(y+\frac{t_{s}}{2}\right) & \text { Equation 2.11. } \\
p=2 \frac{M_{c}+M_{s}}{t_{s}+t_{c}}, M_{i}=\kappa E_{i} I_{i} & \text { where: }
\end{array}
$$

where

$y$ : the distance of the layer of interest from the glass coating/ Ti6Al4V substrate interface,

$M$ : bending moment,

$t$ : thickness,

$w$ : specimen width,

E: Young's modulus,

I: second moment of area of the cross-section.

The Young's modulus and Poisson's ratio of the Ti6Al4V substrate are taken as $110 \mathrm{GPa}$ and 0.34 , respectively ${ }^{376}$. For the presently considered glass coatings, the Young's modulus (35 GPa) and Poisson's ratio (0.26) of 45S5 Bioglass ${ }^{\circledR}$ were assumed. ${ }^{376}$ Based on Eq.2.9-2.12, Young’s modulus of the glass coatings won't significantly influence $G_{I C}$ of the coating/substrate system. , because the thicknesses of coatings were significantly smaller than that of the substrate $\left(t_{d} / t_{s}<0.03\right)$. In the previous study of our research group, Matinmanesh and Rodriguez et al. ${ }^{376}$ coated silicate glasses onto the surface of Ti6Al4V substrates as coatings and measured $G_{I C}$ of the 
coating/substrate system and the residual stresses in the coatings. Since the silicate glasses in this study have similar compositions to those of 45S5 glass, Young's modulus of 45S5 as $35 \mathrm{GPa}$, which was mentioned in the most widely cited references, ${ }^{380,381}$ was used in the calculation of $G_{I C}$ and the residual stresses. ${ }^{376}$ Additionally, Young's moduli of borate glasses have been reported to be about 20-40 GPa ${ }^{382-385}$. Therefore, in this study, we also used Young's modulus as $35 \mathrm{GPa}$ in the calculation of the residual stress in the coatings.

\subsection{Scientific rationale}

HA-coated Ti6Al4V stems have been used in total hip replacement for over 20 years, during which HA coatings have been shown to improve the osseointegration of the implants. However, the cracks in HA coatings and the poor adhesion between the coating and the Ti6Al4V substrate caused by the mismatch in CTE between them limited the long-term application of such coats. Bioactive silicate glass coatings on Ti6Al4V substrates have also been reported to cause similar issues in terms of mismatch in CTE. Unlike HA and bioactive silicate glasses, borate glasses have very similar CTEs to that of Ti6Al4V, which could reduce the residual stress in the coating,

providing better adhesion between the coating and the substrate. Moreover, borate glasses could also improve the osteointegration of the implant, because their stimulatory effects on bone regeneration have been confirmed by the applications in bone scaffolds and drug delivery. Consequently, borate-based glasses are considered promising materials as bioactive coatings on Ti6A14V femoral stems. A higher adhesion strength between the borate glass coating and the Ti6A14V substrate, compared with HA and 45S5 coatings, was reported by a previous study. Unfortunately, the adhesion strength was only measured in a qualitative manner. Furthermore, the 
dissolution of borate glass coatings, which can be an issue in respect of bioactivity and adhesion strength, have rarely been investigated. Therefore, in this project, a novel bioactive borate-based glass series will be formulated and coated onto Ti6Al4V substrates. Suitable coating materials for Ti6A14V substrates with excellent bioactivity, suitable degradation rate, and good mechanical properties are expected to be found in the glass series. Additionally, a novel method will be used to quantitatively measure the cohesive or adhesive strength of the coating/Ti6Al4V substrate construct.

\subsection{Objectives}

Therefore, in the thesis, six borate glasses $(L y-B 0, L y-B 1, L y-B 2, L y-B 3, L y-B 4, L y-B 5)$ based on $\mathrm{B}_{2} \mathrm{O}_{3}-\mathrm{P}_{2} \mathrm{O}_{5}-\mathrm{CaO}-\mathrm{Na}_{2} \mathrm{O}-\mathrm{TiO}_{2}-\mathrm{SrO}$ will be formulated by increasing the concentration of $\mathrm{SrO}$ (from 0 to 25 in mol\%) at the expense of $\mathrm{B}_{2} \mathrm{O}_{3}$. Then, the glasses will be coated onto the surface of the Ti6Al4V substrates using an enamelling technique. The objectives of the thesis are to investigate the influence of:

- increased amounts of $\mathrm{SrO}$ incorporation in the glasses on the structure, CTE, solubility, antibacterial effects and bioactivity of the glass series.

- increased $\mathrm{SrO}$ content in the glasses on the residual stress in the glass coatings, and the Mode I/Mode II critical strain energy release rates of the glass coating/Ti6Al4V substrate system.

- degradation on the mechanical properties of the glass coating/Ti6Al4V substrate constructs. 


\section{Materials and Methods}

\subsection{Characterization of the borate-based glass series}

\subsubsection{Glass synthesis}

Six glasses ( $L y-B O$ to $L y-B 5)$ were formulated based on the $\mathrm{B}_{2} \mathrm{O}_{3}-\mathrm{P}_{2} \mathrm{O}_{5}-\mathrm{CaO}-\mathrm{Na}_{2} \mathrm{O}-\mathrm{TiO}_{2}-\mathrm{SrO}$ glass series with increasing amounts of $\mathrm{SrO}$ (from 0 to $25 \mathrm{~mol} \%$ ) incorporated at the expense of $\mathrm{B}_{2} \mathrm{O}_{3}$. Bioactive borate glasses can have similar CTEs to that of Ti6Al4V, but their high dissolution rate can damage bone cells and bond strength between the coating and substrate (Section 2.8.4). $\mathrm{SrO}$ incorporation in borate glasses has been reported to slow down their dissolution rate, and $\mathrm{Sr}^{2+}$ can improve osteoblasts proliferation (Section 2.9.2). Therefore, we replaced $\mathrm{B}_{2} \mathrm{O}_{3}$ with $\mathrm{SrO}$ in the family of glasses to modify their dissolution rate and improve their bioactivity. The control glass, Ly-BO, was free of SrO. The compositions of the glasses are presented in Table 6. Glasses were prepared by weighing out appropriate amounts of analytical grade reagents in powder form (Fisher Scientific, Ottawa, ON, Canada \& Sigma-Aldrich, Oakville, ON, Canada), firing the mixtures $\left(1300^{\circ} \mathrm{C}, 1 \mathrm{~h}\right)$ in a silica crucible, and subsequently shock quenching into water. The resulting frits were dried, ball-milled and sieved to retrieve powders with a mean particle size of less than $20 \mu \mathrm{m}$.

Table 3.1. Compositions of the borate based glass series, displayed in mol\%.

\begin{tabular}{ccccccc}
\hline & $\boldsymbol{L Y}-\boldsymbol{B O}$ & $\boldsymbol{L Y}-\boldsymbol{B} \boldsymbol{L}$ & $\boldsymbol{L Y}-\boldsymbol{B} \boldsymbol{2}$ & $\boldsymbol{L Y}-\boldsymbol{B 3}$ & $\boldsymbol{L Y}-\boldsymbol{B} \boldsymbol{4}$ & $\boldsymbol{L Y}-\boldsymbol{B 5}$ \\
\hline $\boldsymbol{B}_{2} \boldsymbol{O}_{3}$ & 59 & 54 & 49 & 44 & 39 & 34 \\
$\mathbf{C a O}$ & 13 & 13 & 13 & 13 & 13 & 13 \\
$\boldsymbol{P}_{2} \boldsymbol{O}_{5}$ & 3 & 3 & 3 & 3 & 3 & 3 \\
$\mathrm{Na}_{\mathbf{2}} \boldsymbol{O}$ & 15 & 15 & 15 & 15 & 15 & 15 \\
$\mathrm{TiO}_{2}$ & 10 & 10 & 10 & 10 & 10 & 10 \\
$\mathbf{S r O}$ & 0 & 5 & 10 & 15 & 20 & 25 \\
Total & 100 & 100 & 100 & 100 & 100 & 100 \\
\hline
\end{tabular}




\subsubsection{X-ray Diffraction (XRD) analysis}

Diffraction patterns were collected using a D2 PHASER (Bruker AXS Inc., WI, USA). Powdered samples were packed into plastic sample holders. $\mathrm{CuK} \alpha(1.54 \AA)$ anode was employed with a generator voltage of $30 \mathrm{kV}$ and a tube current of $10 \mathrm{~mA}$, and diffractograms were collected in the range of $20^{\circ}<2 \theta<80^{\circ}$, at a scan step size $0.02^{\circ}$ and a count time of $0.3 \mathrm{~s}$.

\subsubsection{Particle Size Analysis (PSA)}

PSA was performed using a Beckman Coulter Multisizer 4 Particle size analyzer (BeckmanCoulter, Fullerton, CA, USA). Glass samples were evaluated in the range of $0.4-100.0 \mu \mathrm{m}$ and the run length was 60 seconds. Characterization was performed in water at room temperature. Three measurements were recorded for each glass composition and the mean and SD were collected for each.

\subsubsection{Scanning Electron Microscopy (SEM) and Energy-dispersive spectrometry (EDS) analysis}

Sample imaging, including those of the original glass powder were carried out with an FEI Co. Quanta 200F Environmental Scanning Electron Microscope (ESEM) equipped with an EDX Genesis Energy-Dispersive Spectrometer. Secondary electron (SE) and backscattered electron (BSE) images were taken on glass particles and polished disc surfaces. Energy-dispersive spectrometry (EDS) was used to determine the compositions of the six borate glasses. 


\subsubsection{DTA measurement}

A combined differential thermal analyzer-thermal gravimetric analyzer (DTA-TGA, SDT Q600, TA Instruments, New Castle, DE, USA) was used to measure the $\mathrm{T}_{\mathrm{g}} \mathrm{s}$ and the first crystallization temperature $\left(\mathrm{T}_{\mathrm{c} 1} \mathrm{~s}\right)$ for all glass samples. A heating rate of $20^{\circ} \mathrm{C} / \mathrm{min}$ was employed in a nitrogen (N2) atmosphere between $25^{\circ} \mathrm{C}$ to $1000{ }^{\circ} \mathrm{C}$ using $\alpha-\mathrm{Al}_{2} \mathrm{O}_{3}$ as a reference, where a platinum pan was used.

\subsubsection{MAS-NMR measurement}

The ${ }^{31} \mathrm{P}$ and ${ }^{11} \mathrm{~B}$ MAS-NMR spectra for the glass series were recorded with a solid echo sequence on a Bruker AVANCE 500 NMR spectrometer (Agilent Technologies, Inc., Santa Clara, CA, USA) using a $2.5 \mathrm{~mm}$ MAS probe with spinning speeds of $20 \mathrm{kHz}$. The 90 -degree pulse for the central transition was 1.5 microseconds. The echo delay was 100 seconds. Spectra were recorded with at least 32 scans using a $30 \mathrm{~s}$ recycle time. ${ }^{31} \mathrm{P}$ chemical shifts were referenced externally to ammonium dihydrogen phosphate $\left(\mathrm{NH}_{4} \mathrm{H}_{2} \mathrm{PO}_{4}\right)$, which was assigned a chemical shift of $1.0 \mathrm{ppm}$ for the borate-based glasses with respect to $85 \%$ phosphoric acid $\left(\mathrm{H}_{3} \mathrm{PO}_{4}\right)$ at $0 \mathrm{ppm}$.

${ }^{11} \mathrm{~B}$ chemical shifts were referenced externally to boric acid $\left(\mathrm{H}_{3} \mathrm{BO}_{3}\right)$ saturated aqueous solution, which was assigned a chemical shift of $-19.49 \mathrm{ppm}$ with respect to boron trifluoride etherate $\left(\left(\mathrm{C}_{2} \mathrm{H}_{5}\right)_{2} \mathrm{O} \cdot \mathrm{BF}_{3}\right)$ at $0 \mathrm{ppm}$.

\subsubsection{Raman Spectroscopy measurement}

Raman analysis was conducted using a Sierra Reader (Snowy Range Instruments, WY, USA), employing a red laser with an excitation wavelength of $785 \mathrm{~nm}$ and power of $72 \mathrm{~mW}$. Each scan lasted 10 seconds and 5 scans in total were performed for each sample, the average of which was 
recorded. The Sierra Reader built-in software (Snowy Range Peak Software v3.13) combined with GRAMS software (Waltham, MA, USA) was used to generate the spectral data. The peaks in the Raman spectra were fitted using the Gaussian function.

\subsection{Solubility, antibacterial and osteo-stimulatory effects of the borate-based glass series}

\subsubsection{Sample preparation}

Glass powder discs $(2.2 \times \phi 6.4 \mathrm{~mm}, n=9)$ fabricated for the following experiments were produced by pressing the powders into molds and then annealed for $15 \mathrm{~min}$ at $50{ }^{\circ} \mathrm{C}$ above their $\mathrm{T}_{\mathrm{g}}$ s previously determined, Section 3.1 .5 , by a combined differential thermal analyzer-thermal gravimetric analyzer, DTA-TGA, SDT Q600, TA Instruments). The discs were dense after the annealing procedure.

\subsubsection{X-Ray Diffraction (XRD)}

Diffraction patterns were collected using a D2 PHASER (Bruker AXS Inc., WI, USA). Glass powder discs were packed into standard stainless-steel sample holders. CuKa (1.54 $\AA)$ anode was employed with a generator voltage of $30 \mathrm{kV}$ and a tube current of $10 \mathrm{~mA}$. Diffractograms were collected in the range $20^{\circ}<2 \theta<90^{\circ}$, at a scan step size $0.02^{\circ}$ and a count time of 0.3 seconds.

\subsubsection{Atomic Absorption Spectroscopy (AAS)}

Glass powder discs were immersed in $15 \mathrm{ml}$ de-ionized water for 1,7 and 30 days ( 3 samples

of each glass for each incubation period). Ionic concentrations of $\mathrm{Na}^{+}, \mathrm{Ca}^{2+}$ and $\mathrm{Sr}^{2+}$ were evaluated 
from the water extracts utilizing a Perkin Elmer Analyst 800 Atomic Absorption Spectrometer (Waltham, MA, USA). The water extracts were subsequently used for $\mathrm{pH}$ analysis and cell culture testing.

\subsection{4. pH analysis}

Changes in $\mathrm{pH}$ of the water extracts were monitored by a Corning $430 \mathrm{pH}$ meter (Corning, NY, USA). Prior to testing, the $\mathrm{pH}$ meter was calibrated using $\mathrm{pH}$ buffer solution $4.00 \pm 0.02,7.00 \pm$ 0.02 and 10.00 \pm 0.02 (Fisher Scientific, Pittsburgh, PA, USA). Sterile de-ionized water ( $\mathrm{pH}=7.0)$ was used as a control and was measured at each time period (1, 7 and 30 days) for calibration purposes.

\subsubsection{Weight loss}

Weight loss measurements were performed after removing the glass discs from de-ionized water following incubation times of 1,7 and 30 days and dried for 24 hours at $37^{\circ} \mathrm{C}$. The equation used to calculate the weight loss $(\Delta \mathrm{W})$ was:

$$
\Delta W=\frac{W_{0}-W}{W_{0}}
$$

where

$W_{0}$ : the initial weight of the glass disc,

$W$ : the weight of the disc after a certain incubation period.

\subsubsection{Agar disk-diffusion test}


The antibacterial activity of the borate-based glasses was evaluated against $S$. aureus using the agar disk diffusion method. Tryptic Soy Broth (TSB; Sigma Aldrich, Oakville, ON, Canada) was used for the culture of S. aureus. All organisms were grown in $100 \mathrm{~mL}$ TSB to a cell concentration of $1 \times 10^{7}$ cells $/ \mathrm{mL}\left(20 \mathrm{~h}, 37^{\circ} \mathrm{C}\right.$, aerobically, $\left.250 \mathrm{rpm}\right)$. Preparation of the TSA disk-diffusion plates involved aseptically spreading $100 \mu \mathrm{L}$ of the undiluted culture per plate. The pressed glass powder discs with heat treatment were also used in the antibacterial test. Glass powder discs $(n=3)$ were placed on the inoculated plates, and the plates were cultured for 24 hours at $37^{\circ} \mathrm{C}$, sealing the bags to prevent desiccation. Three glass disks, of different treatment, were assessed per plate. Calipers were used to measure the diameter of glass powder discs and the halo of inhibition at three different points for each disk, then zone sizes were calculated as follows:

$$
\text { Inhibition Zone }(\mathrm{mm})=\frac{\text { Halo } \phi-\operatorname{Disc} \phi}{2}
$$

All glasses were analyzed in triplicate and mean zone sizes standard deviations were calculated.

\subsubsection{Cytotoxicity testing}

Pre-osteoblastic MC3T3-E1 cells (ATCC CRL-2593, ATCC, Manassas, VA, USA) were used for this study and were maintained in aMEM media supplemented with 10\% FBS and 1\% (2 mM) L-glutamine (Cambrex, MD, USA) within a cell culture incubator at $37^{\circ} \mathrm{C} / 5 \% \mathrm{CO}_{2} / 95 \%$ air atmosphere. Cells were seeded into 24 well plates at a density of 5500 cells $/ \mathrm{cm}^{2}$ and incubated for 24 hours prior to testing. Culture media $(1 \mathrm{ml})$ was then further supplemented with $100 \mu 1$ of liquid extract (from the solubility samples at 30 days for all glasses; $n=3$ per sample well) and then incubated for 24 hours at $37^{\circ} \mathrm{C} / 5 \% \mathrm{CO}_{2}$. The MTT was added in an amount equal to $10 \%$ of the culture medium volume/well. The cultures were then re-incubated for a further 2 hours $\left(37^{\circ} \mathrm{C} / 5 \%\right.$ 
$\mathrm{CO}_{2}$ ) after which they were removed from the incubator and the resultant formazan crystals dissolved by adding an amount of MTT Solubilisation Solution (10\% Triton x-100 in Acidic Isopropanol $(0.1 \mathrm{n} \mathrm{HCI}))$ equal to the original culture medium volume. Once the crystals were fully dissolved, the absorbance was measured at a wavelength of $570 \mathrm{~nm}$. All results were expressed relative to the metabolic activity of cells seeded (at the same density) on tissue culture plastic $(n=3)$ as controls.

\subsubsection{Statistical analysis}

One-way analysis of variance (ANOVA) was employed to compare the changes in ion release profiles, $\mathrm{pH}$ values, weight loss, inhibition zone and MTT assay data of the experimental materials in relation to 1) different incubation times (e.g. 1, 7 and 30 days), of each composition, and 2) different glass compositions with the same incubation time. The comparison of relevant means was performed using the post hoc Bonferroni test. Differences between groups were deemed significant when $p \leq 0.05$.

\subsection{Mechanical properties and solubility of the borate glass coating/Ti6Al4V substrate system}

\subsubsection{Fabrication of glass coatings onto Ti6Al4V substrates}

Ti6Al4V plates $(88.9 \mathrm{~mm} \times 12.7 \mathrm{~mm} \times 3.2 \mathrm{~mm}$, McMaster-Carr, Elmhurst, Illinois, USA) were polished using 1200 grit sand paper and cleaned using ethanol. The roughness, $R_{a}$, of the plates after polishing was found to be $0.5-0.6 \mu \mathrm{m}$. In order to release the residual stresses in the Ti6Al4V 
plates before coating, they were heated without any constraints up to $650^{\circ} \mathrm{C}$ for 15 minutes. The furnace was then shut off, and the plates were allowed to cool down to room temperature within the furnace.

Glass powder $(<20 \mu \mathrm{m})$ and ethanol $(0.16 \mathrm{~g}$ glass per $1.2 \mathrm{ml}$ ethanol $)$ were mixed inside a standard $5 \mathrm{ml}$ syringe for approximately 1 minute and deposited on the surface of the Ti6Al4V plate placed on a leveled table. The coated samples were air-dried for 30 minutes at room temperature and then were reheated to a temperature between $T_{g}$ and $T_{c 1}$ for 15 minutes, retaining the amorphous nature of the coatings. The furnace was then shut off, and the coated samples cooled down within the furnace.

Coating thicknesses were determined using an optical non-contact profilometer (Nanovea ST400, Microphotonics Inc, PA, US). Three parallel profile traces $4 \mathrm{~mm}$ apart along the longitudinal axis of the substrate with a step size of $5 \mu \mathrm{m}$ were obtained both before and after coating the surface. The waviness profile was extracted by applying a Gaussian filter with a cutoff wavelength of $0.25 \mathrm{~mm}$. The difference in the resulting profiles yielded three thickness profiles per specimen. Point by point averages and standard deviations for each thickness profile were calculated and averaged to obtain the overall average thickness and standard deviation for each specimen.

\subsubsection{Bi-layer DCB specimen}

Bi-layer DCB specimens ${ }^{28}$ (Figure 2.31) were used to measure the Mode I and Mode II critical strain energy release rates $G_{I C}$ and $G_{I I C}$. The coating surface area used for the Mode I and Mode II tests were $76 \mathrm{~mm} \times 12.7 \mathrm{~mm}$ (Figure 3.1 (a)) and $54 \mathrm{~mm} \times 12.7 \mathrm{~mm}$ (Figure 3.1 (b)), respectively. 
A thin layer of a room temperature cure epoxy (J-B Weld 8265-S Cold Weld Compound, Sulphur Springs, TX, USA) was spread onto the glass-coated adherends to attach them to the uncoated Ti6A14V plate. In order to ensure the uniformity of thickness of this layer, before applying the epoxy, a $0.7 \mathrm{~mm}$ diameter wire was inserted around the periphery of the coated specimen. The wire was removed after 10 minutes, by which point the epoxy had set. Then the "double sandwich" specimen was clamped and left at room temperature for 48 hours to complete the cure of the epoxy. Two hinges were glued to the free ends of the specimen (Figure 2.32) using the same quick set epoxy. The bond line between the glass and substrate was covered with diluted type white correction fluid, and the length of the bond line was marked at fixed intervals to facilitate crack length measurement during testing.
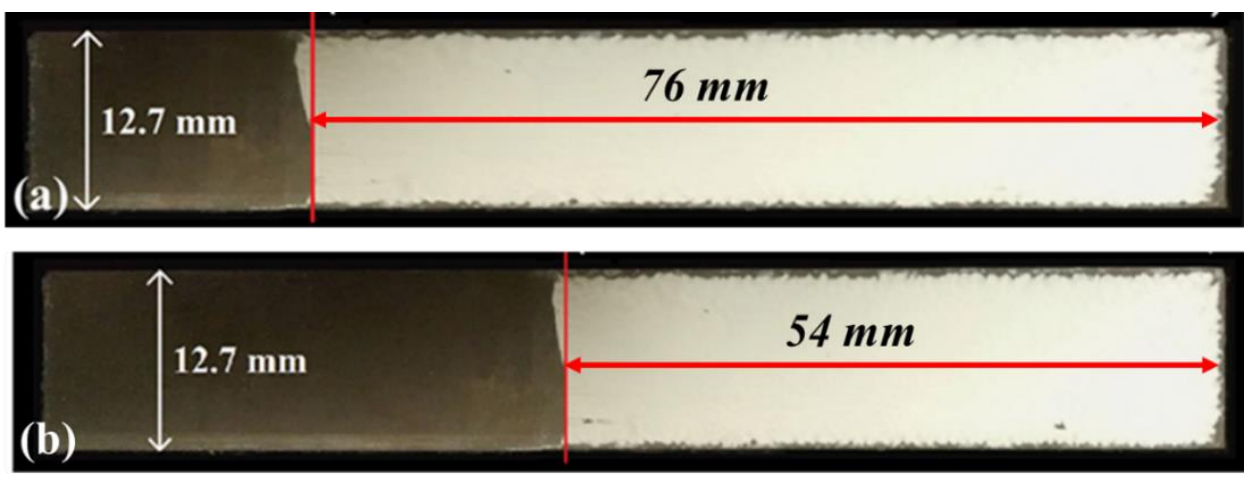

Figure 3.1. The coated samples used for the (a) Mode I and (b) Mode II tests.

\subsubsection{X-ray Diffraction (XRD)}

Diffraction patterns of original glasses and glass coatings were collected using a D2 PHASER (Bruker AXS Inc., WI, USA). Powdered samples and coated Ti6Al4V samples were packed into stainless steel sample holders were packed into stainless steel sample holders. $\mathrm{CuK} \alpha(1.54 \AA)$ anode was employed with a generator voltage of $30 \mathrm{kV}$ and a tube current of $10 \mathrm{~mA}$, and 
diffractograms were collected in the range of $20^{\circ}<2 \theta<80^{\circ}$, at a scan step size $0.02^{\circ}$ and a count time of 0.3 seconds.

\subsubsection{Measurement of the coefficient of thermal expansion (CTE) of the glasses}

Linear dilatometry based on ASTM E228 $8^{386}$ was used to measure the CTEs of the glasses. Glass discs $(\sim 4 \times \phi 6.4 \mathrm{~mm})$ were manufactured by pressing glass powders into a cylindrical mold. The discs were then annealed at the same temperature at which they were enameled. Three discs were stacked to make the final samples $(\sim 12 \times \phi 6.4 \mathrm{~mm})$. The samples were tested from $25^{\circ} \mathrm{C}$ to $300^{\circ} \mathrm{C}$ with a heating rate of $4^{\circ} \mathrm{C} / \mathrm{min}$ where a Netzsch DIL 402 PC dilatometer was applied (Netzsch Instruments, Burlington, MA, USA). The CTE was calculated as follows:

$$
\alpha_{m}=\frac{1}{\Delta T} \frac{\Delta L}{L_{0}}
$$

Equation 3.3.

where

$\alpha_{m}$ : the mean CTE of the sample,

$L_{0}:$ the original length of the sample,

$\Delta T$ and $\Delta L$ : the changes in temperature and length of the specimen respectively.

\subsubsection{Measurement of Mode I critical strain energy release rate $\left(G_{I C}\right)$ of the coating/substrate system}

A United Universal Tester (STM series, United Testing Systems, Inc., Huntington Beach, CA, USA) with a $500 \mathrm{~N}$ load cell was utilized in displacement control at a crosshead displacement rate of $0.5 \mathrm{~mm} / \mathrm{min}$ to load the hinges on the specimens using friction grips. The crack propagation was monitored by a digital microscope camera (OptixCam Summit SK2-14X, Roanoke, VA, USA) 
having a field of view of $3 \mathrm{~mm}$, which was mounted on a motorized stage. Three samples for each coating were tested. The $G_{I C}$ was calculated from the critical load to cause crack propagation, and the crack length, using Eq. (2.6).

\subsubsection{Measurement of residual stress}

The thermal residual stresses in the coating are induced by CTE mismatch between the coating and coating. Since the CTE measurements of Section 3.3.4 were by necessity performed at a lower temperature than the processing temperature of the system, they could not directly be used to determine the residual stresses. Instead, the level of residual stresses can be determined by measuring the change in the curvature of the coated specimens before heating and after cooling down, which is illustrated by Eqs. (2.7)-(2.12). ${ }^{378}$ Three parallel surfaces, $3 \mathrm{~mm}$ apart, using a step size of $10 \mu \mathrm{m}$ along the longitudinal axis on the back side of the Ti6Al4V plates were measured using the optical profilometer, before and after enameling. The waviness profile was extracted by applying a Gaussian filter with a cut-off wavelength of $0.25 \mathrm{~mm}$ (ASME B46.1 ${ }^{387}$ ), and the deformed profile was obtained by subtracting the profiles before and after enameling.

\subsubsection{Measurement of Mode II critical strain energy release rate $\left(G_{I I C}\right)$ of the coating/substrate system}

The Mode II fracture tests were performed using the mixed-mode load jig developed by Fernlund and Spelt ${ }^{388}$ (Figure 3.2), where the desired mode ratio can be generated by adjusting the links lengths $\left(S_{1}-S_{4}\right)^{388}$ :

$$
p_{1}=p_{\max } \times\left(1-\frac{S_{1}}{S_{3}}\right)
$$




$$
p_{2}=p_{1} \times \frac{S_{1}}{S_{2}} \times \frac{1}{1+\frac{S_{3}}{S_{4}}}
$$

where $p_{1}$ and $p_{2}$ are the loads applied to the upper and lower substrates and $p_{\max }$ is the measured load to propagate the crack.

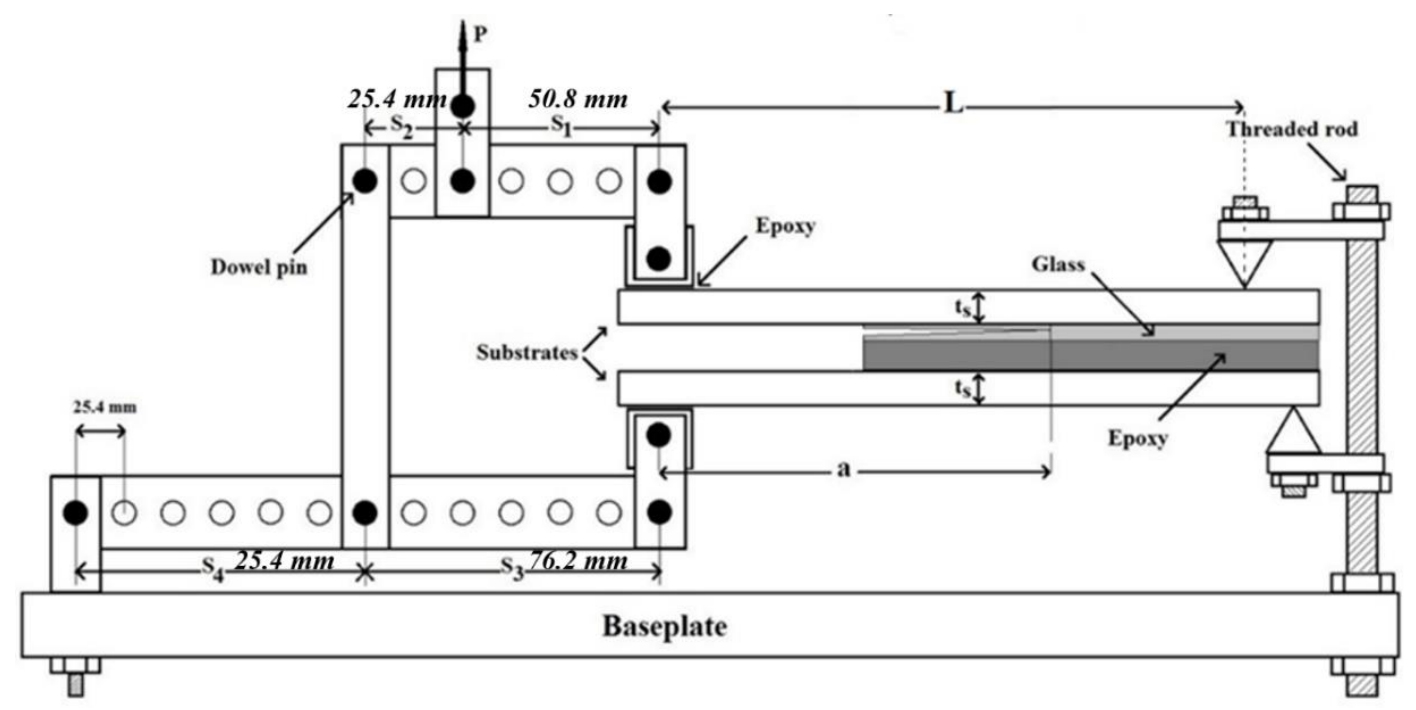

Figure 3.2. Mode II fracture test set up. ${ }^{388}$

Firstly, the load jig was set into a Mode I load condition to create an initial crack in the specimen $(n=3)$ by adjusting the length of the links to $S_{1}=50.8 \mathrm{~mm} S_{2}=25.4 \mathrm{~mm}, S_{3}=76.2 \mathrm{~mm}$ and $S_{4}=-25.4$ $\mathrm{mm}$ (Figure 3.2). Based on Eqs. (3.5) and (3.6), under this loading condition, $p_{l}=-p_{2}$. To create the pre-cracks, the specimens were loaded according to established protocols (Section 3.3.5) for the determination of the critical Mode I strain energy release rate, $G_{I C}$. A United Universal Tester (STM series, United Testing Systems, Inc., Huntington Beach, CA, USA) with a $500 \mathrm{~N}$ load cell was used in displacement control to load the specimens with a crosshead displacement rate of 0.5 $\mathrm{mm} / \mathrm{min}$. A digital microscope camera (OptixCam Summit SK2-14X, Roanoke, VA USA) with a 
high magnification lens having a field of view of $3 \mathrm{~mm}$ was mounted on a movable stage to allow the crack propagation to be monitored. The load was applied to the specimen until the crack propagated and then the pre-crack length, $a_{0}$, was recorded after which the specimen was unloaded and removed. The pre-crack length, $a_{0}$, was chosen to meet the stable fracture criteria for a pure Mode II test $a_{0} / L>0.57$ determined by Fernlund and Spelt ${ }^{388}$, where $L$ is the distance from the line of action of the applied force to the clamp at the root (Figure 3.2).

The specimen was then removed, and the loading jig was set up for the Mode II test. For the link lengths given in the previous paragraph, Eqs. (3.4) and (3.5) and give $p_{1}=p_{2}=\frac{p_{\max }}{3}$. The Mode II critical strain energy release rate can be written as ${ }^{377}$ :

$$
G_{I I c}=\frac{9\left(p_{1} a\right)^{2}}{W_{s}^{2} E t_{s}^{3}}=\frac{\left(p_{\max } a\right)^{2}}{w_{s}^{2} E_{s} t_{s}^{3}}
$$

where

$p_{1}$ : lower adherend load,

$p_{\max }$ the load necessary to propagate the crack,

$w_{s}:$ the width of the substrate,

$E_{s:}$ Young's modulus of the substrate $(110 \mathrm{GPa})$

$a$ : distance from crack tip to the hinge's axis of rotation (Figure 3.2).

The pre-cracked specimens were loaded under this Mode II condition using a United Universal Tester (STM series, United Testing Systems, Inc., Huntington Beach, CA, USA) with a $500 \mathrm{~N}$ load cell in displacement control with a crosshead displacement rate of $1.5 \mathrm{~mm} / \mathrm{min}$ to avoid instabilities ${ }^{389}$. In order to monitor the crack propagation, a digital microscope camera (OptixCam 
Summit SK2-14X, Roanoke, VA USA) with a high magnification lens (field of view of $3 \mathrm{~mm}$ ) was used. The load was applied to the specimen until the crack was visually observed to propagate, also corresponding to a sudden drop in force.

\subsubsection{Degradation of the coatings and weight loss}

The degradation of the coatings was assessed gravimetrically after 2, 6 and 24 hours of immersion of the coated substrates in de-ionized water. The degraded samples were taken out of the water and left for $24 \mathrm{hr}$ at room temperature to completely dry. Using an analytical scale with an accuracy of 0.0001g (QUINTIX213-1S, Sartorius Weighing Technology GmbH, Goettingen, Germany), the weights of the Ti6Al4V bars before $\left(W_{0}\right)$ and after $\left(W_{l}\right)$ coating were measured, then the weight of coated specimens after degradation was measured $\left(W_{2}\right)$. Then the coating weights before and after degradation were calculated as $\left(W_{1}-W_{0}\right)$ and $\left(W_{2}-W_{0}\right)$, respectively, and the weight loss $(\Delta W)$ was then determined as:

$$
\Delta W=\frac{\left(W_{1}-W_{0}\right)-\left(W_{2}-W_{0}\right)}{\left(W_{1}-W_{0}\right)}
$$

These degraded samples were then made into bi-layer DCB specimens according to the procedure in Section 3.3.2 and were load under Mode I (Section 3.3.5) and Mode II loading conditions (Section 3.3.7) to measure their $G_{I C}$ and $G_{I I C}$ values, respectively. This procedure is similar to that previously developed for testing degradable adhesive joints. ${ }^{390,391}$

\subsubsection{Statistical analysis}

One-way analysis of variance (ANOVA) was employed to assess the significance of the changes in the thickness and residual stress of the glass coatings, the measured $G_{I C}$ and $G_{I I C}$ values 
of the glass coating/ Ti6Al4V substrate systems before and after degradation, and the weight loss of glass coatings after different incubation times brought about by changes in the glass compositions. The comparison of relevant means was performed using the post hoc Bonferroni ${ }^{392}$ test. Differences between groups were deemed significant when $p \leq 0.05$. 


\section{Results and Discussion}

\subsection{Characterization of the borate-based glass series}

\subsubsection{XRD and SEM+EDS}

The XRD patterns of the glasses in their as-fired forms are shown in Figure 4.1. The lack of sharp peaks indicates the amorphous nature of all glasses. It is reasonable to assume then, that all changes in the glass series, including $\mathrm{T}_{\mathrm{g}}$ and the amount of $\mathrm{NBO}$ in the glass network (Section 4.1), degradation rate (Section 4.2), and fracture toughness (Section 4.3), are only related to different $\mathrm{SrO}$ contents in the glass compositions rather than the crystalline phases in the glasses.

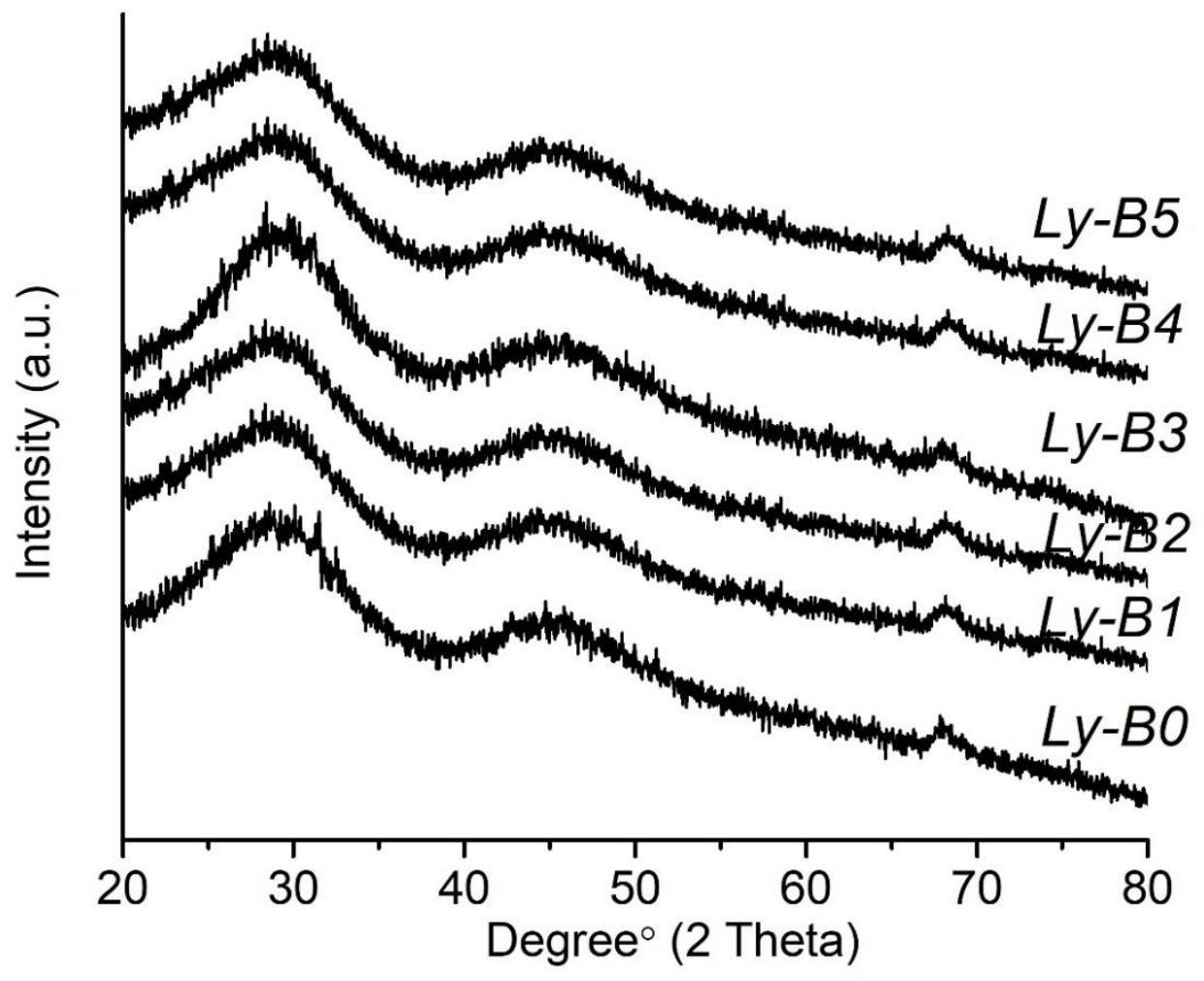

Figure 4.1. XRD patterns of the borate glass series. 
The SEM images with EDS data of the borate glasses are shown in Figure 4.2.
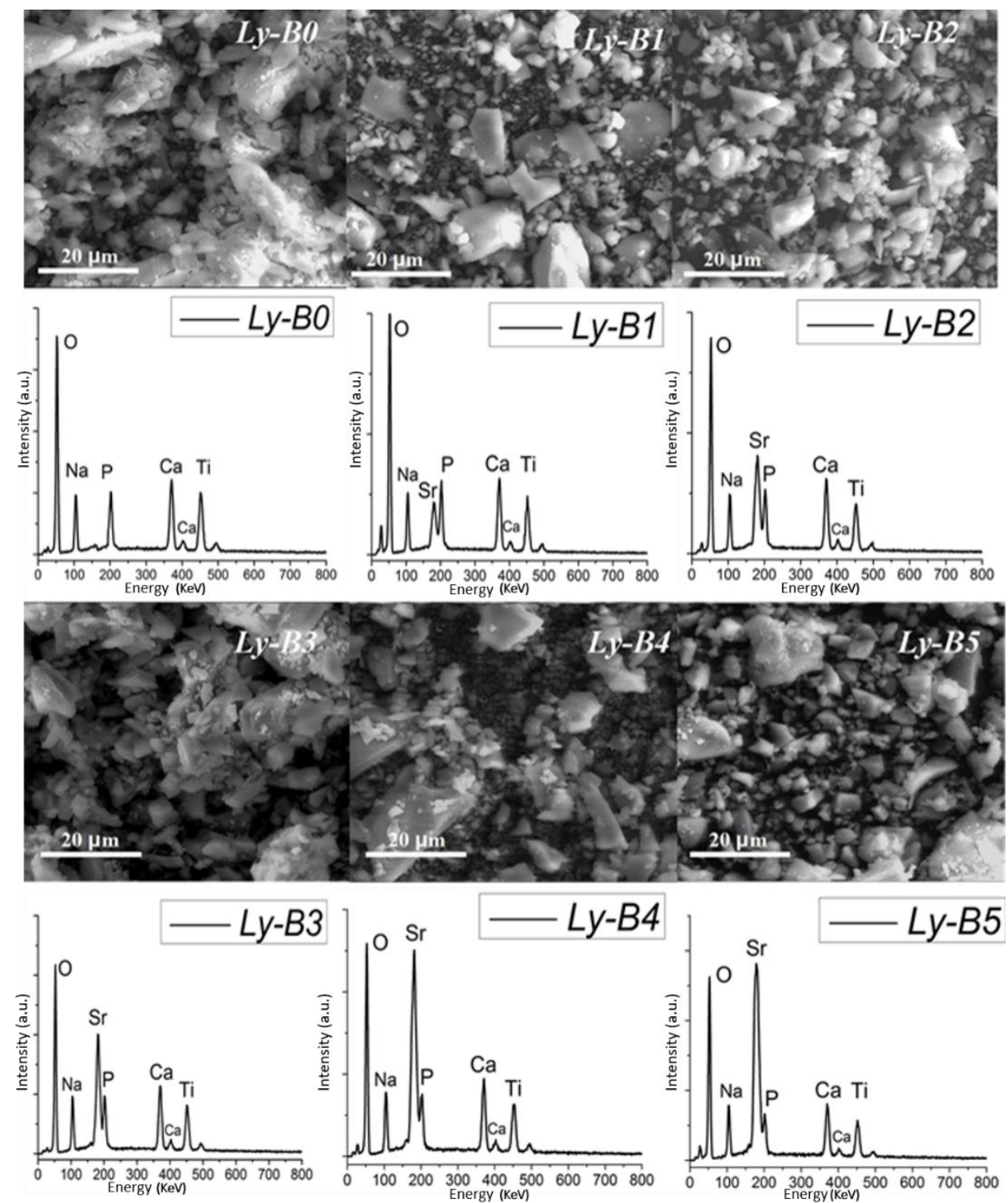

Figure 4.2. SEM images with EDS data of the bioactive borate glass series.

It can be observed from the SEM images that the six glasses have similar morphology. The particles sizes of the glass series will be accurately analyzed in Section 4.1.2. EDS is commonly employed in qualitative, elemental analysis of glass compositions. ${ }^{393-395}$ Since Boron (B) is a light 
element, EDS cannot identify B due to the detection limit. ${ }^{396,397}$ The other elements of the glasses were all confirmed by EDS. The presence of the primary element $(\mathrm{Sr})$ expected in the glass series is revealed by the EDS spectra, except for $L y-B 0$. Additionally, the EDS spectra confirmed an increase in Sr content from $L y-B 1$ to $L y-B 5$.

\subsubsection{Particle size analysis}

Particle sizes of the glass series are shown in Figure 4.3. The mean particle size of each glass was approximately $10 \mu \mathrm{m}$ throughout the series. There was no significant difference $(p \geq 0.05)$ between the particle sizes of the six glasses. Fine particles can dissolve completely in the water during analysis. Therefore, even though very fine particles can be observed in Figure 4.2, they were not shown in the results of the particle size analysis.

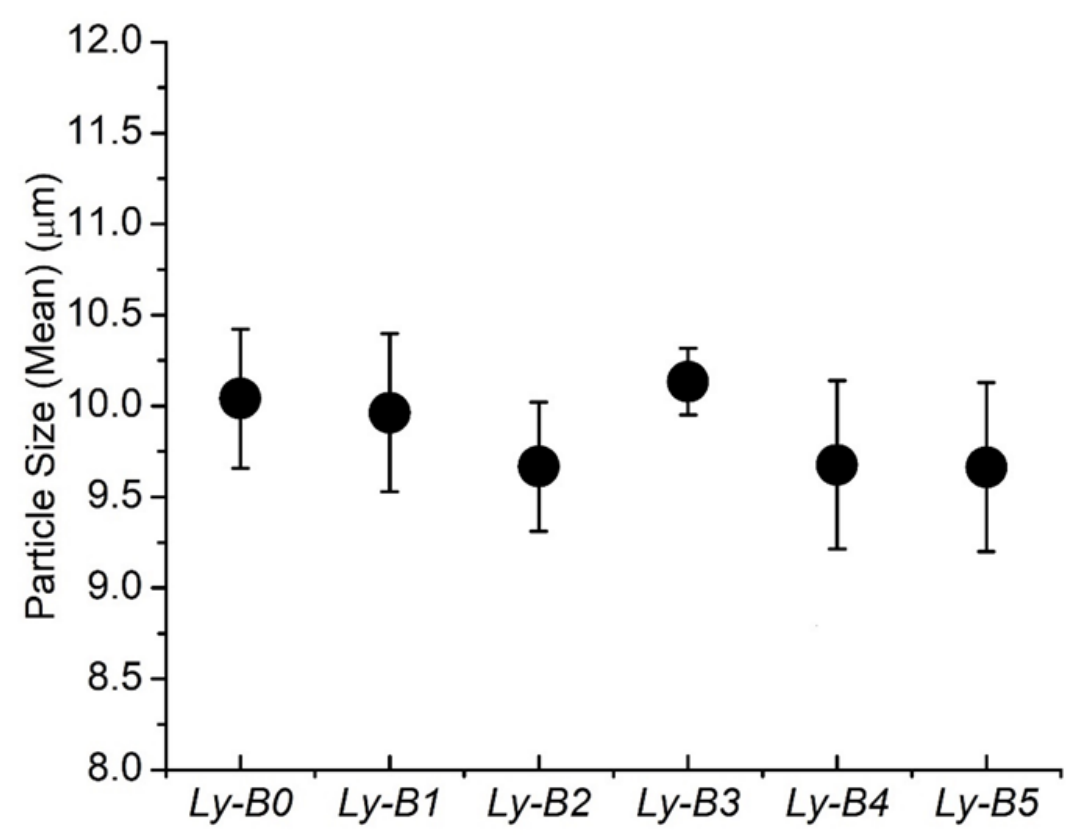

Figure 4.3. Particle size of the borate-based glasses $(n=3)$. Scatter bars indicate the standard deviations. 
Particle size is an important parameter of bioactive glasses because of its influence on the dissolution and bioactivity of the bioactive glasses. ${ }^{398}$ Sepulveda et al. found that the dissolution rates of 45S5 Bioglass ${ }^{\circledR}$ decreased as the particle size increased, because smaller particles have increased the specific ratio of total surface area to volume of the immersion liquid. ${ }^{399}$ Gerruti et $a l .^{400}$ reported that $45 \mathrm{~S} 5$ glasses with greater surface areas (smaller particles sizes) degraded fast

in TRIS-buffered solution, especially in the first $30 \mathrm{~min}$. Furthermore, Schepers et al. ${ }^{401}$ developed 45S5 Bioglass ${ }^{\circledR}$ particles with different sizes (300-350 $\mu \mathrm{m}$ and 100-710 $\left.\mu \mathrm{m}\right)$ and implanted them into the partial edentulous jaws of Beagle dogs. They found the defects filled with glass particles with narrow size range (300-350 $\mu \mathrm{m})$ showed an enhanced repair by new bone formation. However, among the glass particles with wider size range $(100-710 \mu \mathrm{m})$, some large particles (> $350 \mu \mathrm{m})$ rarely reacted with the body fluid, and macrophages moved to the unreacted glass particles to form fibrous tissue instead of new bone. In order to avoid the influence of particle size on the solubility of the glasses, it is necessary to ensure that particle sizes of glasses through the series are similar.

\subsection{3. ${ }^{31} P$ and ${ }^{11} B$ MAS-NMR Spectroscopy}

The results of MAS-NMR spectroscopy for ${ }^{31} \mathrm{P}$ are shown in Figures 4.4, where the chemical shifts increased from $-0.27 \mathrm{ppm}$ to $3.08 \mathrm{ppm}$ with increasing addition of $\mathrm{Sr}^{2+}$. 


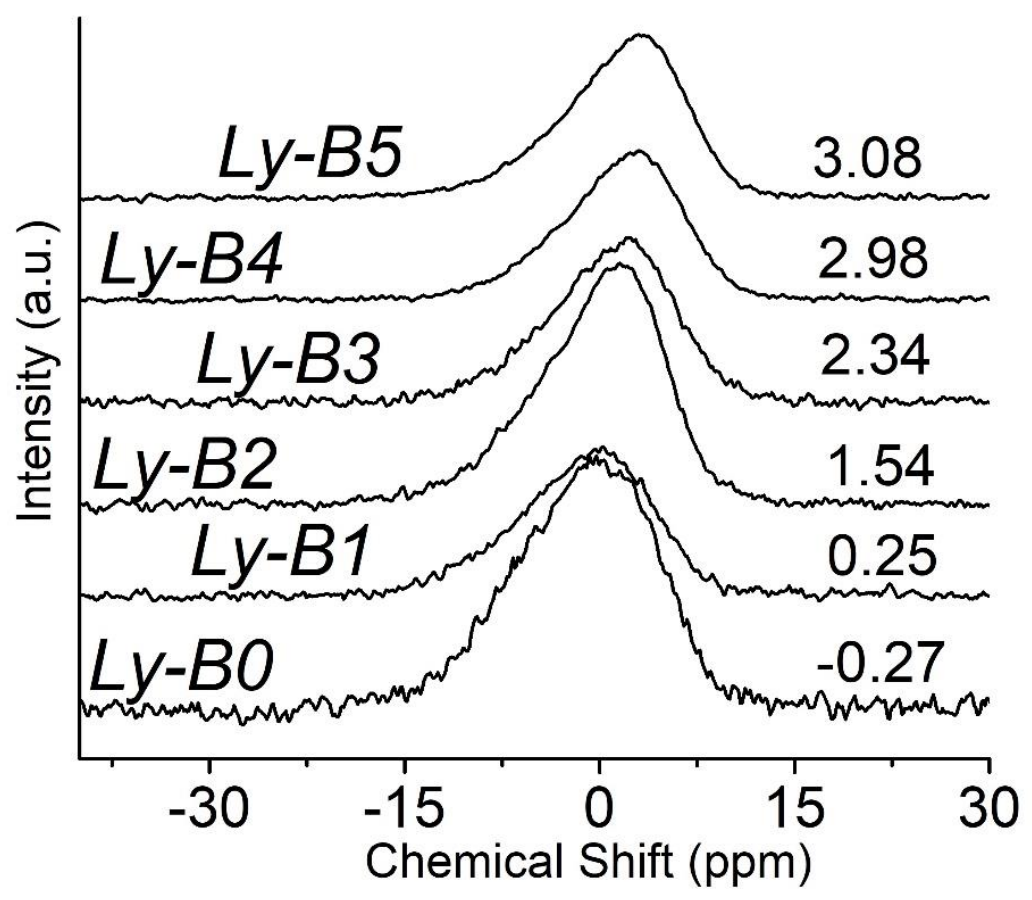

Figure 4.4. ${ }^{31} \mathrm{P}$ MAS-NMR spectra of the borate-based glass series. The peak position of each glass is tagged on the right side.

Considering the chemical composition of the glasses, shifts in the range of -8 to $-0.2 \mathrm{ppm}^{402 \text {, }}$ ${ }^{403}$ represent the phosphate tetrahedral structure, where one phosphate atom bonds to two NBOs and one boron atom through a BO in phosphate-boron glasses. Phosphate tetrahedral is the basic unit in the phosphate glass structure acting as the glass network former charged by alkali and alkaline earth cations. ${ }^{242,402}$ Chemical shifts at $5.3 \pm 0.2 \mathrm{ppm}$ are assigned to phosphate tetrahedra with three NBOs, ${ }^{404}$ indicating the deconstruction of the phosphorus network. ${ }^{402}$ In this borate based glass series, the shifts increased with increasing addition of $\mathrm{Sr}^{2+}$ (Figure 4.4). The shift to higher ppm values is related to the depolymerization of the phosphate network. ${ }^{405}$ Therefore, it can be concluded that phosphate assumes the role of a network former and the increasing $\mathrm{Sr}^{2+}$ content introduces a higher concentration of NBOs in this glass network. 
In the ${ }^{11}$ B MAS-NMR spectra of the borate-based glass series are presented in Figure 4.5. Two peaks, a symmetric peak in the region of 0.2 to $0.6 \mathrm{ppm}$ and a quadrupole broadened peak centered at around $11 \mathrm{ppm}$, are present in all ${ }^{11} \mathrm{~B}$ MAS-NMR spectra.

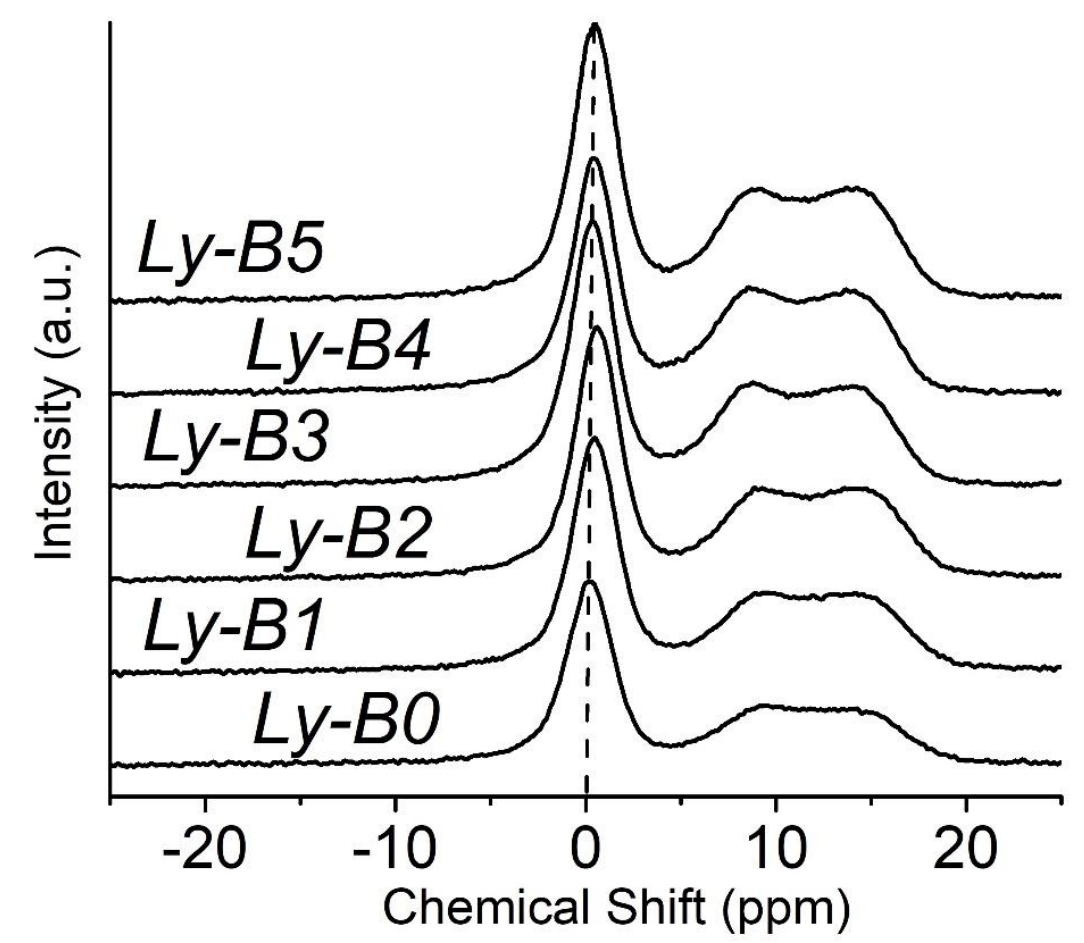

Figure 4.5. ${ }^{11} \mathrm{~B}$ MAS-NMR spectra of the borate-based glass series.

Based on previous studies of ${ }^{11} \mathrm{~B}$ MAS-NMR, $\mathrm{BO}_{4}$ units and $\mathrm{BO}_{3}$ units are assigned in the region of -10 to $2 \mathrm{ppm}^{34,37}$ and 5 to $15 \mathrm{ppm}^{36}$, respectively. Therefore, the centrally symmetric peak in the region of 0.2 to $0.6 \mathrm{ppm}$ is assigned to the four-coordinated borate units $\left(\mathrm{BO}_{4}\right){ }^{36,37}$ The quadrupole broadened peak centered at around $11 \mathrm{ppm}$ arises from the presence of trigonal boron units $\left(\mathrm{BO}_{3}\right) \cdot{ }^{34,36}$ The resonance region of $\mathrm{BO}_{3}$ units was relatively wide with two separate peaks. ${ }^{9}$ The peaks in the higher chemical shift field $(\sim 14 \mathrm{ppm})$ represent "symmetric" sites $\left(\mathrm{BO}_{3 \mathrm{~s}}\right.$, S stands for symmetric) where boron bonds to 1 or $2 \mathrm{NBO}$, and those in the lower chemical shift 
field ( $\sim 9 \mathrm{ppm})$ represent "asymmetric" sites $\left(\mathrm{BO}_{3 \mathrm{~A}}\right.$, A stands for asymmetric) where boron bonds to 0 or $3 \mathrm{NBO} .{ }^{403,406,407}$ Hence, chemical shifts at around $9 \mathrm{ppm}$ and $14 \mathrm{ppm}$ (Figure 4.5) were recorded to be assigned as $\mathrm{BO}_{3 \mathrm{~A}}$ and $\mathrm{BO}_{33}$ respectively. ${ }^{403}$ The $\mathrm{BO}_{3}$ quadrupolar line can be approximated by a Gaussian function to obtain the relative ratio of $\mathrm{BO}_{3}$ and $\mathrm{BO}_{4}$ units. ${ }^{404}$ The relative ratio of $\mathrm{BO}_{4}$ units in the six glasses (from $L y-B O$ to $L y-B 5$ ) are $0.47,0.43,0.42,0.41,0.40$ and 0.37 , which revealed that more NBOs were introduced to the glass network with more addition of $\mathrm{Sr}^{2+}$ contents in the glass series.

\subsubsection{Raman Spectroscopy}

The Raman spectra of the borate glass series are presented in Figure 4.6. It is apparent that the spectra are dominated by a broad peak centered at $1320 \mathrm{~cm}^{-1}$ with a shoulder at $1500 \mathrm{~cm}^{-1}$. In addition, three Raman bands are exhibited at $770 \mathrm{~cm}^{-1}, 860 \mathrm{~cm}^{-1}$ and $940 \mathrm{~cm}^{-1}$.

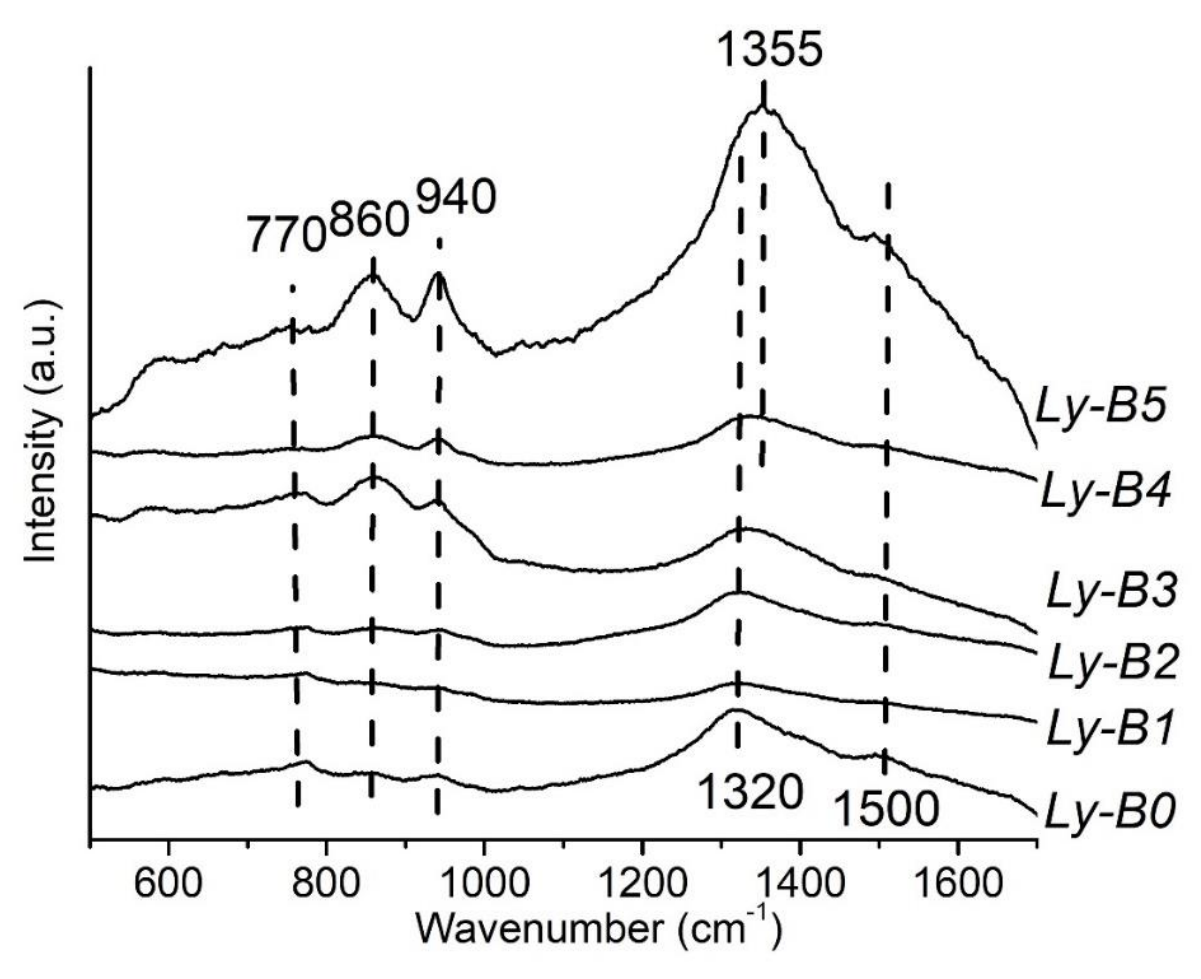

Figure 4.6. Raman spectra of the borate-based glass series. 
The Raman spectra of the borate glasses were fitted by OriginPro 8.1 (OriginLab Corporation, Northampton, MA, US), where $\mathrm{R}^{2}$ is a statistic about the goodness of fitting, $\mathrm{R}^{2}=1$ represents perfectly fitting. ${ }^{408}$ Based on the fitted Raman spectra of the glass series (Figure 4.7), the intensity of the band at $770 \mathrm{~cm}^{-1}$ decreases with increasing $\mathrm{Sr}^{2+}$ contents, while the band intensities at 860 $\mathrm{cm}^{-1}$ and $940 \mathrm{~cm}^{-1}$ increase with the addition of $\mathrm{Sr}^{2+}$. Finally, based on the fitted Raman spectra, the peak areas under $860 \mathrm{~cm}^{-1}, 1320 \mathrm{~cm}^{-1}$ and $1500 \mathrm{~cm}^{-1}$ increase with $\mathrm{Sr}^{2+}$ content.
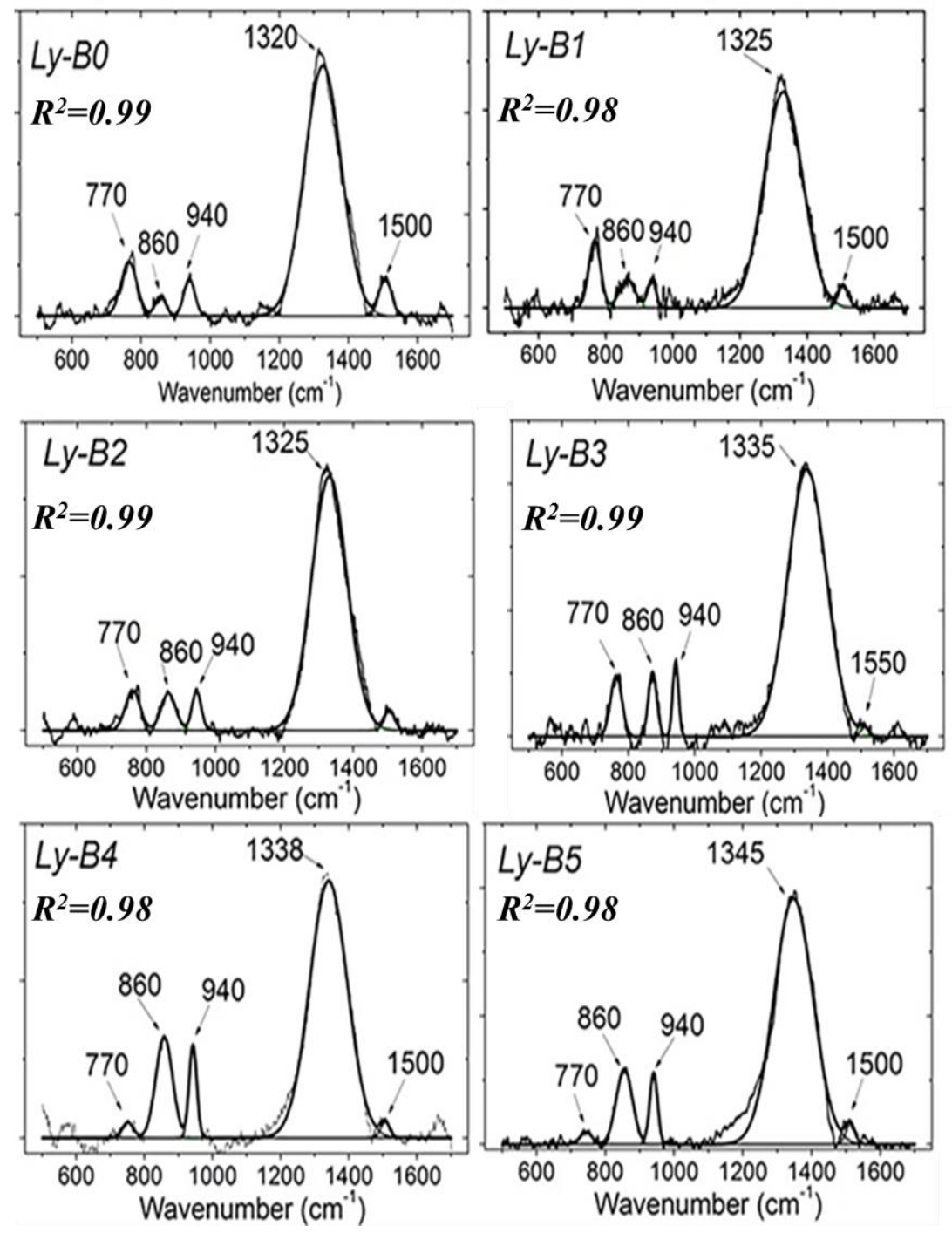

Figure 4.7. Fitted Raman spectra of the borate-based glass series, where $\mathrm{R}^{2} \geq 0.98$. 
According to Raman analysis from previous studies concerning the structure of borate glasses, the peak at $774 \mathrm{~cm}^{-1}$ can be assigned to the symmetric breathing vibration of six-member rings with one $\left[\mathrm{B} \varnothing_{3}\right]$ replaced by $\left[\mathrm{B} \varnothing_{4}\right] .{ }^{230,409}$ The Raman band at $860 \mathrm{~cm}^{-1}$ is related to the symmetric stretching vibrations of B- $\varnothing-\mathrm{B}$ bonds from $\left[\mathrm{B}_{2} \varnothing \mathrm{O}_{4}\right]^{4-} \cdot{ }^{409,}{ }^{410}$ Correspondingly, the bands ranging from 1315 to $1350 \mathrm{~cm}^{-1}$ are attributed to the stretching vibration of terminal $\mathrm{B}-\mathrm{O}^{-}$bonds of $\left[\mathrm{B}_{2} \varnothing \mathrm{O}_{4}\right]^{4-} .{ }^{296,411}$ The Raman band at $940 \mathrm{~cm}^{-1}$ corresponds to [BØ $\left.\emptyset_{4}\right]$ bonding to NBO-containing groups instead of pure $\left[\mathrm{B} \varnothing_{4}\right]$ and orthoborate unites $\left[\mathrm{BO}_{3}\right]^{3-} \cdot{ }^{412-414}$ The Raman bands centering at $1480-1500 \mathrm{~cm}^{-1}$ are due to the presence of $\left[\mathrm{BO}_{2} \mathrm{O}\right]^{-} \cdot{ }^{230,411}$ The assignments of Raman bands of the borate based glass series are summarized in Table 4.1. The increasing intensity of Raman bands at $860 \mathrm{~cm}^{-1}, 940 \mathrm{~cm}^{-1}, 1320 \mathrm{~cm}^{-1}$ and $1500 \mathrm{~cm}^{-1}$ indicate the increased presence of $\left[\mathrm{B} \emptyset_{2} \mathrm{O}\right]^{-}$and $\left[\mathrm{B}_{2} \varnothing \mathrm{O}_{4}\right]^{4-}$ within the glasses with $\mathrm{Sr}^{2+}$ incorporation. It is the formation of NBO that make $\left[\mathrm{B} \emptyset_{3}\right]$ and $\left[\mathrm{B} \emptyset_{4}\right]$ units convert into $\left[\mathrm{B} \varnothing_{2} \mathrm{O}\right]^{-}$and $\left[\mathrm{B}_{2} \varnothing_{4}\right]^{4-} \cdot{ }^{230}$ Raman spectroscopy demonstrates that the increased addition of $\mathrm{Sr}^{2+}$ induces more NBOs in the glass network. Therefore, the increasing intensity of Raman bands at $860 \mathrm{~cm}^{-1}, 940 \mathrm{~cm}^{-1}, 1320 \mathrm{~cm}^{-1}$ and $1500 \mathrm{~cm}^{-1}$ indicate the increased presence of $\left[\mathrm{B} \emptyset_{2} \mathrm{O}\right]^{-}$and $\left[\mathrm{B}_{2} \varnothing \mathrm{O}_{4}\right]^{4-}$ within the glasses as $\mathrm{Sr}^{2+}$ incorporation increases through the glass series. It is the formation of NBO that make $\left[\mathrm{B} \varnothing_{3}\right]$ and $\left[\mathrm{B} \emptyset_{4}\right]$ units convert into $\left[\mathrm{B} \emptyset_{2} \mathrm{O}\right]^{-}$ $\left[\mathrm{B}_{2} \varnothing \mathrm{O}_{4}\right]^{4-}$ and $\left[\mathrm{BO}_{3}\right]^{3-} \cdot 230$

Table 4.1. Assignments of Raman bands of the borate-based glass series.

\begin{tabular}{|c|c|}
\hline Wavelength $\left(\mathrm{cm}^{-1}\right)$ & Assignments \\
\hline$\sim 770$ & A structure with two $\left[\mathrm{B} \varnothing_{4}\right]_{.}{ }^{409}$ \\
\hline$\sim 860$ & Symmetric stretching vibrations of $\mathrm{B}-\varnothing-\mathrm{B}$ bonds from $\left[\mathrm{B}_{2} \varnothing \mathrm{O}_{4}\right]^{4-}{ }^{409}$ \\
\hline$\sim 935-955$ & $\begin{array}{l}\text { Large superstructure group with one }\left(\mathrm{B}_{2} \mathrm{O}_{6} \varnothing_{4} \text { pentaborate group }\right) \text { or } \\
\text { two }\left(\mathrm{B}_{4} \mathrm{O}_{5} \varnothing_{4}-\text { diborate group) }\left[\mathrm{B}_{4}\right] \text { tetrahedra }{ }^{412} \text {, and }\left[\mathrm{BO}_{3}\right]^{3-414} \text {. }\right.\end{array}$ \\
\hline$\sim 1315-1350$ & The stretching vibration of terminal $\mathrm{B}-\mathrm{O}^{-}$bonds of $\left[\mathrm{B}_{2} \varnothing \mathrm{O}_{4}\right]^{4-} \cdot 39,40$ \\
\hline$\sim 1480-1500$ & The structure of $\left[\mathrm{BO}_{2} \mathrm{O}\right] .230,411$ \\
\hline
\end{tabular}


The conversion from $\left[\mathrm{B} \emptyset_{4}\right]$ units into $\left[\mathrm{B} \emptyset_{2} \mathrm{O}\right]^{-}$and $\left[\mathrm{BO}_{3}\right]^{3-}$ caused by the addition of glass network modifier, like $\mathrm{Na}^{+}$, was schematically described as Figure $4.8^{291}$, where the cross-linked structure of $\left[\mathrm{B} \emptyset_{4}\right]$ units is broken into chain-like structure. As a result, the degree of connectivity of the glass decreases. ${ }^{415,416}$

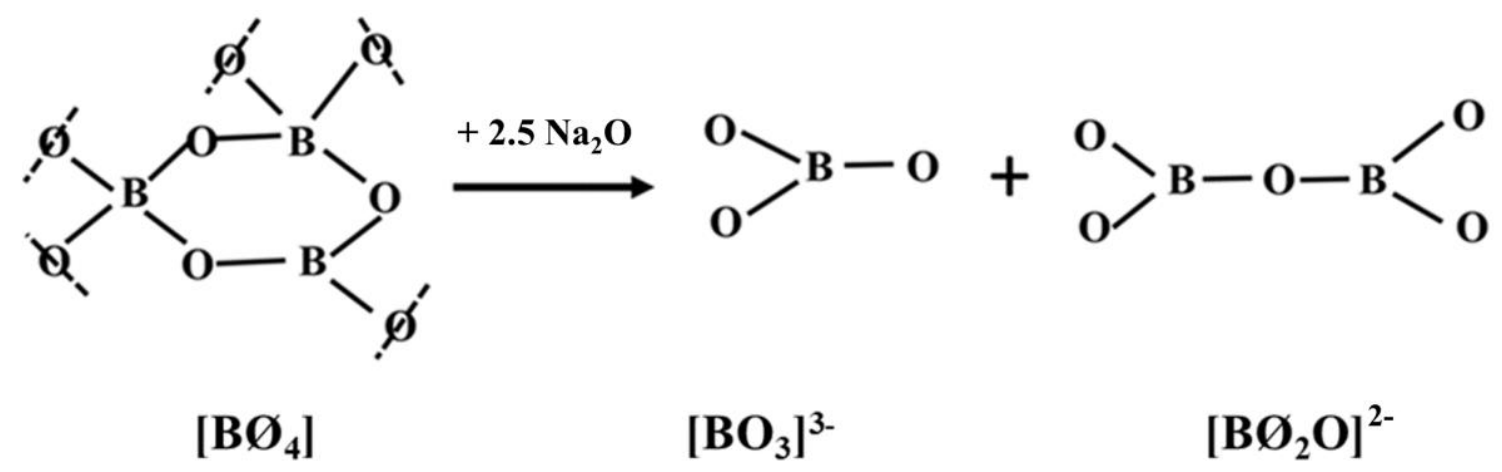

Figure 4.8. The conversion of $\left[\mathrm{B} \varnothing_{4}\right]$ units into $\left[\mathrm{B} \varnothing_{2} \mathrm{O}\right]^{-}$and $\left[\mathrm{BO}_{3}\right]$, where $\varnothing$ represents bridging oxygen. ${ }^{291}$

Beuneu et al. $^{417}$ considered $\mathrm{T}_{\mathrm{g}}$ as the onset temperature where the network of borate glass starts to be opened. Since NBOs break the network of a glass ${ }^{418,419}$ decreasing rigidity, ${ }^{420}$ the glass with more NBOs will exhibit a lower $\mathrm{T}_{\mathrm{g}}{ }^{417}$ The pertinent literature $230,421,422$ reported that $\mathrm{T}_{\mathrm{g}}$ reduces with increased NBO contents in the glass network. Here, since more NBOs were induced by addition of $\mathrm{Sr}^{2+}$ in the glass series, the $\mathrm{T}_{\mathrm{g}}$ of the glasses was expected to decrease with more $\mathrm{Sr}^{2+}$ contents, which will be investigated by DTA measurements (section 4.1.5).

\subsubsection{DTA}

$\mathrm{T}_{\mathrm{gS}}$ and $\mathrm{T}_{\mathrm{c} 1 \mathrm{~S}}$ of the glass series are recorded in Table 4.2. Figure 4.9 shows the trend of glass transition temperature $\left(\mathrm{T}_{\mathrm{g}}\right)$ of the borate based glass series, showing that $\mathrm{T}_{\mathrm{g}}$ gradually increases with increased $\mathrm{Sr}^{2+}$ contents through the glass series. 
Table 4.2. Thermal profiles (DTA curve) of the borate based glass series.

\begin{tabular}{ccccccc}
\hline$\left({ }^{\circ} \mathrm{C}\right)$ & $\boldsymbol{L} \boldsymbol{y}-\boldsymbol{B} \boldsymbol{0}$ & $\boldsymbol{L} \boldsymbol{y}-\boldsymbol{B} \boldsymbol{1}$ & $\boldsymbol{L} \boldsymbol{y}-\boldsymbol{B} \boldsymbol{2}$ & $\boldsymbol{L} \boldsymbol{y}-\boldsymbol{B} \boldsymbol{3}$ & $\boldsymbol{L y}-\boldsymbol{B} \boldsymbol{4}$ & $\boldsymbol{L y}-\boldsymbol{B 5}$ \\
\hline $\boldsymbol{T}_{\boldsymbol{g}}$ & 500 & 510 & 521 & 525 & 535 & 550 \\
$\boldsymbol{T}_{\boldsymbol{c} \boldsymbol{l}}$ & 677 & 690 & 650 & 618 & 629 & 649 \\
\hline
\end{tabular}

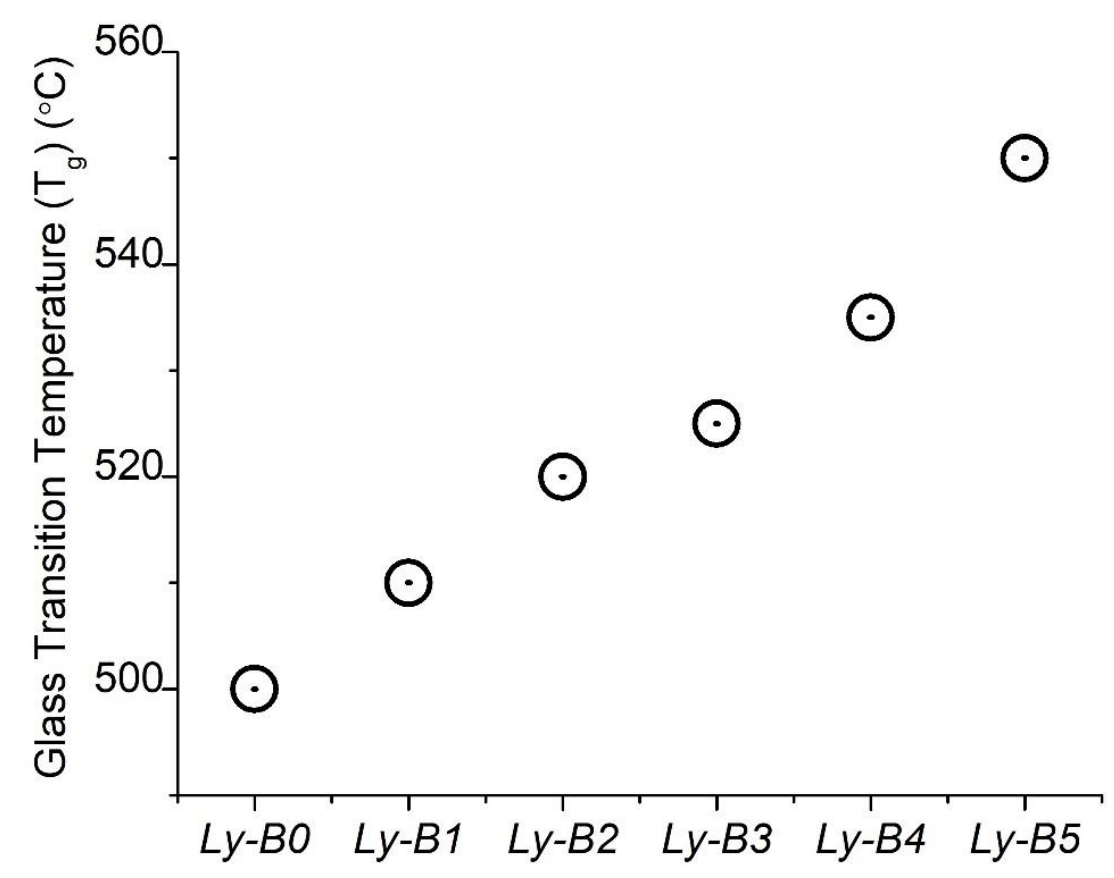

Figure 4.9. Glass transition temperature $\left(\mathrm{T}_{\mathrm{g}}\right)$ of the borate-based glass series.

The results of both Raman spectroscopy and NMR indicate that more NBOs were introduced into the glasses with the increased addition of $\mathrm{Sr}$, while $\mathrm{T}_{\mathrm{g}}$ of the glasses increased with increased Sr incorporation, which is inconsistent with the theory that $\mathrm{T}_{\mathrm{g}}$ decreased with more NBOs in glass structure $^{423}$. It is postulated that the ratio of NBO/BO, or boron-oxygen bonding, is not the only factor influencing $\mathrm{T}_{\mathrm{g}}$. An additional factor is metal-oxygen bonding (R-O) which provides additional cross-links across the borate segments of the glass network to influence $\mathrm{T}_{\mathrm{g}} \cdot{ }^{230}$ The ionic R-O bonding increases $T_{g}$ by enhancing network rigidity; the effect depending on the strength of R-O ( $\left.F_{R-0}\right)$, which was defined as ${ }^{230}$ : 


$$
F_{R-O}=4 \pi^{2} C^{2} \mu v_{e f f}^{2}
$$

Equation 4.1.

where

$C$ : speed of light

$\mu$ : reduced mass of cation site vibration,

$v_{\text {eff: }}$ effective cation site vibration frequency in FT-IR analysis. ${ }^{230}$

The literature confirms that the $\mathrm{T}_{\mathrm{g}} \mathrm{S}$ of borate glasses increase with the enhancement of $\mathrm{F}_{\mathrm{R}-\mathrm{O} .}{ }^{296}$ In addition, $\mathrm{F}_{\mathrm{R}-\mathrm{O}}$ of alkaline earth ions, such as $\mathrm{Ca}^{2+}$ and $\mathrm{Sr}^{2+}$, are higher than those of alkali ions, such as $\mathrm{Na}^{+}$and $\mathrm{K}^{+}$, because divalent ions provide higher coordination numbers with oxygen atoms. ${ }^{344}$ Previous studies ${ }^{424,425}$ demonstrate that increasing $\mathrm{Sr}^{2+}$ contents gradually increased $\mathrm{T}_{\mathrm{g}}$ in borate-based glass systems. Consequently, the increasing amount of $\mathrm{Sr}-\mathrm{O}$ bonding in the glass structure leads to a gradual increase in $\mathrm{T}_{\mathrm{g}}$. We can conclude that through the glass series, increased $\mathrm{Sr}^{2+}$ induced more NBOs in the network, while the increasing amounts of ionic bonds between $\mathrm{Sr}^{2+}$ and oxygen increased the rigidity of the glasses. Young's modulus is the material's resistance to deformation during which bonds between the constituent atoms must be broken and reformed with new neighbors. ${ }^{426}$ Consequently, glasses having greater rigidity, or with higher bond strengths among constituents atoms, were reported to exhibit higher Young's moduli. ${ }^{426,427}$ Shinkai et al. ${ }^{428}$ reported that the fracture toughness of a borate glass series $\left(\mathrm{PbO}-\mathrm{ZnO}-\mathrm{B}_{2} \mathrm{O}_{3}\right)$ had a proportional relationship with Young's modulus of the glasses. Hence, it is postulated that the increased addition of $\mathrm{Sr}^{2+}$ in the glass compositions can increase fracture toughness of the coating/substrate system when the glasses are coated onto Ti6Al4V substrates. This will be further investigated in the mechanical testing section (4.3). 


\subsection{Solubility, antibacterial and osteo-stimulatory effects of the borate-based glass series}

\subsubsection{XRD analysis}

The glass powders were pressed into molds to make discs. Then, the discs were annealed at 50 ${ }^{\circ} \mathrm{C}$ above their $\mathrm{T}_{\mathrm{gS}}$ (Section 4.1.5) to densify them without inducing crystallinity. The XRD patterns of the glass powder discs are shown in Figure 4.10. The absence of sharp peaks in the traces confirmed the amorphous nature of the discs. ${ }^{429,430}$ The objective of this section is to investigate the influence of different $\mathrm{Sr}$ contents on the dissolution rate of the glass series as crystalline phases were reported to inhibit solubility of the bioactive glasses ${ }^{356}$. Therefore, in order to avoid the influence of crystalline phases on the solubility of the glasses, the amorphous nature of the glass discs must be maintained throughout the series.

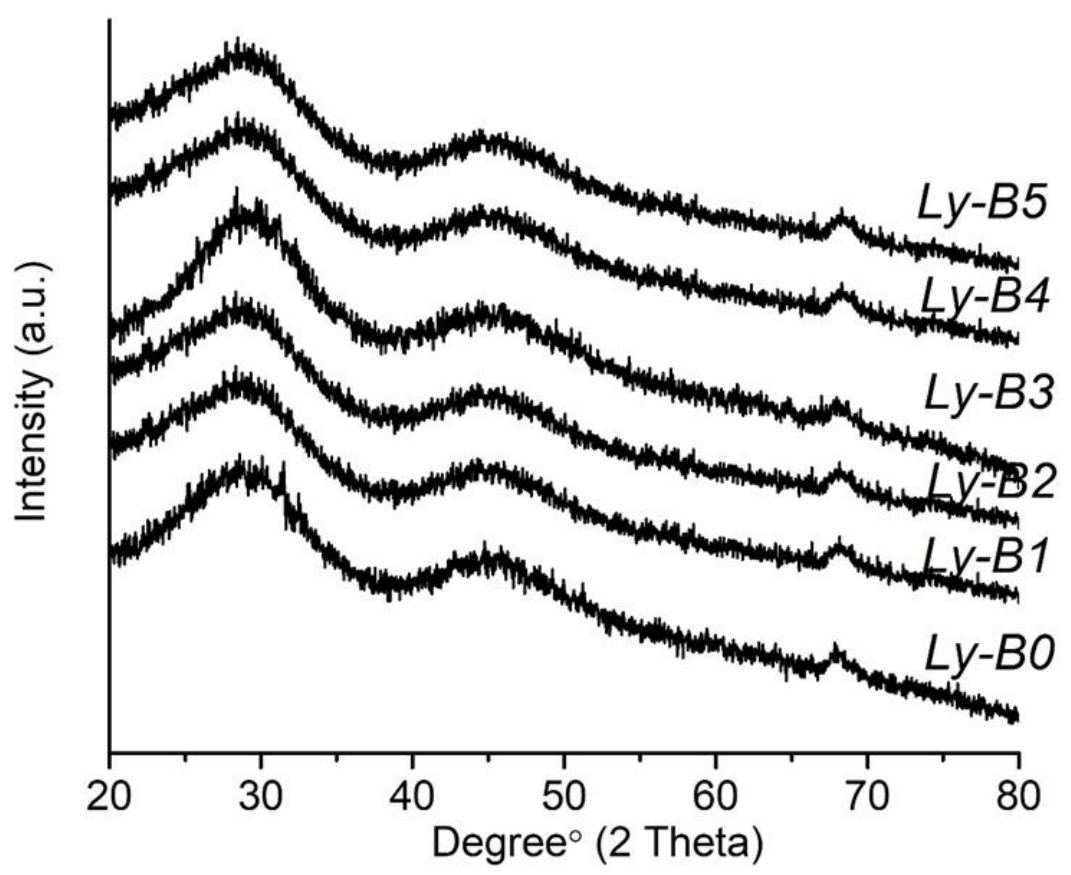

Figure 4.10. XRD patterns of the glass power discs. 


\subsubsection{Atomic Absorption Spectroscopy (AAS)}

The concentrations of $\mathrm{Na}^{+}, \mathrm{Ca}^{2+}$ and $\mathrm{Sr}^{2+}$ released from the components of the glass series, with respect to incubation time and composition, are shown in Figures 4.11-4.13, respectively. Unfortunately, the concentration of $\mathrm{B}^{3+}$ released cannot be accurately determined by AAS because of the insensitivity of this technique for low atomic number elements ${ }^{302}$. For all six glasses, the concentrations of $\mathrm{Na}^{+}$and $\mathrm{Ca}^{2+}$ in the water extracts (Figures 4.11-4.12) were found to significantly increase with incubation time $(p \leq 0.05)$, while the concentrations of $\mathrm{Na}^{+}$and $\mathrm{Ca}^{2+}$ decreased along with increased $\mathrm{Sr}^{2+}$ incorporation $(p \leq 0.05)$ in the glasses after 30-days incubation.

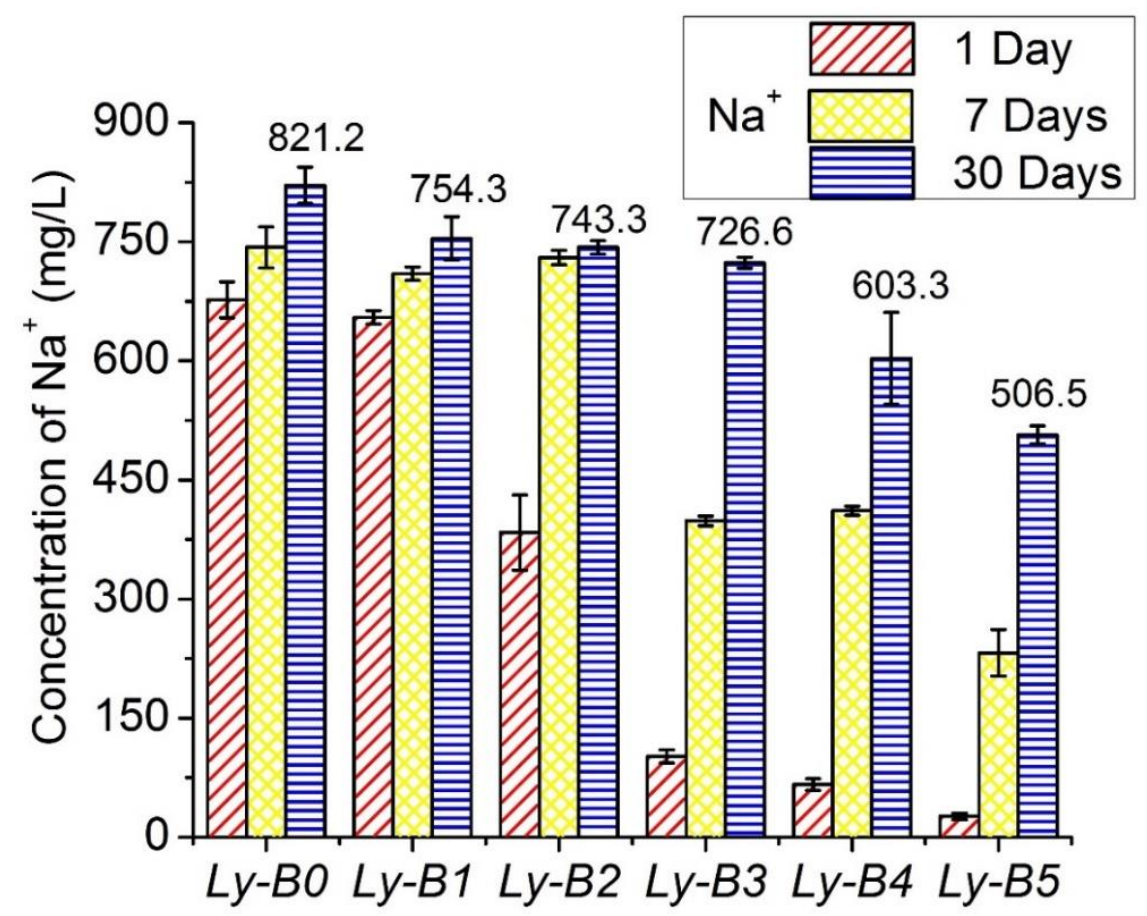

Figure 4.11. Concentration of $\mathrm{Na}^{+}$from the water extracts of the glass series $(n=3)$ versus incubation time. Scatter bars indicate the standard deviations. 


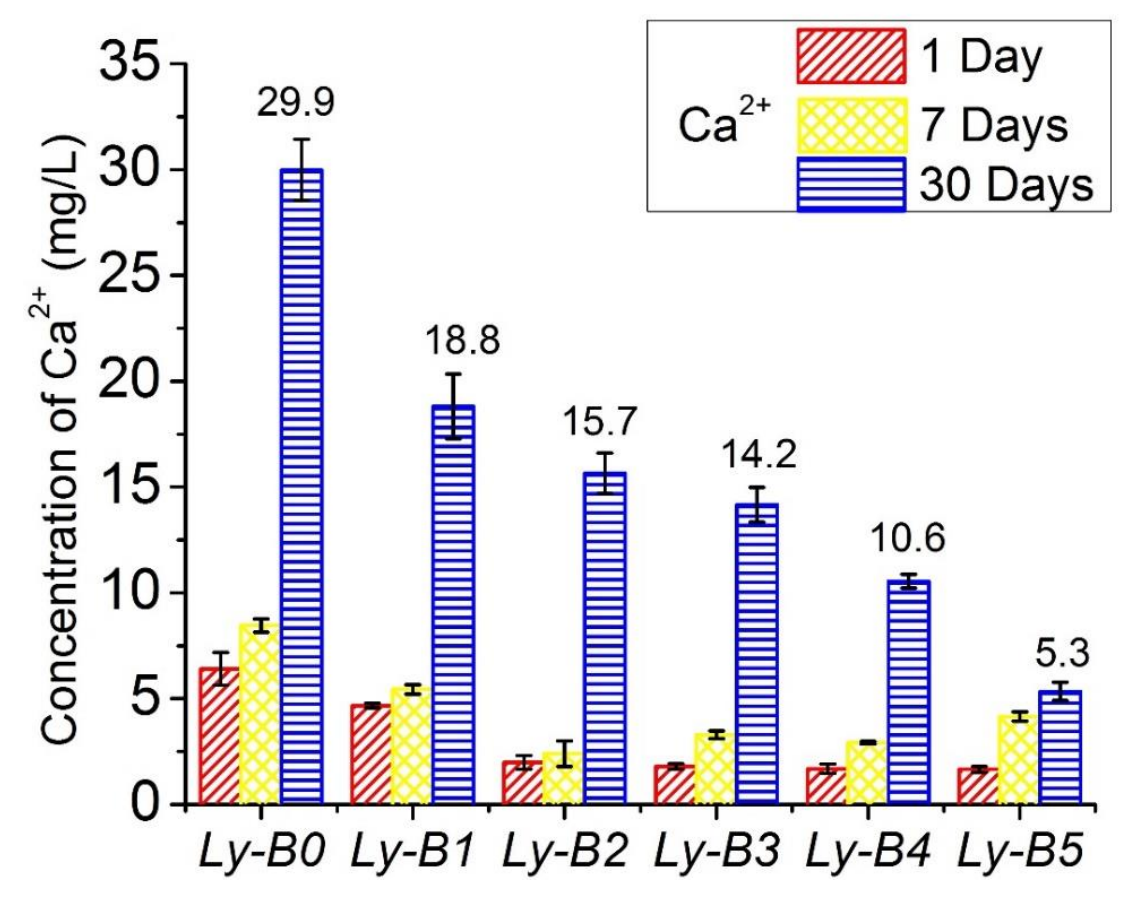

Figure 4.12. Concentration of $\mathrm{Ca}^{2+}$ from the water extracts of the glass series $(n=3)$ versus incubation time. Scatter bars indicate the standard deviations.

The first step in the degradation of glass in an aqueous environment is the ion exchange ${ }^{431,432}$ between the glass network modifier cations and $\mathrm{H}^{+}$from the immersing solution. Usually, the $\mathrm{Na}^{+}-$ water reaction dominates the process due to the initial enrichment of $\mathrm{Na}^{+}$on the glass surface 345 , 432. This explains why the concentrations of $\mathrm{Na}^{+}$released from each glass are higher than those of $\mathrm{Ca}^{2+}$ and $\mathrm{Sr}^{2+}$ (Figures 4.11-4.13). Additional ions are then transported from the glass bulk to the surface to complete the dissolution process. One of the pathways of ion migration is assisted by the correlated forward-backward motion of an ion by moving to an intermediate position and then returning to its initial site after the passage of the migrating ion ${ }^{345}$. The movement of a modifier cation in the matrix involves a change in its coordination, where at least a fraction of the coordinated oxygen atoms has been replaced ${ }^{345}$; that is, a number of R-O bonds have to be broken. It is difficult for $\mathrm{Sr}^{2+}$ to provide such 'transient sites' ${ }^{345}$ due to the high strength of the ionic $\mathrm{Sr}-\mathrm{O}$ 
bonding ${ }^{344}$, thus $\mathrm{Sr}^{2+}$ might block the pathway of other cations. As a result, $\mathrm{Sr}^{2+}$ hindered the movement of other dissolution products, reducing the solubility of the glasses.

As expected, the ion release profile of $\mathrm{Sr}^{2+}$ (Figure 4.13) experienced a significant increase with both incubation time and $\mathrm{Sr}^{2+}$ incorporation in the glass series $(p \leq 0.05)$.

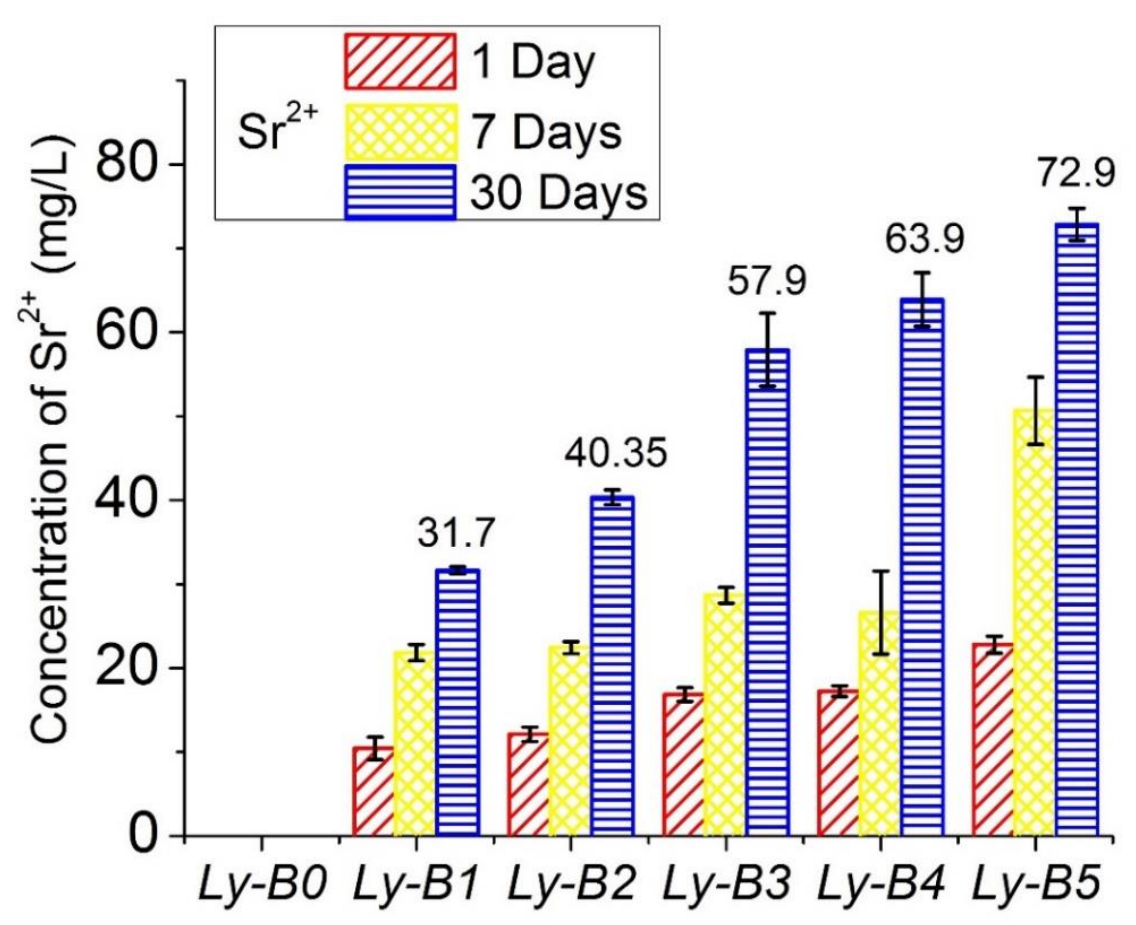

Figure 4.13. Concentration of $\mathrm{Sr}^{2+}$ from the water extracts of the glass series $(n=3)$ versus incubation time. Scatter bars indicate the standard deviations.

The highest $\mathrm{Sr}^{2+}$ concentrations in the water extracts ranged from $31.7 \mathrm{mg} / \mathrm{L}$ to $72.9 \mathrm{mg} / \mathrm{L}$ (from $L y-B 0$ to $L y$-B5, Figure 4.13) after 30-days incubation. Previous studies have reported that $\mathrm{Sr}^{2+}$ concentrations in the range from $8.76 \mathrm{mg} / \mathrm{L}$ to $87.62 \mathrm{mg} / \mathrm{L}$ induce stimulatory effects on osteoblasts and inhibit bone resorption in vitro ${ }^{433,434}$. It has also been reported that the higher the $\mathrm{Sr}^{2+}$ concentration (up to $2102.8 \mathrm{mg} / \mathrm{L}$ ), the greater the inhibitory effect on osteoclast differentiation. ${ }^{435}$ Since the $\mathrm{Sr}^{2+}$ concentration after 30-days incubation for each glass was in the 
range $76 \mathrm{mg} / \mathrm{L}-87.62 \mathrm{mg} / \mathrm{L}$, the incorporation of $\mathrm{Sr}^{2+}$ to this borate-based glass series is expected to be beneficial for bone cell proliferation, and this hypothesis will be investigated by cytotoxicity testing (Section 4.2.6).

\subsubsection{Weight loss}

As ion release from the glass is accompanied by a decrease in mass, weight loss measurements provide a useful parameter for monitoring the kinetics of glass solubility. ${ }^{302}$ Weight losses of the discs with respect to incubation time are shown in Figure 4.14.

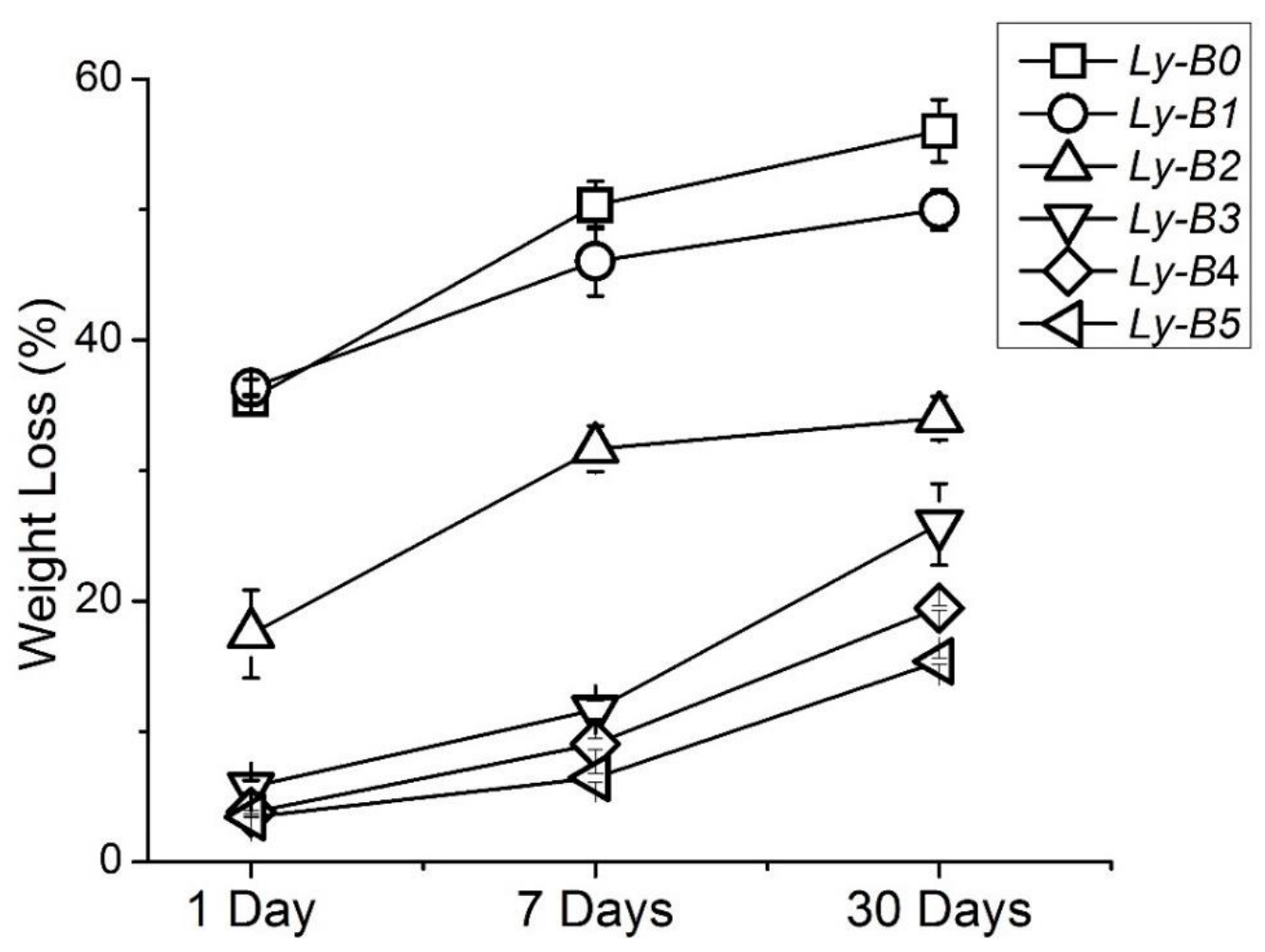

Figure 4.14. Weight loss of the glass discs $(n=3)$ versus incubation time, where scatter bars represent the max and min values of the data, where the lines are used only to guide the eye.

Compared with the control glass ( $L y-B O$, without $\mathrm{SrO})$, the weight loss of the borate glass series significantly decreased $(p \leq 0.05)$ with increased $\mathrm{SrO}$ contents in the glass compositions with every 
immersion time in the de-ionized water, except for $L y-B 1$ after 1-day incubation $(p>0.05)$. Additionally, the weight loss of the glasses with no less than 10 mol\% SrO (Ly-B2-Ly-B5) after 30-days incubation was even lower than those of $L y-B O$ and $L y-B 1$ only after 1-day incubation (Figure 4.14). Weight loss of the glasses resulted from degradation in de-ionized water. ${ }^{302}$ In other words, higher weight loss indicated more ions released from the glass, i.e. a greater level of degradation. Therefore, it can be concluded that increased SrO incorporation, especially $\geq 10$ mol\%, in the glass series retarded the glass dissolution process in de-ionized water.

\subsection{4. $p H$}

$\mathrm{pH}$ of the water extracts of the glass series immersed in de-ionized water over 1, 7 and 30 days are shown in Figure 4.15.

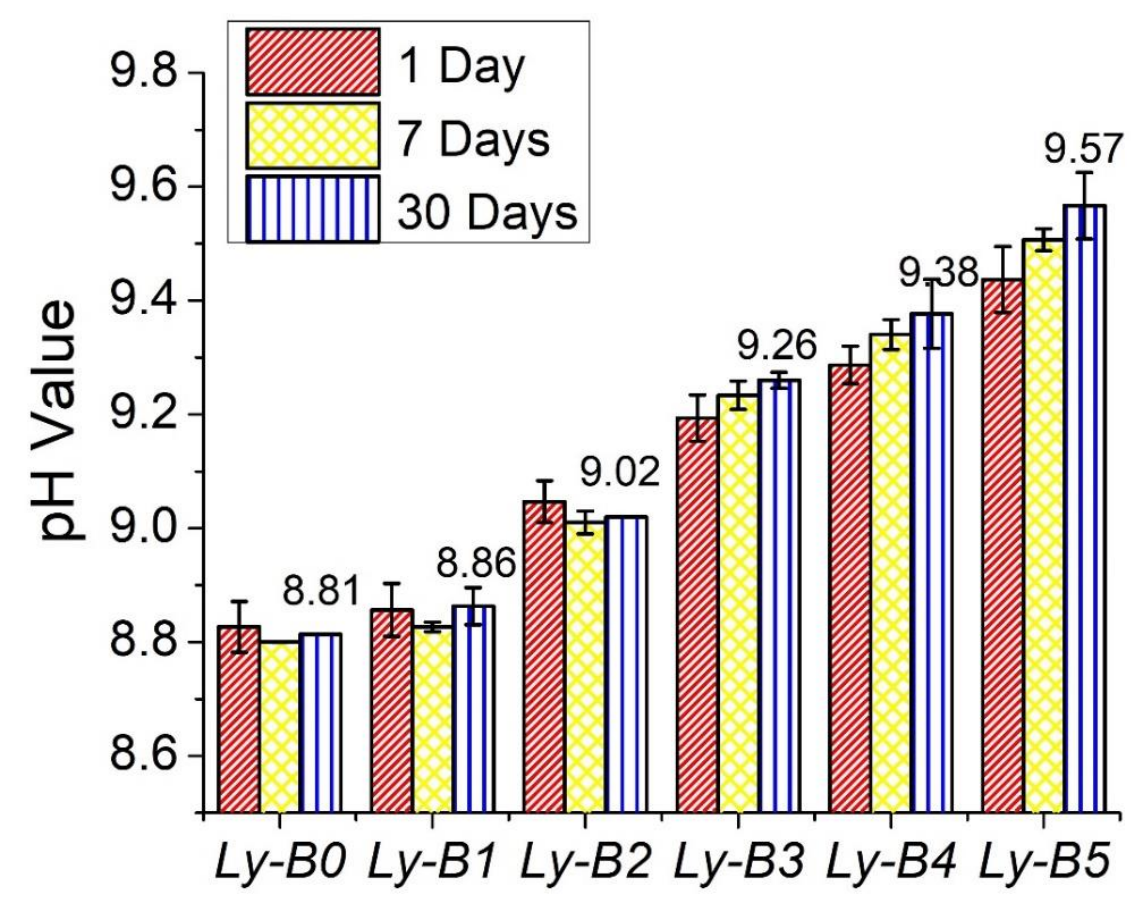

Figure 4.15. $\mathrm{pH}$ values of the water extracts of the glass series $(n=3)$ with different incubation times, where the $\mathrm{pH}$ values of 30-days incubation are tagged on the image. Scatter bars indicate the standard deviation of the data. 
The $\mathrm{pH}$ of de-ionized water is 7.0. ${ }^{436}$ The statistical analysis of $\mathrm{pH}$ profiles of the water samples that the glasses were stored in demonstrated that $\mathrm{pH}$ of the water extracts increased significantly when the glasses contained more than $5 \mathrm{~mol} \%$ addition of $\mathrm{Sr}^{2+}(L y-B 3, L y-B 4$ and $L y-B 5)(p \leq 0.05)$. However, for each glass, $\mathrm{pH}$ values did not change with immersion time $(p \geq 0.05)$.

In the reaction between water and glass, $\mathrm{Na}^{+} / \mathrm{H}^{+}$exchange occurs first, where $\mathrm{H}^{+}$bonds to $\mathrm{NBO}$ and the remaining $\mathrm{OH}^{-}$from the water molecule bonds to $\mathrm{Na}^{+}$forming $\mathrm{NaOH}$. Consequently, $\mathrm{pH}$ of the solution increases. Based on previous studies, the $\mathrm{pH}$ of silicate glasses immersed in a neutral aqueous environment for 30 days is in the range 11 to $12^{429,437}$, while the $\mathrm{pH}$ values of boratebased glasses are in the range 9 to $10^{302,438}$. It is the acidity of $\mathrm{B}(\mathrm{OH})_{3}$ that causes this effect ${ }^{302}$. However, the $\mathrm{pH}$ of the solution still increases, because the strong alkaline $\mathrm{NaOH}$ overwhelms the weak acidic $\mathrm{B}(\mathrm{OH})_{3}$.

The alkali nature of the solutions, resulting from the degradation of the glasses, has a positive influence on bioactivity ${ }^{439,440}$. It has been reported that bone cells respond to $\mathrm{pH}$ change with higher $\mathrm{pH}$ inhibiting osteoclastic activity, thus reducing bone resorption ${ }^{439}$. Pro-resorptive agents such as RANKL and parathyroid hormone (PTH) have little or no stimulatory activity on osteoclasts at $\mathrm{pH}$ of 7.4 or above $\mathrm{e}^{440}$. The results of $\mathrm{pH}$ testing also confirm that, for each glass, the $\mathrm{pH}$ of the water extracts did not significantly change with different incubation times ( $p \geq 0.05$ ). Since the mechanism of bone cell formation is very sensitive to change of acidic balance, precise maintenance of $\mathrm{pH}$ in the blood and extracellular fluid are required ${ }^{308}$.

\subsubsection{Antibacterial effect}


The diameters of inhibition zones of the borate glasses against S. aureus after 24 hours are shown in Figure 4.16. The absence of a bar for $L y-B 5$ indicates that $L y$-B5 glass discs did not create an inhibition zone that is, they had no antibacterial effect against $S$. aureus. The mean sizes of the inhibition zones after 24 hours incubation are: $5.6 \mathrm{~mm}$ for $L y-B 0,5.8 \mathrm{~mm}$ for $L y-B 1,3.5 \mathrm{~mm}$ for $L y-B 2,4.6 \mathrm{~mm}$ for $L y-B 3$ and $4.1 \mathrm{~mm}$ for $L y-B 4$. Based on statistical analysis, there is no difference $(p \geq 0.05)$ among the sizes of the inhibition zones resulting from testing of these five glasses.

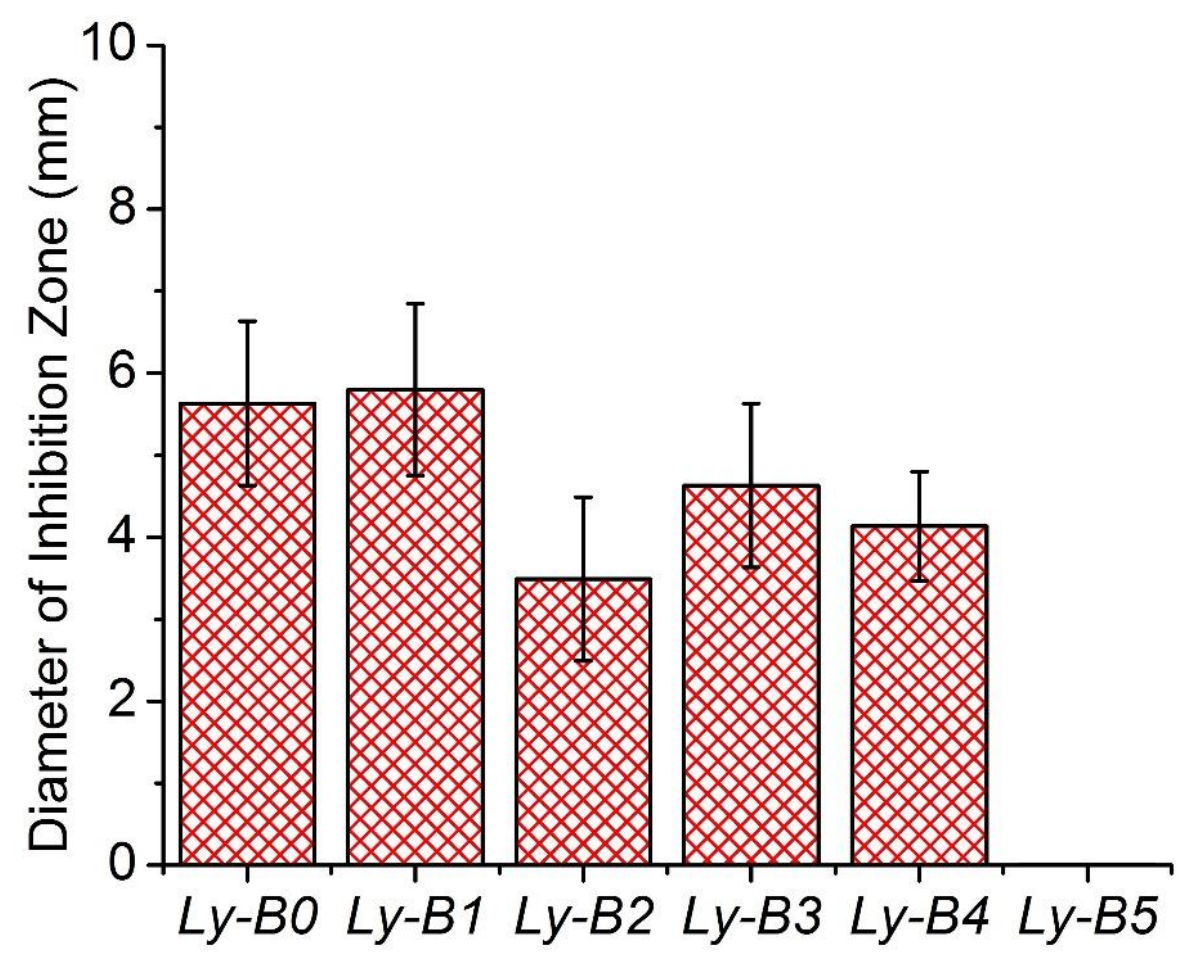

Figure 4.16. Diameters of inhibition zones of the glasses against S. aureus after 24-hours incubation where the max and min values of the data are presented as scatter bars.

Based on previous studies, the antibacterial effect of bioactive glasses has been attributed to dissolution products, such as zinc or silver ions, released into the surrounding bacterial culture. ${ }^{441 \text {, }}$ ${ }^{442}$ These ions can kill bacteria by inhibiting multiple activities in the bacterial cell, such as glycolysis, trans-membrane proton translocation, and acid tolerance. ${ }^{443} \mathrm{Sr}^{2+}$ has been reported to 
exhibit antibacterial activity against $S$. aureus in vitro ${ }^{444}$. Yingguang et al..$^{445}$ reported that the inhibition zone of strontium substituted hydroxyapatite (SrHAP) against $S$. aureus was $17 \mathrm{~mm}$, while the inhibition zone of HAP was just $5 \mathrm{~mm}$, indicating that the addition of $\mathrm{Sr}^{2+}$ in HAP increased the antibacterial effect against $S$. aureus. Brauer et al. postulated that $\mathrm{Sr}^{2+}$ exerts its antibacterial ability by inhibiting bacterial growth and reproduction and impeding permeability of the cytoplasmic membrane, cell wall synthesis, replication of bacterial chromosomes and cell metabolism. ${ }^{342}$ Based on the AAS results (Figure 4.13), increased $\mathrm{Sr}^{2+}$ released from the glasses with higher $\mathrm{Sr}^{2+}$ loadings. However, the inhibition zone did not increase with more $\mathrm{Sr}^{2+}$ incorporation, which might result from insufficient $\mathrm{Sr}^{2+}$ released from the glasses into the TSB culture. Additionally, the dissolution mechanism of $\mathrm{Sr}^{2+}$ in TSB culture using a small volume (100 $\mu \mathrm{L}$ ) might be different from that in de-ionized water. Here, we assume that other dissolution products may contribute to the inhibition zone. It has been reported that boron-containing bioactive glass exerts antibacterial effects against $S$. aureus due to $\mathrm{B}_{2} \mathrm{O}_{3}$ release, but the antibacterial mechanism of the $\mathrm{B}^{3+}$ ion is still unknown ${ }^{437}$. Moreover, Hernandez et al. found that a boron-based antibacterial protein synthesis inhibitors (AN3365) exhibited antibacterial activity against $S$. aureus. ${ }^{446} \mathrm{Na}^{+}$and $\mathrm{Ca}^{2+}$ were also reported to inhibit the growth of $S$. aureus. ${ }^{447,}{ }^{448}$ Thereby, a combined or individual effect of some ions among $\mathrm{BO}_{3}^{3-}, \mathrm{Sr}^{2+}, \mathrm{Na}^{+}$and $\mathrm{Ca}^{2+}$ can make the contribution to the bacteriostatic behavior of the glasses.

The inhibition zones can also be attributed to the imbalance in $\mathrm{pH}$ of the TSB culture caused by the release of these ions instead of these ions themselves. ${ }^{449}$ For bacteria, electrochemical energy referred as pronto-motive force $(P M F)$ is one form of the metabolic energy required for cell growth. ${ }^{450,451}$ The $P M F$ consists of the electrical potential $(\Delta \Psi)$ and the chemical proton potential $(-Z \Delta p H$, where $Z=2.3 R T / F)$, which can be described as: $: 52$ 


$$
P M F=\Delta \Psi-\frac{2.3 R T}{F} \Delta p H
$$

Equation 4.2.

where

$\Delta \Psi:$ membrane potential,

$R$ : gas constant,

$F$ : Faraday constant,

$T$ : temperature,

$\triangle p H: \mathrm{pH}$ difference between the two sides of cell membrane $\left(p H_{\text {in }}-p H_{\text {out }}\right)$.

A stable $P M F$ is critical for bacterial growth, hence the change of external $\mathrm{pH}$ can cause the perturbation of the steady-state condition. ${ }^{453}$ Previous studies ${ }^{454-457}$ revealed that raising external $\mathrm{pH}$ results in an enhancement of $\Delta \Psi$ but a decline of $P M F$. Mates et al ${ }^{454,456}$ reported the directly proportional relationship between the magnitude of $\Delta \Psi$ and the bactericidal effect against $S$. aureus. Since the $P M F$ is essential for the critical bacterial process, such as flagellar motility and nutrient import, the decrease of $P M F$ can lead to the loss of bacterial viability by inhibiting these important functions. ${ }^{458}$ The antibacterial effects of bioactive glasses against $S$. aureus have been considered as a consequence of high $\mathrm{pH}$ values inducing disturbances of the membrane potential of the bacteria. ${ }^{278,437}$ Since the ions released from the glass discs into the TSB culture could cause $\mathrm{pH}$ change, ${ }^{449}$ the antibacterial effects of the glasses also can be a consequence of the $\mathrm{pH}$ change. Since $L y-B 5$ has relatively low degradation rate, there might not be sufficient dissolution products released from the glass discs to the TSB culture to alter $\mathrm{pH}$, resulting in no inhibition zone. Since $\mathrm{pH}$ of the TSB culture after 24 hours incubation was not measured, further experiments are required to confirm this theory. 


\subsubsection{Cytotoxicity testing}

The cytotoxicity results from glass powder disc extracts after 30-days immersion in de-ionized water are shown in Figure 4.17. There is no difference $(p \geq 0.05)$ among the cell metabolic activity of $L y-B 0, L y-B 1, L y-B 2$ and $L y-B 3$ glasses. Moreover, there were significant differences between the cell viability of the control group and those of the four glasses $(p \leq 0.05)$, which indicated a significant decrease in the viability. However, cell proliferation was significantly enhanced ( $p \leq$ 0.05) in response to the $L y-B 4(105 \%)$ and $L y-B 5(120 \%)$ glass formulations. Compared to the control group, the enhancement of cell metabolic activity on $L y-B 5$ was significant $(p=0.002)$.

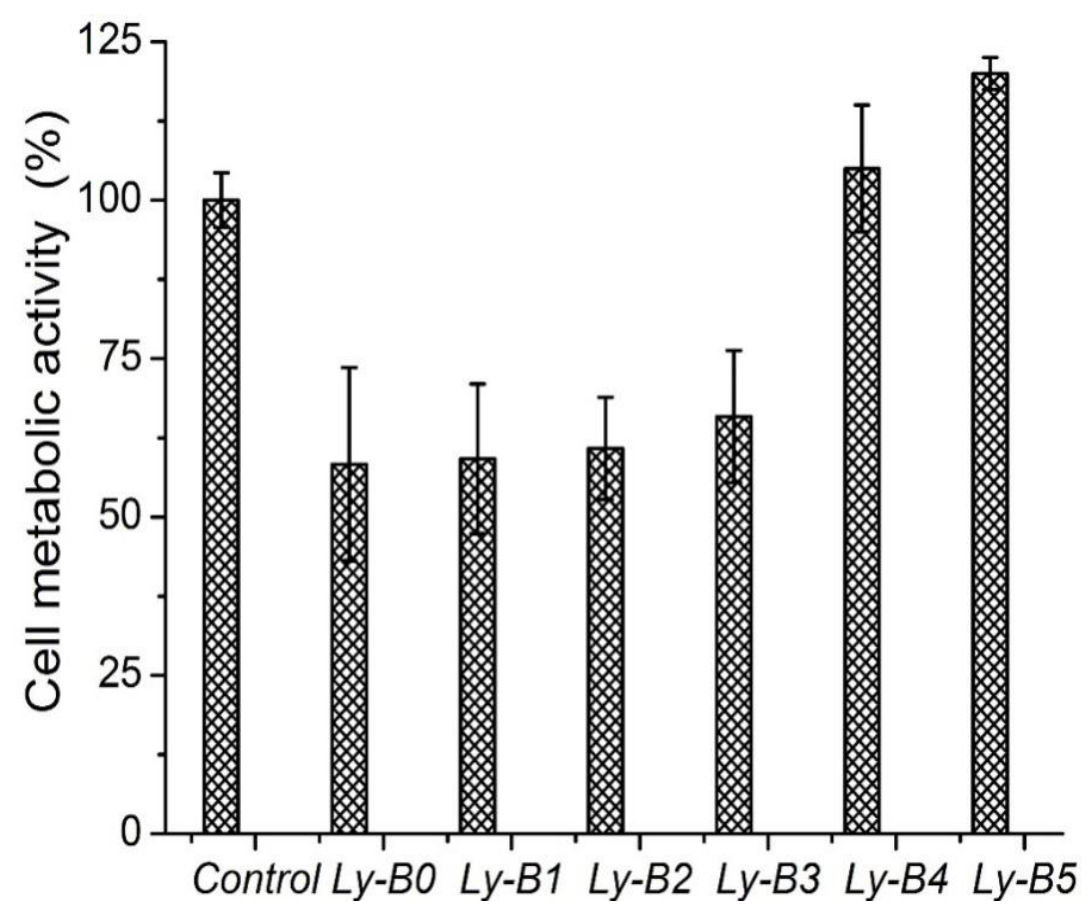

Figure 4.17. Cell metabolic activity from sintered glass powder discs ( $n=3)$ extracts after 30-days incubation. Scatter bars indicate the standard deviations.

Based on the results of $\mathrm{pH}$ and $\mathrm{AAS}$ analysis, concentrations of $\mathrm{Sr}^{2+}$ ions released increased with increasing $\mathrm{Sr}^{2+}$ content in the glass. It has been reported that high concentrations of $\mathrm{BO}_{3}{ }^{3-}$ 
(>1mg/L) inhibit proliferation of osteoblasts (MC3T3-E1) $)^{305,459}$, while concentrations of $\mathrm{Sr}^{2+}$ in the range from $8.76 \mathrm{mg} / \mathrm{L}$ to $87.62 \mathrm{mg} / \mathrm{L}$ promote the proliferation of osteoblasts (MC3T3-E1) in vitro $^{460}$. Seal and Weeth ${ }^{461}$ fed rats deionized water with 0,150 and $300 \mathrm{mg} / \mathrm{L}$ boron by adding $\mathrm{Na}_{2} \mathrm{~B}_{4} \mathrm{O}_{7}$ water; after 70 days, they found the plasma ALP of the rats fed deionized water with 300 $\mathrm{mg} / \mathrm{L}$ reduced activity by $31 \%$. ALP is one of the phenotypic markers of the osteoblast differentiation. ${ }^{264-266}$ The negative influence of the high concentration of boron on ALP might be one explanation of its adverse effect on osteoblast proliferation. A study by Isaac et al. considering Sr-containing bioactive glasses reported that the expression of Runx2, Osx, and ALP activity significantly increased with higher Sr content in the glass compositions. ${ }^{263}$ Runx2 is sufficient to encourage the expression of osteoblast markers in the non-osteoblastic cell ${ }^{22}$ and can regulate expression of genes encoding osteocalcin. ${ }^{23}$ Osx is a transcription factor essential for osteoblast differentiation. ${ }^{21,24}$ In a study of Sr-substituted bioactive glasses, Gentleman et al. ${ }^{340}$ found an enhancement of ALP activity and a decrease in TRAP activity when substituting $\mathrm{Sr}^{2+}$ for $\mathrm{Ca}^{2+}$ in the glass compositions. These facts explain why Sr-containing bioactive glasses can promote the proliferation of osteoblast cells and inhibit the proliferation of osteoclasts in vitro. ${ }^{340,462}$ Therefore, the borate-based glasses with $20 \mathrm{~mol} \%$ (Ly-B4) and $25 \mathrm{~mol} \%(L y-B 5) \mathrm{Sr}^{2+}$ incorporated in the glass series promote osteoblast proliferation.

\subsection{Mechanical properties and solubility of the borate glass coating/Ti6Al4V substrate system}

\subsubsection{XRD analysis}


The glasses were coated onto Ti6A14V plates. Then the coated samples were heated at certain temperatures (outlined in Figure 4.18) for $15 \mathrm{~min}$ and subsequently left to furnace cool. XRD patterns of all the glass coatings are shown in Figure 4.18, where the coating temperatures are tagged. The broad XRD patterns without any detectable sharp peaks confirm the amorphous nature of the glass coatings. Crystalline phases are capable of affecting solubility ${ }^{460,463}$, bioactivity ${ }^{356}$ and mechanical properties ${ }^{463,464}$ of bioactive glasses. It is necessary to retain the amorphous structure of all the glass coatings to investigate the mechanical properties and solubility of the glass coating/Ti6Al4V substrate only considering the influence of different glass compositions.

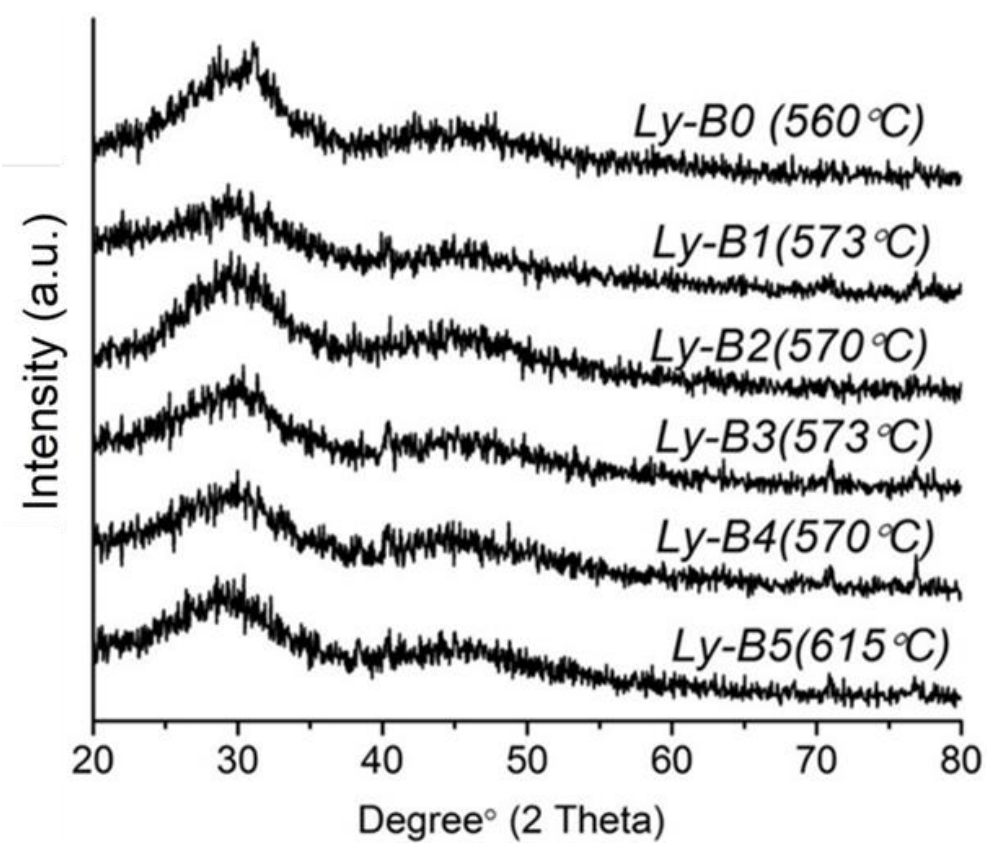

Figure 4.18. XRD patterns of all the glass coatings, where the coating temperature are tagged in the image.

\subsubsection{Measurement of Mode I critical strain energy release rate (GIC) of the constructs}

The $G_{I C}$ values and the thickness of the glass coatings are shown in Figure 4.19. The mean thickness of the coatings was approximately $95 \mu \mathrm{m}$, and there was no significant difference ( $p \geq$ 
0.05 ) among the thicknesses of all the samples. The mean $G_{I C}$ values increased from $6.56 \mathrm{~J} / \mathrm{m}^{2}$ for the system using the $L y-B 0$ glass to $14.61 \mathrm{~J} / \mathrm{m}^{2}$ for the $L y-B 5$. Compared with the control glass ( $L y$ $B 0$ ), the increase in $G_{I C}$ with $15-25 \mathrm{~mol} \%$ addition of $\mathrm{Sr}^{2+}$ contents in the glass series, i.e., $L y-B 3$, $L y-B 4$ and $L y-B 5$, was statistically significant $(p \leq 0.05)$, while there was no significant difference ( $p>0.05$ ) amongst the $G_{I C}$ values for $L y-B 0, L y-B 1$ and $L y-B 2$.

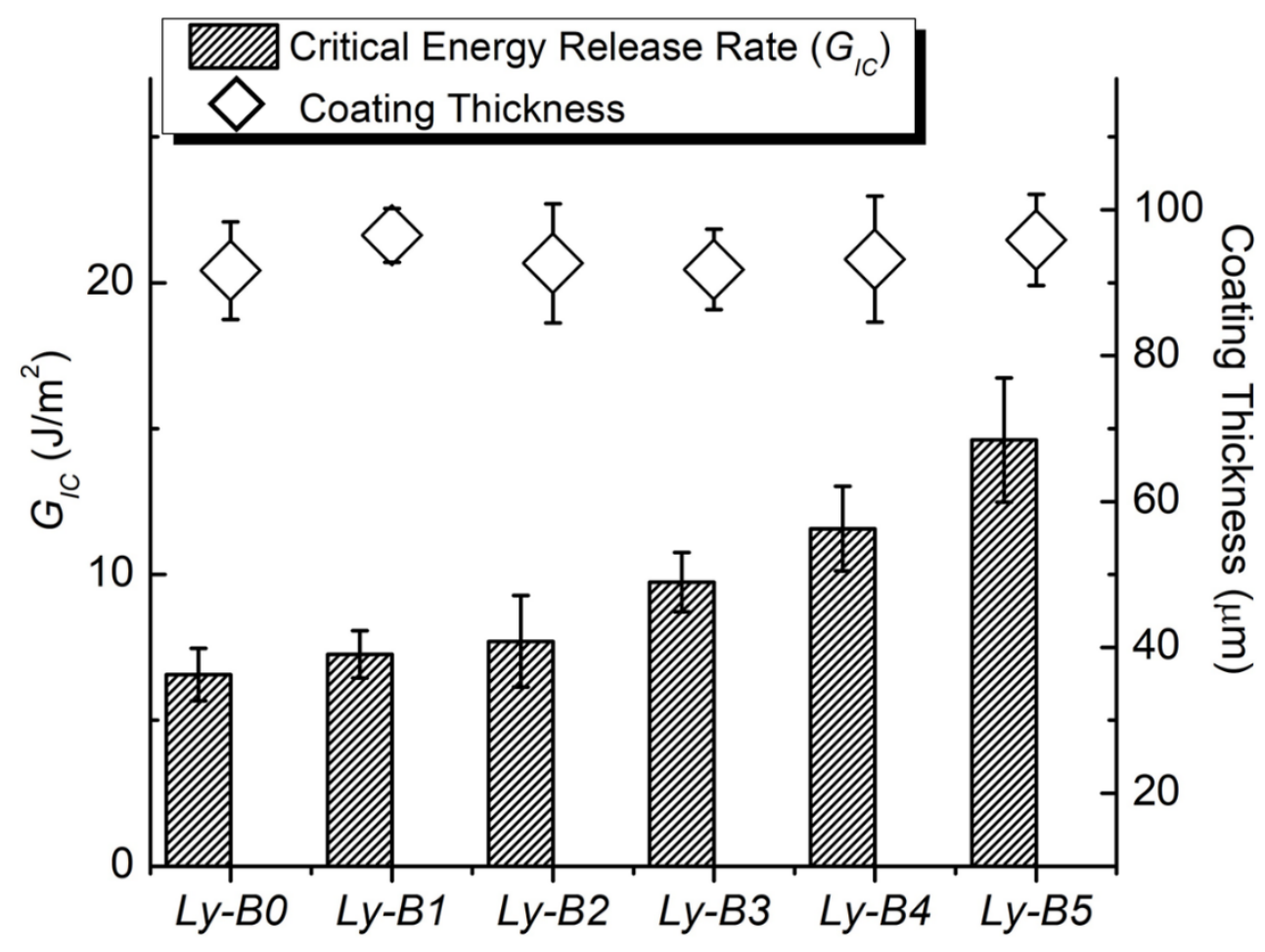

Figure 4.19. Mode I critical strain energy release rate $\left(G_{I C}\right)$ and the thickness of the borate-based glass coating-Ti6A14V substrate system. Scatter bars indicate the standard deviation of the data.

Shinkai et al. found that, for a borate-based glass series $\left(\mathrm{B}_{2} \mathrm{O}_{3}-\mathrm{ZnO}-\mathrm{PbO}\right)$, glasses with higher Young's modulus have higher fracture toughness. ${ }^{428}$ The relationship between Young's modulus $(E)$ and fracture toughness $\left(K_{I C}\right)$ can be described as ${ }^{465,466}$ : 


$$
K_{I C}=\left\{\frac{\lambda \sqrt{2}}{\pi a_{0}^{1 / 2}\left(1-v^{2}\right)^{1 / 2}}\right\}\{E\}
$$

Equation 4.3.

where

$v$ : Poisson's ratio,

$a_{0}$ : an interatomic spacing,

$\lambda$ : the range of distance over which the interatomic force acts.

This relationship can be written in a simple way ${ }^{465,466 \text { : }}$

$$
K_{I C}=(S)(E)
$$

Equation 4.4.

where $(S)=\left\{\frac{\lambda \sqrt{2}}{\pi a_{0}^{1 / 2}\left(1-v^{2}\right)^{1 / 2}}\right\}$ which is the structural component of the fracture toughness.

For the thin film in the plane stress condition ${ }^{467}$ such as the glass coatings in this work, $G_{I C}$ is a measure of the fracture toughness ${ }^{377}$ because there is a direct relationship between the $G_{I C}$ and $K_{I C}{ }^{468,469}$ :

$$
K_{I C}=\sqrt{G_{I C} E}
$$

where

E: Young's modulus.

There was a glass layer left on the substrate surface after the Mode I test, indicating the fracture occurred in the coating itself instead of the interface between the glass coating and Ti6Al4V substrate. Thus, the fracture toughness of the glass itself is critical to the $G_{I C}$ value of the coating/substrate system. In the glass series, glasses incorporated with more $\mathrm{Sr}^{2+}$ possessing higher 
$\mathrm{T}_{\mathrm{g}}$ should have higher Young's modulus (Section 4.1.5) ${ }^{426,427}$ and $K_{I C}($ Eqs. (4.3) - (4.5)), which can explain why $G_{I C}$ increased with more addition of $\mathrm{Sr}^{2+}$ in the glass series. Since $G_{I C}$ can be a measurement of the fracture toughness of the coating/substrate system, ${ }^{377}$ the incorporation of 15 $25 \mathrm{~mol} \% \mathrm{Sr}^{2+}(L y-B 3, L y-B 4$ and $L y-B 5)$ enhanced the fracture toughness of the glass coating/Ti6Al4V substrate system.

There is limited literature regarding the $G_{I C}$ values for bioactive glass, bioceramic, and glassceramic coatings. However, previous studies have reported $G_{I C}$ values of $0.8 \mathrm{~J} / \mathrm{m}^{2}$ for a bioceramic $\left(57 \mathrm{SiO}_{2}-34 \mathrm{CaO}-6 \mathrm{Na}_{2} \mathrm{O}-3 \mathrm{Al}_{2} \mathrm{O}_{3}\right.$, in mol\%) coating on an aluminum substrate ${ }^{470}$, and $0.065 \mathrm{~J} / \mathrm{m}^{2}$ for a glass-ceramic $\left(57 \mathrm{SiO}_{2}-34 \mathrm{CaO}-6 \mathrm{Na}_{2} \mathrm{O}-3 \mathrm{Al}_{2} \mathrm{O}_{3}\right.$, in mol\%) trabecular-like coating on a ceramic $\left(\mathrm{Al}_{2} \mathrm{O}_{3}\right)$ substrate ${ }^{471}$. A study by Matinmanesh et al. indicated that $G_{I C}$ value of a silicate glass $\left(52 \mathrm{SiO}_{2}-12 \mathrm{CaO}-6 \mathrm{P} 2 \mathrm{O} 5-14 \mathrm{Na}_{2} \mathrm{O}-16 \mathrm{ZnO}\right.$, in mol\%) coating on a Ti6Al4V substrate was 6.2 $\mathrm{J} / \mathrm{m}^{2}{ }^{376}$ The thickness of the silicate glass coatings $(90 \mu \mathrm{m})$ of that study is very similar to those of the borate glass coatings $(\sim 95 \mu \mathrm{m})$ in this study. In this study, the $G_{I C}$ values for all the borate glasses ranged from $6.56 \mathrm{~J} / \mathrm{m}^{2}$ to $14.61 \mathrm{~J} / \mathrm{m}^{2}$, indicating that the fracture toughness of the borate glass coating/Ti6Al4V substrate construct is higher than that of the silicate glass/Ti6Al4V substrate construct.

\subsubsection{Measurement of Mode II critical strain energy release rate (GIIC) of the constructs and residual stress}

Based on the results of the Mode I test, there was no difference among $L y-B O, L y-B 1$ and $L y$ $B 2(p>0.05)$, but the $G_{I C}$ value of $L y-B 3$ was significantly higher than that of $L y-B O(p \leq 0.05)$, and only the $G_{I C}$ value of $L y$-B5 was significantly higher than that of $L y-B 3(p \leq 0.05)$. Therefore, as mentioned in Section 3.3.1, only the residual stress and $G_{I I C}$ values for $L y-B O, L y-B 3$ and $L y-B 5$ 
were measured. The residual stresses in the glass coatings for $L y-B O$ and $L y-B 3$ were $9.7 \pm 1.0$ MPa and $8.1 \pm 0.7 \mathrm{MPa}$ (tensile), respectively, and the residual stress of that for $L y-B 5$ was $-9.1 \pm$ 1.5 MPa (compressive) (Figure 4.20).

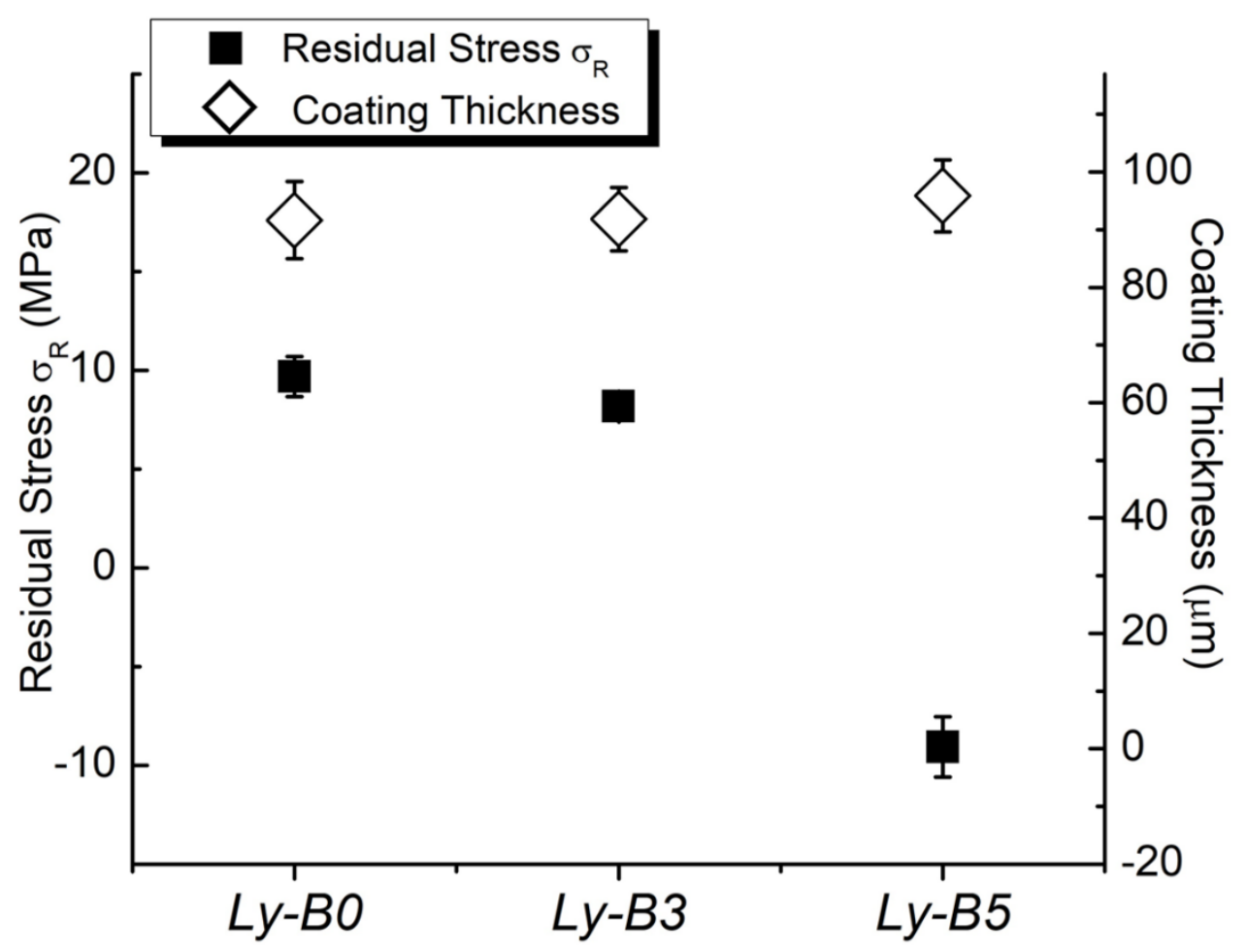

Figure 4.20. The thickness and residual stress in the glass coatings $(n=3)$, where the scatter bars represent the max and min values of the data.

There was no significant difference between the thicknesses of the glass coatings $(p>0.05)$ (Figure 4.20). Thus the influence of coating thickness on the residual stress ${ }^{376}$ was avoided. In

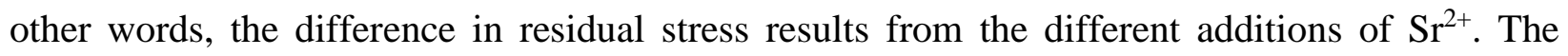
residual stress is caused by the mismatch of the CTEs between the coatings and substrate. Based on Eqs. (2.6) to (2.11), it is negative (compressive) in the coating when the CTE of the coating is lower than that of Ti6Al4V, and the coating has a positive residual (tensile) stress when its CTE is higher than that of Ti6Al4V. Therefore, the magnitude of the residual stress can be considered 
as an indicator of the CTE of the glass coating. Furthermore, the CTE of $L y-B O$ and $L y-B 3$ should be higher than that of Ti6Al4V, while the CTE of $L y-B 5$ should be lower than that of Ti6Al4V. A study by Rodriguez et al. ${ }^{472}$ showed that the absolute values of the residual stress in two borate glass (BRT) $\left(\mathrm{B}_{2} \mathrm{O}_{3}-\mathrm{CaO}-\mathrm{Na}_{2} \mathrm{O}-\mathrm{P}_{2} \mathrm{O}_{5}-\mathrm{TiO}_{2}-\mathrm{ZnO}\right)$ coatings on Ti6Al4V substrates were both around $-18 \mathrm{MPa}$, and the corresponding CTEs of the two glasses were $~ 9.05 \times 10^{-6} / \mathrm{C}^{\circ}$ and $\sim 9.11 \times 10^{-6} / \mathrm{C}^{\circ}$ respectively. Since the absolute values of residual stresses of the glass coatings in this project are lower than those in BRT glasses ${ }^{472}$, approximately only $10 \mathrm{MPa}$, the CTEs of these glasses should be closer to that of Ti6Al4V $\left(9.5 \times 10^{-6} / \mathrm{C}^{\circ}\right)$ than the BRT glasses ${ }^{472}$ were.

Based on the CTE measurement experiment, the CTEs of $L y-B O, L y-B 3$ and $L y-B 5$ are $\sim 9.83 \times$ $10^{-6} / \mathrm{C}^{\circ}, \sim 9.59 \times 10^{-6} / \mathrm{C}^{\circ}$ and $\sim 9.37 \times 10^{-6} / \mathrm{C}^{\circ}$ respectively (Figure 4.21 ). Moreover, the residual stresses in the $L y-B O$ and $L y-B 3$ coatings were tensile, and that in the $L y-B 5$ coatings was compressive. These facts are consistent with the hypothesis that the residual stress in the coating is tensile when the CTE of the coating is larger than that of the substrate, while, when the CTE of the coating is smaller than that of the substrate, the residual stress in the coating is compressive. As expected, the CTEs of the three glasses were all closer to that of Ti6Al4V than the BRT glasses, and the CTE of $L y-B 3$, which had the smallest residual stress, was closest to that of Ti6Al4V. Therefore, even though the CTE measurements (Figure 4.2.1) were taken by necessity at a much lower temperature than the processing temperature, the trend in residual stress (Figure 4.20), obtained using the deformed substrate profiles, is nevertheless consistent with these results. Additionally, even though in general the Young's modulus of the coating can affect the calculations of residual stresses (Eq. 2.8-2.12) in all cases reported here, the residual stresses' result was found to be insensitive to the young's modulus of the glass (E) because the glass coating thickness in all cases was significantly smaller than the substrate thickness $\left(\mathrm{t}_{\mathrm{c}} / \mathrm{t}_{\mathrm{s}}<0.03\right)$. 


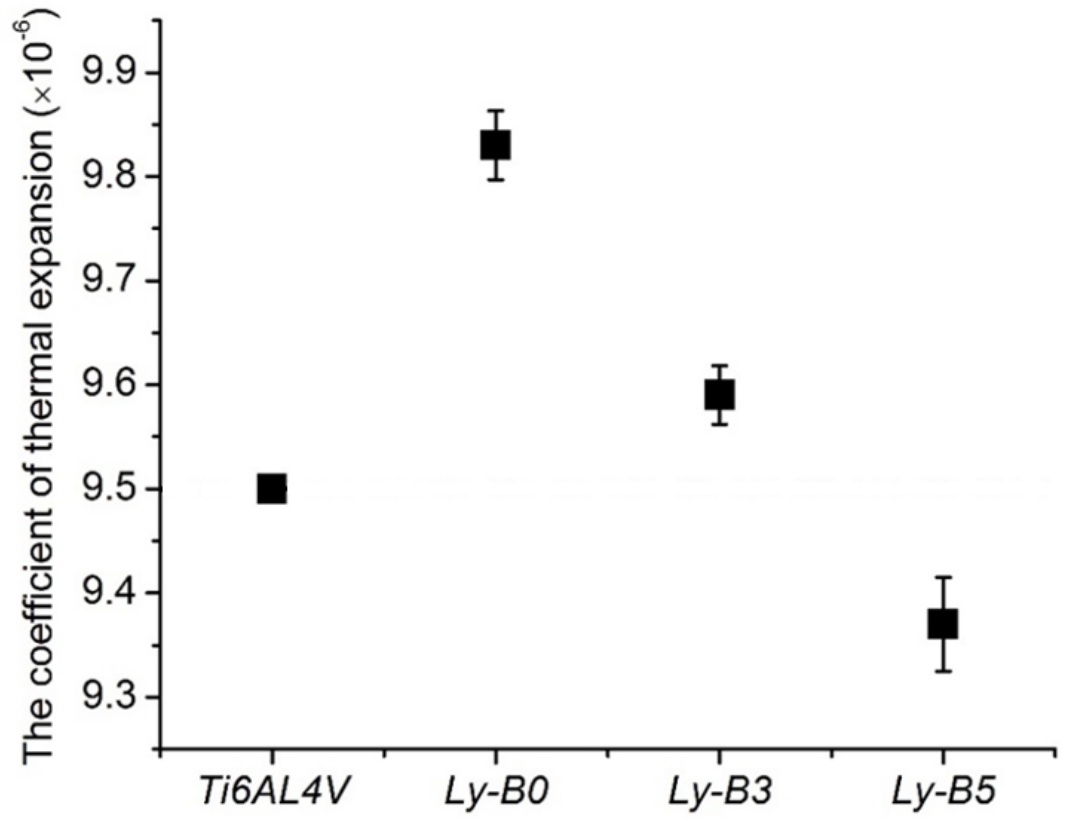

Figure 4.21. The CTEs of Ti6Al4V ${ }^{196}, L y-B 0, L y-B 3$ and $L y-B 5(n=3)$. Scatter bars indicate the max and min values of the data.

The shear strength of the bioactive coating/implant substrate system is also a critical factor affecting the success and long-term stability of the coated implantation. ${ }^{198,306}$ The bone-implant interface bears shear force after implantation, which has been reported to cause coating delamination. ${ }^{306}$ Hence, the critical Mode II strain energy release rate $\left(G_{I I C}\right)$ was also determined as a quantitative measurement of the fracture toughness of the glass coating/Ti6Al4V substrate system under shear loading.

The $G_{I I C}$ values of the coating/substrate constructs, $26.04 \pm 3.85 \mathrm{~J} / \mathrm{m}^{2}$ for $L y-B 0,36.07 \pm 3.82$ $\mathrm{J} / \mathrm{m}^{2}$ for $L y-B 3$ and $46.92 \pm 3.31 \mathrm{~J} / \mathrm{m}^{2}$ for $L y-B 5$, were significantly higher $(p \leq 0.05)$ than the corresponding $G_{I C}$ values of the glass coatings (Figure 4.22). 


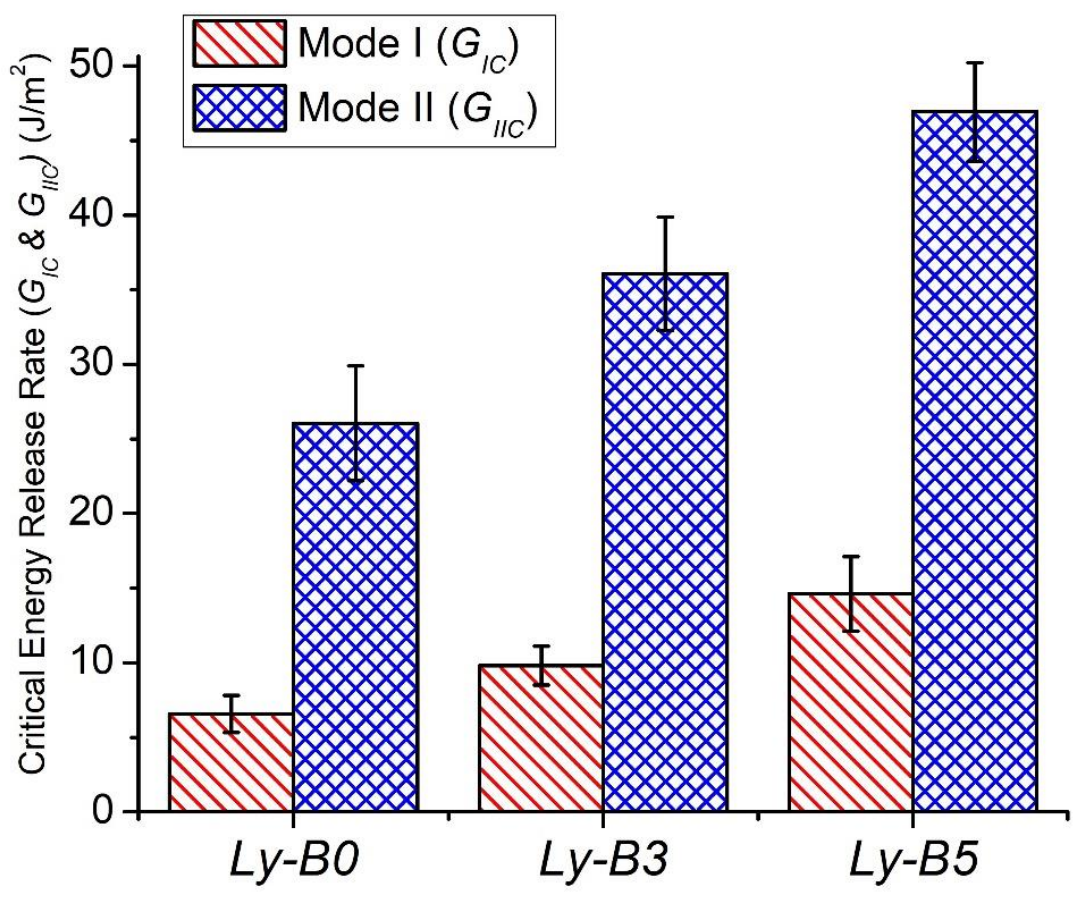

Figure 4.22. The critical energy release rate of Mode I $\left(G_{I C}\right)$ and Mode II $\left(G_{I C}\right)$ of glass coating/Ti6Al4V substrate systems $(n=3)$, where the bars represent the max and min values of the data.

The fact that the $G_{I I C}$ values were much higher than the corresponding $G_{I C}$ was expected due to the increased frictional contact and locking between the crack facets under Mode II loading, thus requiring a higher driving force for the crack advancement. ${ }^{473}$ A study by Gillanders et al. ${ }^{474}$ found that $G_{I I C}$ of bulk soda lime glass was about four times of its $G_{I C}$. Additionally, the $G_{I I C}$ values increased with increasing $\mathrm{Sr}^{2+}$ contents $(p \leq 0.05)$, which is in accordance with the results of the Mode I test.

\subsubsection{Measurement of GIC and GIIC values of the constructs after degradation}

The degradation of coatings has been previously found to result in a decrease in the coatingsubstrate bond strength. ${ }^{302}$ Therefore, $G_{I C}$ and $G_{I I C}$ values of the glass coating/Ti6Al4V substrate system after degradation were measured to determine the influence of different degradation times 
on the fracture toughness of the construct. Since the glass coatings for $L y-B O$ and $L y-B 3$ delaminated after about 24-hours incubation, their $G_{I C}$ and $G_{I I C}$ values were measured after 2-hours incubation instead of 24-hours. The delamination of the $L y-B O$ and $L y$-B3 coatings after 24-hours incubation was considered as an adhesive failure because no glass remained on the substrate surface.

Ion release from the glass is accompanied by a decrease in mass. Therefore, the weight loss measurements can be a useful parameter for monitoring the kinetics of glass solubility. The weight loss of the glass coatings with respect to incubation time is shown in Figure 4.23. The weight loss decreased in line with increased addition of $\mathrm{Sr}^{2+}$ in the glasses under any incubation time $(p \leq$ 0.05 ), indicating that the solubility of the glass coatings was slowed down with increased $\mathrm{Sr}^{2+}$ incorporation.

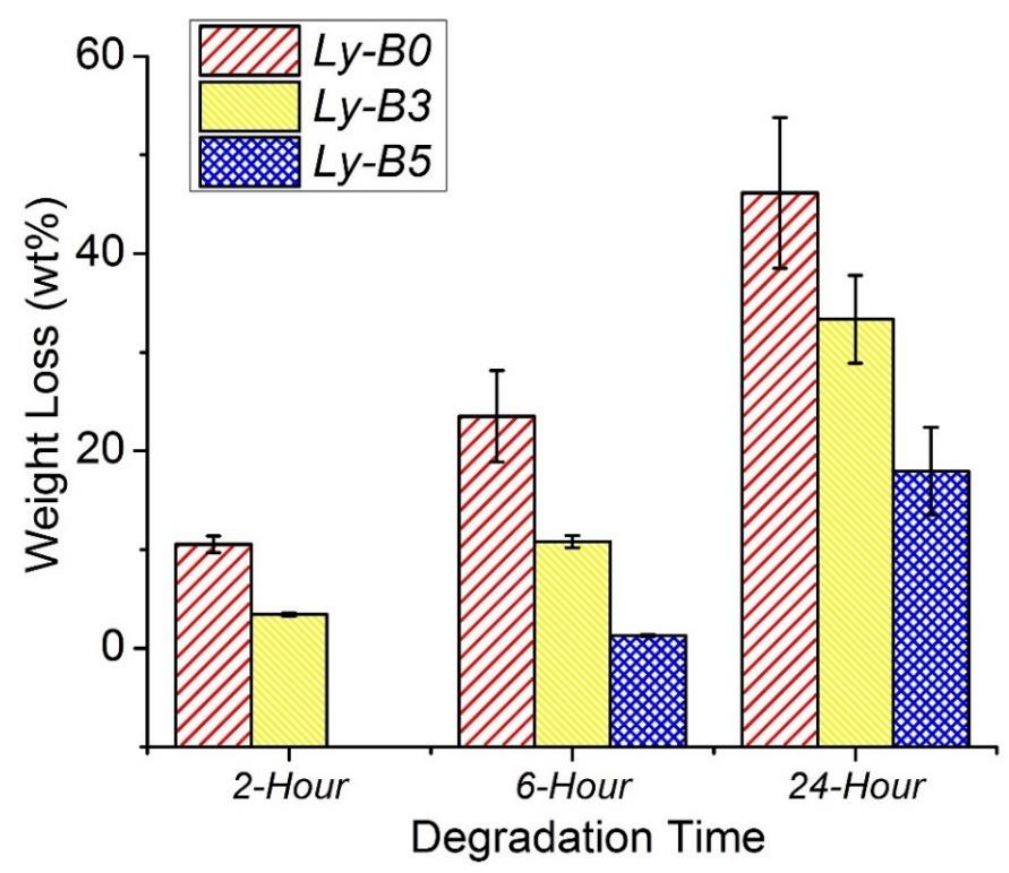

Figure 4.23. Weight loss of the coatings after different incubation times, where the scatter bars represent the max and min values of the data. 
As discussed in section 4.2.2, $\mathrm{Sr}^{2+}$ can retard the dissolution rate of the borate glasses, which can explain why the weight loss of the coatings decreased with more $\mathrm{Sr}^{2+}$ incorporation in the glasses. Besides the chemical composition, the residual stress in the glass coating can be another factor influencing the solubility of the coating/substrate system. The chemical potential of any species can be presented as ${ }^{200}$ :

$$
\mu=\mu^{0}+R T \ln a+\frac{\sigma_{k k} \Omega}{3} \quad \text { Equation 4.6. }
$$

where

$\mu$ : the chemical potential,

$\mu^{0}$ : the chemical potential under standard conditions,

$a:$ the thermodynamic activity,

$\sigma_{k k}:$ the stress tensor,

$\Omega$ : the molar volume of the species under consideration

$R$ : gas constant,

$T$ : absolute temperature of the system.

It has been demonstrated that there is an equilibrium ${ }^{475,476}$ between soluble materials (such as bioactive glass and HA) and water when they dissolve into water, where the free energy, $\Delta \mathrm{G}^{0}$, is zero. This fact can be illustrated as ${ }^{476}$ :

$$
\Delta G^{o}=\mu_{G}-\mu_{D}=R T \ln \frac{a_{G}}{a_{D}}=0
$$

where $\mathrm{D}$ and $\mathrm{G}$ present dissolution products and the glass coating respectively. 
When a residual stress acts, the equilibrium will be broken by the chemical potential alternative. As a result, a new equilibrium condition is generated by an alternate value of solubility products ${ }^{476}$ :

$$
\Delta G^{o}=\frac{\sigma_{k k} \Omega}{3}+R T \ln \frac{a_{G}}{a_{D}}=0 \quad \text { Equation } 4.8
$$

Therefore, the ratio of the activity of solubility products under residual stress and stress-free conditions is ${ }^{476}$ :

$$
\frac{a_{D}}{a_{G}}=\exp \left(\frac{\sigma_{k k} \Omega}{3 R T}\right)
$$

$R, T$ and $\Omega$ are constant, so $\frac{a_{D}}{a_{G}}$ is positively proportional to the residual stress, $\sigma_{K K}$, in the glass coating. The thermodynamic activity, $a$, is also called the effective concentration. Therefore, the concentrations of the dissolution products, i.e. the degradation rate, can be influenced by the magnitude of the residual stress residual stress. Previous studies ${ }^{477,478}$ confirmed the theory, where the compressive residual stress reduced the dissolution rate of 45S5 Bioglass ${ }^{\circledR}$.

The $G_{I C}$ and $G_{I I C}$ values of the glass coating/Ti6Al4V substrate system for any glass composition significantly decreased $(p \leq 0.05)$ for any incubation time (Figure 4.24). 

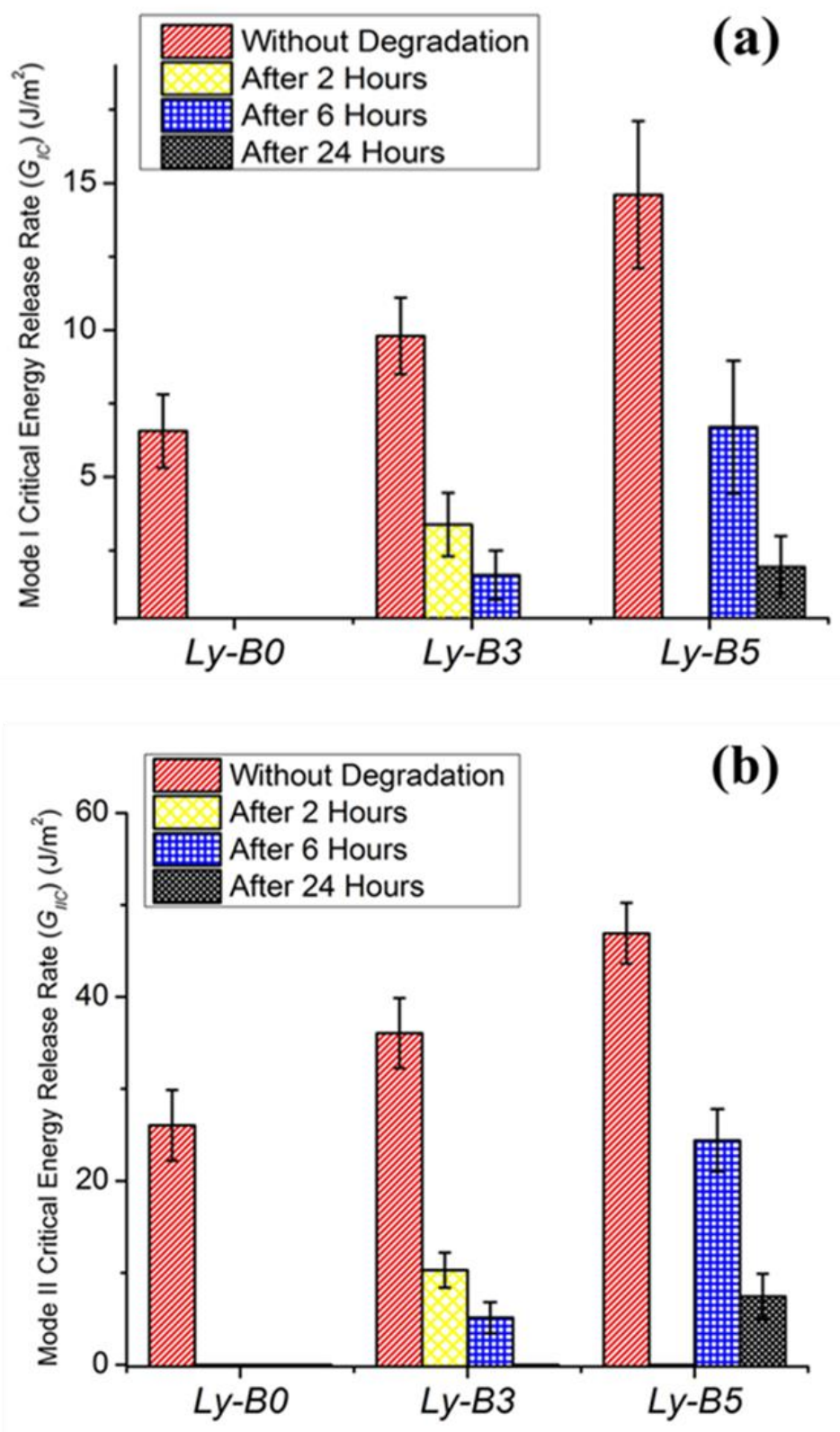

Figure 4.24. The critical strain energy release rate in (a) Mode I $\left(G_{I C}\right)$ and (b) Mode II $\left(G_{I I C}\right)$ of the borate-based glass coating/Ti6Al4V substrate systems before and after degradation with different incubation times, where scatter bars indicate the min and max values.

There was no bond left between the $L y-B O$ coating and Ti6Al4V substrate even after only 2 hours due to the rapid degradation of $L y-B O$, and it was therefore not possible to measure its $G_{I C}$ and $G_{I I C}$ value after degradation. The $G_{I C}$ and $G_{I I C}$ values of the glass coating/Ti6Al4V substrate 
systems for $L y-B 3$ and $L y-B 5$ significantly decreased $(p \leq 0.05)$ with immersion time. The only exception is that there was no significant difference $(p>0.05)$ between $G_{I C}$ values for $L y-B 3$ after 2-hour and 6-hour degradation, and there was no bond strength left between the $L y$-B3 coating and Ti6Al4V substrate after 24 hours. These results agree with the expectation that the degradation of the coating weakens the bond strength between the coating and the substrate. The crack path after degradation for all cases that could be tested, was through the glass, far away from the coating surface and very close to the glass/substrate interface. This confirms that the presented $G_{I C}$ and $G_{I I C}$ values in Figure 2.24, are measures of the toughness of the glass/metal system as a whole and not just the toughness of the corrosion products on top of the degraded glass. 


\section{Conclusions and Future Work}

\subsection{Conclusions}

A series of borate-based glasses were formulated with increasing additions of SrO. The glasses were fully characterized and their solubility in de-ionized water was evaluated. The glasses were then coated onto Ti6Al4V substrates. The mechanical properties of the resulting glass/substrate constructs were evaluated. Increasing SrO incorporation was found to inhibit the solubility of the glasses, while positively influencing bioactivity of the glasses and mechanical properties of the resulting glass/Ti6Al4V constructs. It can be concluded that:

- Borate-based glasses with increasing SrO content were successfully formulated using the meltquenching method. XRD results confirmed the amorphous structure of all the glasses.

- In this borate-based glass series, increasing $\mathrm{SrO}$ content at the expense of $\mathrm{B}_{2} \mathrm{O}_{3}$ induced the formation of larger amounts of NBOs and gradual increases of $\mathrm{T}_{\mathrm{g}}$.

- $\mathrm{Sr}^{2+}$ doping retarded the dissolution rate of the borate-based glass series.

- The borate-based glass series with higher $\mathrm{Sr}^{2+}$ contents $(20 \mathrm{~mol} \%$ and $25 \mathrm{~mol})$ promoted proliferation of osteoblastic cells, while the other glasses impeded such growth.

- All members of the series, except for $L y$-B5, exhibited bacteriostatic behavior against $S$. aureus after 24 hours, which can be a result of a combined or individual effect of some of the dissolution products or the $\mathrm{pH}$ change of TSB culture caused by the dissolution productions.

- The incorporation of $15-25 \mathrm{~mol} \% \mathrm{SrO}(L y-B 3, L y-B 4$ and $L y-B 5)$ significantly increased the Mode I and Mode II energy release rate of the borate glass coating/Ti6Al4V substrate system.

- Increased addition of $\mathrm{SrO}$ retarded the degradation of the glass coatings. 
- The $G_{I C}$ and $G_{I I C}$ values of the glass coating/Ti6AL4V substrate system for any glass composition significantly decreased $(p \leq 0.05)$ with increased degradation time.

- Only the $L y-B 5$ glass coating was still bonded to the Ti6Al4V substrate after 24-hours of degradation. The $L y-B 0$ glass coating delaminated from the substrate after only 2-hours due to its high degradation rate.

\subsection{Novel contributions}

Novel bioactive borate glasses with different $\mathrm{SrO}$ contents were formulated as bioactive coatings for the Ti6Al4V substrate to address the undesirable long-term stability of the HA coating caused by the residual stress due to the mismatch of CTEs between HA and Ti6Al4V. In this thesis, evidence that the borate glass coatings can be alternatives to HA is offered by the very close CTEs of the glasses to that of Ti6Al4V and the small magnitude of residual stresses in glass coatings. Additionally, the measured $G_{I C}$ values for the glass coating/Ti6Al4V substrate system were higher than those previous reported in the literature for silicate and borate glasses.

The incorporation of $\mathrm{SrO}$, especially 20 to $25 \mathrm{~mol} \%$, in the borate glasses not only modified their dissolution rates but also improved their osteo-stimulatory effect, which is beneficial to their application as bioactive coatings for Ti6Al4V stems.

In the thesis, the Mode II critical energy release rate $\left(\mathrm{G}_{I I C}\right)$ of borate glass coating/Ti6Al4V substrate constructs were determined for the first time as a measure of fracture toughness of the coating/substrate system under shear stress. $\mathrm{G}_{I I C}$ values significantly increased with the additions of $\mathrm{SrO}$ in the glasses. The measured $\mathrm{G}_{I I C}$ values in this thesis can be references for the future research. 


\subsection{Future work}

The primary objective of this project was to investigate the influence of different $\mathrm{Sr}^{2+}$ doping on the structure, solubility, bioactivity and antibacterial capability of a novel borate-based glass series, and subsequently the mechanical properties of constructs where the glasses were coated onto a Ti6Al4V substrates. Based on the results of this work, future studies of the glass coating/Ti6Al4V substrate system should consider:

- Investigating the ability of the glass /Ti6Al4V construct to support the attachment and proliferation of osteoblasts, and to influence their morphology. In the experiment, $1 \mathrm{ml}$ cell/media $(10,000$ cells per/ml media) solution will be seeded onto the surface of the glasscoated Ti6Al4V bars and they will be incubated at $37^{\circ} \mathrm{C}$ for 24,48 and 72 hours. SEM will then be used to observe the amount and morphology of the cells.

- Investigating the influence of the Ti6Al4V substrate roughness on the fracture toughness of the coating/substrate construct. Previous studies reported that the fracture toughness of HA /Ti6A14V systems increased with a higher Ti6A14V roughness. In this experiment, $L y-B 5$ would be coated onto Ti6Al4V substrates with different roughnesses (1.5 and $3 \mu \mathrm{m})$ using enamelling and Mode I $\left(G_{I C}\right)$ and Mode II $\left(G_{I I C}\right)$ fracture toughnesses of the coating/substrate constructs would be measured.

- Animal studies. The influence of the glass coatings on bone re-growth will be evaluated by using the Hampshire-cross female sheep. A cubiod shaped hole will be drilled in the femur of a sheep, and a coated Ti6Al4V implant will be inserted into the hole. After 6 months, a section of the femur of the sheep containing the implant and the surronding bone will be removed and analysed by histological techniques. 


\section{References}

1. R. A. Jaffin and C. L. Berman, "The excessive loss of Branemark fixtures in type IV bone: a 5year analysis," J. Periodontol., 62[1] 2-4 (1991).

2. M. E. Müller, S. Nazarian, P. Koch, and J. Schatzker, "The comprehensive classification of fractures of long bones." Springer Science \& Business Media, (2012).

3. B. Clarke, "Normal bone anatomy and physiology," Clin. J. Am. Soc. Nephrol., 3[Supplement 3] S131-S39 (2008).

4. D. Boyd, "Zinc-based glass polyalkenoate cements for skeletal applications." in, Vol. PhD. University of Limerick, 2005.

5. U. G. Wegst, H. Bai, E. Saiz, A. P. Tomsia, and R. O. Ritchie, "Bioinspired structural materials," Nat. Mater., 14[1] 23-36 (2015).

6. J. Black, R. Mattson, and E. Korostoff, "Haversian osteons: size, distribution, internal structure, and orientation," J. Biomed. Mater. Res., 8[5] 299-319 (1974).

7. J.-Y. Rho, L. Kuhn-Spearing, and P. Zioupos, "Mechanical properties and the hierarchical structure of bone," Med. Eng. Phys., 20[2] 92-102 (1998).

8. D. J. Hadjidakis and I. I. Androulakis, "Bone remodeling," Ann. Ny. Acad. Sci., 1092[1] 385-96 (2006).

9. S. Cowin and D. Hegedus, "Bone remodeling I: theory of adaptive elasticity," J. Elasticity., 6[3] 313-26 (1976).

10. T. Hayami, M. Pickarski, G. A. Wesolowski, J. Mclane, A. Bone, J. Destefano, G. A. Rodan, and L. T. Duong, "The role of subchondral bone remodeling in osteoarthritis: reduction of cartilage degeneration and prevention of osteophyte formation by alendronate in the rat anterior cruciate ligament transection model," Arthritis. Rheum., 50[4] 1193-206 (2004).

11. A. E. Grigoriadis, Z.-Q. Wang, M. G. Cecchini, W. Hofstetter, R. Felix, H. A. Fleisch, and E. F. Wagner, "c-Fos: a key regulator of osteoclast-macrophage lineage determination and bone remodeling," Science, 266[5184] 443-49 (1994).

12. S. R. Goldring and M. B. Goldring, "Eating bone or adding it: the Wnt pathway decides," Nat. Med., 13[2] 133-35 (2007).

13. M. Zaidi, B. Moonga, D. W. Moss, and I. MacIntyre, "Inhibition of osteoclastic acid phosphatase abolishes bone resorption," Biochem. Bioph. Res. Co, 159[1] 68-71 (1989).

14. S. L. Teitelbaum, "Bone resorption by osteoclasts," Science, 289[5484] 1504-08 (2000). 
15. N. A. Sims and J. H. Gooi, "Bone remodeling: Multiple cellular interactions required for coupling of bone formation and resorption," pp. 444-51 in Semin. Cell Dev. Biol. Vol. 19.

16. R. L. Jilka, R. S. Weinstein, T. Bellido, P. Roberson, A. M. Parfitt, and S. C. Manolagas, "Increased bone formation by prevention of osteoblast apoptosis with parathyroid hormone," $J$. Clin. Invest., 104[4] 439-46 (1999).

17. T. Komori, H. Yagi, S. Nomura, A. Yamaguchi, K. Sasaki, K. Deguchi, Y. Shimizu, R. Bronson, Y.-H. Gao, and M. Inada, "Targeted disruption of Cbfa1results in a complete lack of bone formation owing to maturational arrest of osteoblasts," Cell, 89[5] 755-64 (1997).

18. B. Henderson and S. P. Nair, "Hard labour: bacterial infection of the skeleton," Trends Microbiol., 11[12] 570-77 (2003).

19. O. Kollet, A. Dar, and T. Lapidot, "The multiple roles of osteoclasts in host defense: bone remodeling and hematopoietic stem cell mobilization," Annu. Rev. Immunol., 25 51-69 (2007).

20. U. Kini and B. Nandeesh, "Physiology of bone formation, remodeling, and metabolism," pp. 29-57. in Radionuclide and hybrid bone imaging. Springer, 2012.

21. E. F. Eriksen, "Cellular mechanisms of bone remodeling," Rev. Endocr. Meta. Disord., 11[4] 219-27 (2010).

22. M. Fakhry, E. Hamade, B. Badran, R. Buchet, and D. Magne, "Molecular mechanisms of mesenchymal stem cell differentiation towards osteoblasts," World J. Stem Cells, 5[4] 136-48 (2013).

23. J. B. Lian, G. S. Stein, A. Javed, A. J. Van Wijnen, J. L. Stein, M. Montecino, M. Q. Hassan, T. Gaur, C. J. Lengner, and D. W. Young, "Networks and hubs for the transcriptional control of osteoblastogenesis," Rev. Endocr. Meta. Disord., 7[1-2] 1-16 (2006).

24. K. Nakashima, X. Zhou, G. Kunkel, Z. Zhang, J. M. Deng, R. R. Behringer, and B. de Crombrugghe, "The novel zinc finger-containing transcription factor osterix is required for osteoblast differentiation and bone formation," Cell, 108[1] 17-29 (2002).

25. L. Qin, P. Qiu, L. Wang, X. Li, J. T. Swarthout, P. Soteropoulos, P. Tolias, and N. C. Partridge, "Gene expression profiles and transcription factors involved in parathyroid hormone signaling in osteoblasts revealed by microarray and bioinformatics," J. Biol. Chem., 278[22] 19723-31 (2003).

26. L. L. Hench, "Genetic design of bioactive glass," J. Eur. Ceram. Soc., 29[7] 1257-65 (2009).

27. M. Murshed, D. Harmey, J. L. Millán, M. D. McKee, and G. Karsenty, "Unique coexpression in osteoblasts of broadly expressed genes accounts for the spatial restriction of ECM mineralization to bone," Gene. Dev., 19[9] 1093-104 (2005). 
28. M. Mizuno, R. Fujisawa, and Y. Kuboki, "Type I collagen-induced osteoblastic differentiation of bone-marrow cells mediated by collagen- $\alpha 2 \beta 1$ integrin interaction," J. Cell Physiol., 184[2] 207-13 (2000).

29. C. Bellows, J. Aubin, and J. Heersche, "Initiation and progression of mineralization of bone nodules formed in vitro: the role of alkaline phosphatase and organic phosphate," Bone Miner., 14[1] 27-40 (1991).

30. S. V. Reddy and G. D. Roodman, "Control of osteoclast differentiation," Crit. Rev. Eukaryot. Gene Expr., 8[1] (1998).

31. P. Giannoudis, N. Kanakaris, and T. Einhorn, "Interaction of bone morphogenetic proteins with cells of the osteoclast lineage: review of the existing evidence," Osteoporosis. Int., 18[12] 1565-81 (2007).

32. H. Yasuda, N. Shima, N. Nakagawa, K. Yamaguchi, M. Kinosaki, S.-i. Mochizuki, A. Tomoyasu, K. Yano, M. Goto, and A. Murakami, "Osteoclast differentiation factor is a ligand for osteoprotegerin/osteoclastogenesis-inhibitory factor and is identical to TRANCE/RANKL," Proc. Natl. Acad. Sci., 95[7] 3597-602 (1998).

33. K. Kobayashi, N. Takahashi, E. Jimi, N. Udagawa, M. Takami, S. Kotake, N. Nakagawa, M. Kinosaki, K. Yamaguchi, and N. Shima, "Tumor necrosis factor $\alpha$ stimulates osteoclast differentiation by a mechanism independent of the ODF/RANKL-RANK interaction," J. Exp. Med., 191[2] 275-86 (2000).

34. M. C. Horowitz, Y. Xi, K. Wilson, and M. A. Kacena, "Control of osteoclastogenesis and bone resorption by members of the TNF family of receptors and ligands," Cytokine. Growth F. R., 12[1] 9-18 (2001).

35. Y. Hirashima, N. Ishiguro, S. Kondo, and H. Iwata, "Osteoclast induction from bone marrow cells is due to pro-inflammatory mediators from macrophages exposed to polyethylene particles: A possible mechanism of osteolysis in failed THA," J. Biomed. Mater. Res., 56[2] 177-83 (2001).

36. G. A. Rodan and T. J. Martin, "Therapeutic approaches to bone diseases," Science, 289[5484] 1508-14 (2000).

37. N. Dalbeth, T. Smith, B. Nicolson, B. Clark, K. Callon, D. Naot, D. O. Haskard, F. M. McQueen, I. R. Reid, and J. Cornish, "Enhanced osteoclastogenesis in patients with tophaceous gout: urate crystals promote osteoclast development through interactions with stromal cells," Arthritis. Rheum., 58[6] 1854-65 (2008).

38. B. Kirstein, T. J. Chambers, and K. Fuller, "Secretion of tartrate-resistant acid phosphatase by osteoclasts correlates with resorptive behavior," J. Cell Biochem., 98[5] 1085-94 (2006). 
39. D. Lacey, E. Timms, H.-L. Tan, M. Kelley, C. Dunstan, T. Burgess, R. Elliott, A. Colombero, G. Elliott, and S. Scully, "Osteoprotegerin ligand is a cytokine that regulates osteoclast differentiation and activation," Cell, 93[2] 165-76 (1998).

40. J. A. Buckwalter and J. A. Martin, "Osteoarthritis," Adv. Drug Deliver. Rev, 58[2] 150-67 (2006).

41. K. Sinusas, "Osteoarthritis: diagnosis and treatment," Am. Fam. Physician., 85[1] (2012).

42. T. Towheed, L. Maxwell, M. Judd, M. Catton, M. C. Hochberg, and G. A. Wells, "Acetaminophen for osteoarthritis," The Cochrane Library (2006).

43. D. J. Hunter and G. H. Lo, "The management of osteoarthritis: an overview and call to appropriate conservative treatment," Rheum. Dis. Clin. N. Am., 34[3] 689-712 (2008).

44. S. F. S. Clair, C. Higuera, V. Krebs, N. A. Tadross, J. Dumpe, and W. K. Barsoum, "Hip and knee arthroplasty in the geriatric population," Clin. Geriatr. Med., 22[3] 515-33 (2006).

45. R. L. Barrack, R. Mulroy, and W. H. Harris, "Improved cementing techniques and femoral component loosening in young patients with hip arthroplasty. A 12-year radiographic review," Bone Joint J., 74[3] 385-89 (1992).

46. D. Wheeler, M. Montfort, and S. McLoughlin, "Differential healing response of bone adjacent to porous implants coated with hydroxyapatite and 45S5 bioactive glass," J. Biomed. Mater. Res., 55[4] 603-12 (2001).

47. Y. Shaked, P. Dickson, and K. Workman, "The coach program-a "joint" approach to patient education and support," pp. 259-63 in Healthcare. Vol. 4.

48. H. Maradit Kremers, D. R. Larson, C. S. Crowson, W. K. Kremers, R. E. Washington, C. A. Steiner, W. A. Jiranek, and D. J. Berry, "Prevalence of total hip and knee replacement in the united states," J. Bone Joint Surg. Am., 97[17] 1386-97 (2015).

49. S. Kurtz, K. Ong, E. Lau, F. Mowat, and M. Halpern, "Projections of primary and revision hip and knee arthroplasty in the United States from 2005 to 2030," J. Bone Joint Surg., 89[4] 780-85 (2007).

50. T. McTighe, D. Brazil, J. Keggi, L. Keppler, and E. J. McPherson, "Short-Stem Designs for Total Hip Arthroplasty: Neck Stabilized Femoral Components." in. Callaghan J, Beaule P, Clohisy J, et al. The Adult Hip. 3rd ed. Philadelphia: Wolters Kluwer Health.

51. O. H. Brady, B. A. Masri, D. S. Garbuz, and C. P. Duncan, "Rheumatology: 10. Joint replacement of the hip and knee — when to refer and what to expect," Can. Med. Assoc. J., 163[10] 1285-91 (2000). 
52. I. D. Learmonth, C. Young, and C. Rorabeck, "The operation of the century: total hip replacement," Lancet., 370[9597] 1508-19 (2007).

53. B. Fink, S. Wessel, G. Deuretzbacher, M. Protzen, and W. Ruther, "Midterm results of "thrust plate" prosthesis," J. Arthroplasty, 22[5] 703-10 (2007).

54. M. Long and H. Rack, "Titanium alloys in total joint replacement-a materials science perspective," Biomaterials., 19[18] 1621-39 (1998).

55. M. E. Müller, "The benefits of metal-on-metal total hip replacements," Clin. Orthop. Relat. R., 311 54-59 (1995).

56. J. Charnley, "Anchorage of the femoral head prosthesis to the shaft of the femur," Bone Joint J., 42B 28-30 (1960).

57. C. B. Rieker, "Tribology of total hip arthroplasty prostheses," EFORT Open Reviews, 1[2] 5257 (2016).

58. A. Palitsch, M. Hannig, P. Ferger, and M. Balkenhol, "Bonding of acrylic denture teeth to MMA/PMMA and light-curing denture base materials: the role of conditioning liquids," J. Dent., 40[3] 210-21 (2012).

59. K. Abdel-Kader, S. Allcock, D. Walker, and S. Chaudhry, "Boneloc bone-cement: Experience in hip arthroplasty during a 3-year period," J. Arthroplasty, 16[7] 811-19 (2001).

60. L. Cristofolini, A. S. Teutonico, L. Monti, A. Cappello, and A. Toni, "Comparative in vitro study on the long term performance of cemented hip stems: validation of a protocol to discriminate between "good" and "bad" designs," J. Biomech., 36[11] 1603-15 (2003).

61. D. A. Nussbaum, P. Gailloud, and K. Murphy, "The chemistry of acrylic bone cements and implications for clinical use in image-guided therapy," J. Vasc. Interv. Radiol, 15[2] 121-26 (2004).

62. G. Lewis, "Properties of acrylic bone cement: state of the art review," J. Biomed. Mater. Res. A, 38[2] 155-82 (1997).

63. E. Unosson, "Mechanical properties and spreading characteristics of bone cement for spinal applications." in, Vol. Master. Uppsala University, 2010.

64. C. S. Ranawat, A. S. Ranawat, and V. J. Rasquinha, "Mastering the art of cemented femoral stem fixation," J. Arthroplasty, 19[4] 85-91 (2004).

65. N. Nuño and M. Amabili, "Modelling debonded stem-cement interface for hip implants: effect of residual stresses," Clin. Biomech., 17[1] 41-48 (2002).

66. J. Webb and R. Spencer, "The role of polymethylmethacrylate bone cement in modern orthopaedic surgery," Bone Joint J., 89[7] 851-57 (2007). 
67. M. A. Miller, M. J. Terbush, J. R. Goodheart, T. H. Izant, and K. A. Mann, "Increased initial cement-bone interlock correlates with reduced total knee arthroplasty micro-motion following in vivo service," J. Biomech., 47[10] 2460-66 (2014).

68. W. Walsh, M. Svehla, J. Russell, M. Saito, T. Nakashima, R. Gillies, W. Bruce, and R. Hori, "Cemented fixation with PMMA or Bis-GMA resin hydroxyapatite cement: effect of implant surface roughness," Biomaterials., 25[20] 4929-34 (2004).

69. S. Deb and G. Koller, "Acrylic bone cement: genesis and evolution," pp. 167-82. Orthopaedic bone cements, (2008).

70. R. Vaishya, M. Chauhan, and A. Vaish, "Bone cement," J. Clin. Orthop. Trauma, 4[4] 157-63 (2013).

71. J. Charnley, "Anchorage of the femoral head prosthesis," (1960).

72. D. J. Berry, W. S. Harmsen, M. E. Cabanela, and B. F. Morrey, "Twenty-five-year survivorship of two thousand consecutive primary Charnley total hip replacements," J. Bone Joint Surg., 84[2] 171-77 (2002).

73. V. J. Rasquinha and C. S. Ranawat, "Durability of the cemented femoral stem in patients 60 to 80 years old," Clin. Orthop. Relat. R., 419 115-23 (2004).

74. B. F. Kavanagh, S. Wallrichs, M. Dewitz, D. Berry, B. Currier, D. Ilstrup, and M. B. Coventry, "Charnley low-friction arthroplasty of the hip: twenty-year results with cement," J. Arthroplasty, 9[3] 229-34 (1994).

75. Y. Liu, J. Park, G. Njus, and D. Stienstra, "Bone-particle-impregnated bone cement: An in vitro study," J. Biomed. Mater. Res. A, 21[2] 247-61 (1987).

76. G. Starke, C. Birnie, and P. van den Blink, "Numerical modelling of cement polymerisation and thermal bone necrosis, "pp. 163-72 in Third international symposium on computer methods in biomechanics and biomedical engineering. Gordon and Breach, London.

77. N. Dunne and R. W. Ormsby, "MWCNT Used in Orthopaedic Bone Cements, ," (2011).

78. M. Jasty, W. Maloney, C. Bragdon, D. O'connor, T. Haire, and W. Harris, "The initiation of failure in cemented femoral components of hip arthroplasties," Bone Joint J., 73[4] 551-58 (1991).

79. T. Harrigan, J. Kareh, D. O'Connor, D. Burke, and W. Harris, "A finite element study of the initiation of failure of fixation in cemented femoral total hip components," J. Orthopaed. Res., 10[1] 134-44 (1992).

80. H.-g. Willert, H. Bertram, and G. H. Buchhorn, "Osteolysis in Alloarthroplasty of the Hip: The Role of Ultra-High Molecular Weight Polyethylene Wear Particles," Clin. Orthop. Relat. R., 258 95-107 (1990). 
81. N. Udagawa, N. Takahashi, T. Katagiri, T. Tamura, S. Wada, D. M. Findlay, T. J. Martin, H. Hirota, T. Taga, and T. Kishimoto, "Interleukin (IL)-6 induction of osteoclast differentiation depends on IL-6 receptors expressed on osteoblastic cells but not on osteoclast progenitors," $J$. Exp. Med., 182[5] 1461-68 (1995).

82. C. Löwik, G. Van der Pluijm, H. Bloys, K. Hoekman, O. Bijvoet, L. Aarden, and S. Papapoulos, "Parathyroid hormone (PTH) and PTH-like protein (PLP) stimulate interleukin-6 production by osteogenic cells: a possible role of interleukin-6 in osteoclastogenesis," Biochem. Bioph. Res. Co, 162[3] 1546-52 (1989).

83. D. Howie, B. Vernon-Roberts, R. Oakeshott, and B. Manthey, "A rat model of resorption of bone at the cement-bone interface in the presence of polyethylene wear particles," $J$ Bone Joint Surg Am, 70[2] 257-63 (1988).

84. J. Lam, S. Takeshita, J. E. Barker, O. Kanagawa, F. P. Ross, and S. L. Teitelbaum, "TNF- $\alpha$ induces osteoclastogenesis by direct stimulation of macrophages exposed to permissive levels of RANK ligand," J. Clin. Invest., 106[12] 1481-88 (2000).

85. D. L. Shardlow, M. H. Stone, E. Ingham, and J. Fisher, "Cement particles containing radioopacifiers stimulate pro-osteolytic cytokine production from a human monocytic cell line," Bone Joint J., 85[6] 900-05 (2003).

86. Y. Nakashima, D.-H. Sun, M. Trindade, L. Chun, Y. Song, S. Goodman, D. Schurman, W. Maloney, and R. Smith, "Induction of macrophage CC chemokine expression by titanium alloy and bone cement particles," J. Bone Joint Surg. Br., 81[1] 155-62 (1999).

87. K. D. Merkel, J. M. Erdmann, K. P. McHugh, Y. Abu-Amer, F. P. Ross, and S. L. Teitelbaum, "Tumor necrosis factor- $\alpha$ mediates orthopedic implant osteolysis," Am. J. Pathol., 154[1] 203-10 (1999).

88. D. S. Hungerford and L. C. Jones, "The rationale of cementless revision of cemented arthroplasty failures," Clin. Orthop. Relat. R., 235 12-24 (1988).

89. R. Z. Legeros and R. G. Craig, "Strategies to affect bone remodeling: osteointegration," $J$. Bone. Miner. Res., 8[S2] S583-S96 (1993).

90. B. T. Palumbo, K. L. Morrison, A. S. Baumgarten, M. I. Stein, G. J. Haidukewych, and T. L. Bernasek, "Results of revision total hip arthroplasty with modular, titanium-tapered femoral stems in severe proximal metaphyseal and diaphyseal bone loss," J. Arthroplasty, 28[4] 690-94 (2013).

91. S. Nakamura, N. Arai, T. Kobayashi, and T. Matsushita, "Fixation of an anatomically designed cementless stem in total hip arthroplasty," Advances in orthopedics, 2012 (2012).

92. R. S. J. Burnett, "Total hip arthroplasty: techniques and results," BCMJ, 52[9] 455-64 (2010). 
93. D. Lakstein, D. Backstein, O. Safir, Y. Kosashvili, and A. E. Gross, "Revision total hip arthroplasty with a porous-coated modular stem: 5 to 10 years followup," Clin. Orthop. Relat. Res., 468[5] 1310-15 (2010).

94. T. Phillips, S. Messieh, and P. McDonald, "Femoral stem fixation in hip replacement. A biomechanical comparison of cementless and cemented prostheses," Bone Joint J., 72[3] 431-34 (1990).

95. C. A. Engh and J. D. Bobyn, "The influence of stem size and extent of porous coating on femoral bone resorption after primary cementless hip arthroplasty," Clin. Orthop. Relat. R., 2317 28 (1988).

96. C. A. Engh, V. Mohan, J. P. Nagowski, C. J. S. Terefenko, and C. A. Engh, "Influence of stem size on clinical outcome of primary total hip arthroplasty with cementless extensively porouscoated femoral components," J. Arthroplasty, 24[4] 554-59 (2009).

97. R. Heekin, J. Callaghan, W. Hopkinson, C. Savory, and J. Xenos, "The porous-coated anatomic total hip prosthesis, inserted without cement. Results after five to seven years in a prospective study," J. Bone. Joint. Surg. Am, 75[1] 77-91 (1993).

98. Y.-H. Kim, J.-S. Kim, and S.-H. Cho, "Primary total hip arthroplasty with a cementless porouscoated anatomic total hip prosthesis: 10-to 12-Year results of prospective andconsecutive series," J. Arthroplasty, 14[5] 538-48 (1999).

99. H. S. Khanuja, J. J. Vakil, M. S. Goddard, and M. A. Mont, "Cementless femoral fixation in total hip arthroplasty," J. Bone. Joint. Surg. Am, 93[5] 500-09 (2011).

100. M.-S. Park, B.-W. Choi, S.-J. Kim, and J.-H. Park, "Plasma spray-coated Ti femoral component for cementless total hip arthroplasty," J. Arthroplasty, 18[5] 626-30 (2003).

101. A. V. Lombardi Jr, K. R. Berend, T. H. Mallory, M. D. Skeels, and J. B. Adams, "Survivorship of 2000 tapered titanium porous plasma-sprayed femoral components," Clin. Orthop. Relat. R., 467[1] 146-54 (2009).

102. A. Grübl, C. Chiari, A. Giurea, M. Gruber, A. Kaider, M. Marker, H. Zehetgruber, and F. Gottsauner-Wolf, "Cementless total hip arthroplasty with the rectangular titanium Zweymüller stem," J. Bone Joint Surg., 88[10] 2210-15 (2006).

103. O. Reigstad, P. Siewers, M. Røkkum, and B. Espehaug, "Excellent long-term survival of an uncemented press-fit stem and screw cup in young patients: follow-up of 75 hips for 15-18 years," Acta orthop., 79[2] 194-202 (2008).

104. J. Pellier, J. Geringer, and B. Forest, "Fretting-corrosion between 316L SS and PMMA: Influence of ionic strength, protein and electrochemical conditions on material wear. Application to orthopaedic implants," Wear, 271[9] 1563-71 (2011). 
105. G. Sovak, A. Weiss, and I. Gotman, "Osseointegration of Ti6A14V alloy implants coated with titanium nitride by a new method," Bone Joint J., 82[2] 290-96 (2000).

106. M. Geetha, A. Singh, R. Asokamani, and A. Gogia, "Ti based biomaterials, the ultimate choice for orthopaedic implants-a review," Prog. Mater. Sci., 54[3] 397-425 (2009).

107. M. Niinomi, "Recent metallic materials for biomedical applications," Metall. Mater. Trans. A, 33[3] 477-86 (2002).

108. M. Balazic, J. Kopac, M. J. Jackson, and W. Ahmed, "Review: titanium and titanium alloy applications in medicine," Int. J. Nano Biomater., 1[1] 3-34 (2007).

109. D. Williams, "Definitions in biomaterials, Amsterdam." in. Oxford-New York-Tokio, Elsevier, 1987.

110. D. F. Williams, "On the mechanisms of biocompatibility," Biomaterials., 29[20] 2941-53 (2008).

111. K. Das, S. Bose, and A. Bandyopadhyay, "Surface modifications and cell-materials interactions with anodized Ti," Acta Biomater., 3[4] 573-85 (2007).

112. S. Steinemann, G. Winter, and J. Leray, "Evaluation of biomaterials," Willey, New York (USA) 5435-38 (1980).

113. R. S. Namba, J. H. Keyak, A. S. Kim, L. P. Vu, and H. B. Skinner, "Cementless Implant Composition and Femoral Stress: A Finite Element Analysis," Clin. Orthop. Relat. R., 347 261-67 (1998).

114. C. Lavernia, M. D’Apuzzo, V. Hernandez, and D. Lee, "Thigh pain in primary total hip arthroplasty: the effects of elastic moduli," J. Arthroplasty, 19[7] 10-16 (2004).

115. R. Bourne, C. Rorabeck, M. Ghazal, and M. Lee, "Pain in the thigh following total hip replacement with a porous-coated anatomic prosthesis for osteoarthrosis. A five-year follow-up study," J. Bone. Joint. Surg. Am, 76[10] 1464-70 (1994).

116. H. S. Khanuja, J. J. Vakil, M. S. Goddard, and M. A. Mont, "Cementless femoral fixation in total hip arthroplasty," J. Bone Joint Surg. Am., 93[5] 500-09 (2011).

117. M. M. Dewidar, K. A. Khalil, and J. Lim, "Processing and mechanical properties of porous 316L stainless steel for biomedical applications," T. Nonferr. Metal Soc., 17[3] 468-73 (2007).

118. H. Agins, N. Alcock, M. Bansal, E. Salvati, P. Wilson, P. Pellicci, and P. Bullough, "Metallic wear in failed titanium-alloy total hip replacements. A histological and quantitative analysis," Journal of Bone and Joint Surgery, 170[3] 347-56 (1988).

119. J. Disegi, "Titanium alloys for fracture fixation implants," Injury, 31 D14-D17 (2000). 
120. J. B. Meding, M. R. Galley, and M. A. Ritter, "High survival of uncemented proximally porous-coated titanium alloy femoral stems in osteoporotic bone," Clin. Orthop. Relat. Res., 468[2] 441-47 (2010).

121. J. R. McLaughlin and K. R. Lee, "Uncemented total hip arthroplasty with a tapered femoral component: a 22-to 26-year follow-up study," Orthopedics., 33[9] (2010).

122. M. Huber, G. Reinisch, G. Trettenhahn, K. Zweymüller, and F. Lintner, "Presence of corrosion products and hypersensitivity-associated reactions in periprosthetic tissue after aseptic loosening of total hip replacements with metal bearing surfaces," Acta Biomater., 5[1] 172-80 (2009).

123. Y.-H. Kim and V. Kim, "Results of the Harris-Galante cementless hip prosthesis," The Journal of bone and joint surgery. British volume, 74[1] 83-87 (1992).

124. B. Van der Wal, A. Rahmy, B. Grimm, G. Blake, I. Heyligers, and A. Tonino, "The influence of implant design on periprosthetic bone remodelling of two types of uncemented HA-coated hip stems. A two-year follow-up study using DEXA," Hip Int., 16[1] 8 (2006).

125. H. Kienapfel, C. Sprey, A. Wilke, and P. Griss, "Implant fixation by bone ingrowth," $J$. Arthroplasty, 14[3] 355-68 (1999).

126. S. A. Hacking, J. D. Bobyn, M. Tanzer, and J. J. Krygier, "The osseous response to corundum blasted implant surfaces in a canine hip model," Clin. Orthop. Relat. R., 364 240-53 (1999).

127. N. Harrison, P. McHugh, W. Curtin, and P. Mc Donnell, "Micromotion and friction evaluation of a novel surface architecture for improved primary fixation of cementless orthopaedic implants," J. Mech. Behav. Biomed. Mater., 21 37-46 (2013).

128. S. D. Cook, S. L. Salkeld, L. P. Patron, and R. L. Barrack, "The effect of demineralized bone matrix gel on bone ingrowth and fixation of porous implants," J. Arthroplasty, 17[4] 402-08 (2002).

129. R. Huiskes, H. Weinans, H. Grootenboer, M. Dalstra, B. Fudala, and T. Slooff, "Adaptive bone-remodeling theory applied to prosthetic-design analysis," J. Biomech., 20[11-12] 1135-50 (1987).

130. D. F. Scott and W. L. Jaffe, "Host-bone response to porous-coated cobalt-chrome and hydroxyapatite-coated titanium femoral components in hip arthroplasty: Dual-energy X-ray Absorptiometry Analysis of Paired Bilateral Cases at 5 to 7 Years," J. Arthroplasty, 11[4] 429-37 (1996).

131. O. G. Sköldenberg, H. S. Bodén, M. O. Salemyr, T. E. Ahl, and P. Y. Adolphson, "Periprosthetic proximal bone loss after uncemented hip arthroplasty is related to stem size: DXA measurements in 138 patients followed for 2-7 years," Acta orthop., 77[3] 386-92 (2006). 
132. C. K. McCarthy, G. G. Steinberg, M. Agren, D. Leahey, E. Wyman, and D. T. Baran, "Quantifying bone loss from the proximal femur after total hip arthroplasty," Bone Joint J., 73[5] 774-78 (1991).

133. R. Huiskes, H. Weinans, and B. Van Rietbergen, "The relationship between stress shielding and bone resorption around total hip stems and the effects of flexible materials," Clin. Orthop. Relat. R., 274 124-34 (1992).

134. J. Shibli, K. Aguiar, L. Melo, S. d'Avila, E. Zenóbio, M. Faveri, G. Iezzi, and A. Piattelli, "Histological comparison between implants retrieved from patients with and without osteoporosis," Int. J. Oral Max. Surg., 37[4] 321-27 (2008).

135. I. C. Clarke, P. Campbell, and N. Kossovsky, "Debris-mediated osteolysis-a cascade phenomenon involving motion, wear, particulates, macrophage induction, and bone lysis." in Particulate debris from medical implants: mechanisms of formation and biological consequences. ASTM International, 1992.

136. A. Pancanti, M. Bernakiewicz, and M. Viceconti, "The primary stability of a cementless stem varies between subjects as much as between activities," J. Biomech., 36[6] 777-85 (2003).

137. K. Søballe, E. S. Hansen, H. B-Rasmussen, P. H. Jørgensen, and C. Bünger, "Tissue ingrowth into titanium and hydroxyapatite-coated implants during stable and unstable mechanical conditions," J. Orthopaed. Res., 10[2] 285-99 (1992).

138. R. Pilliar, J. Lee, and C. Maniatopoulos, "Observations on the effect of movement on bone ingrowth into porous-surfaced implants," Clin. Orthop. Relat. R., 208 108-13 (1986).

139. Y. Abu-Amer, I. Darwech, and J. C. Clohisy, "Aseptic loosening of total joint replacements: mechanisms underlying osteolysis and potential therapies," Arthritis Res. Ther., 9[1] 1 (2007).

140. D. R. Murdoch, S. A. Roberts, V. G. Fowler, M. A. Shah, S. L. Taylor, A. J. Morris, and G. R. Corey, "Infection of orthopedic prostheses after Staphylococcus aureus bacteremia," Clin. Infect. Dis., 32[4] 647-49 (2001).

141. L. Pulido, E. Ghanem, A. Joshi, J. J. Purtill, and J. Parvizi, "Periprosthetic joint infection: the incidence, timing, and predisposing factors," Clin. Orthop. Relat. R., 466[7] 1710-15 (2008).

142. N. N. Mahomed, J. A. Barrett, J. N. Katz, C. B. Phillips, E. Losina, R. A. Lew, E. Guadagnoli, W. H. Harris, R. Poss, and J. A. Baron, "Rates and outcomes of primary and revision total hip replacement in the United States medicare population," J. Bone. Joint. Surg. Am., 85[1] 27-32 (2003).

143. C. B. Phillips, J. A. Barrett, E. Losina, N. N. Mahomed, E. A. Lingard, E. Guadagnoli, J. A. Baron, W. H. Harris, R. Poss, and J. N. Katz, "Incidence rates of dislocation, pulmonary embolism, and deep infection during the first six months after elective total hip replacement," J. Bone. Joint. Surg. Am., 85[1] 20-26 (2003). 
144. K. J. Ure, H. C. Amstutz, S. Nasser, and T. P. Schmalzried, "Direct-exchange arthroplasty for the treatment of infection after total hip replacement. An average ten-year follow-up," J. Bone. Joint. Surg. Am, 80[7] 961-68 (1998).

145. S. Nishimura, T. Tsurumoto, A. Yonekura, K. Adachi, and H. Shindo, "Antimicrobial susceptibility of Staphylococcus aureus and Staphylococcus epidermidis biofilms isolated from infected total hip arthroplasty cases," J. Orthop. Sci., 11[1] 46-50 (2006).

146. N. Ramaniraka, L. Rakotomanana, and P.-F. Leyvraz, "The fixation of the cemented femoral component," Bone Joint J., 82[2] 297-303 (2000).

147. M. Katsikogianni and Y. Missirlis, "Concise review of mechanisms of bacterial adhesion to biomaterials and of techniques used in estimating bacteria-material interactions," Eur. Cell Mater., 8[3] (2004).

148. Q. Feng, J. Wu, G. Chen, F. Cui, T. Kim, and J. Kim, "A mechanistic study of the antibacterial effect of silver ions on Escherichia coli and Staphylococcus aureus," J. Biomed. Mater. Res., 52[4] 662-68 (2000).

149. A. Taglietti, Y. A. Diaz Fernandez, E. Amato, L. Cucca, G. Dacarro, P. Grisoli, V. Necchi, P. Pallavicini, L. Pasotti, and M. Patrini, "Antibacterial activity of glutathione-coated silver nanoparticles against gram positive and gram negative bacteria," Langmuir., 28[21] 8140-48 (2012).

150. W. V. Arnold, M. E. Shirtliff, and P. Stoodley, "Bacterial biofilms and periprosthetic infections," J. Bone Joint Surg., 95[24] 2223-29 (2013).

151. S. R. Clarke, R. Mohamed, L. Bian, A. F. Routh, J. F. Kokai-Kun, J. J. Mond, A. Tarkowski, and S. J. Foster, "The Staphylococcus aureus surface protein IsdA mediates resistance to innate defenses of human skin," Cell Host Microbe., 1[3] 199-212 (2007).

152. P. Y. Ong, T. Ohtake, C. Brandt, I. Strickland, M. Boguniewicz, T. Ganz, R. L. Gallo, and D. Y. Leung, "Endogenous antimicrobial peptides and skin infections in atopic dermatitis," New Engl. J. Med., 347[15] 1151-60 (2002).

153. J.-M. Ghigo, "Natural conjugative plasmids induce bacterial biofilm development," Nature, 412[6845] 442-45 (2001).

154. Y. H. An and R. J. Friedman, "Concise review of mechanisms of bacterial adhesion to biomaterial surfaces," J. Biomed. Mater. Res., 43[3] 338-48 (1998).

155. C. Heilmann, M. Hussain, G. Peters, and F. Götz, "Evidence for autolysin-mediated primary attachment of Staphylococcus epidermidis to a polystyrene surface," Mol. Microbiol., 24[5] 101324 (1997). 
156. J. M. Patti, B. L. Allen, M. J. McGavin, and M. Hook, "MSCRAMM-mediated adherence of microorganisms to host tissues," Annu. Rev. Microbiol., 48[1] 585-617 (1994).

157. S. J. Foster, "Molecular characterization and functional analysis of the major autolysin of Staphylococcus aureus 8325/4," J. Bacteriol., 177[19] 5723-25 (1995).

158. R. P. Novick, "Autoinduction and signal transduction in the regulation of staphylococcal virulence," Mol. Microbiol., 48[6] 1429-49 (2003).

159. C. Heilmann, "Adhesion mechanisms of staphylococci," pp. 105-23. in Bacterial Adhesion. Springer, 2011.

160. L. Montanaro, P. Speziale, D. Campoccia, S. Ravaioli, I. Cangini, G. Pietrocola, S. Giannini, and C. R. Arciola, "Scenery of Staphylococcus implant infections in orthopedics," Future Microbiol., 6[11] 1329-49 (2011).

161. S. E. Cramton, C. Gerke, N. F. Schnell, W. W. Nichols, and F. Götz, "The intercellular adhesion (ica) locus is present in Staphylococcus aureus and is required for biofilm formation," Infect. Immun., 67[10] 5427-33 (1999).

162. M. E. Rupp, P. D. Fey, C. Heilmann, and F. Götz, "Characterization of the importance of Staphylococcus epidermidis autolysin and polysaccharide intercellular adhesin in the pathogenesis of intravascular catheter-associated infection in a rat model," J. Infect. Dis., 183[7] 1038-42 (2001).

163. M. E. Rupp, J. S. Ulphani, P. D. Fey, K. Bartscht, and D. Mack, "Characterization of the importance of polysaccharide intercellular adhesin/hemagglutinin of Staphylococcus epidermidis in the pathogenesis of biomaterial-based infection in a mouse foreign body infection model," Infect. Immun., 67[5] 2627-32 (1999).

164. E. E. Mann, K. C. Rice, B. R. Boles, J. L. Endres, D. Ranjit, L. Chandramohan, L. H. Tsang, M. S. Smeltzer, A. R. Horswill, and K. W. Bayles, "Modulation of eDNA release and degradation affects Staphylococcus aureus biofilm maturation," PloS One., 4[6] e5822 (2009).

165. B. R. Boles and A. R. Horswill, "Staphylococcal biofilm disassembly," Trends Microbiol., 19[9] 449-55 (2011).

166. M. J. Huseby, A. C. Kruse, J. Digre, P. L. Kohler, J. A. Vocke, E. E. Mann, K. W. Bayles, G. A. Bohach, P. M. Schlievert, and D. H. Ohlendorf, "Beta toxin catalyzes formation of nucleoprotein matrix in staphylococcal biofilms," Proc. Natl. Acad. Sci., 107[32] 14407-12 (2010).

167. C. R. Arciola, "Host defense against implant infection: the ambivalent role of phagocytosis," Int. J. Artif. Organs, 33[9] 565-67 (2010).

168. R. Patel, "Biofilms and antimicrobial resistance," Clin. Orthop. Relat. R., 437 41-47 (2005). 
169. H. Ceri, M. Olson, C. Stremick, R. Read, D. Morck, and A. Buret, "The Calgary Biofilm Device: new technology for rapid determination of antibiotic susceptibilities of bacterial biofilms," J. Clin. Microbiol., 37[6] 1771-76 (1999).

170. E. E. Braxton, G. D. Ehrlich, L. Hall-Stoodley, P. Stoodley, R. Veeh, C. Fux, F. Z. Hu, M. Quigley, and J. C. Post, "Role of biofilms in neurosurgical device-related infections," Neurosurg. Rev., 28[4] 249-55 (2005).

171. H. Oonishi, M. Yamamoto, H. Ishimaru, E. Tsuji, S. Kushitani, M. Aono, and Y. Ukon, "The effect of hydroxyapatite coating on bone growth into porous titanium alloy implants," Bone Joint J., 71[2] 213-16 (1989).

172. A. Montali, "Antibacterial coating systems," Injury, 37[2] S81-S86 (2006).

173. R. Geesink, K. de Groot, and C. Klein, "Bonding of bone to apatite-coated implants," J. Bone Joint Sur. Br., 70[1] 17-22 (1988).

174. E. Mohseni, E. Zalnezhad, and A. Bushroa, "Comparative investigation on the adhesion of hydroxyapatite coating on Ti-6Al-4V implant: A review paper," Int. J. Adhes. Adhes., 48 238-57 (2014).

175. S. B. Goodman, Z. Yao, M. Keeney, and F. Yang, "The future of biologic coatings for orthopaedic implants," Biomaterials., 34[13] 3174-83 (2013).

176. R. G. Geesink, K. De Groot, and C. P. Klein, "Chemical Implant Fixation Using HydroxylApatite Coatings: The Development of a Human Total Hip Prosthesis for Chemical Fixation to Bone Using Hydroxyl-Apatite Coatings on Titanium Substrates," Clin. Orthop. Relat. R., 225 14770 (1987).

177. T. Albrektsson, P.-I. Brånemark, H.-A. Hansson, and J. Lindström, "Osseointegrated titanium implants: requirements for ensuring a long-lasting, direct bone-to-implant anchorage in man," Acta Orthop. Scand., 52[2] 155-70 (1981).

178. E. Mohseni, E. Zalnezhad, and A. R. Bushroa, "Comparative investigation on the adhesion of hydroxyapatite coating on Ti-6Al-4V implant: A review paper," Int. J. Adhes. Adhes., 48 23857 (2014).

179. R. Geesink, K. de Groot, and C. Klein, "Bonding of bone to apatite-coated implants," Bone Joint J., 70[1] 17-22 (1988).

180. P. Ducheyne, S. Radin, and L. King, "The effect of calcium phosphate ceramic composition and structure on in vitro behavior. I. Dissolution," J. Biomed. Mater. Res. A, 27[1] 25-34 (1993).

181. K. A. Gross, C. C. Berndt, D. D. Goldschlag, and V. J. Iacono, "In vitro changes of hydroxyapatite coatings," Int. J. Oral Max. Impl., 12[5] (1997). 
182. A. Herrera, J. Mateo, J. Gil-Albarova, A. Lobo-Escolar, E. Ibarz, S. Gabarre, Y. Más, and L. Gracia, "Cementless Hydroxyapatite Coated Hip Prostheses," BioMed Res. Int. (2015).

183. J.-H. Cho, J. P. Garino, S.-K. Choo, K.-Y. Han, J.-H. Kim, and H.-K. Oh, "Seven-year results of a tapered, titanium, hydroxyapatite-coated cementless femoral stem in primary total hip arthroplasty," Clin. Orthop. Surg., 2[4] 214-20 (2010).

184. M. Coathup, G. Blunn, N. Flynn, C. Williams, and N. Thomas, "A comparison of bone remodelling around hydroxyapatite-coated, porous-coated and grit-blasted hip replacements retrieved at post-mortem," Bone Joint J., 83[1] 118-23 (2001).

185. Y. Ghani, M. J. Coathup, K. A. Hing, and G. W. Blunn, "Development of a hydroxyapatite coating containing silver for the prevention of peri-prosthetic infection," J. Orthopaed. Res., 30[3] 356-63 (2012).

186. Q. Feng, F. Cui, T. Kim, and J. Kim, "Ag-substituted hydroxyapatite coatings with both antimicrobial effects and biocompatibility," J. Mater. Sci. Lett., 18[7] 559-61 (1999).

187. Y. Chen, X. Zheng, Y. Xie, C. Ding, H. Ruan, and C. Fan, "Anti-bacterial and cytotoxic properties of plasma sprayed silver-containing HA coatings," J. Mater. Sci. - Mater. Med., 19[12] 3603-09 (2008).

188. W. Chen, Y. Liu, H. Courtney, M. Bettenga, C. Agrawal, J. Bumgardner, and J. Ong, "In vitro anti-bacterial and biological properties of magnetron co-sputtered silver-containing hydroxyapatite coating," Biomaterials., 27[32] 5512-17 (2006).

189. S. Liau, D. Read, W. Pugh, J. Furr, and A. Russell, "Interaction of silver nitrate with readily identifiable groups: relationship to the antibacterialaction of silver ions," Lett. Appl. Microbiol., 25[4] 279-83 (1997).

190. S. Overgaard, "Calcium phosphate coatings for fixation of bone implants. Evaluated mechanically and histologically by stereological methods," Acta orthop., 71[s297] 1-74 (2001).

191. J. L. Ong, D. L. Carnes, and K. Bessho, "Evaluation of titanium plasma-sprayed and plasmasprayed hydroxyapatite implants in vivo," Biomaterials., 25[19] 4601-06 (2004).

192. G. Darimont, R. Cloots, E. Heinen, L. Seidel, and R. Legrand, "In vivo behaviour of hydroxyapatite coatings on titanium implants: a quantitative study in the rabbit," Biomaterials., 23[12] 2569-75 (2002).

193. R. Pilliar, D. Deporter, P. Watson, M. Pharoah, M. Chipman, N. Valiquette, S. Carter, and K. De Groot, "The effect of partial coating with hydroxyapatite on bone remodeling in relation to porous-coated titanium-alloy dental implants in the dog," J. Dent. Res., 70[10] 1338-45 (1991). 
194. S. Nakamura, R. Otsuka, H. Aoki, M. Akao, N. Miura, and T. Yamamoto, "Thermal expansion of hydroxyapatite- $\beta$-tricalcium phosphate ceramics," Thermochimica acta, 165[1] 5772 (1990).

195. Y.-C. Yang and E. Chang, "Measurements of residual stresses in plasma-sprayed hydroxyapatite coatings on titanium alloy," Surf. Coat. Technol., 190[1] 122-31 (2005).

196. J. Elmer, T. Palmer, S. Babu, and E. Specht, "In situ observations of lattice expansion and transformation rates of $\alpha$ and $\beta$ phases in Ti-6Al-4V," Mater. Sci. Eng., A, 391[1] 104-13 (2005).

197. Y.-P. Lu, M.-S. Li, S.-T. Li, Z.-G. Wang, and R.-F. Zhu, "Plasma-sprayed hydroxyapatite titania composite bond coat for hydroxyapatite coating on titanium substrate," Biomaterials., 25[18] 4393-403 (2004).

198. S. Zhang, Y. Wang, X. Zeng, K. Cheng, M. Qian, D. Sun, W. Weng, and W. Chia, "Evaluation of interfacial shear strength and residual stress of sol-gel derived fluoridated hydroxyapatite coatings on Ti6Al4V substrates," Eng. Fract. Mech., 74[12] 1884-93 (2007).

199. Y. Tsui, C. Doyle, and T. Clyne, "Plasma sprayed hydroxyapatite coatings on titanium substrates Part 1: Mechanical properties and residual stress levels," Biomaterials., 19[22] 2015-29 (1998).

200. V. Sergo, O. Sbaizero, and D. R. Clarke, "Mechanical and chemical consequences of the residual stresses in plasma sprayed hydroxyapatite coatings," Biomaterials., 18[6] 477-82 (1997).

201. X. Chen, M. Zhang, X. Pu, G. Yin, X. Liao, Z. Huang, and Y. Yao, "Characteristics of heattreated plasma-sprayed $\mathrm{CaO}-\mathrm{MgO}-\mathrm{SiO}_{2}$-based bioactive glass-ceramic coatings on $\mathrm{Ti}-6 \mathrm{Al}-4 \mathrm{~V}$ alloy," Surf. Coat. Technol., 249[0] 97-103 (2014).

202. G. Greaves, A. Fontaine, P. Lagarde, D. Raoux, and S. Gurman, "Local structure of silicate glasses," Nature, 293 611-16 (1981).

203. R. K. Brow, R. J. Kirkpatrick, and G. L. Turner, "The short range structure of sodium phosphate glasses I. MAS NMR studies," J. Non-cryst. Solids., 116[1] 39-45 (1990).

204. C.-P. P. Chou and D. Turnbull, "Transformation behavior of Pd $\square$ Au $\square$ Si metallic glasses," J. Non-cryst. Solids., 17[2] 169-88 (1975).

205. P. G. Debenedetti and F. H. Stillinger, "Supercooled liquids and the glass transition," Nature, 410[6825] 259-67 (2001).

206. J. E. Shelby, "Introduction to glass science and technology." Royal Society of Chemistry, (2005). 
207. P. G. Debenedetti, T. M. Truskett, C. P. Lewis, and F. H. Stillinger, "Theory of supercooled liquids and glasses: Energy landscape and statistical geometry perspectives," Adv. Chem. Eng., 28 21-79 (2001).

208. E. B. Moore and V. Molinero, "Structural transformation in supercooled water controls the crystallization rate of ice," Nature, 479[7374] 506-08 (2011).

209. D. Turnbull, "Under what conditions can a glass be formed?," Contemp. Phys., 10[5] 473-88 (1969).

210. M. Amsler, J. A. Flores-Livas, L. Lehtovaara, F. Balima, S. A. Ghasemi, D. Machon, S. Pailhes, A. Willand, D. Caliste, and S. Botti, "Crystal structure of cold compressed graphite," Phys. Rev. Lett., 108[6] 065501 (2012).

211. D. Turnbull, "Formation of crystal nuclei in liquid metals," J. Appl. Phys., 21[10] 1022-28 (1950).

212. C. A. Angell, "Structural instability and relaxation in liquid and glassy phases near the fragile liquid limit," J. Non-cryst. Solids., 102[1-3] 205-21 (1988).

213. O. Narayanaswamy, "A model of structural relaxation in glass," J. Am. Ceram. Soc., 54[10] 491-98 (1971).

214. C. A. Angell, K. L. Ngai, G. B. McKenna, P. F. McMillan, and S. W. Martin, "Relaxation in glassforming liquids and amorphous solids," J. Appl. Phys., 88[6] 3113-57 (2000).

215. H. Fecht and W. Johnson, "Entropy and enthalpy catastrophe as a stability limit for crystalline material," Nature, 334[6177] 50-51 (1988).

216. M. G. Tucker, M. T. Dove, and D. A. Keen, "Application of the reverse Monte Carlo method to crystalline materials," J. Appl. Crystallogr., 34[5] 630-38 (2001).

217. S. A. Brawer and W. B. White, "Raman spectroscopic investigation of the structure of silicate glasses. I. The binary alkali silicates," J. Chem. Phys., 63[6] 2421-32 (1975).

218. R. Bell and P. Dean, "The structure of vitreous silica: Validity of the random network theory," Philos. Mag., 25[6] 1381-98 (1972).

219. W. H. Zachariasen, "The atomic arrangement in glass," J. Am. Chem. Soc., 54[10] 3841-51 (1932).

220. K. H. Sun, "Fundamental condition of glass formation," J. Am. Ceram. Soc., 30[9] 277-81 (1947).

221. R. Bell, N. Bird, and P. Dean, "The vibrational spectra of vitreous silica, germania and beryllium fluoride," J. Phys. C Solid State Phys., 1[2] 299 (1968). 
222. R. Kerner and J. Phillips, "Quantitative principles of silicate glass chemistry," Solid State Commun., 117[1] 47-51 (2000).

223. U. Hoppe, "A structural model for phosphate glasses," J. Non-cryst. Solids., 195[1-2] 138-47 (1996).

224. D. Zielniok, C. Cramer, and H. Eckert, "Structure/Property Correlations in Ion-Conducting Mixed-Network Former Glasses: Solid-State NMR Studies of the System $\mathrm{Na}_{2} \mathrm{O}-\mathrm{B}_{2} \mathrm{O}_{3}-\mathrm{P}_{2} \mathrm{O}_{5}$," Chem. Mater., 19[13] 3162-70 (2007).

225. D. Larink, H. Eckert, M. Reichert, and S. W. Martin, "Mixed Network Former Effect in IonConducting Alkali Borophosphate Glasses: Structure/Property Correlations in the System $\left[\mathrm{M}_{2} \mathrm{O}\right]$ $1 / 3\left[\left(\mathrm{~B}_{2} \mathrm{O}_{3}\right) \times\left(\mathrm{P}_{2} \mathrm{O}_{5}\right) 1-\mathrm{x}\right] 2 / 3$ (M= Li, K, Cs)," J. Phys. Chem. C, 116[50] 26162-76 (2012).

226. R. Youngman and J. Zwanziger, "Multiple boron sites in borate glass detected with dynamic angle spinning nuclear magnetic resonance," J. Non-cryst. Solids., 168[3] 293-97 (1994).

227. G. J. Mohini, N. Krishnamacharyulu, G. S. Baskaran, P. V. Rao, and N. Veeraiah, "Studies on influence of aluminium ions on the bioactivity of $\mathrm{B}_{2} \mathrm{O}_{3}-\mathrm{SiO}_{2}-\mathrm{P}_{2} \mathrm{O}_{5}-\mathrm{Na}_{2} \mathrm{O}-\mathrm{CaO}$ glass system by means of spectroscopic studies," Appl. Surf. Sci., 287 46-53 (2013).

228. J. W. Chan, T. Huser, S. Risbud, and D. Krol, "Modification of the fused silica glass network associated with waveguide fabrication using femtosecond laser pulses," Appl. Phys. A, 76[3] 36772 (2003).

229. Y. Nageno, H. Takebe, K. Morinaga, and T. Izumitani, "Effect of modifier ions on fluorescence and absorption of $\mathrm{Eu}^{3+}$ in alkali and alkaline earth silicate glasses," J. Non-cryst. Solids., 169[3] 288-94 (1994).

230. Y. Yiannopoulos, G. D. Chryssikos, and E. Kamitsos, "Structure and properties of alkaline earth borate glasses," Phys. Chem. Glasses., 42[3] 164-72 (2001).

231. T. J. Pinnavaia, I. D. Johnson, and M. Lipsicas, "A ${ }^{29} \mathrm{Si}$ MAS NMR study of tetrahedral site distributions in the layered silicic acid $\mathrm{H}^{+}$-magadiite $\left(\mathrm{H}_{2} \mathrm{Si}_{14} \mathrm{O}{ }_{2} \cdot{ }_{9} \cdot \mathrm{nH}_{2} \mathrm{O}\right)$ and in Na+-magadiite $\left(\mathrm{Na}_{2} \mathrm{Si}_{14} \mathrm{O}_{29} \cdot \mathrm{nH}_{2} \mathrm{O}\right)$," J. Solid State Chem., 63[1] 118-21 (1986).

232. N. Zotov and H. Keppler, "The influence of water on the structure of hydrous sodium tetrasilicate glasses," Am. Mineral., 83[7-8] 823-34 (1998).

233. S. Ispas, M. Benoit, P. Jund, and R. Jullien, "Structural and electronic properties of the sodium tetrasilicate glass Na $2 \mathrm{Si} 4 \mathrm{O} 9$ from classical and ab initio molecular dynamics simulations," Phys. Rev. B, 64[21] 214206 (2001).

234. K. Wallace, R. Hill, J. Pembroke, C. Brown, and P. Hatton, "Influence of sodium oxide content on bioactive glass properties," J. Mater. Sci. - Mater. Med., 10[12] 697-701 (1999). 
235. R. Hill, "An alternative view of the degradation of bioglass," J. Mater. Sci. Lett., 15[13] 112225 (1996).

236. W. G. Woods, "An introduction to boron: history, sources, uses, and chemistry," Environ. Health Pers., 102[Suppl 7] 5 (1994).

237. Y. Cheng, H. Xiao, C. Shuguang, and B. Tang, "Structure and crystallization of $\mathrm{B}_{2} \mathrm{O}_{3}-\mathrm{Al}_{2} \mathrm{O}_{3}-$ $\mathrm{SiO}_{2}$ glasses," Physica B Condens. Matter., 404[8] 1230-34 (2009).

238. L. L. Hench, "The story of Bioglass®," J. Mater. Sci. - Mater. Med., 17[11] 967-78 (2006).

239. L. L. Hench, R. J. Splinter, W. Allen, and T. Greenlee, "Bonding mechanisms at the interface of ceramic prosthetic materials," J. Biomed. Mater. Res., 5[6] 117-41 (1971).

240. L. L. Hench and H. Paschall, "Direct chemical bond of bioactive glass-ceramic materials to bone and muscle," J. Biomed. Mater. Res. A, 7[3] 25-42 (1973).

241. L. Hench, A. Clark, and H. Schaake, "Effects of microstructure on the radiation stability of amorphous semiconductors," J. Non-cryst. Solids., 8 837-43 (1972).

242. J. Jones and A. Clare, "Bio-glasses: an introduction." John Wiley \& Sons, (2012).

243. L. L. Hench, "Chronology of bioactive glass development and clinical applications," N. J. G. C., 37 (2013).

244. C. Chemarin and B. Champagnon, "Medium range order in sodium silicate glasses: role of the network modifier," J. Non-cryst. Solids., 243[2] 281-84 (1999).

245. R. M. Day, A. R. Boccaccini, S. Shurey, J. A. Roether, A. Forbes, L. L. Hench, and S. M. Gabe, "Assessment of polyglycolic acid mesh and bioactive glass for soft-tissue engineering scaffolds," Biomaterials., 25[27] 5857-66 (2004).

246. M. N. Rahaman, D. E. Day, B. S. Bal, Q. Fu, S. B. Jung, L. F. Bonewald, and A. P. Tomsia, "Bioactive glass in tissue engineering," Acta Biomater., 7[6] 2355-73 (2011).

247. S. Verrier, J. J. Blaker, V. Maquet, L. L. Hench, and A. R. Boccaccini, "PDLLA/Bioglass® composites for soft-tissue and hard-tissue engineering: an in vitro cell biology assessment," Biomaterials., 25[15] 3013-21 (2004).

248. L. Bi, S. Jung, D. Day, K. Neidig, V. Dusevich, D. Eick, and L. Bonewald, "Evaluation of bone regeneration, angiogenesis, and hydroxyapatite conversion in critical-sized rat calvarial defects implanted with bioactive glass scaffolds," J. Biomed. Mater. Res. A, 100[12] 3267-75 (2012). 
249. Q. Fu, M. N. Rahaman, H. Fu, and X. Liu, "Silicate, borosilicate, and borate bioactive glass scaffolds with controllable degradation rate for bone tissue engineering applications. I. Preparation and in vitro degradation," J. Biomed. Mater. Res. A, 95[1] 164-71 (2010).

250. Z. Xie, X. Liu, W. Jia, C. Zhang, W. Huang, and J. Wang, "Treatment of osteomyelitis and repair of bone defect by degradable bioactive borate glass releasing vancomycin," J. Control Release., 139[2] 118-26 (2009).

251. L. L. Hench, D. E. Day, W. Höland, and V. M. Rheinberger, "Glass and medicine," Int. J. App.Glass Sci., 1[1] 104-17 (2010).

252. T. Albrektsson and C. Johansson, "Osteoinduction, osteoconduction and osseointegration," Eur. Spine. J., 10[2] S96-S101 (2001).

253. L. L. Hench, "Bioceramics: from concept to clinic," J. Am. Ceram. Soc., 74[7] 1487-510 (1991).

254. D. D. Deligianni, N. D. Katsala, P. G. Koutsoukos, and Y. F. Missirlis, "Effect of surface roughness of hydroxyapatite on human bone marrow cell adhesion, proliferation, differentiation and detachment strength," Biomaterials., 22[1] 87-96 (2000).

255. T. Albrektsson and C. Johansson, "Osteoinduction, osteoconduction and osseointegration," Eur. Spine. J., 10 S96-S101 (2001).

256. J. Wilson-Hench, "Osteoinduction," Progress in biomedical engineering, 429 (1987).

257. H. Oonishi, L. Hench, J. Wilson, F. Sugihara, E. Tsuji, M. Matsuura, S. Kin, T. Yamamoto, and S. Mizokawa, "Quantitative comparison of bone growth behavior in granules of Bioglass, AW glass-ceramic, and hydroxyapatite," J. Biomed. Mater. Res., 51[1] 37-46 (2000).

258. S. Maeno, Y. Niki, H. Matsumoto, H. Morioka, T. Yatabe, A. Funayama, Y. Toyama, T. Taguchi, and J. Tanaka, "The effect of calcium ion concentration on osteoblast viability, proliferation and differentiation in monolayer and 3D culture," Biomaterials., 26[23] 4847-55 (2005).

259. P. J. Marie, "The calcium-sensing receptor in bone cells: a potential therapeutic target in osteoporosis," Bone, 46[3] 571-76 (2010).

260. P. Valerio, M. Pereira, A. Goes, and M. F. Leite, "Effects of extracellular calcium concentration on the glutamate release by bioactive glass (BG60S) preincubated osteoblasts," Biomed. Mater., 4[4] 045011 (2009).

261. I.-S. Kwun, Y.-E. Cho, R.-A. R. Lomeda, H.-I. Shin, J.-Y. Choi, Y.-H. Kang, and J. H. Beattie, "Zinc deficiency suppresses matrix mineralization and retards osteogenesis transiently with catchup possibly through Runx 2 modulation," Bone, 46[3] 732-41 (2010). 
262. E. Saino, S. Grandi, E. Quartarone, V. Maliardi, D. Galli, N. Bloise, L. Fassina, M. De Angelis, P. Mustarelli, and M. Imbriani, "In vitro calcified matrix deposition by human osteoblasts onto a zinc-containing bioactive glass," Eur. Cell Mater., 21[2] 59-72 (2011).

263. J. Isaac, J. Nohra, J. Lao, E. Jallot, J.-M. Nedelec, A. Berdal, and J.-M. Sautier, "Effects of strontium-doped bioactive glass on the differentiation of cultured osteogenic cells," Eur. Cell Mater., 21 130-43 (2011).

264. Y. Takuwa, C. Ohse, E. A. Wang, J. M. Wozney, and K. Yamashita, "Bone morphogenetic protein-2 stimulates alkaline phosphatase activity and collagen synthesis in cultured osteoblastic cells, MC3T3-E1," Biochem. Bioph. Res. Co, 174[1] 96-101 (1991).

265. E. Bergeron, M. Marquis, I. Chretien, and N. Faucheux, "Differentiation of preosteoblasts using a delivery system with BMPs and bioactive glass microspheres," J. Mater. Sci. - Mater. Med., 18[2] 255-63 (2007).

266. K. Leung, K. Fung, A. Sher, C. Li, and K. Lee, "Plasma bone-specific alkaline phosphatase as an indicator of osteoblastic activity," Bone Joint J., 75[2] 288-92 (1993).

267. G. E. Merwin, "Bioglass middle ear prosthesis: preliminary report," Ann. Otol. Rhinol. Laryngol., 95[1] 78-82 (1986).

268. K. R. Rust, G. T. Singleton, J. Wilson, and P. J. Antonelli, "Bioglass middle ear prosthesis: long-term results," Otol. Neurotol., 17[3] 371-74 (1996).

269. I. Izquierdo-Barba, A. J. Salinas, and M. Vallet-Regí, "Bioactive glasses: from macro to nano," Int. J. App.Glass Sci., 4[2] 149-61 (2013).

270. H. R. Stanley, M. B. Hall, A. E. Clark, C. J. King III, L. L. Hench, and J. J. Berte, "Using 45S5 bioglass cones as endosseous ridge maintenance implants to prevent alveolar ridge resorption: a 5-year evaluation," Int. J. Oral Max. Impl., 12[1] (1997).

271. A. Fetner, M. Hartigan, and S. Low, "Periodontal repair using PerioGlas in nonhuman primates: clinical and histologic observations," Compendium (Newtown, Pa.), 15[7] 932, 35-8; quiz 39 (1994).

272. D. Carmagnola, S. Abati, S. Celestino, M. Chiapasco, D. Bosshardt, and N. P. Lang, "Oral implants placed in bone defects treated with Bio-Oss ${ }^{\circledR}$, Ostim ${ }^{\circledR}$-Paste or PerioGlas: an experimental study in the rabbit tibiae," Clin. Oral Implan. Res, 19[12] 1246-53 (2008).

273. S. B. Low, C. J. King, and J. Krieger, "An evaluation of bioactive ceramic in the treatment of periodontal osseous defects," Int. J. Periodont. Rest, 17[4] (1997).

274. E. S. Rosenberg, S.-C. Cho, N. Elian, Z. N. Jalbout, S. Froum, and C. I. Evian, "A comparison of characteristics of implant failure and survival in periodontally compromised and periodontally healthy patients: a clinical report," Int. J Oral. Maxillofac. Implants, 19[6] 873-79 (2004). 
275. J. Zamet, U. Darbar, G. Griffiths, W. Burgin, and H. Newman, "Particulate bioglass (Perioglas R) in the treatment of periodontal intrabony defects," J. Dent. Res., 76[Specia] 291-91 (1997).

276. G. K. Sándor, J. Numminen, J. Wolff, T. Thesleff, A. Miettinen, V. J. Tuovinen, B. Mannerström, M. Patrikoski, R. Seppänen, and S. Miettinen, "Adipose Stem Cells Used to Reconstruct 13 Cases With Cranio-Maxillofacial Hard-Tissue Defects," Stem Cells Transl. Med., 3[4] 530-40 (2014).

277. M. Peltola, K. Aitasalo, J. Suonpää, M. Varpula, and A. Yli-Urpo, "Bioactive glass S53P4 in frontal sinus obliteration: A long-term clinical experience," Head \& neck, 28[9] 834-41 (2006).

278. N. Lindfors, P. Hyvönen, M. Nyyssönen, M. Kirjavainen, J. Kankare, E. Gullichsen, and J. Salo, "Bioactive glass S53P4 as bone graft substitute in treatment of osteomyelitis," Bone, 47[2] 212-18 (2010).

279. J. McAndrew, C. Efrimescu, E. Sheehan, and D. Niall, "Through the looking glass; bioactive glass S53P4 (BonAlive $\left.{ }^{\circledR}\right)$ in the treatment of chronic osteomyelitis," Irish J. Med. Sci., 182[3] 509-11 (2013).

280. J. Gomez-Vega, E. Saiz, A. Tomsia, G. Marshall, and S. Marshall, "Bioactive glass coatings with hydroxyapatite and Bioglass ${ }^{\circledR}$ particles on Ti-based implants. 1. Processing," Biomaterials., 21[2] 105-11 (2000).

281. D. Bellucci, V. Cannillo, and A. Sola, "Coefficient of thermal expansion of bioactive glasses: Available literature data and analytical equation estimates," Ceram. Int., 37[8] 2963-72 (2011).

282. L. Peddi, R. K. Brow, and R. F. Brown, "Bioactive borate glass coatings for titanium alloys," J. Mater. Sci. - Mater. Med., 19[9] 3145-52 (2008).

283. I. Donald, P. Mallinson, B. Metcalfe, L. Gerrard, and J. Fernie, "Recent developments in the preparation, characterization and applications of glass-and glass-ceramic-to-metal seals and coatings," J. Mater. Sci., 46[7] 1975-2000 (2011).

284. J. Pavon, E. Jimenez-Pique, M. Anglada, S. Lopez-Esteban, E. Saiz, and A. Tomsia, "Stresscorrosion cracking by indentation techniques of a glass coating on Ti6Al4V for biomedical applications," J. Eur. Ceram. Soc., 26[7] 1159-69 (2006).

285. X. Chen, M. Zhang, X. Pu, G. Yin, X. Liao, Z. Huang, and Y. Yao, "Characteristics of heattreated plasma-sprayed $\mathrm{CaO}-\mathrm{MgO}-\mathrm{SiO}_{2}$-based bioactive glass-ceramic coatings on $\mathrm{Ti}-6 \mathrm{Al}-4 \mathrm{~V}$ alloy," Surf. Coat. Technol., 249 97-103 (2014).

286. X. Chen, X. Liao, Z. Huang, P. You, C. Chen, Y. Kang, and G. Yin, "Synthesis and characterization of novel multiphase bioactive glass-ceramics in the $\mathrm{CaO}-\mathrm{MgO}-\mathrm{SiO}_{2}$ system," $J$. Biomed. Mater. Res. Part B Appl. Biomater., 93[1] 194-202 (2010). 
287. S. Lopez-Esteban, E. Saiz, S. Fujino, T. Oku, K. Suganuma, and A. P. Tomsia, "Bioactive glass coatings for orthopedic metallic implants," J. Eur. Ceram. Soc., 23[15] 2921-30 (2003).

288. E. Saiz, M. Goldman, J. M. Gomez-Vega, A. P. Tomsia, G. W. Marshall, and S. J. Marshall, "In vitro behavior of silicate glass coatings on Ti6Al4V," Biomaterials., 23[17] 3749-56 (2002).

289. J. Gomez-Vega, E. Saiz, and A. Tomsia, "Glass-based coatings for titanium implant alloys," J. Biomed. Mater. Res. A, 46[4] 549-59 (1999).

290. M. O’Donnell and R. Hill, "Influence of strontium and the importance of glass chemistry and structure when designing bioactive glasses for bone regeneration," Acta Biomater., 6[7] 2382-85 (2010).

291. W. L. Konijnendijk and J. M. Stevels, "The structure of borate glasses studied by Raman scattering," J. Non-cryst. Solids., 18[3] 307-31 (1975).

292. R. L. Mozzi and B. Warren, "The structure of vitreous boron oxide," J. Appl. Crystallogr., 3[4] 251-57 (1970).

293. D. Grseom, "Borate Glasses Structure, Properties and Applications," Plenum Press, New York (1978).

294. A. Silver and P. Bray, "Nuclear Magnetic Resonance Absorption in Glass. I. Nuclear Quadrupole Effects in Boron Oxide, Soda-Boric Oxide, and Borosilicate Glasses," J. Chem. Phys., 29[5] 984-90 (1958).

295. G. Jellison and P. Bray, "A structural interpretation of $\mathrm{B}^{10}$ and $\mathrm{B}^{11}$ NMR spectra in sodium borate glasses," J. Non-cryst. Solids., 29[2] 187-206 (1978).

296. Y. Yiannopoulos, G. D. Chryssikos, and E. Kamitsos, "Structure and properties of alkaline earth borate glasses," Phys. Chem. Glasses-B., 42[3] 164-72 (2001).

297. T. Yano, N. Kunimine, S. Shibata, and M. Yamane, "Structural investigation of sodium borate glasses and melts by Raman spectroscopy. II. Conversion between $\mathrm{BO}_{4}$ and $\mathrm{BO}_{2} \mathrm{O}^{-}$units at high temperature," J. Non-cryst. Solids., 321[3] 147-56 (2003).

298. W. Huang, M. N. Rahaman, D. E. Day, and Y. Li, "Mechanisms for converting bioactive silicate, borate, and borosilicate glasses to hydroxyapatite in dilute phosphate solution," Phys. Chem. Glasses., 47[6] 647-58 (2006).

299. W. Huang, M. N. Rahaman, D. E. Day, and Y. Li, "Mechanisms for converting bioactive silicate, borate, and borosilicate glasses to hydroxyapatite in dilute phosphate solution," Phys. Chem. Glasses-B., 47[6] 647-58 (2006).

300. S. B. Jung and D. E. Day, "Conversion kinetics of silicate, borosilicate, and borate bioactive glasses to hydroxyapatite," Phys. Chem. Glasses-B, 50[2] 85-88 (2009). 
301. J. A. Wojcik, "Hydroxyapatite formation on a silicate and borate glass," (1999).

302. W. Huang, D. E. Day, K. Kittiratanapiboon, and M. N. Rahaman, "Kinetics and mechanisms of the conversion of silicate (45S5), borate, and borosilicate glasses to hydroxyapatite in dilute phosphate solutions," J. Mater. Sci. - Mater. Med., 17[7] 583-96 (2006).

303. P. Lopes, B. L. Ferreira, P. Gomes, R. Correia, M. Fernandes, and M. Fernandes, "Silicate and borate glasses as composite fillers: a bioactivity and biocompatibility study," J. Mater. Sci. Mater. Med., 22[6] 1501-10 (2011).

304. A. El-Ghannam, P. Ducheyne, and I. M. Shapiro, "Bioactive material template for in vitro, synthesis of bone," J. Biomed. Mater. Res., 29[3] 359-70 (1995).

305. R. F. Brown, M. N. Rahaman, A. B. Dwilewicz, W. Huang, D. E. Day, Y. Li, and B. S. Bal, "Effect of borate glass composition on its conversion to hydroxyapatite and on the proliferation of MC3T3-E1 cells," J. Biomed. Mater. Res. A, 88[2] 392-400 (2009).

306. L. Sun, C. C. Berndt, K. A. Gross, and A. Kucuk, "Material fundamentals and clinical performance of plasma-sprayed hydroxyapatite coatings: a review," J. Biomed. Mater. Res., 58[5] 570-92 (2001).

307. J. R. Jones, "Review of bioactive glass: from Hench to hybrids," Acta Biomater., 9[1] 445786 (2013).

308. T. R. Arnett, "Acid-base regulation of bone metabolism," pp. 255-67 in Int. Congr. Ser. Vol. 1297.

309. J. R. Jones, L. M. Ehrenfried, and L. L. Hench, "Optimising bioactive glass scaffolds for bone tissue engineering," Biomaterials., 27[7] 964-73 (2006).

310. Q. Fu, E. Saiz, M. N. Rahaman, and A. P. Tomsia, "Bioactive glass scaffolds for bone tissue engineering: state of the art and future perspectives," Mater. Sci. Eng. C, 31[7] 1245-56 (2011).

311. K. Kolan, "Borate Bioactive Glass Scaffolds Made By The Selective Laser Sintering Process," pp. 816-26. in Proceedings of the 24th Annual International Solid Freeform Fabrication Symposium. Rolla, Missouri, 2014.

312. X. Liu, H. Pan, H. Fu, Q. Fu, M. N. Rahaman, and W. Huang, "Conversion of borate-based glass scaffold to hydroxyapatite in a dilute phosphate solution," Biomed. Mater., 5[1] 015005 (2010).

313. Y. Gu, W. Huang, M. N. Rahaman, and D. E. Day, "Bone regeneration in rat calvarial defects implanted with fibrous scaffolds composed of a mixture of silicate and borate bioactive glasses," Acta Biomater., 9[11] 9126-36 (2013). 
314. L. Bi, B. Zobell, X. Liu, M. N. Rahaman, and L. F. Bonewald, "Healing of critical-size segmental defects in rat femora using strong porous bioactive glass scaffolds," Mater. Sci. Eng. C, 42 816-24 (2014).

315. S. B. Jung, "Borate based bioactive glass scaffolds for hard and soft tissue engineering." in, Vol. PhD. Missouri University of Science and Technology, 2010.

316. S. Zhao, L. Li, H. Wang, Y. Zhang, X. Cheng, N. Zhou, M. N. Rahaman, Z. Liu, W. Huang, and C. Zhang, "Wound dressings composed of copper-doped borate bioactive glass microfibers stimulate angiogenesis and heal full-thickness skin defects in a rodent model," Biomaterials., 53 379-91 (2015).

317. P. Wray, "Cotton candy'that heals," Am. Ceram. Soc. Bull., 90[4] 24-31 (2011).

318. G. Mohammad, H. Pandey, and K. Tripathib, "Diabetic wound healing and its angiogenesis with special reference to nanoparticles," Dig. J. Nanomater. Bios., 3 203-08 (2008).

319. Y. Lin, R. F. Brown, S. B. Jung, and D. E. Day, "Angiogenic effects of borate glass microfibers in a rodent model," J. Biomed. Mater. Res. A, 102[12] 4491-99 (2014).

320. R. A. Carano and E. H. Filvaroff, "Angiogenesis and bone repair," Drug Discov. Today, 8[21] 980-89 (2003).

321. L. Bi, M. N. Rahaman, D. E. Day, Z. Brown, C. Samujh, X. Liu, A. Mohammadkhah, V. Dusevich, J. D. Eick, and L. F. Bonewald, "Effect of bioactive borate glass microstructure on bone regeneration, angiogenesis, and hydroxyapatite conversion in a rat calvarial defect model," Acta Biomater., 9[8] 8015-26 (2013).

322. P. Collin-Osdoby, "Role of vascular endothelial cells in bone biology," J. Cell Biochem., 55[3] 304-09 (1994).

323. P. V. Giannoudis, H. Dinopoulos, and E. Tsiridis, "Bone substitutes: an update," Injury, 36[3] S20-S27 (2005).

324. S. Nandi, S. Roy, P. Mukherjee, B. Kundu, D. De, and D. Basu, "Orthopaedic applications of bone graft \& graft substitutes: a review," Indian J. Med. Res., 132 15-30 (2010).

325. H. Ding, C.-J. Zhao, X. Cui, Y.-F. Gu, W.-T. Jia, M. N. Rahaman, Y. Wang, W.-H. Huang, and C.-Q. Zhang, "A novel injectable borate bioactive glass cement as an antibiotic delivery vehicle for treating osteomyelitis," PloS One., 9[1] e85472 (2014).

326. W.-T. Jia, X. Zhang, S.-H. Luo, X. Liu, W.-H. Huang, M. N. Rahaman, D. E. Day, C.-Q. Zhang, Z.-P. Xie, and J.-Q. Wang, "Novel borate glass/chitosan composite as a delivery vehicle for teicoplanin in the treatment of chronic osteomyelitis," Acta Biomater., 6[3] 812-19 (2010). 
327. X. Liu, Z. Xie, C. Zhang, H. Pan, M. N. Rahaman, X. Zhang, Q. Fu, and W. Huang, "Bioactive borate glass scaffolds: in vitro and in vivo evaluation for use as a drug delivery system in the treatment of bone infection," J. Mater. Sci. - Mater. Med., 21[2] 575-82 (2010).

328. X. Zhang, W. Jia, Y. Gu, W. Xiao, X. Liu, D. Wang, C. Zhang, W. Huang, M. N. Rahaman, and D. E. Day, "Teicoplanin-loaded borate bioactive glass implants for treating chronic bone infection in a rabbit tibia osteomyelitis model," Biomaterials., 31[22] 5865-74 (2010).

329. S. A. Goldstein, "The mechanical properties of trabecular bone: dependence on anatomic location and function," J. Biomech., 20[11] 1055-61 (1987).

330. K. Mittal, "Adhesion measurement of thin films," Act. passive electron. compon., 3[1] 21-42 (1976).

331. W. Xiao, S.-H. Luo, X.-J. Wei, C.-Q. Zhang, W.-H. Huang, J.-K. Chen, Y. Cai, Y. Rui, and M. N. Rahaman, "Evaluation of Ti implants coated with Ag-containing borate bioactive glass for simultaneous eradication of infection and fracture fixation in a rabbit tibial model," J. Mater. Res., 27[24] 3147-56 (2012).

332. R. B. Rao, D. K. Rao, and N. Veeraiah, "The role of titanium ions on structural, dielectric and optical properties of $\mathrm{Li}_{2} \mathrm{O}-\mathrm{MgO}-\mathrm{B}_{2} \mathrm{O}_{3}$ glass system," Mater. Chem. Phys., 87[2] 357-69 (2004).

333. P. J. Marie, "Strontium ranelate: new insights into its dual mode of action," Bone, 40[5] S5S8 (2007).

334. D. Gonbeau, C. Guimon, G. Pfister-Guillouzo, A. Levasseur, G. Meunier, and R. Dormoy, "XPS study of thin films of titanium oxysulfides," Surf. Sci., 254[1] 81-89 (1991).

335. A. Wren, A. Coughlan, K. Smale, S. Misture, B. P. Mahon, O. Clarkin, and M. Towler, "Fabrication of $\mathrm{CaO}-\mathrm{NaO}-\mathrm{SiO}_{2} / \mathrm{TiO}_{2}$ scaffolds for surgical applications," J. Mater. Sci. - Mater. Med., 23[12] 2881-91 (2012).

336. A. Wren, F. Laffir, A. Kidari, and M. Towler, "The structural role of titanium in $\mathrm{Ca}-\mathrm{Sr}-\mathrm{Zn}-$ Si/Ti glasses for medical applications," J. Non-cryst. Solids., 357[3] 1021-26 (2011).

337. Y. S. M. Alajerami, S. Hashim, W. M. S. W. Hassan, and A. T. Ramli, "The effect of titanium oxide on the optical properties of lithium potassium borate glass," J. Mol. Struct., 1026 159-67 (2012).

338. Y. Jiang, H. Genant, and J. Zhao, "Effect of strontium ranelate on 3D cortical and trabecular microstructure in postmenopausal osteoporosis in multicenter, double-blind, and placebo controlled studies," pp. S44-S44 in J. Bone. Miner. Res. Vol. 21.

339. P. J. Meunier, C. Roux, E. Seeman, S. Ortolani, J. E. Badurski, T. D. Spector, J. Cannata, A. Balogh, E.-M. Lemmel, and S. Pors-Nielsen, "The effects of strontium ranelate on the risk of 
vertebral fracture in women with postmenopausal osteoporosis," New Engl. J. Med., 350[5] 45968 (2004).

340. E. Gentleman, Y. C. Fredholm, G. Jell, N. Lotfibakhshaiesh, M. D. O'Donnell, R. G. Hill, and M. M. Stevens, "The effects of strontium-substituted bioactive glasses on osteoblasts and osteoclasts in vitro," Biomaterials., 31[14] 3949-56 (2010).

341. C. Wu, Y. Zhou, C. Lin, J. Chang, and Y. Xiao, "Strontium-containing mesoporous bioactive glass scaffolds with improved osteogenic/cementogenic differentiation of periodontal ligament cells for periodontal tissue engineering," Acta Biomater., 8[10] 3805-15 (2012).

342. D. S. Brauer, N. Karpukhina, G. Kedia, A. Bhat, R. V. Law, I. Radecka, and R. G. Hill, "Bactericidal strontium-releasing injectable bone cements based on bioactive glasses," J. R. Soc. Interface rsif20120647 (2012).

343. M. H. Alkhraisat, C. Rueda, J. Cabrejos-Azama, J. Lucas-Aparicio, F. T. Mariño, J. T. GarciaDenche, L. B. Jerez, U. Gbureck, and E. L. Cabarcos, "Loading and release of doxycycline hyclate from strontium-substituted calcium phosphate cement," Acta Biomater., 6[4] 1522-28 (2010).

344. J. Lao, J.-M. Nedelec, and E. Jallot, "New strontium-based bioactive glasses: physicochemical reactivity and delivering capability of biologically active dissolution products," J. Mater. Chem., 19[19] 2940-49 (2009).

345. A. Tilocca, "Sodium migration pathways in multicomponent silicate glasses: Car-Parrinello molecular dynamics simulations," J. Chem. Phys., 133[1] 014701 (2010).

346. J. Christoffersen, M. R. Christoffersen, N. Kolthoff, and O. Bärenholdt, "Effects of strontium ions on growth and dissolution of hydroxyapatite and on bone mineral detection," Bone, 20[1] 4754 (1997).

347. A. Cormack, J. Du, and T. Zeitler, "Alkali ion migration mechanisms in silicate glasses probed by molecular dynamics simulations," Phys. Chem. Chem. Phys., 4[14] 3193-97 (2002).

348. A. Cormack, J. Du, and T. Zeitler, "Sodium ion migration mechanisms in silicate glasses probed by molecular dynamics simulations," J. Non-cryst. Solids., 323[1] 147-54 (2003).

349. R. t. Shannon, "Revised effective ionic radii and systematic studies of interatomic distances in halides and chalcogenides," Acta Crystallographica Section A: Crystal Physics, Diffraction, Theoretical and General Crystallography, 32[5] 751-67 (1976).

350. J. Long, S. Xu, J. Cai, N. Jiang, J. Lu, K. Ostrikov, and C. Diong, "Structure, bonding state and in-vitro study of Ca-P-Ti film deposited on Ti6Al4V by RF magnetron sputtering," Mater. Sci. Eng. C, 20[1] 175-80 (2002).

351. Y. Yang, J. L. Ong, and J. Tian, "Deposition of highly adhesive ZrO 2 coating on Ti and CoCrMo implant materials using plasma spraying," Biomaterials., 24[4] 619-27 (2003). 
352. V. Palka, E. Poštrková, and H. Koerten, "Some characteristics of hydroxylapatite powder particles after plasma spraying," Biomaterials., 19[19] 1763-72 (1998).

353. Y.-C. Yang, E. Chang, and S. Lee, "Mechanical properties and Young's modulus of plasmasprayed hydroxyapatite coating on Ti substrate in simulated body fluid," J. Biomed. Mater. Res. A, 67[3] 886-99 (2003).

354. S. Takeuchi, M. Ito, and K. Takeda, "Modelling of residual stress in plasma-sprayed coatings: Effect of substrate temperature," Surf. Coat. Technol., 43 426-35 (1990).

355. S. Brown, I. Turner, and H. Reiter, "Residual stress measurement in thermal sprayed hydroxyapatite coatings," J. Mater. Sci. - Mater. Med., 5[9] 756-59 (1994).

356. P. Li, Q. Yang, F. Zhang, and T. Kokubo, "The effect of residual glassy phase in a bioactive glass-ceramic on the formation of its surface apatite layerin vitro," J. Mater. Sci. - Mater. Med., 3[6] 452-56 (1992).

357. J. Ma, C. Chen, D. Wang, X. Meng, and J. Shi, "Influence of the sintering temperature on the structural feature and bioactivity of sol-gel derived $\mathrm{SiO}_{2}-\mathrm{CaO}-\mathrm{P}_{2} \mathrm{O}_{5}$ bioglass," Ceram. Int., 36[6] 1911-16 (2010).

358. V. Cannillo and A. Sola, "Different approaches to produce coatings with bioactive glasses: Enamelling vs plasma spraying," J. Eur. Ceram. Soc., 30[10] 2031-39 (2010).

359. S. Martorana, A. Fedele, M. Mazzocchi, and A. Bellosi, "Surface coatings of bioactive glasses on high strength ceramic composites," Appl. Surf. Sci., 255[13] 6679-85 (2009).

360. A. Sola, D. Bellucci, and V. Cannillo, "Enamelled coatings produced with low-alkaline bioactive glasses," Surf. Coat. Technol., 248 1-8 (2014).

361. A. Lynn and D. DuQuesnay, "Hydroxyapatite-coated Ti-6Al-4V: Part 1: the effect of coating thickness on mechanical fatigue behaviour," Biomaterials., 23[9] 1937-46 (2002).

362. C. Kwok, P. Wong, F. Cheng, and H. Man, "Characterization and corrosion behavior of hydroxyapatite coatings on Ti6A14V fabricated by electrophoretic deposition," Appl. Surf. Sci., 255[13] 6736-44 (2009).

363. Z. Mohammadi, A. Ziaei-Moayyed, and A. S.-M. Mesgar, "Adhesive and cohesive properties by indentation method of plasma-sprayed hydroxyapatite coatings," Appl. Surf. Sci., 253[11] 496065 (2007).

364. S. Zhang, Z. Xianting, W. Yongsheng, C. Kui, and W. Wenjian, "Adhesion strength of solgel derived fluoridated hydroxyapatite coatings," Surf. Coat. Technol., 200[22] 6350-54 (2006).

365. M. J. Azizpour, M. Jalali, and H. Fasihi, "Adhesion strength evaluation methods in thermally sprayed coatings," World Acad. Sci. Eng. Technol., 6[1] 337-39 (2012). 
366. G. Singh, S. Singh, and S. Prakash, "Surface characterization of plasma sprayed pure and reinforced hydroxyapatite coating on Ti6Al4V alloy," Surf. Coat. Technol., 205[20] 4814-20 (2011).

367. A. Vencl, S. Arostegui, G. Favaro, F. Zivic, M. Mrdak, S. Mitrović, and V. Popovic, "Evaluation of adhesion/cohesion bond strength of the thick plasma spray coatings by scratch testing on coatings cross-sections," Tribol. Int., 44[11] 1281-88 (2011).

368. S. Journal of Biomedical Materials Research Part ALeeuwenburgh, J. Wolke, L. Lommen, T. Pooters, J. Schoonman, and J. Jansen, "Mechanical properties of porous, electrosprayed calcium phosphate coatings," J. Biomed. Mater. Res. A, 78[3] 558-69 (2006).

369. M. Laugier, "The development of the scratch test technique for the determination of the adhesion of coatings," Thin Solid Films, 76[3] 289-94 (1981).

370. Z. Chen, K. Zhou, X. Lu, and Y. C. Lam, "A review on the mechanical methods for evaluating coating adhesion," Acta Mech., 225[2] 431-52 (2014).

371. Y. Xie and H. Hawthorne, "A model for compressive coating stresses in the scratch adhesion test," Surf. Coat. Technol., 141[1] 15-25 (2001).

372. S. Bull, "Failure mode maps in the thin film scratch adhesion test," Tribol. Int., 30[7] 491-98 (1997).

373. P. Steinmann and H. Hintermann, "A review of the mechanical tests for assessment of thinfilm adhesion," J. Vac. Sci. Technol. A, 7[3] 2267-72 (1989).

374. S. Bull and E. Berasetegui, "An overview of the potential of quantitative coating adhesion measurement by scratch testing," Tribol. Int., 39[2] 99-114 (2006).

375. A. Ameli, M. Papini, and J. Spelt, "Evolution of crack path and fracture surface with degradation in rubber-toughened epoxy adhesive joints: Application to open-faced specimens," Int. J. Adhes. Adhes., 31[6] 530-40 (2011).

376. A. Matinmanesh, O. Rodriguez, M. Towler, P. Zalzal, E. Schemitsch, and M. Papini, "Quantitative evaluation of the adhesion of bioactive glasses onto Ti6Al4V substrates," Mater. Design., 97 213-21 (2016).

377. T. L. Anderson and T. Anderson, "Fracture mechanics: fundamentals and applications." CRC press, (2005).

378. Y. Yu, I. Ashcroft, and G. Swallowe, "An experimental investigation of residual stresses in an epoxy-steel laminate," Int. J. Adhes. Adhes., 26[7] 511-19 (2006).

379. M. H. Protter and P. E. Protter, "Calculus with analytic geometry." Jones \& Bartlett Learning, (1988). 
380. T. Kokubo, H.-M. Kim, and M. Kawashita, "Novel bioactive materials with different mechanical properties," Biomaterials., 24[13] 2161-75 (2003).

381. I. Thompson and L. Hench, "Mechanical properties of bioactive glasses, glass-ceramics and composites," Proc. Inst. Mech. Eng. H., 212[2] 127-36 (1998).

382. Y. B. Saddeek, "Structural and acoustical studies of lead sodium borate glasses," J. Alloy. Compd., 467[1] 14-21 (2009).

383. T. Rouxel, "Elastic Properties and Short-to Medium-Range Order in Glasses," J. Am. Ceram. Soc., 90[10] 3019-39 (2007).

384. A. Makishima and J. D. Mackenzie, "Calculation of bulk modulus, shear modulus and Poisson's ratio of glass," J. Non-cryst. Solids., 17[2] 147-57 (1975).

385. A. A. El-Moneim, "Quantitative analysis of elastic moduli and structure of $\mathrm{B}_{2} \mathrm{O}_{3}-\mathrm{SiO}_{2}$ and $\mathrm{Na}_{2} \mathrm{O}-\mathrm{B}_{2} \mathrm{O}_{3}-\mathrm{SiO}_{2}$ glasses," Physica B Condens. Matter., 325 319-32 (2003).

386. A. Standard, "Annual book of ASTM standards," Vol. 4, (2004).

387. J. Raja, M. Grant, and P. Stumpf, "Surface Texture (Surface Roughness, Waviness, and Lay), An American National Standard." ASME, New York, (1996).

388. G. Fernlund and J. Spelt, "Mixed-mode fracture characterization of adhesive joints," Compos. Sci. Technol., 50[4] 441-49 (1994).

389. L. F. da Silva, D. A. Dillard, B. Blackman, and R. D. Adams, "Testing adhesive joints: best practices." John Wiley \& Sons, (2012).

390. A. Ameli, S. Azari, M. Papini, and J. Spelt, "Characterization and prediction of fracture properties in hygrothermally degraded adhesive joints: an open-faced approach," J. Adhes. Sci. Technol., 27[10] 1080-103 (2013).

391. A. Ameli, N. Datla, S. Azari, M. Papini, and J. Spelt, "Prediction of environmental degradation of closed adhesive joints using data from open-faced specimens," Compos. Struct., 94[2] 779-86 (2012).

392. M. Zehnder, E. Söderling, J. Salonen, and T. Waltimo, "Preliminary evaluation of bioactive glass S53P4 as an endodontic medication in vitro," J. Endodont., 30[4] 220-24 (2004).

393. P. KUISMA-KURSULA and J. Räisänen, "Scanning Electron Microscopy-energy Dispersive Spectrometry and Proton Induced X-RAY Emission Analyses of Medieval Glass From Koroinen " Archaeometry, 41[1] 71-79 (1999).

394. P. Kuisma-Kursula, "Accuracy, precision and detection limits of SEM-WDS, SEM-EDS and PIXE in the multi-elemental analysis of medieval glass," X Ray. Spectrom., 29[1] 111-18 (2000). 
395. M. Verità, R. Basso, M. T. Wypyski, and R. Koestler, "X-Ray Microanalysis Of Ancient Glassy Materials: A Comparative Study of Wavelength Dispersive and Energy Dispersive Techniques," Archaeometry, 36[2] 241-51 (1994).

396. P. Niranatlumpong and $\mathrm{H}$. Koiprasert, "Phase transformation of $\mathrm{NiCrBSi}-\mathrm{WC}$ and $\mathrm{NiBSi}-$ WC arc sprayed coatings," Surf. Coat. Technol., 206[2] 440-45 (2011).

397. M. Friedrich, A. Schulze, G. Prösch, C. Walter, D. Weikert, N. M. Binh, and D. R. Zahn, "Investigation of chemically treated basalt and glass fibres," Microchimica Acta, 133[1-4] 171-74 (2000).

398. M. Vogel, C. Voigt, U. M. Gross, and C. M. Müller-Mai, "In vivo comparison of bioactive glass particles in rabbits," Biomaterials., 22[4] 357-62 (2001).

399. P. Sepulveda, J. Jones, and L. Hench, "In vitro dissolution of melt-derived $45 \mathrm{~S} 5$ and sol-gel derived 58S bioactive glasses," J. Biomed. Mater. Res. A, 61[2] 301-11 (2002).

400. M. G. Cerruti, D. Greenspan, and K. Powers, "An analytical model for the dissolution of different particle size samples of Bioglass ${ }^{\circledR}$ in TRIS-buffered solution," Biomaterials., 26[24] 4903-11 (2005).

401. E. Schepers and P. Ducheyne, "Bioactive glass particles of narrow size range for the treatment of oral bone defects: a 1-24 month experiment with several materials and particle sizes and size ranges," J. Oral Rehabil., 24[3] 171-81 (1997).

402. R. Christensen, G. Olson, and S. W. Martin, "Structural Studies of Mixed Glass Former 0.35 $\mathrm{Na}_{2} \mathrm{O}+0.65\left[\mathrm{x} \mathrm{B}_{2} \mathrm{O}_{3}+(1-\mathrm{x}) \mathrm{P}_{2} \mathrm{O}_{5}\right]$ Glasses by Raman and ${ }^{11} \mathrm{~B}$ and ${ }^{31} \mathrm{P}$ Magic Angle Spinning Nuclear Magnetic Resonance Spectroscopies," J. Phys. Chem. B, 117[7] $2169-79$ (2013).

403. M. Zeyer-Düsterer, L. Montagne, G. Palavit, and C. Jäger, "Combined 17 O NMR and 11 B31 P double resonance NMR studies of sodium borophosphate glasses," Solid State Nucl. Mag., 27[1] 50-64 (2005).

404. D. Qiu, P. Guerry, I. Ahmed, D. M. Pickup, D. Carta, J. C. Knowles, M. E. Smith, and R. J. Newport, "A high-energy X-ray diffraction, ${ }^{31} \mathrm{P}$ and ${ }^{11} \mathrm{~B}$ solid-state NMR study of the structure of aged sodium borophosphate glasses," Mater. Chem. Phys., 111[2] 455-62 (2008).

405. R. K. Brow, "Review: the structure of simple phosphate glasses," J. Non-cryst. Solids., 263 $1-28(2000)$.

406. J. F. Stebbins, P. Zhao, and S. Kroeker, "Non-bridging oxygens in borate glasses: characterization by ${ }^{11} \mathrm{~B}$ and ${ }^{17} \mathrm{O}$ MAS and 3QMAS NMR," Solid State Nucl. Mag., 16[1] 9-19 (2000). 
407. S. Sen, Z. Xu, and J. Stebbins, "Temperature dependent structural changes in borate, borosilicate and boroaluminate liquids: high-resolution ${ }^{11} \mathrm{~B},{ }^{29} \mathrm{Si}$ and ${ }^{27} \mathrm{Al}$ NMR studies," J. Noncryst. Solids., 226[1] 29-40 (1998).

408. L. Leslie, A. Hansen, K. Wright, B. Deutsch, and N. Bigelow, "Creation and detection of skyrmions in a Bose-Einstein condensate," Phys. Rev. Lett., 103[25] 250401 (2009).

409. E. Anghel, M. Zaharescu, S. Zuca, and E. Pavlatou, "Structure and phase diagram of the $\mathrm{Na}_{2} \mathrm{~B}_{4} \mathrm{O}_{7}-\mathrm{Na}_{3} \mathrm{AlF}_{6}$ system," J. Mater. Sci., 34[16] 3923-29 (1999).

410. B. Dwivedi and B. Khanna, "Cation dependence of Raman scattering in alkali borate glasses," J. Phys. Chem. Solids., 56[1] 39-49 (1995).

411. E. Kamitsos, M. Karakassides, and G. D. Chryssikos, "Vibrational spectra of magnesiumsodium-borate glasses. 2. Raman and mid-infrared investigation of the network structure," J. Phys. Chem., 91[5] 1073-79 (1987).

412. A. A. Osipov and L. M. Osipova, "Raman scattering study of barium borate glasses and melts," J. Phys. Chem. Solids., 74[7] 971-78 (2013).

413. S. Cael, J. L. Koenig, and J. Blackwell, "Infrared and Raman spectroscopy of carbohydrates: part III: Raman spectra of the polymorphic forms of amylose," Carbohyd. Res., 29[1] 123-34 (1973).

414. W. L. Konijnendijk and J. Stevels, "The structure of borosilicate glasses studied by Raman scattering," J. Non-cryst. Solids., 20[2] 193-224 (1976).

415. F. Fusco, H. Tuller, and D. Button, "Lithium, sodium and potassium transport in fast ion conducting glasses: trends and models," Met. Sci. Eng. B, 13[2] 157-64 (1992).

416. I. Hager, "Elastic moduli of boron oxyfluoride glasses: experimental determinations and application of Makishima and Mackenzie's theory," J. Mater. Sci., 37[7] 1309-13 (2002).

417. O. Majérus, L. Cormier, G. Calas, and B. Beuneu, "Temperature-induced boron coordination change in alkali borate glasses and melts," Phys. Rev. B, 67[2] 024210 (2003).

418. A. N. Begum and V. Rajendran, "Structure investigation of $\mathrm{TeO}_{2}-\mathrm{BaO}$ glass employing ultrasonic study," Mater. Lett., 61[11] 2143-46 (2007).

419. V. Veeranna Gowda and R. Anavekar, "Elastic properties and spectroscopic studies of lithium lead borate glasses," Ionics, 10[1] 103-08 (2004).

420. Y. Vaills, T. Qu, M. Micoulaut, F. Chaimbault, and P. Boolchand, "Direct evidence of rigidity loss and self-organization in silicate glasses," J. Phys. Condens. Matter, 17[32] 4889 (2005). 
421. J. Zhong and P. J. Bray, "Change in boron coordination in alkali borate glasses, and mixed alkali effects, as elucidated by NMR," J. Non-cryst. Solids., 111[1] 67-76 (1989).

422. E. Kamitsos, "Infrared studies of borate glasses," Phys. Chem. Glasses., 44[2] 79-87 (2003).

423. J. J. Hudgens, R. K. Brow, D. R. Tallant, and S. W. Martin, "Raman spectroscopy study of the structure of lithium and sodium ultraphosphate glasses," J. Non-cryst. Solids., 223[1-2] 21-31 (1998).

424. H. Sinouh, L. Bih, M. Azrour, A. El Bouari, S. Benmokhtar, B. Manoun, B. Belhorma, T. Baudin, $\mathrm{P}$. Berthet, and D. Solas, "Effect of $\mathrm{TiO}_{2}$ and $\mathrm{SrO}$ additions on some physical properties of $33 \mathrm{Na}_{2} \mathrm{O}-\mathrm{xSrO}-\mathrm{xTiO}_{2}-(50-2 \mathrm{x}) \mathrm{B}_{2} \mathrm{O}_{3}-17 \mathrm{P}_{2} \mathrm{O}_{5}$ glasses," J. Therm. Anal. Calorim., 111[1] 40108 (2013).

425. Y. Ohta, M. Shimada, and M. Koizumi, "Properties and structure of lithium borate and strontium borate glasses," J. Am. Ceram. Soc., 65[11] 572-74 (1982).

426. T. Watanabe, K. Muratsubaki, Y. Benino, H. Saitoh, and T. Komatsu, "Hardness and elastic properties of $\mathrm{Bi}_{2} \mathrm{O}_{3}$-based glasses," J. Mater. Sci., 36[10] 2427-33 (2001).

427. N. Soga, "Three-band theory and elastic moduli of glass," J. Non-cryst. Solids., 52[1-3] 36575 (1982).

428. N. Shinkai, R. Bradt, and G. E. Rindone, "Elastic Modulus and Fracture Toughness of Ternary PbO-ZnO-B ${ }_{2} \mathrm{O}_{3}$ Glasses," J. Am. Ceram. Soc., 65[2] 123-26 (1982).

429. V. Petkov, T. Ohta, Y. Hou, and Y. Ren, "Atomic-Scale Structure of Nanocrystals by HighEnergy X-ray Diffraction and Atomic Pair Distribution Function Analysis: Study of $\mathrm{Fe}_{\mathrm{x}} \mathrm{Pd}_{100-\mathrm{x}}(\mathrm{x}=$ 0, 26, 28, 48) Nanoparticles," J. Phys. Chem. C, 111[2] 714-20 (2007).

430. B. E. Warren and J. Biscee, "The structure of silica glass by X-ray diffraction studies," J. Am. Ceram. Soc., 21[2] 49-54 (1938).

431. A. Tilocca and A. N. Cormack, "Surface signatures of bioactivity: MD simulations of 45S and 65S silicate glasses," Langmuir., 26[1] 545-51 (2009).

432. A. Tilocca and A. N. Cormack, "Modeling the Water- Bioglass Interface by Ab Initio Molecular Dynamics Simulations," ACS App.l Mater. Interfaces., 1[6] 1324-33 (2009).

433. P. Marie, P. Ammann, G. Boivin, and C. Rey, "Mechanisms of action and therapeutic potential of strontium in bone," Calcified. Tissue. Int., 69[3] 121-29 (2001).

434. S. Murphy, D. Boyd, S. Moane, and M. Bennett, "The effect of composition on ion release from Ca-Sr-Na-Zn-Si glass bone grafts," J. Mater. Sci. - Mater. Med., 20[11] 2207-14 (2009). 
435. A. Goel, R. R. Rajagopal, and J. M. Ferreira, "Influence of strontium on structure, sintering and biodegradation behaviour of $\mathrm{CaO}-\mathrm{MgO}-\mathrm{SrO}-\mathrm{SiO}_{2}-\mathrm{P}_{2} \mathrm{O}_{5}-\mathrm{CaF}_{2}$ glasses," Acta Biomater., 7[11] 4071-80 (2011).

436. F.-J. Xu, E.-T. Kang, and K.-G. Neoh, "pH-and temperature-responsive hydrogels from crosslinked triblock copolymers prepared via consecutive atom transfer radical polymerizations," Biomaterials., 27[14] 2787-97 (2006).

437. E. Munukka, O. Leppäranta, M. Korkeamäki, M. Vaahtio, T. Peltola, D. Zhang, L. Hupa, H. Ylänen, J. I. Salonen, and M. K. Viljanen, "Bactericidal effects of bioactive glasses on clinically important aerobic bacteria," J. Mater. Sci. - Mater. Med., 19[1] 27-32 (2008).

438. D. Zhao, W. Huang, M. N. Rahaman, D. E. Day, and D. Wang, "Mechanism for converting $\mathrm{Al}_{2} \mathrm{O}_{3}$-containing borate glass to hydroxyapatite in aqueous phosphate solution.," Acta Biomater., 5[4] 1265-73 (2009).

439. T. R. Arentt and D. W. Dempster, "Effect of $\mathrm{pH}$ on bone resorption by rat osteoclasts in vitro," Endocrinology, 119[1] 119-24 (1986).

440. T. R. Arnett, "Extracellular pH regulates bone cell function," J. Nutr., 138[2] 415S-18S (2008).

441. A. Hoppe, N. S. Güldal, and A. R. Boccaccini, "A review of the biological response to ionic dissolution products from bioactive glasses and glass-ceramics," Biomaterials., 32[11] 2757-74 (2011).

442. D. Boyd, O. Clarkin, A. Wren, and M. Towler, "Zinc-based glass polyalkenoate cements with improved setting times and mechanical properties," Acta Biomater., 4[2] 425-31 (2008).

443. D. Boyd, H. Li, D. Tanner, M. Towler, and J. Wall, "The antibacterial effects of zinc ion migration from zinc-based glass polyalkenoate cements," J. Mater. Sci. - Mater. Med., 17[6] 48994 (2006).

444. N. D. Ravi, R. Balu, and T. Sampath Kumar, "Strontium-Substituted Calcium Deficient Hydroxyapatite Nanoparticles: Synthesis, Characterization, and Antibacterial Properties," J. Am. Ceram. Soc., 95[9] 2700-08 (2012).

445. Y. Lin, Z. Yang, J. Cheng, and L. Wang, "Synthesis, characterization and antibacterial property of strontium half and totally substituted hydroxyapatite nanoparticles," Journal of Wuhan University of Technology-Mater. Sci. Ed., 23[4] 475-79 (2008).

446. V. Hernandez, T. Crépin, A. Palencia, S. Cusack, T. Akama, S. J. Baker, W. Bu, L. Feng, Y. R. Freund, and L. Liu, "Discovery of a novel class of boron-based antibacterials with activity against gram-negative bacteria," Antimicrob. Agents. Ch, 57[3] 1394-403 (2013). 
447. D. Zhang, O. Leppäranta, E. Munukka, H. Ylänen, M. K. Viljanen, E. Eerola, M. Hupa, and L. Hupa, "Antibacterial effects and dissolution behavior of six bioactive glasses," J. Biomed. Mater. Res. A, 93[2] 475-83 (2010).

448. P. J. Petersen, P. A. Bradford, W. J. Weiss, T. M. Murphy, P. Sum, and S. J. Projan, "In vitro and in vivo activities of tigecycline (GAR-936), daptomycin, and comparative antimicrobial agents against glycopeptide-intermediate Staphylococcus aureus and other resistant gram-positive pathogens," Antimicrob. Agents. Ch, 46[8] 2595-601 (2002).

449. A. Wren, A. Coughlan, P. Hassanzadeh, and M. Towler, "Silver coated bioactive glass particles for wound healing applications," J. Mater. Sci. - Mater. Med., 23[5] 1331-41 (2012).

450. D. G. Hardie, "AMP-activated protein kinase — an energy sensor that regulates all aspects of cell function," Gene. Dev., 25[18] 1895-908 (2011).

451. D. L. Scott, S. Ramanathan, W. Shi, B. P. Rosen, and S. Daunert, "Genetically engineered bacteria: electrochemical sensing systems for antimonite and arsenite," Anal. Chem., 69[1] 16-20 (1997).

452. P. Breeuwer and T. Abee, "Assessment of the membrane potential, intracellular $\mathrm{pH}$ and respiration of bacteria employing fluorescence techniques," Molecular microbial ecology manual, 8 1563-80 (2004).

453. E. R. Kashket, "The proton motive force in bacteria: a critical assessment of methods," Annu. Rev. Microbiol., 39[1] 219-42 (1985).

454. S. Mates, L. Patel, H. Kaback, and M. Miller, "Membrane potential in anaerobically growing Staphylococcus aureus and its relationship to gentamicin uptake," Antimicrob. Agents. Ch, 23[4] 526-30 (1983).

455. E. Kashket, "Proton motive force in growing Streptococcus lactis and Staphylococcus aureus cells under aerobic and anaerobic conditions," J. Bacteriol., 146[1] 369-76 (1981).

456. S. M. Mates, E. S. Eisenberg, L. J. Mandel, L. Patel, H. R. Kaback, and M. H. Miller, "Membrane potential and gentamicin uptake in Staphylococcus aureus," Proc. Natl. Acad. Sci., 79[21] 6693-97 (1982).

457. E. Eisenberg, L. Mandel, H. Kaback, and M. Miller, "Quantitative association between electrical potential across the cytoplasmic membrane and early gentamicin uptake and killing in Staphylococcus aureus," J. Bacteriol., 157[3] 863-67 (1984).

458. M. A. Farha, C. P. Verschoor, D. Bowdish, and E. D. Brown, "Collapsing the proton motive force to identify synergistic combinations against Staphylococcus aureus," Chem. Biol., 20[9] 1168-78 (2013). 
459. S. S. Hakki, B. S. Bozkurt, and E. E. Hakki, "Boron regulates mineralized tissue-associated proteins in osteoblasts (MC3T3-E1)," J. Trace. Elem. Med. Bio, 24[4] 243-50 (2010).

460. Y. Li, L. Placek, A. Coughlan, F. Laffir, D. Pradhan, N. Mellott, and A. Wren, "Investigating the influence of $\mathrm{Na}^{+}$and $\mathrm{Sr}^{2+}$ on the structure and solubility of $\mathrm{SiO}_{2}-\mathrm{TiO}_{2}-\mathrm{CaO}-\mathrm{Na}_{2} \mathrm{O} / \mathrm{SrO}$ bioactive glass," J. Mater. Sci. - Mater. Med., 26[2] 1-12 (2015).

461. B. S. Seal and H. J. Weeth, "Effect of boron in drinking water on the male laboratory rat," $B$. Environ. Contam. Tox, 25[1] 782-89 (1980).

462. A. Hoppe, V. Mouriño, and A. R. Boccaccini, "Therapeutic inorganic ions in bioactive glasses to enhance bone formation and beyond," Biomaterials Science, 1[3] 254-56 (2013).

463. Y. Li, A. Coughlan, F. Laffir, D. Pradhan, N. Mellott, and A. Wren, "Investigating the mechanical durability of bioactive glasses as a function of structure, solubility and incubation time," J. Non-cryst. Solids., 380 25-34 (2013).

464. Q. Z. Chen, I. D. Thompson, and A. R. Boccaccini, "45S5 Bioglass@-derived glass-ceramic scaffolds for bone tissue engineering," Biomaterials., 27[11] 2414-25 (2006).

465. W. Richard, "Deformation and fracture mechanics of engineering materials." Wiley Global Education, (1976).

466. N. Shinkai, R. Bradt, and G. E. Rindone, "Elastic Modulus and Fracture Toughness of Ternary PbO-ZnO-B2O3 Glasses," J. Am. Ceram. Soc., 65[2] 123-26 (1982).

467. T. L. Anderson, "Fracture mechanics: fundamentals and applications," Third ed. CRC press, (2017).

468. S. Mindess, F. V. Lawrence, and C. E. Kesler, "The J-integral as a fracture criterion for fiber reinforced concrete," Cement Concrete Res., 7[6] 731-42 (1977).

469. H. S. Min and S. C. Kim, "Fracture toughness of polysulfone/epoxy semi-IPN with morphology spectrum," Polym. Bull., 42[2] 221-27 (1999).

470. F. Baino and C. Vitale-Brovarone, "Wollastonite-containing bioceramic coatings on alumina substrates: design considerations and mechanical modelling," Ceram. Int., 41[9] 11464-70 (2015).

471. Q. Chen, F. Baino, N. M. Pugno, and C. Vitale-Brovarone, "Bonding strength of glassceramic trabecular-like coatings to ceramic substrates for prosthetic applications," Mater. Sci. Eng. C, 33[3] 1530-38 (2013).

472. O. Rodriguez, A. Matinmanesh, S. Phull, E. H. Schemitsch, P. Zalzal, O. M. Clarkin, M. Papini, and M. R. Towler, "Silica-Based and Borate-Based, Titania-Containing Bioactive Coatings Characterization: Critical Strain Energy Release Rate, Residual Stresses, Hardness, and Thermal Expansion," J. Funct. Biomater., 7[4] 32 (2016). 
473. A. G. Evans and J. W. Hutchinson, "Effects of non-planarity on the mixed mode fracture resistance of bimaterial interfaces," Acta Metall., 37[3] 909-16 (1989).

474. R. Streit and I. Finnie, "ethods for Determining the Mode I and Mode II Fracture Toughness of Glass Using Thermal Stresses," J. Eeg. Mater. T., 112151 (1990).

475. D. Ravaine and J. Souquet, "A thermodynamic approach to ionic conductivity in oxide glasses - part 2. A statistical model for the variations of the chemical potential of the constituents in binary alkali oxide glasses," Phys. Chem. Glasses., 19[5] 115-20 (1978).

476. Y. Han, $\mathrm{K} . \mathrm{Xu}$, and J. Lu, "Dissolution response of hydroxyapatite coatings to residual stresses," J. Biomed. Mater. Res., 55[4] 596-602 (2001).

477. D. Li, F. Yang, and J. Nychka, "Indentation-induced residual stresses in $45 \mathrm{~S} 5$ bioglass and the stress effect on the material dissolution," Eng. Fract. Mech., 75[17] 4898-908 (2008).

478. J. A. Nychka, S. L. Mazur, S. Kashyap, D. Li, and F. Yang, "Dissolution of bioactive glasses: The effects of crystallinity coupled with stress," Jom, 61[9] 45-51 (2009). 